\title{
WestVirginiaUniversity
}

THE RESEARCH REPOSITORY @ WVU

Graduate Theses, Dissertations, and Problem Reports

2004

\section{Evaluation of jointed plain concrete pavement (JPCP) with FRP dowels}

Hui Li

West Virginia University

Follow this and additional works at: https://researchrepository.wvu.edu/etd

\section{Recommended Citation}

Li, Hui, "Evaluation of jointed plain concrete pavement (JPCP) with FRP dowels" (2004). Graduate Theses, Dissertations, and Problem Reports. 1573.

https://researchrepository.wvu.edu/etd/1573

This Thesis is protected by copyright and/or related rights. It has been brought to you by the The Research Repository @ WVU with permission from the rights-holder(s). You are free to use this Thesis in any way that is permitted by the copyright and related rights legislation that applies to your use. For other uses you must obtain permission from the rights-holder(s) directly, unless additional rights are indicated by a Creative Commons license in the record and/ or on the work itself. This Thesis has been accepted for inclusion in WVU Graduate Theses, Dissertations, and Problem Reports collection by an authorized administrator of The Research Repository @ WVU. For more information, please contact researchrepository@mail.wvu.edu. 
Evaluation of Jointed Plain Concrete Pavement (JPCP) with FRP Dowels

By

Hui Li

Thesis submitted to the

College of Engineering and Mineral Resources

at West Virginia University

in partial fulfillment of the requirements

for the degree of

\author{
Master of Science \\ in \\ Civil Engineering
}

\author{
P.V. Vijay, Ph.D., Chair \\ Hota GangaRao, Ph.D., Co-chair \\ Udaya Halabe, Ph.D.
}

Department of Civil and Environmental Engineering

\author{
Morgantown, West Virginia \\ 2004
}

Keyword: FRP dowel, dowel, JPCP, pavement joint, Load transfer efficiency, LTE, relative deflection, joint rehabilitation 


\section{ABSTRACT \\ Evaluation of Jointed Plain Concrete Pavement (JPCP) with FRP Dowels}

\section{Hui Li}

Objectives of this study are to evaluate FRP dowel bars as load transferring devices in JPCP under HS-25 static and fatigue loads and compare their response with JPCP consisting of steel dowels. Along with laboratory and field evaluations of JPCP with FRP and steel dowels, analytical modeling of dowel response has been carried out in terms of maximum bending deflection, relative deflection and bearing stress of dowels. In addition, field rehabilitation of JPCP was carried out in this research using FRP dowels to evaluate its long term performance.

Laboratory tests conducted in this study include static and fatigue load application corresponding to HS-25 load and 1.5 times HS-25 load on concrete slabs (11" and 12" depth) with 1.5" and 1.0" steel and FRP dowels at different spacings (12", 6").

FRP dowel bars were field installed in corridor-H pavement project on Rt.219, Elkins WV. Both 1.5" and 1.0" diameter FRP dowels were installed in the field with 6", 8", 9" and 12" spacings. Load calibrated field tests were conducted on these pavements using WVDOT truck in 2002 and 2003. FRP dowel bars with 1.5" diameter were also utilized for pavement rehabilitation near junction of Rt. 857 and Rt. 119, University Avenue, Morgantown, WV. Field data collected through automatic data acquisition system included strain and joint deflections, which were used for assessing joint load transfer efficiency, joint relative deflection, and pavement performance.

Theoretical calculations are provided through different examples for JPCP with FRP and steel dowels by varying dowel diameter, spacing, dowel material properties, joint width, and base material properties.

This research shows that Jointed Plain Concrete Pavement with FRP dowels provide very good Load Transfer Efficiency (LTE) up to and beyond 90\%, which exceeds AASHTO criteria of $70 \%$ or APCA criteria of $60 \%$ (equivalent to another measure Joint Effectiveness of 75\%). JPCP with FRP dowels also provided sufficient LTE after 5 million cycles of fatigue tests under HS-25 loading conducted in the Major Unit Laboratory, WVU. 
To my wife, Xiaojuan Liu (Jenny),

To my daughter, Julianna Li,

And to my parents, Wentan Li and Lianjing Zheng 


\section{ACKNOWLEDGEMENTS}

I would like to express my gratitude and appreciation to Dr. P.V. Vijay, for his numerous contributions in helping me develop and complete the whole research with this thesis. I sincerely appreciate his kindness and help provided whenever needed. Special thanks are extended to Dr. Hota GangaRao, my academic and research co-advisor, who provided constructive comments and valuable insight into all areas of this thesis. Also I would like to thank Dr. Udaya Halabe for providing important advice and suggestions in this research. I also want to thank FHWA and WVDOT for sponsoring and funding this project.

I would like to thank my friend, Mr. Woraphot Prachasaree for his continuous help during this research. I also appreciate the assistance provided by my friends Mr. Jose Basto, Miss Ranee Rajappa, Mr. Vijay Tripathi, Mr. Raghuram Aditham and Mr. Krit Laosiriphong. I enjoyed the opportunity to work with all of them. The time spent with them will be remembered.

Finally, I would like to thank my wife, Xiaojuan, for her love, patience and support during my entire research work. 


\section{TABLE OF CONTENTS}

Chapter 1 INTRODUCTION--

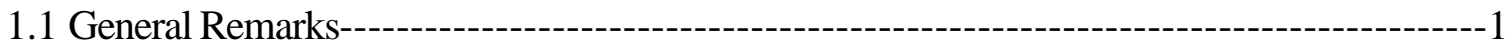

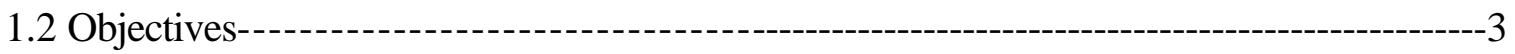

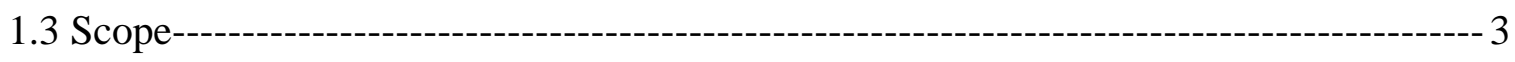

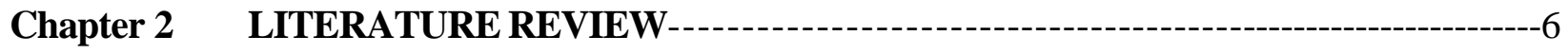

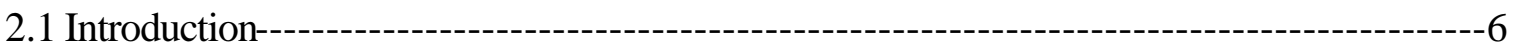

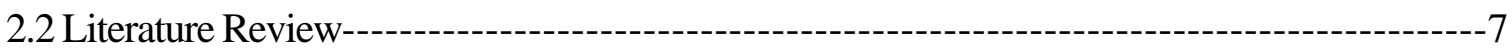

Chapter 3 MATERIALS, EQUPMENT AND LAB TESTING PROCEDURES--------10

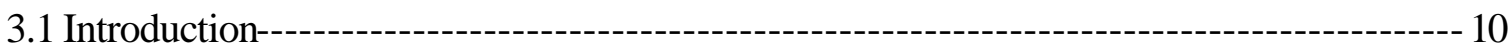

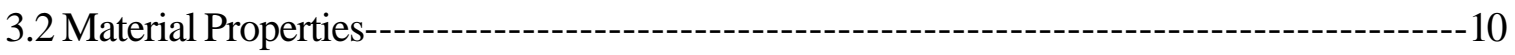

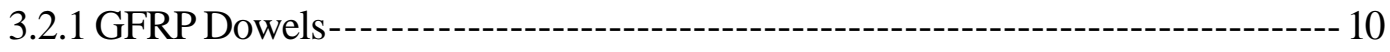

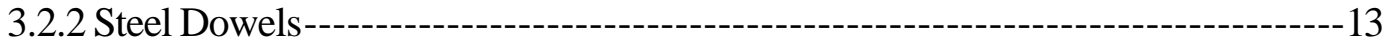

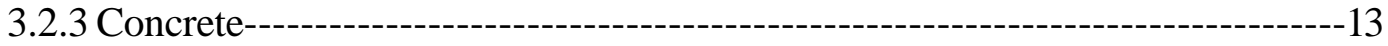

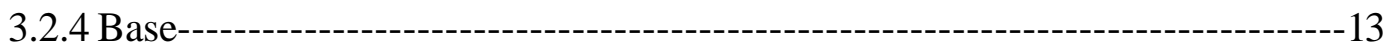

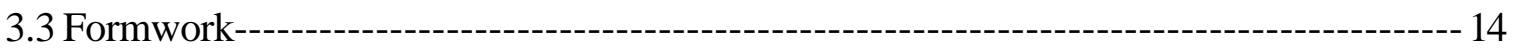

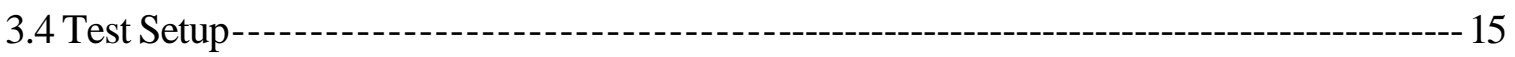

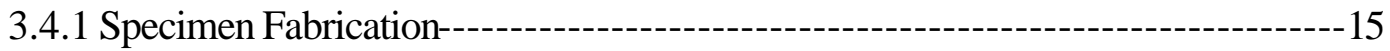

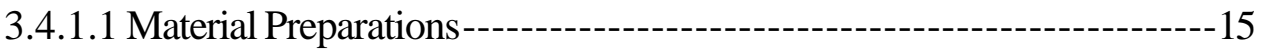

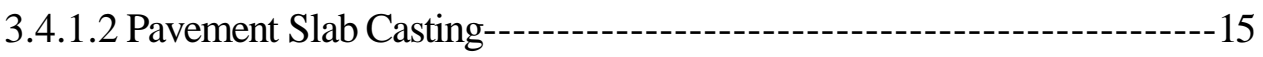

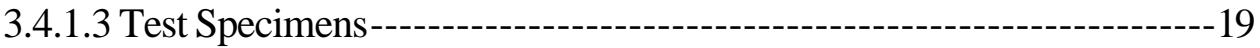

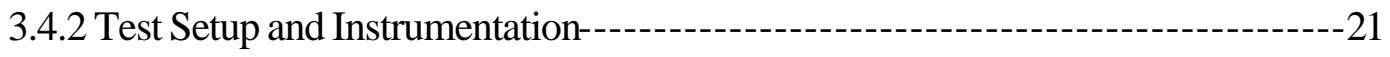

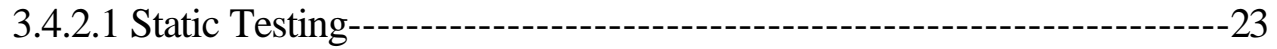




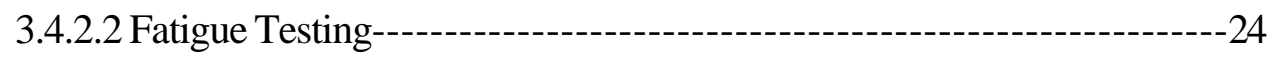

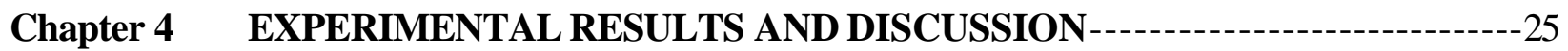

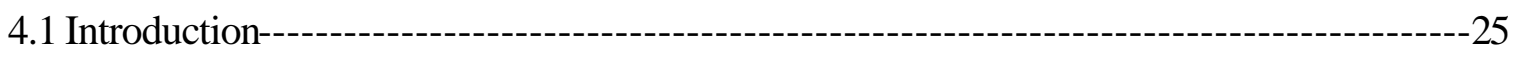

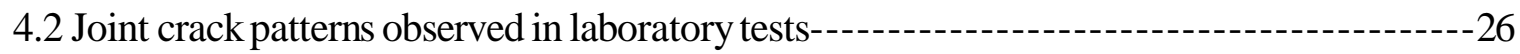

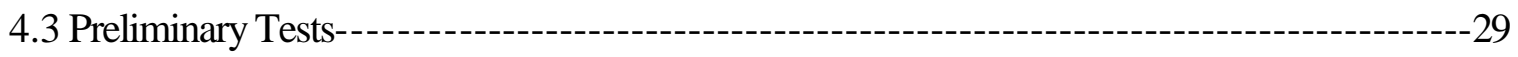

4.4 Joint Deflections and Joint Load Transfer Efficiency (LTE)-----------------------------29

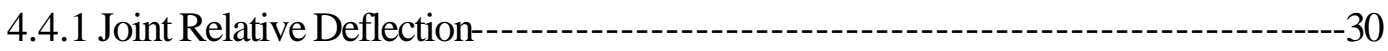

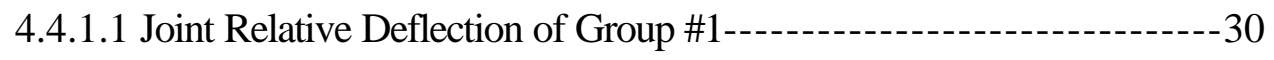

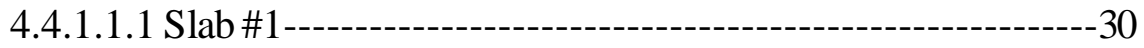

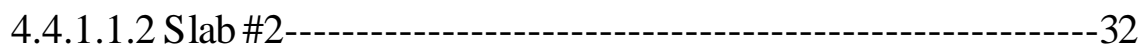

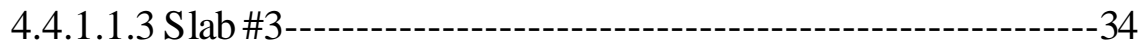

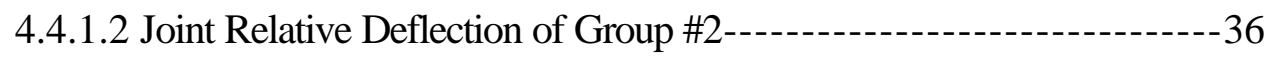

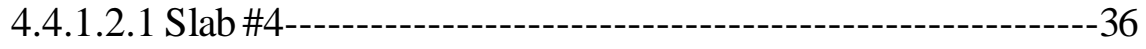

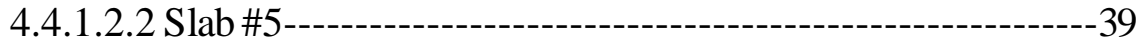

4.4.1.3 Analysis of Relative Deflection---:--- 40

4.4.1.3.1 $\quad$ Analysis for Specimen Group \#1 as

per Table 4.1 (6" spacing) ------------------------40

4.4.1.3.2 Analysis for Specimen Group \#2 (12” spacing)-------42

4.4.2 Joint Load Transfer Efficiency (LTE) ----------------------------------43

4.4.2.1 Load Transfer Efficiency of Group \#1-----------------------44

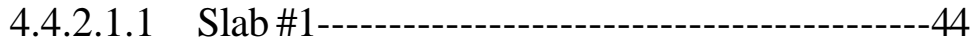

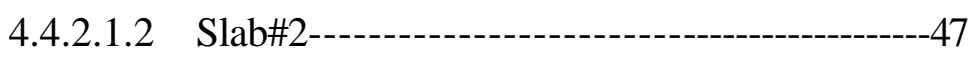

4.4.2.1.3 Slab \#3 --------------------------------------------48 
4.4.2.2 Joint Load Transfer Efficiency of Group \#2-----------------49

4.4.2.2.1 Slab\#4---------------------------------------------49

4.4.2.2.2 Slab\#5--------------------------------------------52

4.4.2.3 Analysis and Discussion for Joint Load Transfer

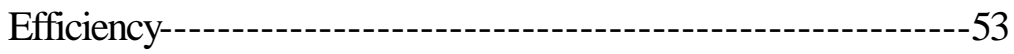

4.4.2.3.1 Analysis and Discussion for

Slab Group \#1 (6” spacing)-------------------53

4.4.2.3.2 Analysis and Discussion for

Slab Group \#2 (12” spacing) ----------------55

4.4.3 Special Investigations on Pavement Pumping Problem------------------ 56

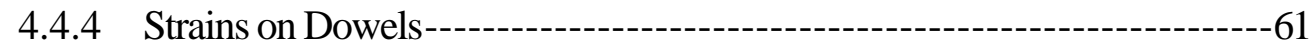

Chapter 5 FIELD APPLICATIONS AND TEST RESULTS--

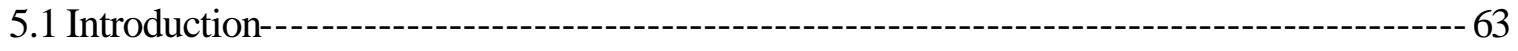

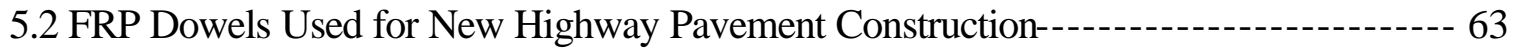

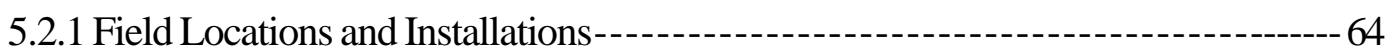

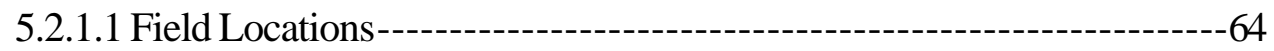

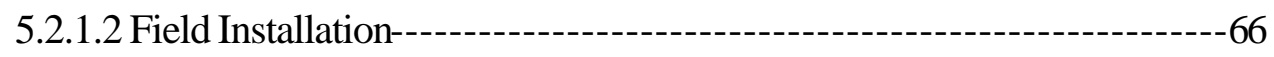

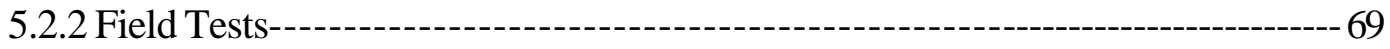

5.2.2.1 Field Test Before Opening Highway To Traffic In July 2002----------69

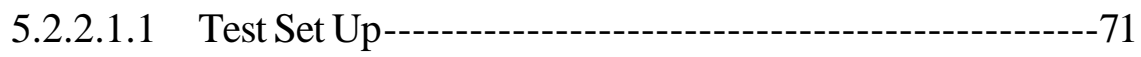

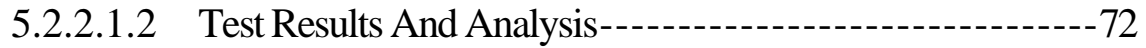

5.2.2.1.2.1 Strain Data From Field Static Tests---------------72

5.2.2.1.2.2 Strain Data From Dynamic Tests- - - - - - - - - 77 


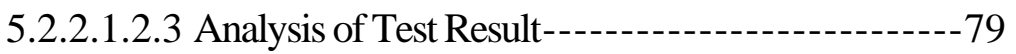

5.2.2.1.2.4 Deflection Data---------------------------------80

5.2.2.2 Field Test After Highway Opened To Traffic, June 2003-------------80

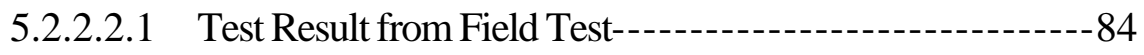

5.2.2.2.2 Analysis of Test Results----------------------------87

5.3 FRP Dowels Used for Highway Pavement Rehabilitation----------------------------90

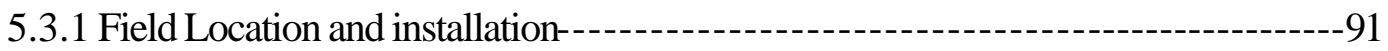

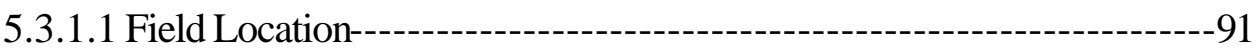

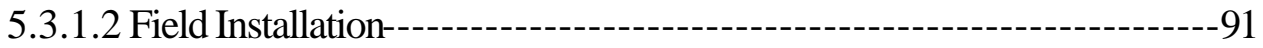

5.3.2 Field Tests---_-_-

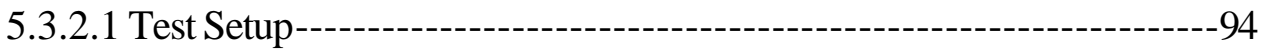

5.3.2.2 Results And Analysis----------------------------------------------94

5.3.2.2.1 FRP Dowel Group------------------------------------------ 95

5.3.2.2.2 Steel Dowel Group------------------------------------------ 96

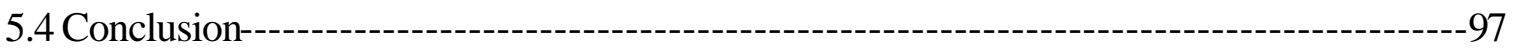

Chapter 6 ANALYTICAL EVALUATION---100

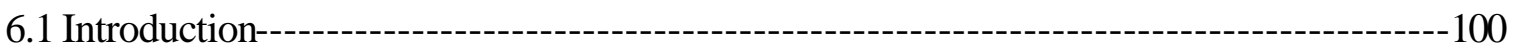

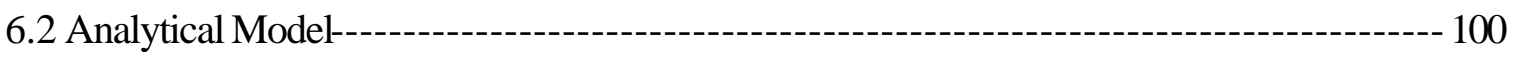

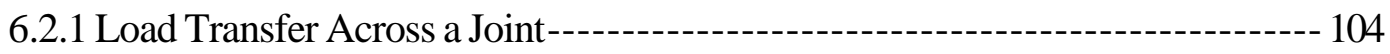

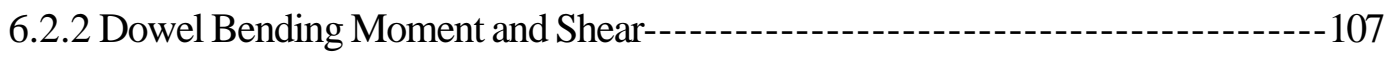

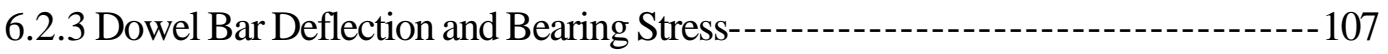

6.2.4 Bearing Stress Between Dowel/Concrete Interface-------------------------109

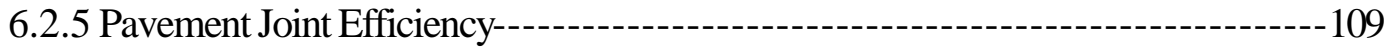


6.3 Theoretical Calculation Samples for FRP and Steel Dowel Group

6.3.1 Theoretical Calculation for Dowel Group with 1.5-inch

Diameter Dowels------------------------------------------------------------------111

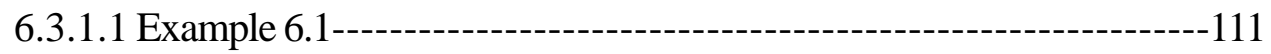

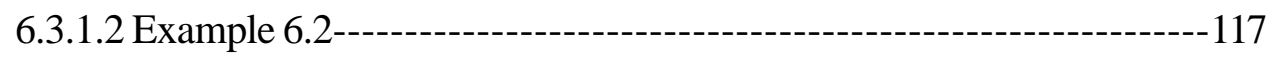

6.3.2 Theoretical Calculation for Dowel Group with 1.0-inch

Diameter Dowels-----------------------------------------------------------------120

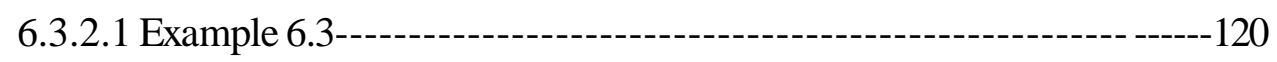

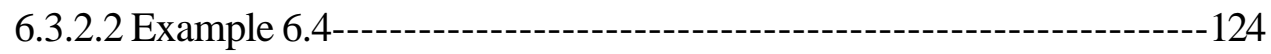

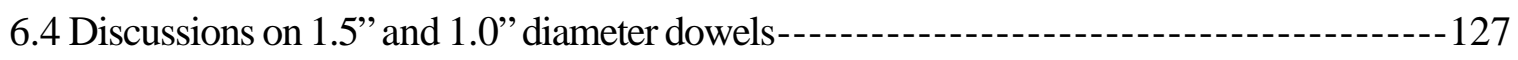

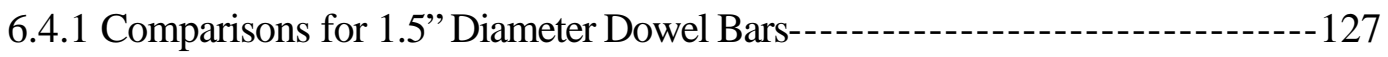

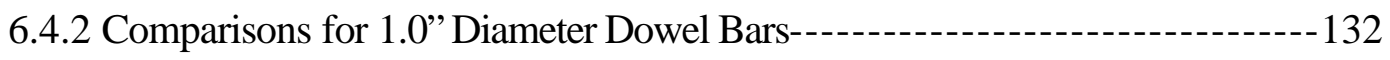

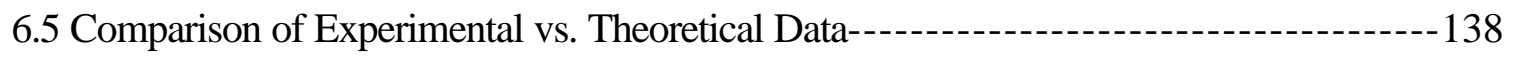

6.6 Analytical Investigation with Respect to FRP Dowel-Concrete Bearing Stress-----------139

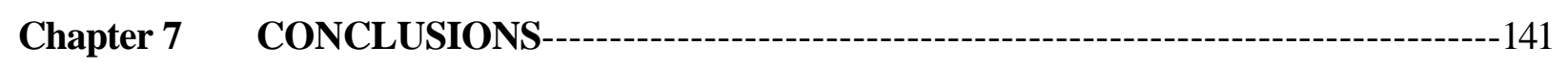

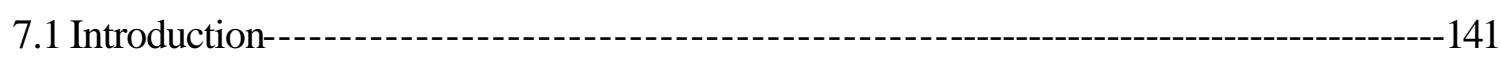

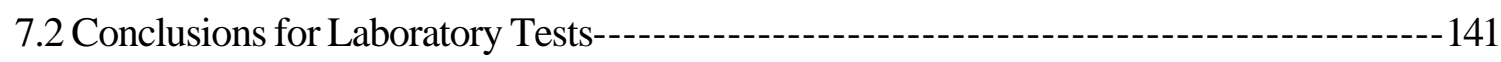

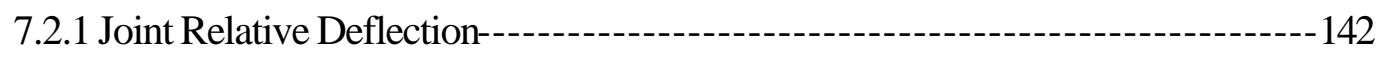

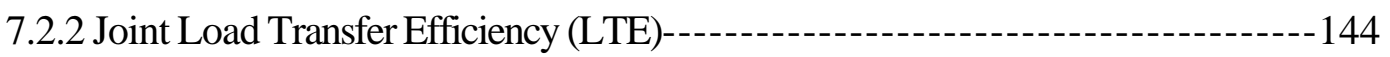

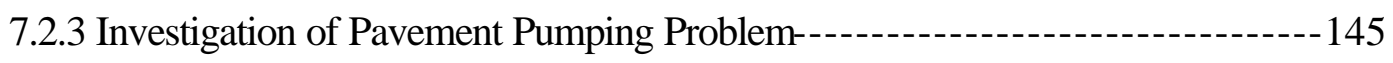

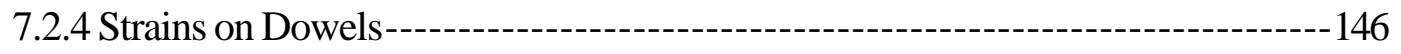

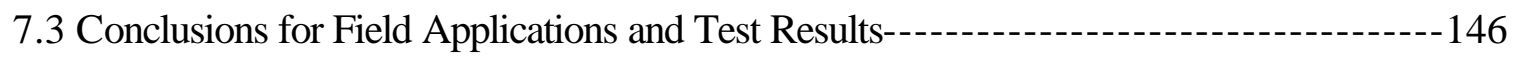


7.3.1 Conclusions for FRP Dowels Used for New Highway

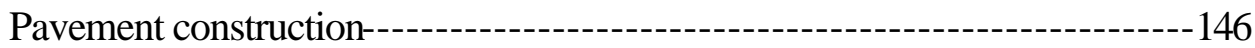

7.3.2 Conclusions for FRP Dowels Used for Highway Pavement

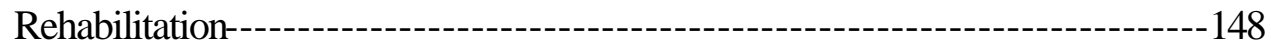

7.4 Conclusions for Analytical Evaluation---:-- 149

7.4.1 Conclusions for 1.5" Diameter Dowel with 12" C/C Spacing-----------------149

7.4.2 Conclusions for 1.0" Diameter Dowel with 6" C/C Spacing-------------------152

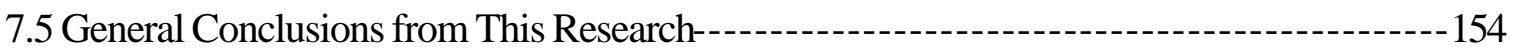

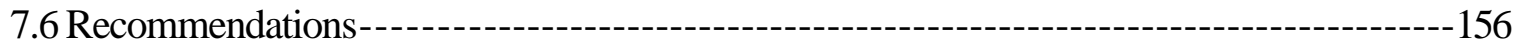

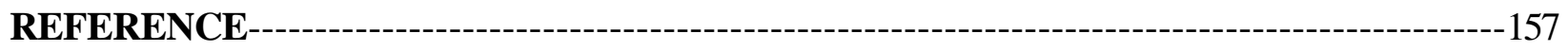

\section{APPENDIX A}

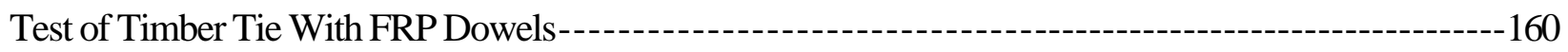

\section{APPENDIX B}

Analytical Evaluation of Effect of FRP Dowel Shear Modulus on Pavement

Relative Deflection-------------------------------------------------------------------------------------------168

\section{APPENDIX C}

Fiber Burnout Tests for Determining Fiber Weight Fraction and Fiber Volume Fraction

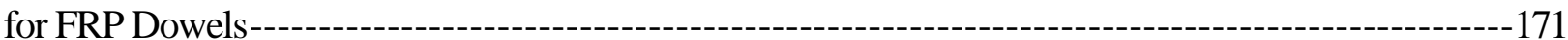




\section{List of Tables}

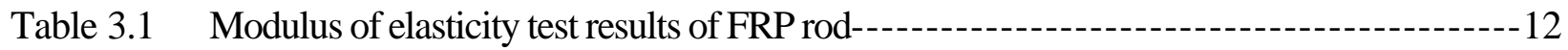

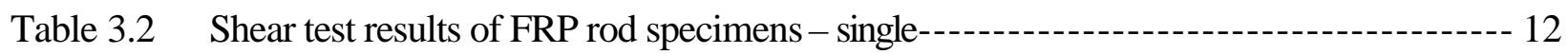

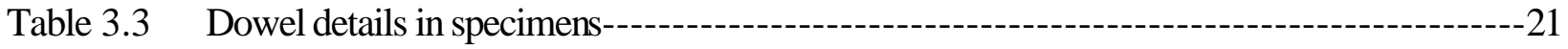

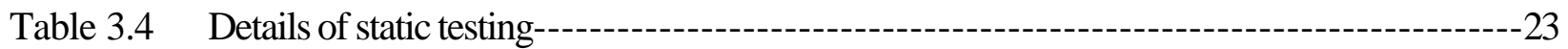

Table 3.5 Details of fatigue testing--

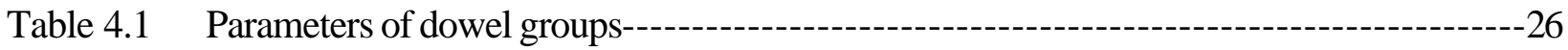

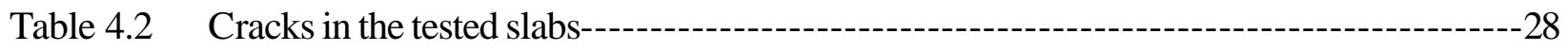

Table 4.3 Static load applied for specimen \#1--

Table 4.4 Load applied for fatigue tests on slab \#1---

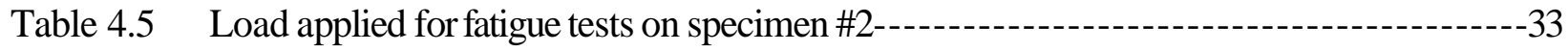

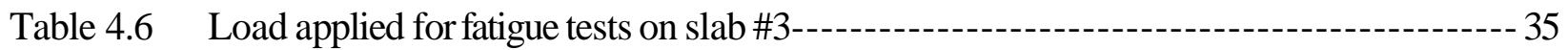

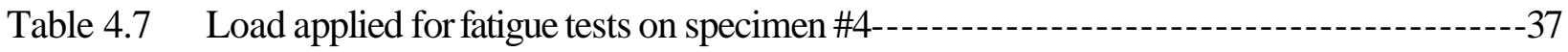

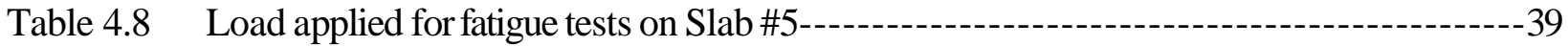

Table 4.9 Load applied for fatigue tests on Specimen \#5---

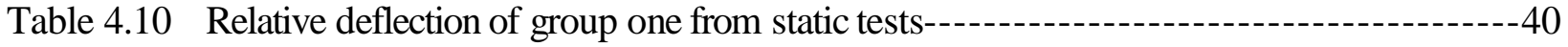

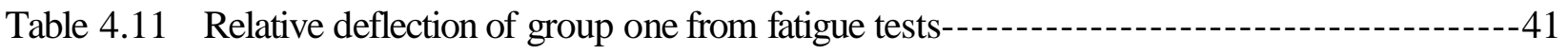

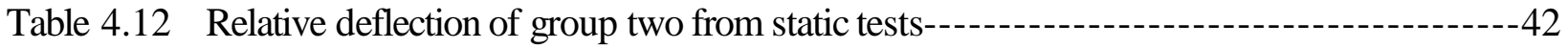

Table 4.13 Relative deflection of group two from fatigue tests---:-

Table 4.14 Load transfer efficiency of group one from static tests--------------------------------53

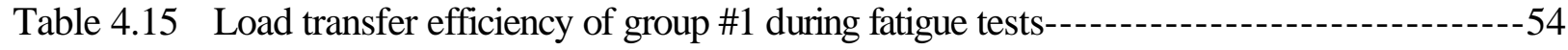


Table 4.16 Load transfer efficiency of group two from static tests under corresponding

HS25 Load----------------------------------------------------------------------------------------55

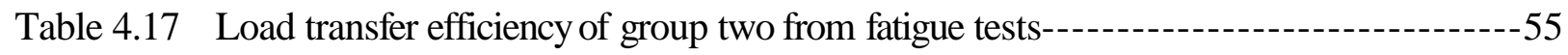

Table 4.18 Evaluation of pumping issue under 10 kips loading---

Table 4.19 Evaluation of pumping issue under 3 kips loading---on

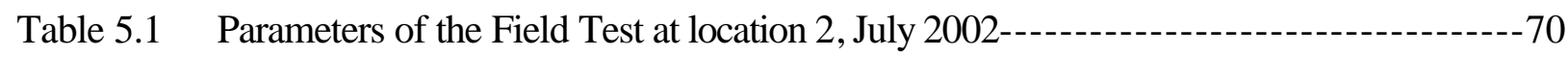

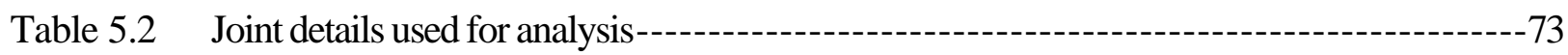

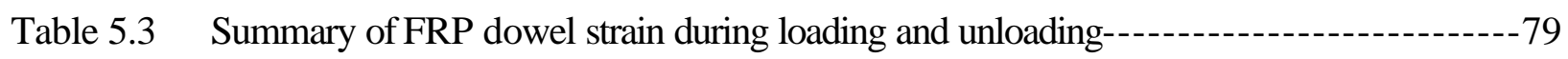

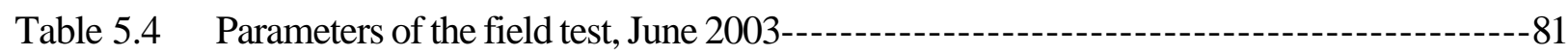

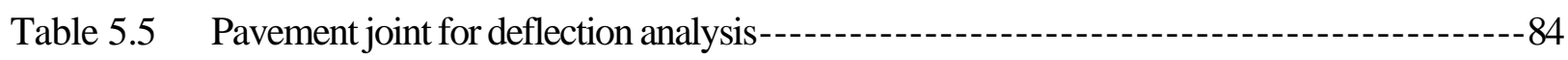

Table 5.6 Summary of joint deflection under maximum loading force---

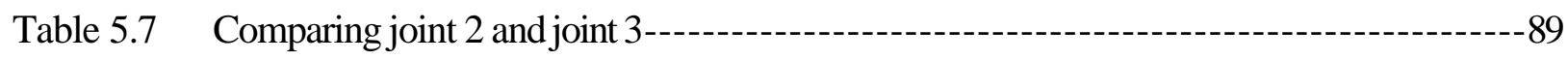

Table 6.1 Calculation summaries for 1.5 " diameter dowel $\left(\mathrm{k}=400 \mathrm{pci}, \mathrm{f}_{\mathrm{c}}{ }^{\prime}=4500 \mathrm{psi}\right)$------------127

Table 6.2 Peak bearing stress and average bearing stress in

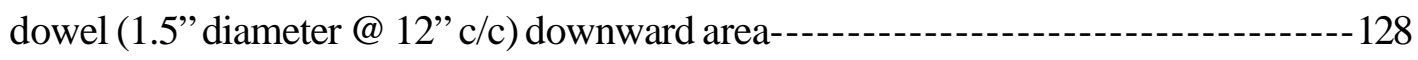

Table 6.3 Peak bearing stress and average bearing stress within 1"

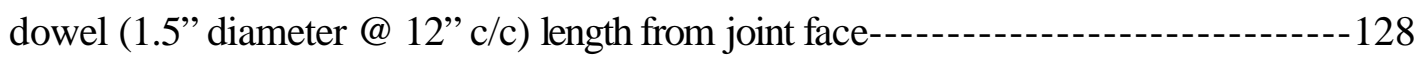

Table 6.4 Calculation summaries for 1.0" diameter dowel $\left(\mathrm{k}=400 \mathrm{pci}, \mathrm{f}_{\mathrm{c}}\right.$ ' $\left.=4500 \mathrm{psi}\right)-----------133$

Table 6.5 Peak bearing stress and average bearing stress in

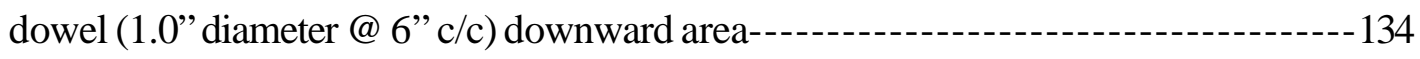

Table 6.6 Peak bearing stress and average bearing stress within

1" dowel (1.0" diameter @ 6" c/c) length from joint face-

Table 6.7 Comparison of Experiments vs. Theory for Slab Relative 


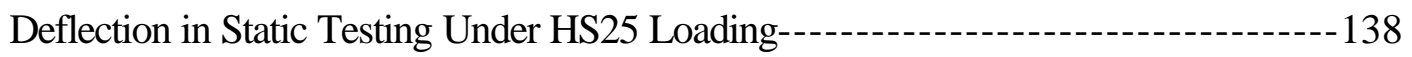

Table A.1 Strains during loading and unloading on Case-I-A---:-

Table A.2 Strains during loading and unloading on Case-I-B---:--

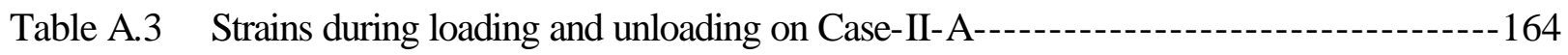

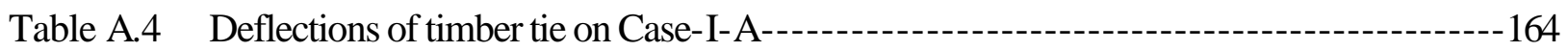

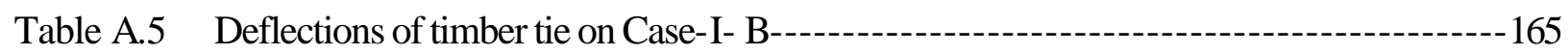

Table B.1 Relative deflection with low dowel shear modulus $\left(\mathrm{G}_{\mathrm{d}}=0.4 \times 10^{6} \mathrm{psi}\right)----------------169$

Table B.2 Relative deflection with high dowel shear modulus $\left(\mathrm{G}_{\mathrm{d}}=7.5 \times 10^{6} \mathrm{psi}\right)$----------------169

Table C.1 FWF and FVF for FRP dowel with 1.0" diameter---1

Table C.2 FWF and FVF for FRP dowel with 1.5" diameter---:--- 171 


\section{List of Figures}

Figure 1.1 Exposed failures with rusted dowel bars (WS DOT Pavement Guide)--------------------2

Figure 2.1 Typical pavements problems: Faulting and Pumping (American Highway

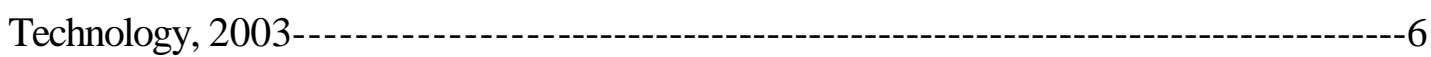

Figure 3.1 FRP dowels (1.5" and 1.0" diameter) ---

Figure 3.2 Steel dowels (1.5" and 1.0" diameter)---13

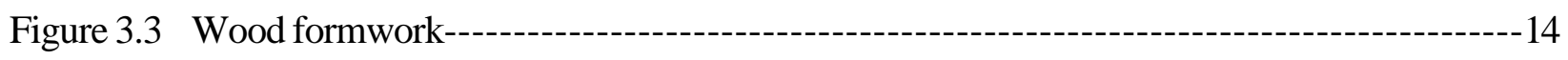

Figure 3.4 Dimensions of formwork (inches)--

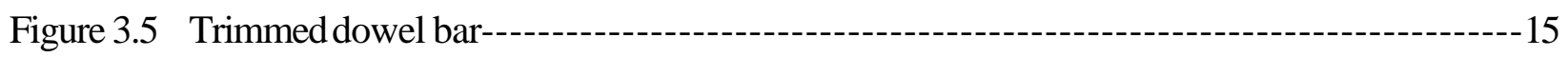

Figure 3.6 Instrumented dowels and steel plate positioned in the wood formwork-----------------16

Figure 3.7 Placing concrete into formwork-----

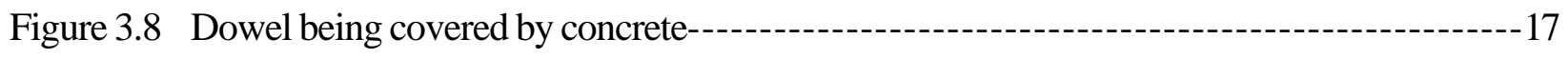

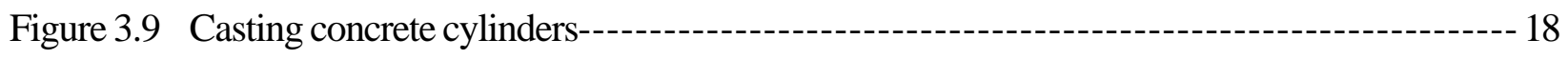

Figure 3.10 Surface finished specimens---:-10

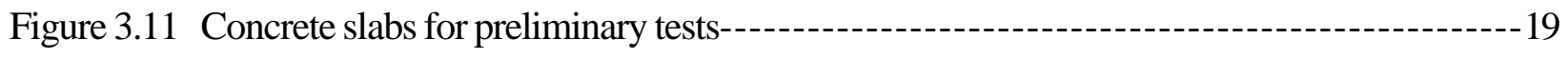

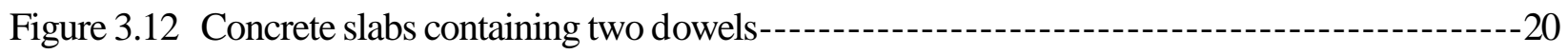

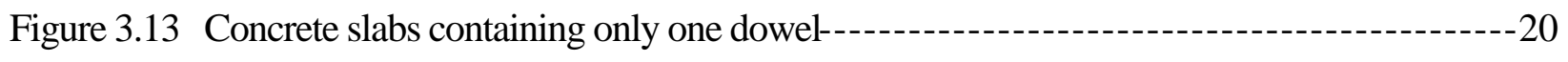

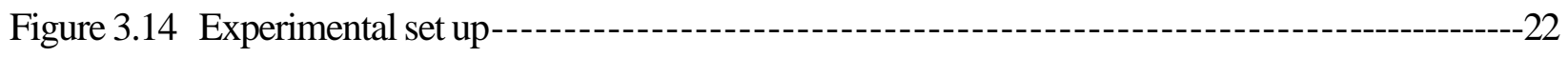

Figure 3.15 LVDTs positioned on both sides of the joint---

Figure 4.1 Typical crack observed in Slabs \#1, \#4 and \#5 (Table 4.1)------------------------27

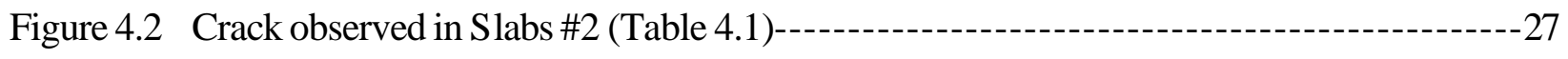

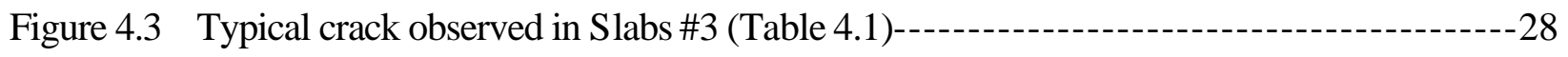




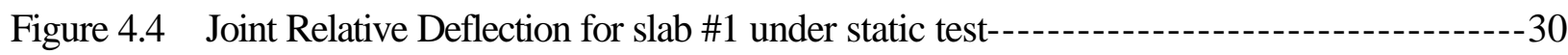

Figure 4.5 Relative deflections under HS25 loading for slab \#1 at joint

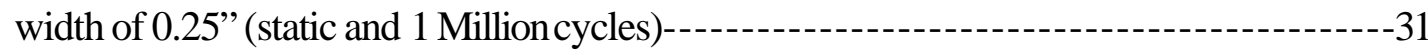

Figure 4.6 Relative deflections for slab \#1 under fatigue tests (joint width increased from 0.25 " to 0.4 " from 2 to 5 Million cycles)--

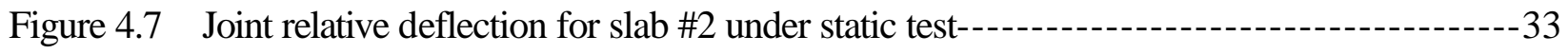

Figure 4.8 Relative deflections for specimen \#2 (0 to 2 million cycles)---------------------------34

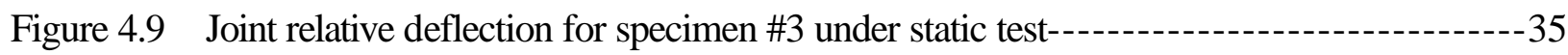

Figure 4.10 Relative deflections for specimen \#3 (0 to 1.25 million cycles)--------------------- 36

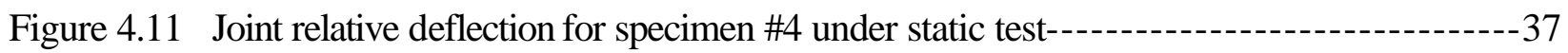

Figure 4.12 Pavement deflections under fatigue test for slab \#4 (0 to 5 million

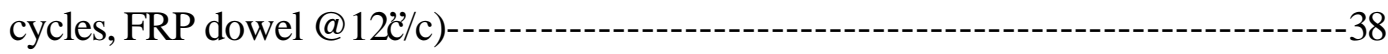

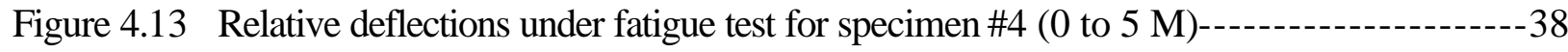

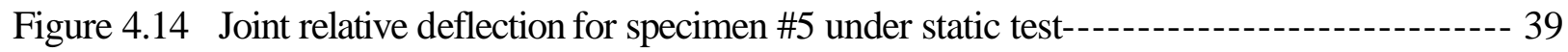

Figure 4.15 Relative deflections under fatigue test for specimen \#5 (0 to $5 \mathrm{M}$ )--------------------40

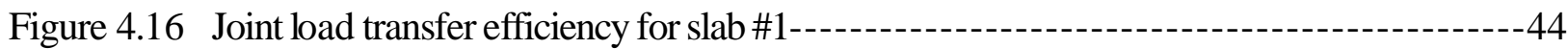

Figure 4.17 LTE corresponding to HS25-loading for slab \#1 (1.0"diameter @ 6"c/c), (Static and 1 MillionCycles)--.-1-

Figure 4.18 LTE for slab \#1 under fatigue tests (>1 Million cycles \& joint width

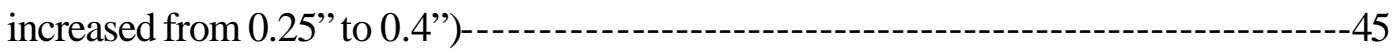

Figure 4.19 Dowel-concrete interface condition in slab \#1 after 5 million load cycles----------------46

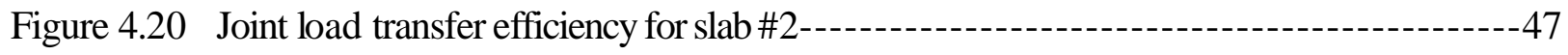

Figure 4.21 LTE under fatigue tests (HS25 loading) for slab \#2 (0 to 1 million cycles)--------------47 
Figure 4.22 LTE under fatigue test for slab \#2 (1 to 2 million)---

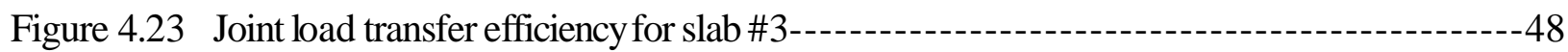

Figure 4.24 LTE under fatigue test for slab \#3 (0 to 1.25 million)-----------------------------49

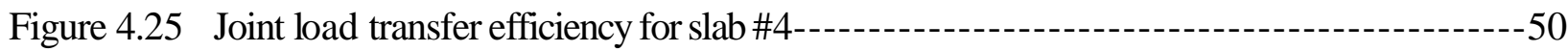

Figure 4.26 LTE under fatigue test for slab \#4 (0 to 5 million)-----

Figure 4.27 Dowel-concrete interface condition in slab \#4 after 5 million load cycles-----------------52

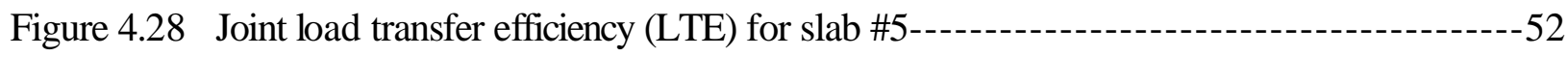

Figure 4.29 LTE under fatigue test for slab \#5 (0 to 5 Million)---1--- 53

Figure 4.30 Case one-2 ft. base material removal under loaded side of slabs-----------------------57

Figure 4.31 Relative deflection for pumping tests (Case one-2 ft. base removal)--------------------57

Figure 4.32 Load transfer efficiency for pumping tests (Case one-2 ft. base removal)---------------58

Figure 4.33 Case two- $1 \mathrm{ft}$. base material removal under both sides of slabs---------------------58

Figure 4.34 Relative deflection for pumping tests under 3 kips loading (Case

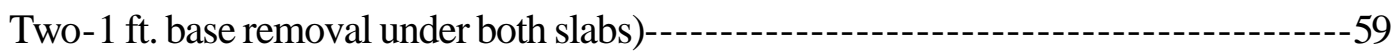

Figure 4.35 Load transfer efficiency for pumping tests under 3 kips loading (Case

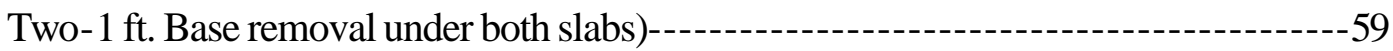

Figure 4.36 Strain gage reading in slab \#1 (1.0" diameter @ 6" c/c) from static test to 1 million cycles under HS25 loading)---:---

Figure 4.37 Strain gage reading in slab \#4 (1.5” diameter @ 12" c/c) from static

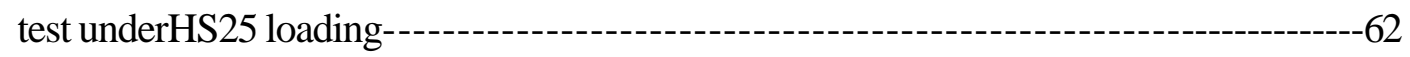

Figure 5.1 Dowel installation at location 1 of corridor H, Rt. 250, Elkins, WV--------------64

Figure 5.2 FRP dowel positions at location 1 of corridor H, Rt. 250, Elkins,

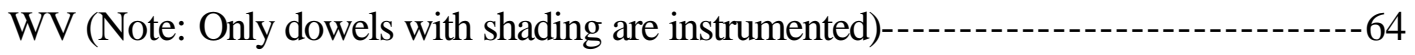


Figure 5.3 FRP dowel bars at location 2 of corridor H, Rt. 219, Elkins, WV-------------------65

Figure 5.4 FRP dowel positions at location No.2 of corridor H, Rt. 219, Elkins, WV-----------65

Figure 5.5 FRP dowel bars bonded with strain gages at loaded and unloaded side----------------66

Figure 5.6 Embeddable concrete strain gage with dowels---1--

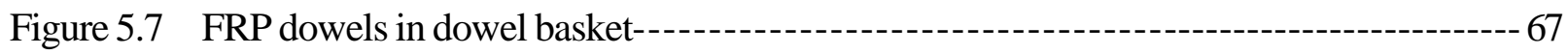

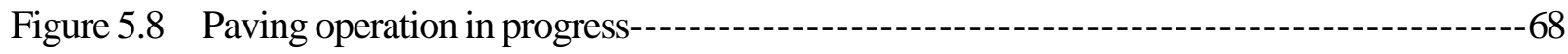

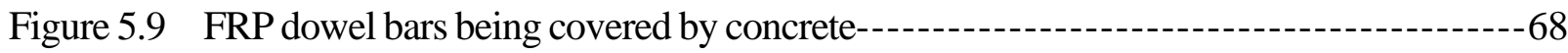

Figure 5.10 Dial gages for measuring pavement deflection under truck loading----------------------71

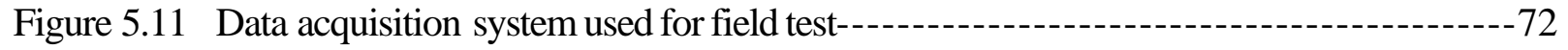

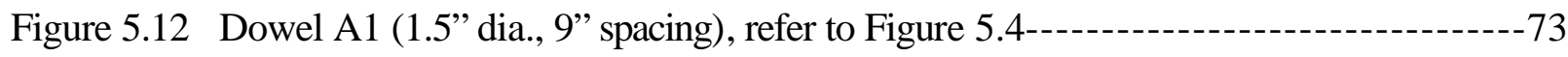

Figure 5.13 Stains in dowel during loading and unloading cases for gage

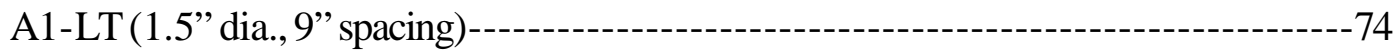

Figure 5.14 Dowel A2 (1.5” dia., 12” spacing), refer to Figure 5.4-----------------------------74

Figure 5.15 Strains in dowel during Loading and unloading cases for gage A2-LT

(1.5" dia., 12”spacing), refer to Figure 5.4------------------------------------------75

Figure 5.16 Dowel C5 (1.0" dia. 6" spacing), refer to Figure 5.4--15

Figure 5.17 Strains in dowel during loading case for gage C5-U1 (1.0" dia., 6"

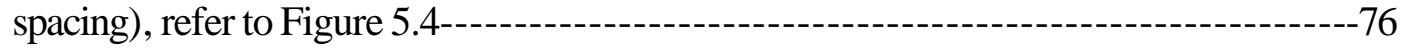

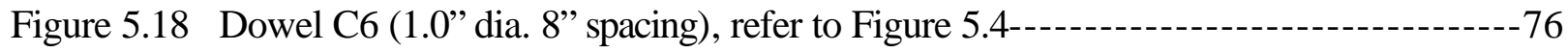

Figure 5.19 Strains on dowel during loading case for gage C6-U1 (1.0” dia., 8”

spacing), refer to Figure 5.4----

Figure 5.20 Strain from gage A1-LT (1.5”FRP dowel @ 9" spacing) from dynamic tests---------78

Figure 5.21 Strain from gage A2-LT (1.5” FRP dowel @ 12” spacing) from dynamic tests--------78 


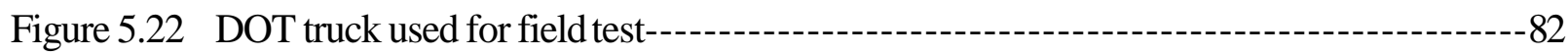

Figure 5.23 WVDOT truck positioned near a joint for test---

Figure 5.24 Two LVDTs measuring pavement deflections across a joint------------------------83

Figure 5.25 Measuring distance from tire to LVDTs (when loading is away from selected

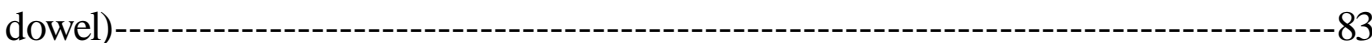

Figure 5.26 Deflection on pavement joint No. 3 (with 1.5" dia. \& 12” spacing FRP dowels)

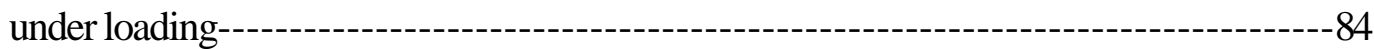

Figure 5.27 Deflection on pavement joint No.2 (with 1.5" dia. \& 9" spacing FRP dowels)

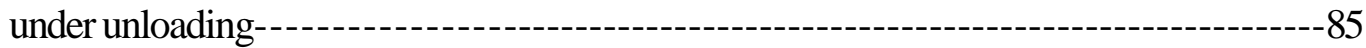

Figure 5.28 Deflection on pavement joint No.2 (with 1.5" dia. \& 9" spacing FRP dowels) under loading $-85$

Figure 5.29 Deflection on pavement joint No.5 (with 1.0" dia. \& 8" spacing FRP dowels) under loading $-86$

Figure 5.30 Deflection on pavement joint No.6 (with 1.0" dia. \& 6" spacing FRP dowels)

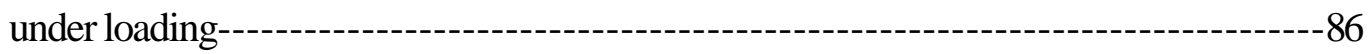

Figure 5.31 Comparison of LTE from field test (average value was used for joint No.2)---------88

Figure 5.32 Comparison of Relative Deflection from field test (average value was used for joint 2

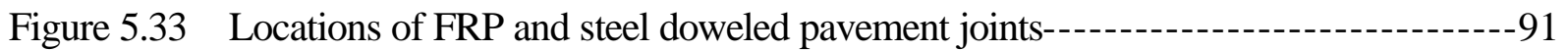

Figure 5.34 Drilling holes for inserting dowels---:-1-

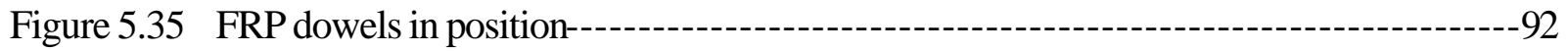

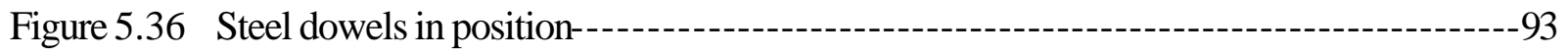

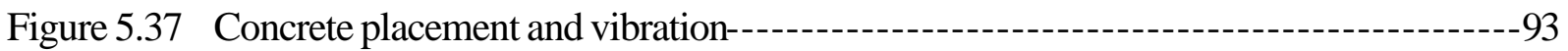




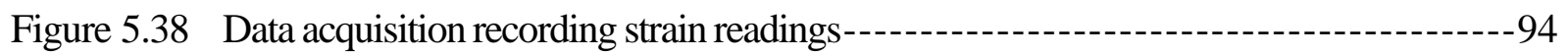

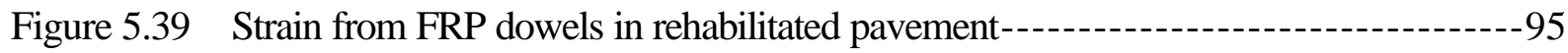

Figure 5.40 Strain from steel dowel in rehabilitated pavement-----------------------------------96

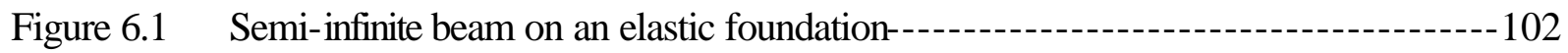

Figure 6.2 Slope and deflection of dowel at joint face---

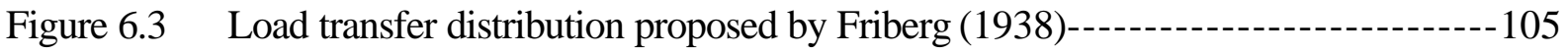

Figure 6.4 Load transfer distribution proposed by Tabatabaie et al. (1979)-----------------106

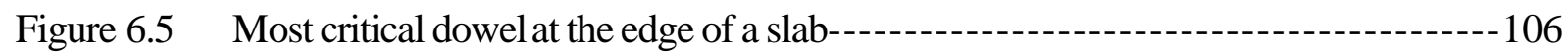

Figure 6.6 Relative deflection between concrete slabs (Porter and Guinn, 2002)---------------108

Figure 6.7 Expansion joint model used for theoretical calculation---

Figure 6.8 Steps for calculating critical dowel load, joint relative deflection

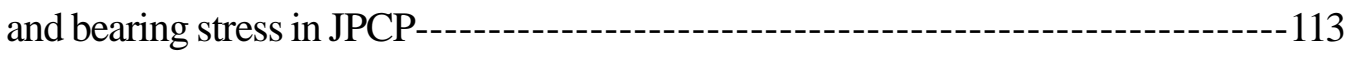

Figure 6.9 Generalized effective dowels for load distribution--------------------------------114

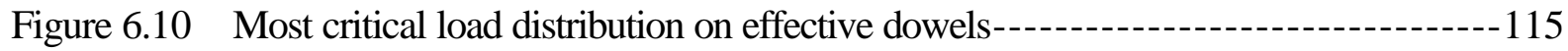

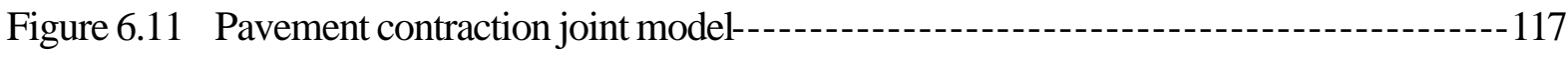

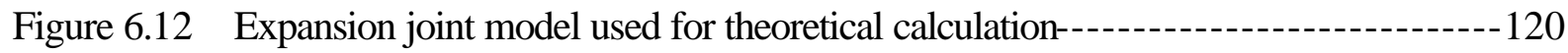

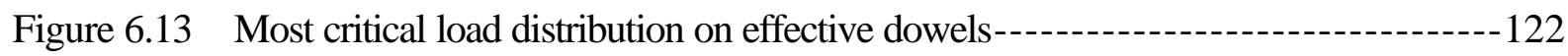

Figure 6.14 Dowel deflected shape (1.5" diameter)---129

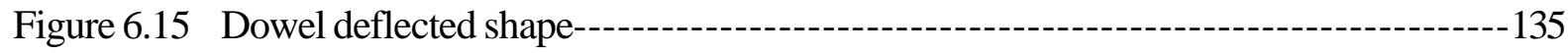

Figure A.1 Lab test of timber tie with FRP dowel bar as the load transfer device---------------160

Figure A.2 Four timber test cases---161

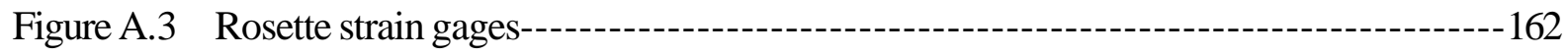

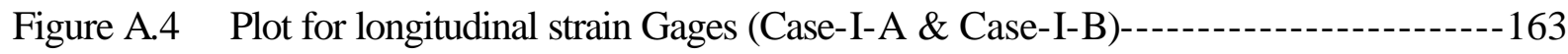




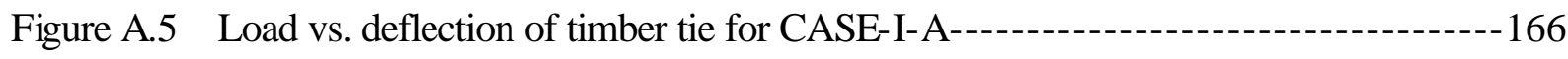

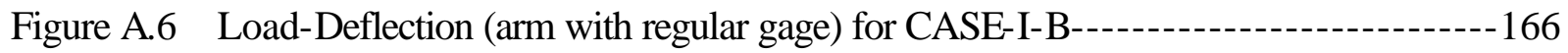

Figure B.1 Components of Relative Deflection for Dowel Types A (1.0" diameter) and $\mathrm{B}\left(1.5\right.$ " diameter), with $\mathrm{k}=400 \mathrm{pci}, \mathrm{f}_{\mathrm{c}}^{\prime}=4500 \mathrm{psi}$, Joint width $=0.25$ " and

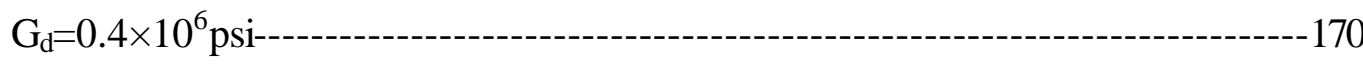

Figure B.2 Components of Relative Deflection for Dowel Types A (1.0" diameter) and $\mathrm{B}\left(1.5^{\prime \prime}\right.$ diameter), with $\mathrm{k}=400 \mathrm{pci}, \mathrm{f}_{\mathrm{c}}{ }^{\prime}=4500 \mathrm{psi}$, Joint width $=0.25 "$ and

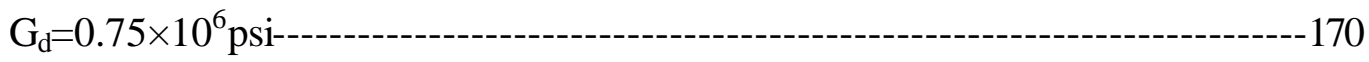




\section{Chapter 1}

\section{INTRODUCTION}

\subsection{General Remarks}

US highways and roads made of Joint Plain Concrete Pavement (JPCP) use load transfer devices called dowels across joints of a series of contiguous concrete slabs. Joints allow the movement and deformation of pavement to occur under mechanical loading and thermal variations. Joints may either be parallel to traffic (longitudinal joint) or perpendicular to traffic (transverse joints). Typical problems of jointed concrete pavement without an effective load transfer device include faulting, pumping or corner breaks.

Pavement joints supported with dowels have a longer service life than joints without dowels (AASHTO, 1993). Over time, traffic traveling over the joint may crush the concrete surrounding the dowel bar and cause voids due to excessive bearing stresses between the dowel and surrounding concrete. Concrete crushing may take place due to stress concentration where the dowel contacts concrete at the joint face directly above and below the dowel. Looseness of dowel support can decrease the load transfer efficiency (LTE) across the joint and accelerate pavement damage (Friberg, 1940).

Corrosion of the dowel bar can potentially bind or lock the joint. When locking of the joint occurs, no thermal expansion is allowed and new cracks parallel to the joint are formed directly behind the dowel bars in the concrete. As temperature decreases, contraction of the concrete widens the new cracks leading to reduction of load transfer. Once there is no load transferred across the joint, load is then transferred to the subgrade and differential settlement occurs in the adjacent slabs. Differential settlement of the 
adjacent slabs creates uneven surface and discontinuity at the joints, making vehicle travel uncomfortable and leading to slab repair or replacement.

Currently, steel dowels typically epoxy-coated with a diameter of 1.0 inch or 1.5 inch and length of 18 inches are widely used in JPCP. However, this coating is usually nicked or scraped before installation, leading to dowel corrosion and deterioration (Figure 1.1). FRP dowel bars, which are resistant to corrosive environments can be used as effective load transfer mechanism in JPCP. Currently polymer matrix composites such as fiber reinforced plastics (FRP) are being used in a broad range of structural applications within the aerospace, automotive, marine and construction industries, due to their superior strength to weight ratio and high corrosion resistance (Vijay and GangaRao, 1999).

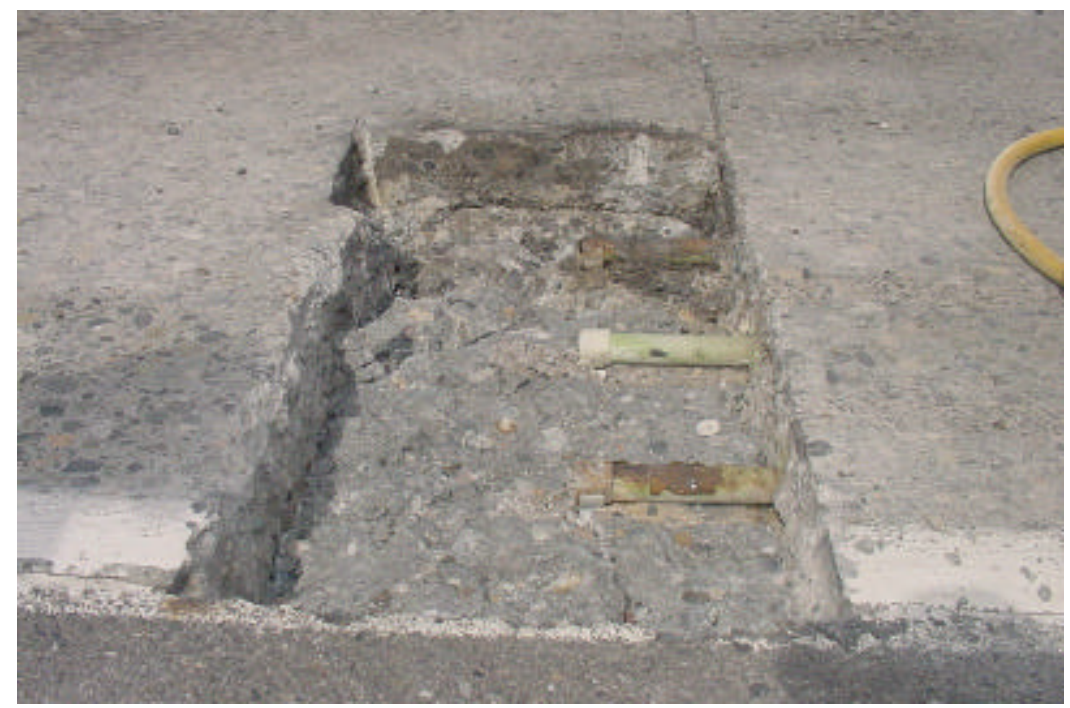

Figure 1.1 Exposed failures with rusted dowel bars (WS DOT Pavement Guide)

In this research, response of concrete pavement with FRP dowels is investigated through laboratory experiments and field implementation. 


\subsection{Objectives}

The main objectives of this study are to evaluate:

1. To evaluate FRP dowel bars with 1.5" and 1.0" diameter spaced at different intervals as load transferring devices in JPCP under HS25 static and fatigue loads and compare their response (relative deflection and load transfer efficiency) with JPCP consisting of steel dowels under laboratory and field conditions.

2. To evaluate the performance (strain and deflection) of JPCP rehabilitated with FRP and steel dowels.

3. To model FRP and steel dowel response and that of the pavement in terms of dowel maximum bending deflection, relative deflection and bearing stress.

\subsection{Scope}

1. Details of laboratory tests conducted at WVU structural laboratory are as follows:

i. Two jointed concrete slabs with 1.5" diameter FRP dowels and 12" slab depth were tested under static loads during preliminary static load investigation.

ii. Five jointed concrete slabs with 1.5" and 1.0" steel and FRP dowels having different spacings (12", 6") were tested under static and fatigue loads corresponding to HS25 load and 1.5 times HS25 load. Slab depth was 11 " for all the five slabs, similar to field installation depth. 
iii. Pavement performance (load transfer efficiency, relative deflection and dowel strain) with FRP and steel dowels was evaluated with respect to:
a. Dowel diameter
b. Dowel spacing

by using identical slab thickness, $\mathrm{f}_{\mathrm{c}}$, joint depth and width.

2. FRP dowel bars were field installed in new highway JPCP construction on Rt.219, Elkins WV. Both 1.5" and 1.0" diameter FRP dowels were installed in the field and dowel spacings used were 6", 8", 9" and 12". Two field tests were conducted and results were analyzed and discussed.

3. FRP dowel bars with 1.5" diameter were installed for pavement rehabilitation near the intersection of Rt. 857 and Rt. 119, University Avenue, Morgantown, WV. Dowel strains due to regular traffic were analyzed and discussed.

4. Analysis and discussions corresponding to theoretical calculations are provided for four different examples of pavements with FRP and steel dowels in terms of dowel diameter, spacing, dowel material properties, joint width, and base material properties.

This report is organized into 7 chapters. Chapter 1 describes objectives and scope of this research. Chapter 2 deals with the literature review. Chapter 3 describes materials and laboratory test setup used in this research. Chapter 4 discusses experimental results from laboratory tests. Chapter 5 presents field installation, field load test results and discussions. Theoretical evaluations are presented in Chapter 6. Finally, Chapter 7 
provides summary and conclusions of this research including suggestions for future research. Appendix A describes a preliminary test on timber ties consisting of a FRP dowel as load transfer device. Appendix B is an analytical evaluation of effects of FRP dowel shear modulus on pavement relative deflection. Appendix $\mathrm{C}$ describes the details of burnout tests for determining Fiber Weight Fraction (FWF) and Fiber Volume Fraction (FVF) of FRP dowels with 1.0" and 1.5" diameter. 


\section{Chapter 2}

\section{LITERATURE REVIEW}

\subsection{Introduction}

In Jointed Plain Concrete Pavements, inadequate load transfer across the joint will cause substantially higher stresses and deflections due to joint loading than those due to interior loading. A dowel bar trans fers part of an applied wheel load from the loaded slab across the joint to the adjacent unloaded slab. Load transfer through dowel bars significantly reduces stresses and deflections due to joint loading, leading to minimized faulting and pumping (Fig. 2.1). Faulting is the difference in elevation across the joint of the two slabs, while pumping is defined as the expulsion of subgrade material through joints and along the edges of the pavement (Ambroz, 2003).

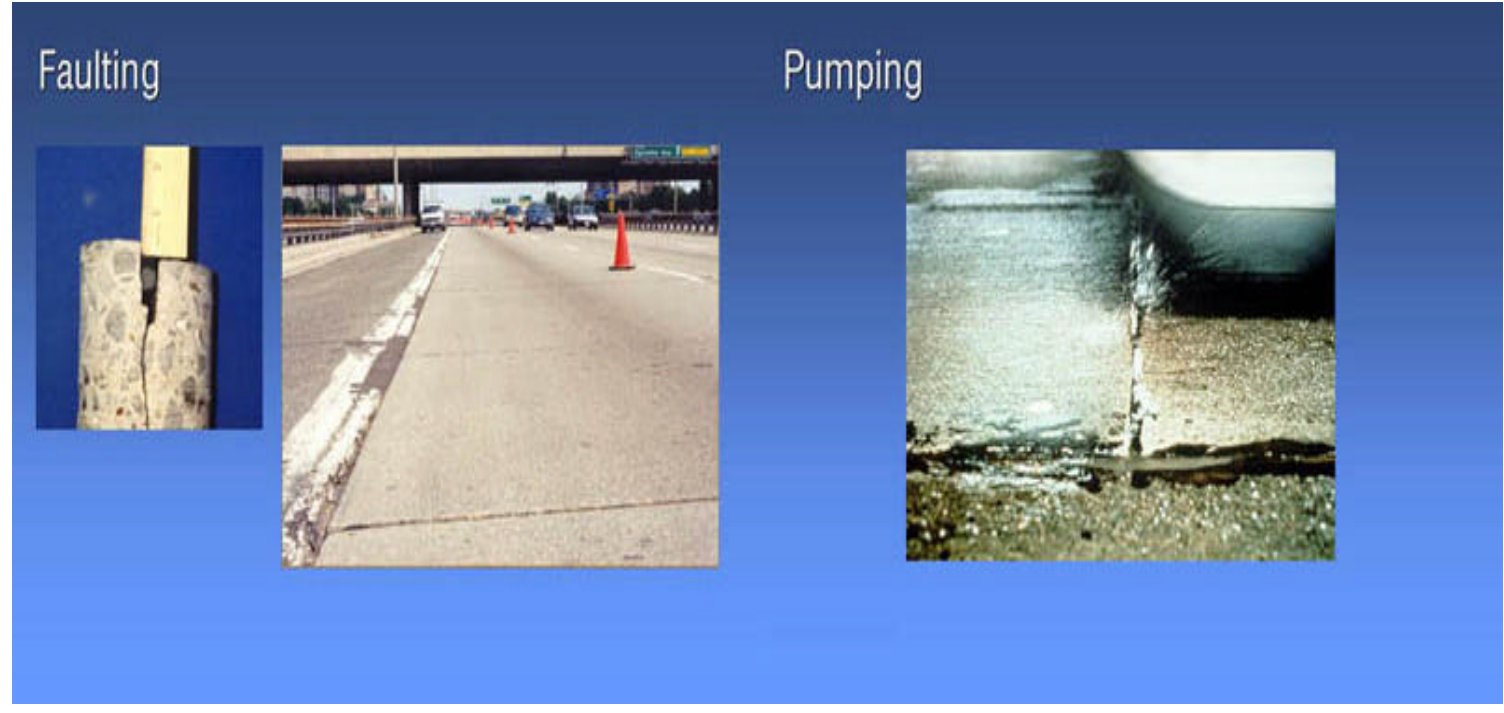

Figure 2.1 Typical pavements problems: Faulting and Pumping (American Highway

Technology, 2003) 


\subsection{Literature Reviews}

Currently, FRP dowels have not been widely used in concrete pavements for highway. However, a number of projects in the United States and Canada that have used these composite materials for highway pavement, on an experimental basis.

In 1983, the Ohio Department of Transportation (ODOT) installed several FRP dowel bars to evaluate long-term performance in sections of Interstate 77 in Guernsey County and Ohio State Route 7 in Belmont County. In 1998, the Market Development Alliance (MDA) of the composites industry organized the extraction and testing of samples of these dowel bars. GFRP Dowel Bars were found to be virtually unaffected by approximately 15 years of field service and exposure in pavement service.

In 1997, FRP dowel bars were installed in a high performance pavement project on US 65 bypass near Des Moines, IA. Length of the pavement sections with FRP dowels was $440 \mathrm{ft}$. and $417 \mathrm{ft}$. with $20 \mathrm{ft}$. joint spacing (skewed) and dowel bars on 12 inch and 8 inch spacing, respectively. Indications are that the FRP Dowels have been performing well. Additional alternative Dowel Bar projects utilizing FRP Dowels have been installed in Illinois, Iowa, Kansas, Minnesota, Ohio, Wisconsin and Manitoba.

Brown and Bartholomew (1993) found that FRP dowels made of vinyl ester resins compared well with steel dowels in the scaled model tests. Experimental load transfer percentages were in agreement with theoretical values, and fell within the $35 \%$ to $40 \%$ range predicted for standard joints under typical subgrade conditions. They recommend approximately 20 to 30 percent increase in dowel diameter to maintain deflections, concrete bearing stresses, and load transfer percentages at comparable levels with joints containing steel dowels. 
Ahmed et al. (2001) from University of Manitoba, Canada, have conducted researches for Glass Fiber-Reinforced Polymer (GFRP) dowels. In the ir experimental program, round GFRP dowel bar having a $38-\mathrm{mm}(1.5$ ") diameter and the second is a concrete-filled GFRP pipe having a 60-mm (2.36") outside diameter were evaluated under laboratory and a field implementation. The field test section was constructed on a regional highway in the city of Winnipeg.

They concluded that GFRP dowels subjected to FWD tests in the field showed that LTEs of GFRP dowels are comparable to those produced by steel dowels, provided the diameter of the GFRP dowel is $20-30 \%$ larger than the steel dowel. The larger diameter results in a reduction in bearing stresses that in turn reduces the potential for faulting.

Tests conducted by Eddie et al. (2001) showed that the joint effectiveness of GFRP dowels to be in the range of $86 \%$ to $100 \%$ effectiveness using a weak subgrade and $90 \%$ to $97 \%$ using a stiff subgrade. ACPA criteria for successful joint load transfer is $75 \%$.

Porter (2002) and other researchers in Iowa State University studied use of GFPR dowels for JPCP with contraction. They concluded that:

- The 1.5-inch diameter GFRP dowels spaced at 12-inch centers were inadequate in transferring load for the anticipated design life of the pavement.

- The 1.5-inch diameter GFRP dowels spaced at 6-inch centers were effective in transferring load over the anticipated design life of the pavement. 
Literature review indicates contradictory conclusions on the LTE of 1.5" FRP dowels. Suggestions are also provided by researcher to increase dowel bar diameter from 1.5 " to 1.75 ". Some researchers have noted increased relative deflection with an increased diameter. Hence, it was decided to utilize 1.5" and 1.0" dowel diameter in this research with $69.47 \%$ and $72 \%$ fiber weight fraction, respectively. Chapter 3 describes materials and laboratory test setup used in this research. 


\section{Chapter 3}

\section{MATERIALS, EQUPMENT AND LAB TESTING PROCEDURES}

\subsection{Introduction}

Mechanical properties of dowel bars affect the behavior and performance of JPCP provided with FRP and steel dowels. This chapter discusses mechanical properties of FRP and steel dowels, and test setup in the Major Unit Laboratory of West Virginia University. Seven full-scale jointed plain concrete pavements (Two with a dimension of 12 "x12"x120" and five with 12"x11"x120") were cast with simulated contraction or saw cut joint. The specimens were subjected to both static load and fatigue load with a frequency of about 4.0 hertz.

\subsection{Material Properties}

Class K concrete (3750 psi and 4500 psi), two different diameters (1.5" and 1.0”) of Glass Fiber Reinforced Polymer (GFRP) dowel and epoxy coated steel dowels were used for casting the concrete pavements in the structural laboratory. Relevant material properties are provided in this section.

Two slabs used for preliminary testing consisted of $\mathrm{f}_{\mathrm{c}}$ ' of $3750 \mathrm{psi}$, and for rest of the five slabs, $\mathrm{f}_{\mathrm{c}}$ ' was found to be 4500 psi through cylinder tests.

\subsubsection{GFRP Dowels}

GFRP dowels were provided by RJD Industries, Inc. GFRP dowels are pultruded with continuous E glass filaments and polyester resin. Typically, filaments are drawn through a resin bath, sized by an appropriate die, to form the dowel bar. A UV inhibitor is added to the resin to resist effects of sunlight. Dowels with 1.5" and 1.0" diameter were used in this project. Other researchers have commented on using 1.75" diameter FRP 
dowel bars instead of 1.5" diameter. However, researchers (Porter, 2002) have noted that increased bar diameter will result in larger relative deflection. Hence, it was decided to utilize lower diameter bars in this research.

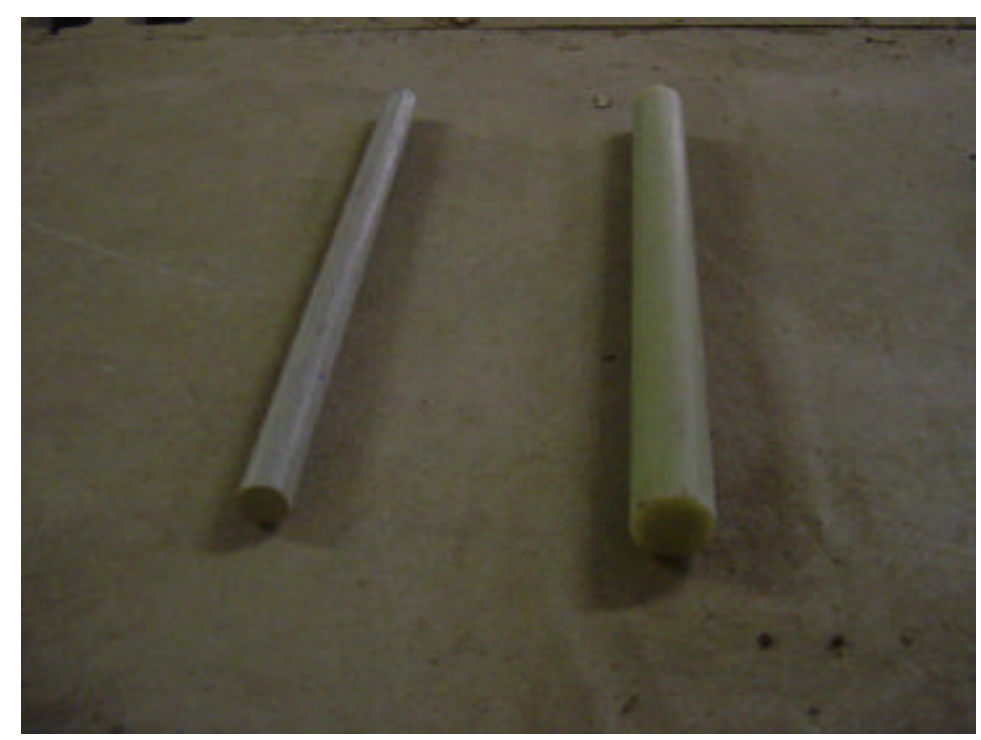

Figure 3.1 FRP dowels (1.5” and 1.0” diameter)

Figure 3.1 shows two types of GFRP dowels used in this research. Tables 3.1 and 3.2 show properties of FRP bars listed by the manufacturer. 
Table 3.1 MODULUS OF ELASTICITY TEST RESULTS OF FRP ROD SPECIMENS - ASTM D3916 (RJD Industries, Inc.)

\begin{tabular}{|c|c|c|c|c|c|c|c|}
\hline Type & $\begin{array}{c}\text { Nominal } \\
\text { Dia. (in.) }\end{array}$ & $\begin{array}{c}\text { Actual } \\
\text { Dia. (in.) }\end{array}$ & $\begin{array}{c}\text { Area } \\
\text { Sq. (in.) }\end{array}$ & $\begin{array}{c}\text { Ultimate } \\
\text { Load (lbs.) }\end{array}$ & $\begin{array}{c}\text { Tensile } \\
\text { Stress (psi) }\end{array}$ & $\begin{array}{c}\text { Elongation } \\
\%\end{array}$ & $\begin{array}{c}\text { MOE } \\
\text { Msi }\end{array}$ \\
\hline \hline \multirow{2}{*}{$\mathrm{A}$} & 1.0000 & 0.9713 & 0.7394 & 66539 & 89986 & 0.094 & 6.0 \\
\cline { 2 - 8 } & 1.0000 & 0.9700 & 0.7390 & 65204 & 88235 & 0.091 & 6.0 \\
\hline Average & 1.0000 & 0.9707 & 0.7392 & 65872 & 89111 & 0.093 & 6.0 \\
\hline \hline \multirow{2}{*}{$\mathrm{B}$} & 1.5000 & 1.4932 & 1.7512 & 134440 & 76772 & 0.219 & 5.2 \\
\cline { 2 - 9 } & 1.5000 & 1.4933 & 1.7514 & 137000 & 78226 & 0.179 & 5.0 \\
\hline Average & 1.5000 & 1.4933 & 1.7513 & 135720 & 77499 & 0.199 & 5.1 \\
\hline \hline
\end{tabular}

Table 3.2 SHEAR TEST RESULTS OF FRP ROD SPECIMENS - SINGLE

SHEAR FIXTURE (RJD Industries, Inc.)

\begin{tabular}{|c|c|c|c|c|c|}
\hline Type & $\begin{array}{c}\text { Nominal Dia. } \\
\text { (in.) }\end{array}$ & $\begin{array}{c}\text { Actual } \\
\text { Dia. (in.) }\end{array}$ & $\begin{array}{c}\text { Area } \\
\text { Sq. (in.) }\end{array}$ & $\begin{array}{c}\text { Ultimate } \\
\text { Load (lbs.) }\end{array}$ & $\begin{array}{c}\text { Shear } \\
\text { Stress (psi) }\end{array}$ \\
\hline \hline \multirow{3}{*}{ A } & 1.0000 & 0.9703 & 0.7390 & 28600 & 38700 \\
\cline { 2 - 6 } & 1.0000 & 0.9700 & 0.7380 & 30300 & 41060 \\
\cline { 2 - 6 } & 1.0000 & 0.9702 & 0.7390 & 27200 & 36810 \\
\hline Average & 1.0000 & 0.9702 & 0.7387 & 28700 & 38857 \\
\hline \hline \multirow{2}{*}{ B } & 1.5000 & 1.4923 & 1.7490 & 33982 & 19429 \\
\cline { 2 - 6 } & 1.5000 & 1.4935 & 1.7519 & 31782 & 18142 \\
\hline Average & 1.5000 & 1.4929 & 1.7505 & 32882 & 18786 \\
\hline \hline
\end{tabular}




\subsubsection{Steel Dowels}

The steel dowels used in this research were Grade 40 plain uncoated steel or epoxy coated steel. Dowels with 1.5" and 1.0" diameter were used for laboratory experiments and field installation.

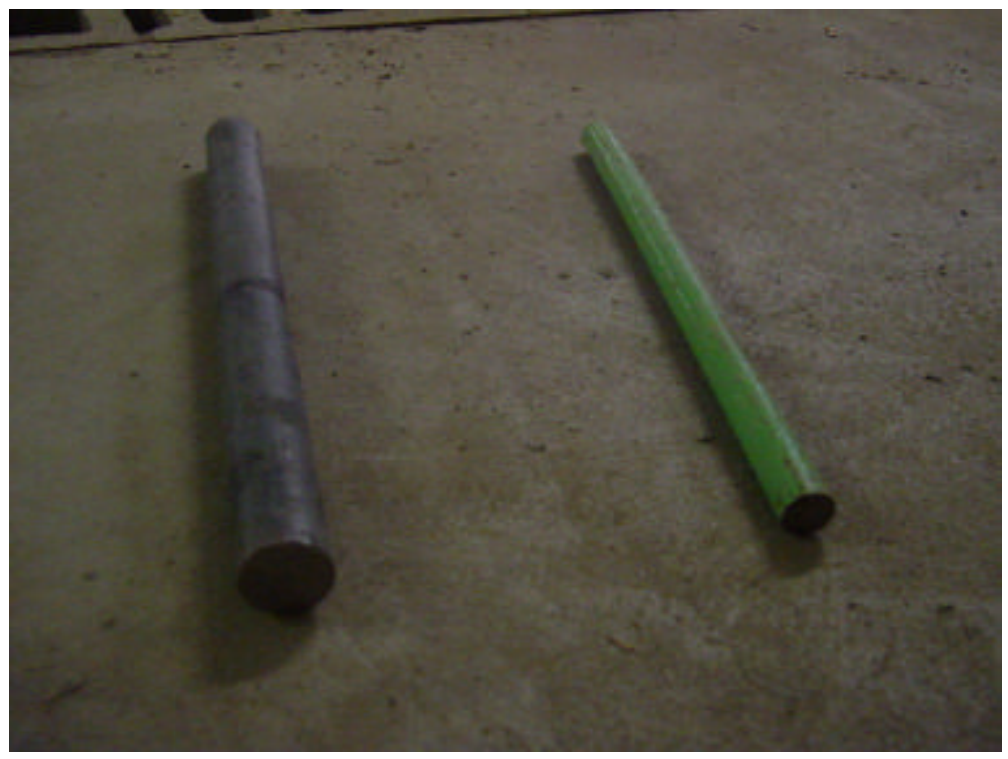

Figure 3.2 Steel dowels (1.5” and 1.0" diameter)

\subsubsection{Concrete}

Class $\mathrm{K}$ ready-mixed concrete was used for laboratory slab casting. It was supplied by Hoy REDI-MIX Company, Morgantown, WV. Compressive strength of concrete was 3750 psi for 12 " thick slabs and 4500 psi for 11 " thick slabs. Concrete was poured in formwork and removed after 24 hours. The concrete beams were cured 28 days by wet burlap and plastic sheet covering.

\subsubsection{Base}

To simulate a stiff subgrade used in the field, a base layer of limestone aggregates was prepared and compacted to a depth of 16 inches in a wood framed bin described in Section 3.3. The modulus of subgrade reaction $\mathrm{k}$ was determined from plate loading tests 
in the laboratory. Based on the measured values, an average of 400 pci was used for all our tests employing aggregate base. The value was also applied to the theoretical calculations.

\subsection{Formwork}

Figures 3.3 and 3.4 show wood formworks made for casting concrete slabs in the laboratory.

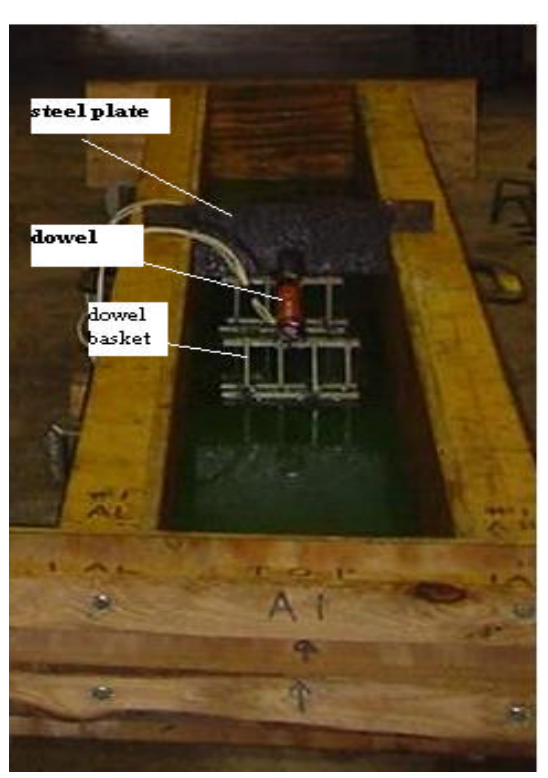

Figure 3.3 Wood formwork

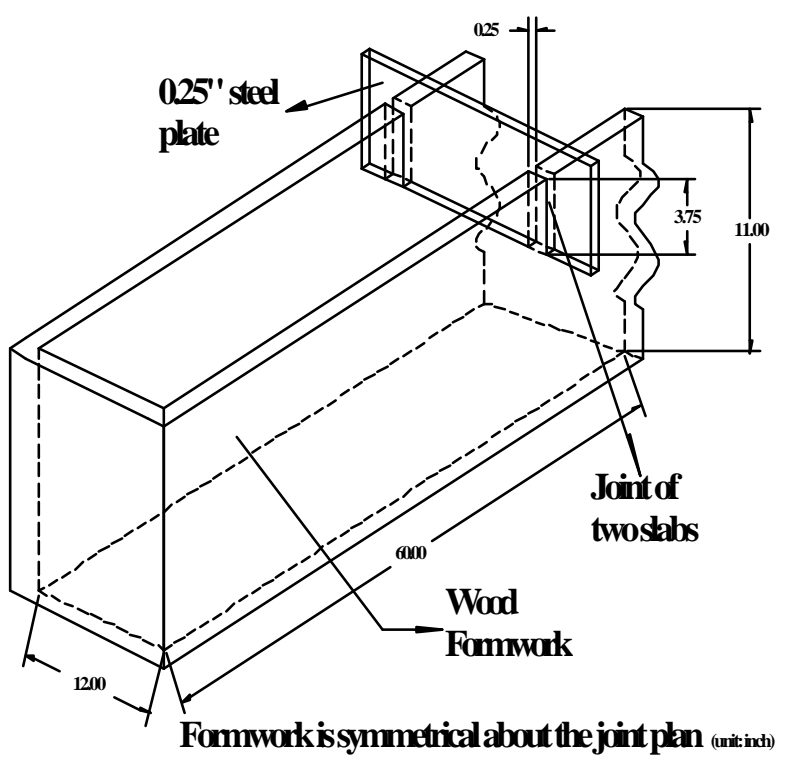

Figure 3.4 Dimensions of formwork (inches) 


\subsection{Test Setup}

\subsubsection{Specimen Fabrication}

Seven different slabs were cast with FRP and steel dowels using different spacing and diameters.

\subsubsection{Material Preparations}

FRP and Steel dowels were prepared with slots at locations where strain gages were going to be placed.

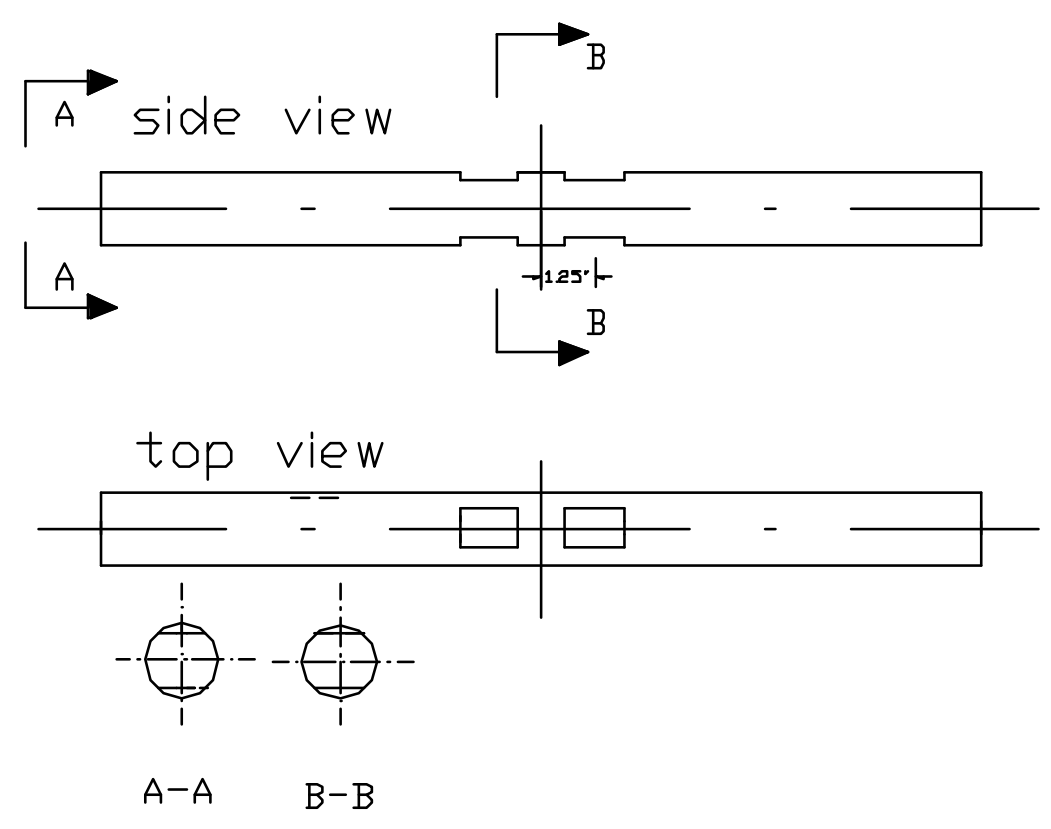

Figure 3.5 Trimmed dowel bar

Uniaxial strain gages were bonded to dowels at slot position shown in Fig. 3.5. Strain gages were protected by using M-Coat-J (Polysulfide) from Vishay Measurements Group.

\subsubsection{Pavement Slab Casting}

The inside walls of wood formworks were oiled so that concrete pavement slabs could be easily demolded. Strain gage instrumented dowels were then placed in dowel 
baskets to properly center them in the joint. Steel plate with $1 / 4$ " thickness was placed in the middle to simulate a contraction or saw-cut joint in the concrete pavement (Figures 3.3 and 3.4).

Class $\mathrm{K}$ concrete conforming to the WVDOT-DOH specification was used for casting (Fig. 3.9). Concrete cylinders were simultaneously cast to obtain concrete compressive strength. Twenty-four hours after casting the beams and cylinders, curing was carried out using wet burlaps.

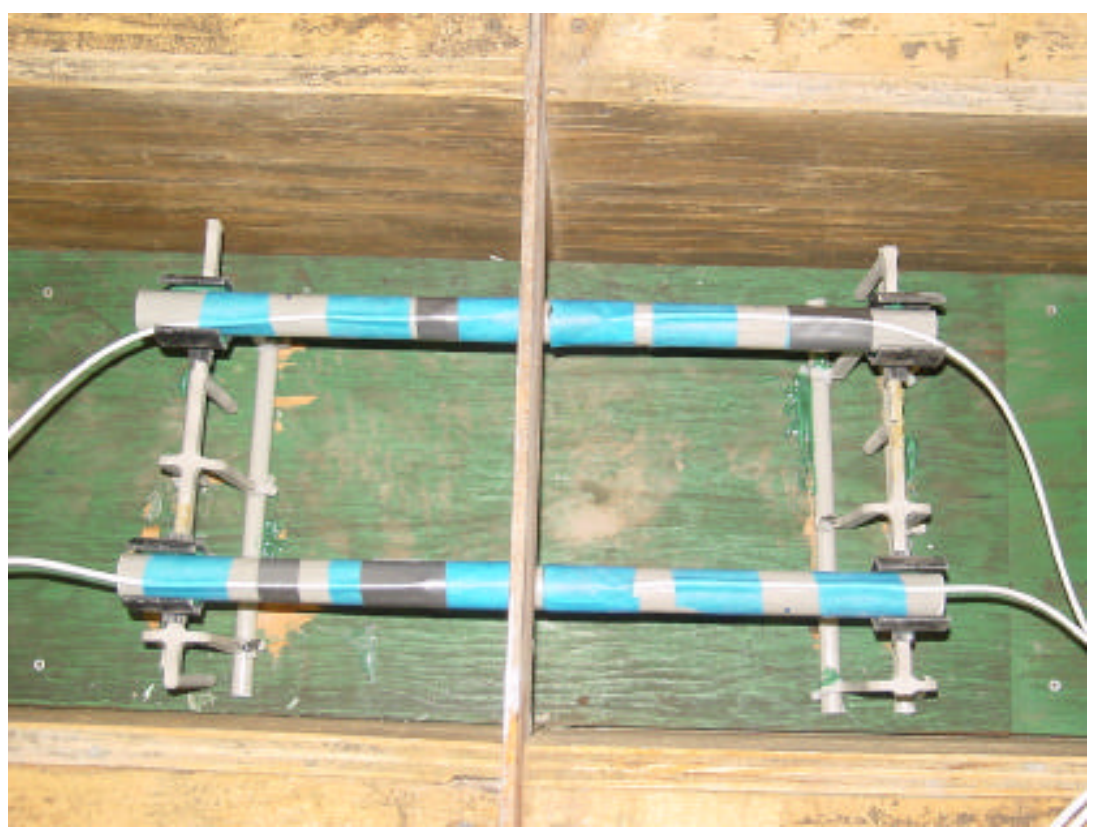

Figure 3.6 Instrumented dowels and steel plate positioned in the wood formwork 


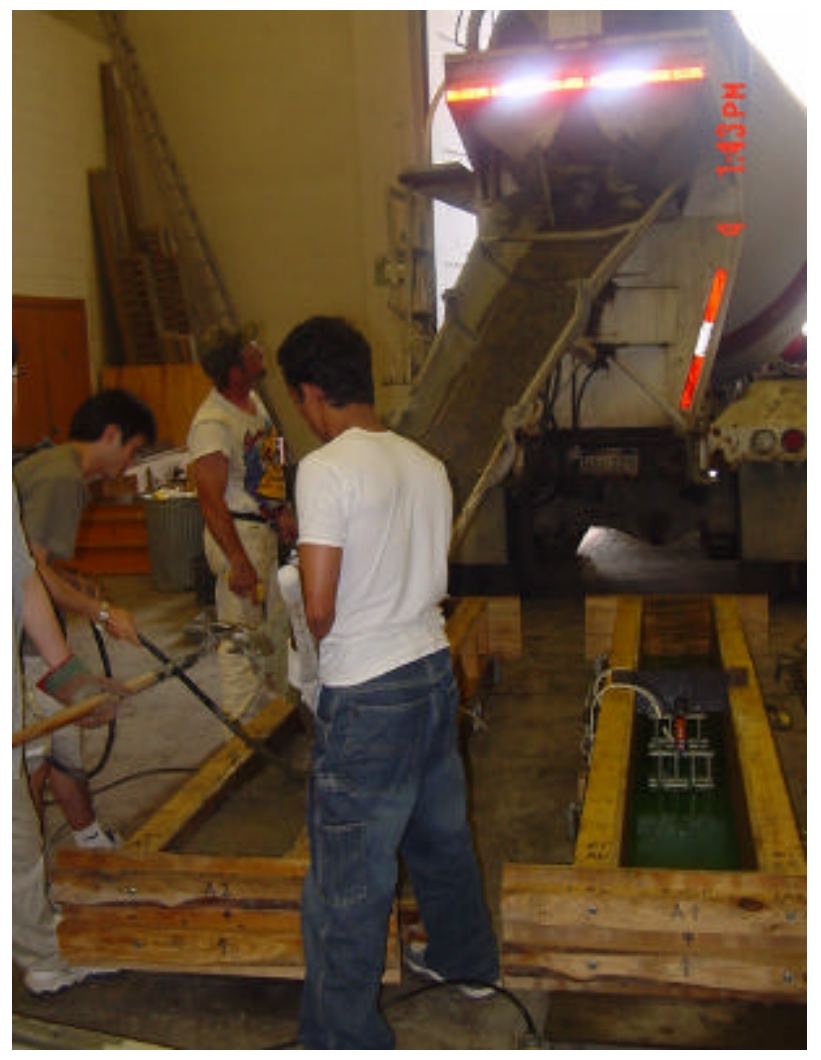

Figure 3.7 Placing concrete into formwork

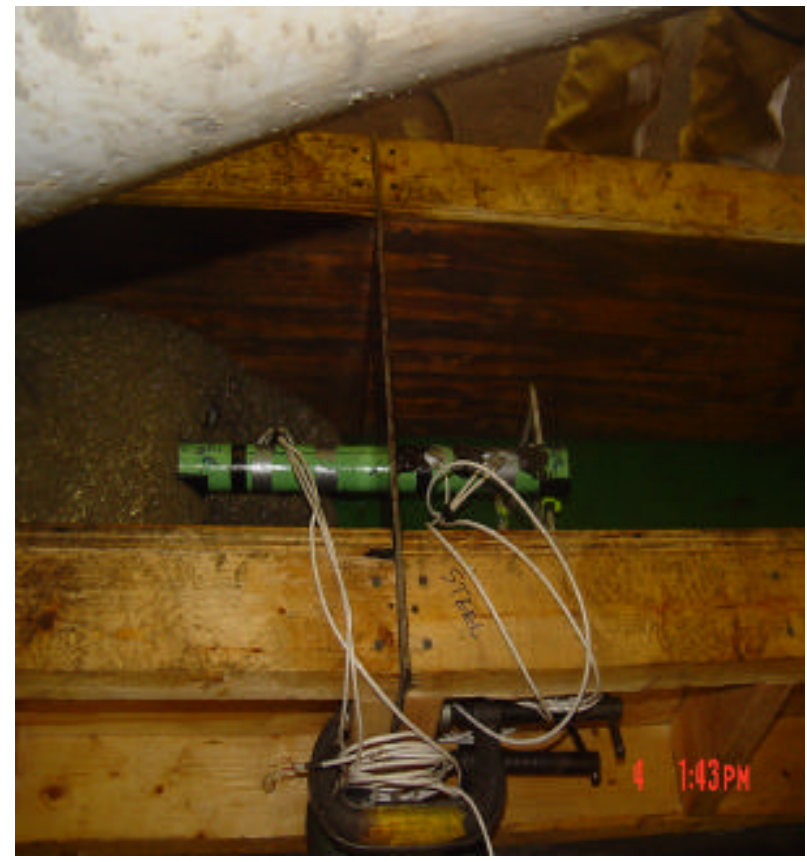

Figure 3.8 Dowel being covered by concrete 


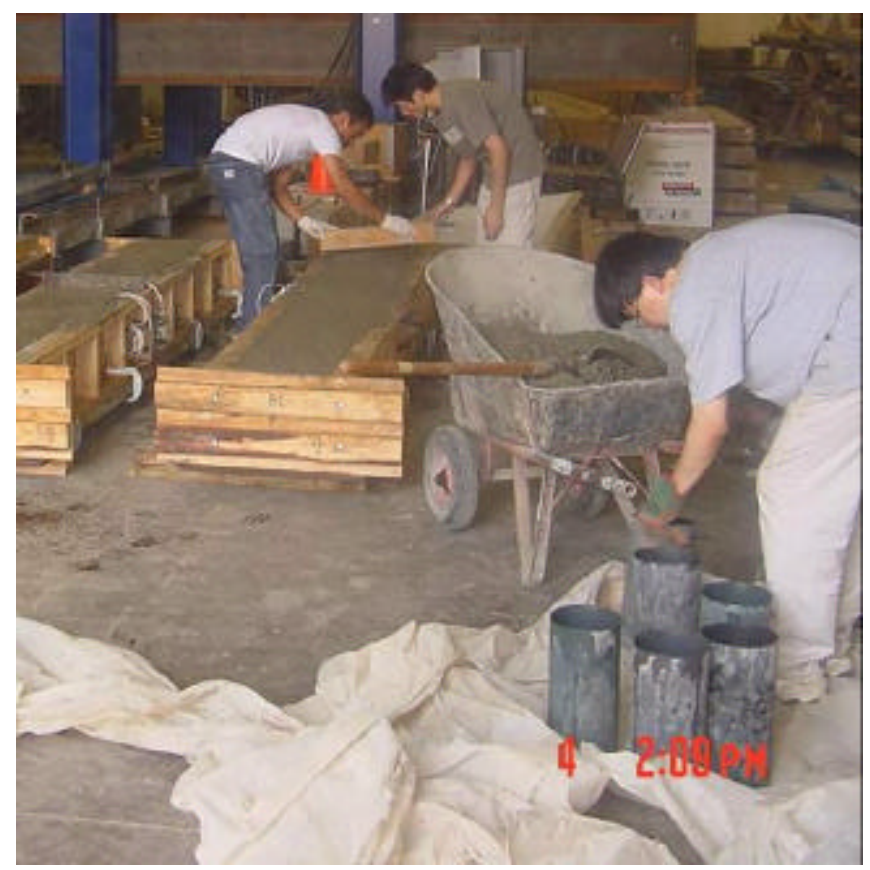

Figure 3.9 Casting concrete cylinders

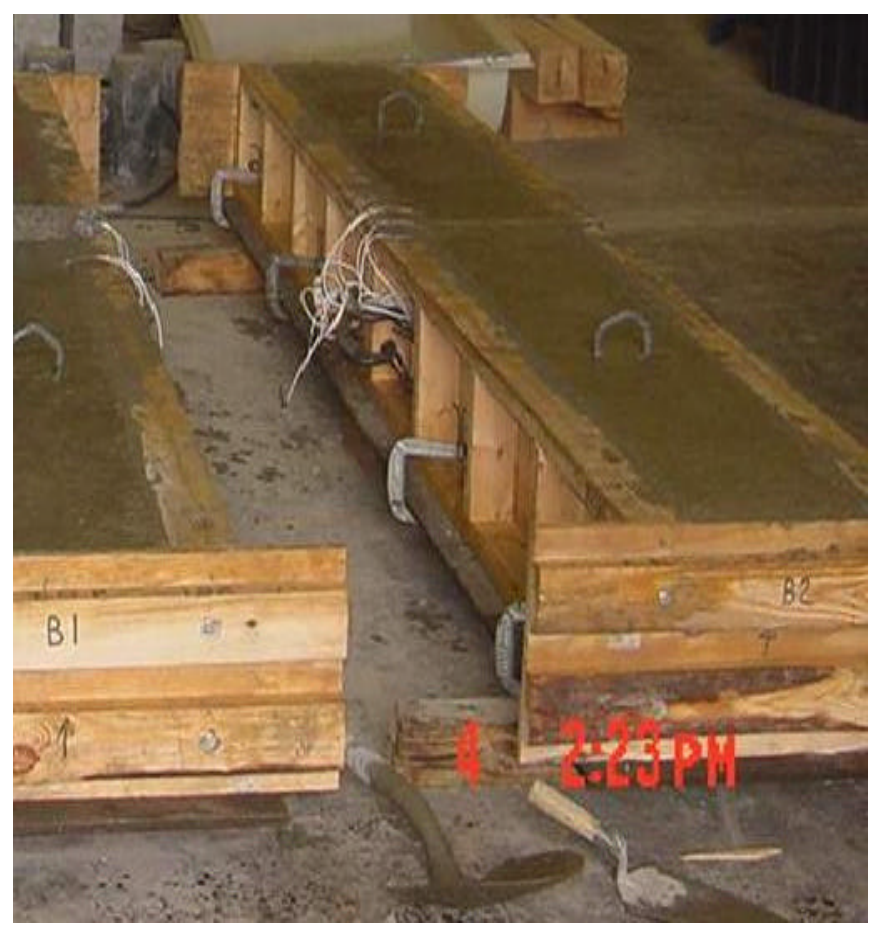

Figure 3.10 Surface finished spe cimens 


\subsubsection{Test Specimens}

Two specimens with a dimension of 12"x12"x120" (Fig. 3.11) were cast for preliminary tests. Only FRP dowels were used as load transfer devices in these two specimens.

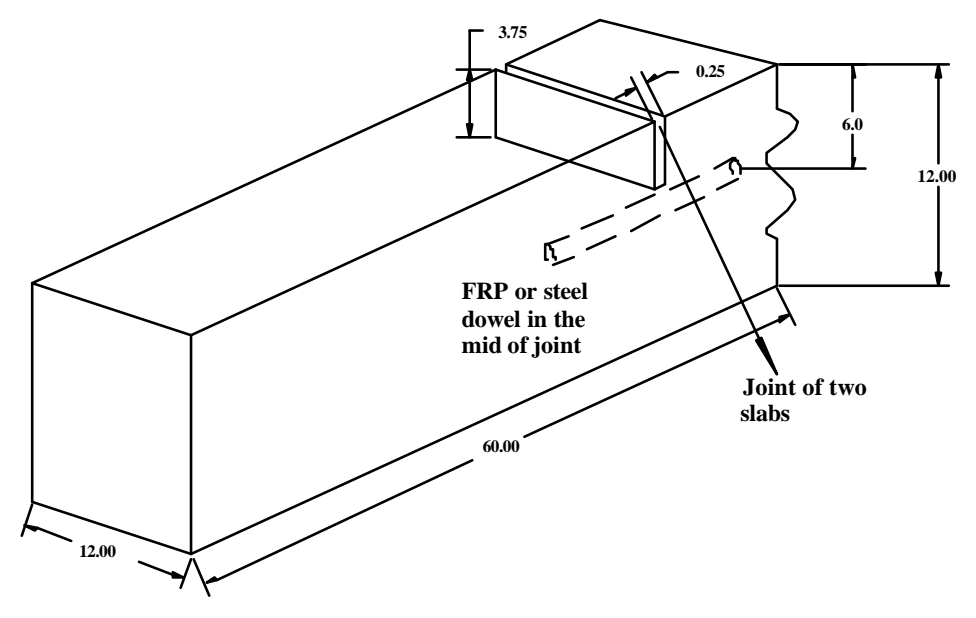

specimen is symmetrical about the joint plan (unit: inch)

\section{Figure 3.11 Concrete slabs for preliminary tests}

Five different concrete slabs were cast with FRP and steel dowels with different spacings and diameters (Table 3.3). Two Embeddable Strain Gages were positioned vertically on both sides of a dowel across the joint to measure concrete strain at loaded side and unloaded side. Details of concrete specimens are provided in Figures 3.12 and 3.13 and Table 3.3. 


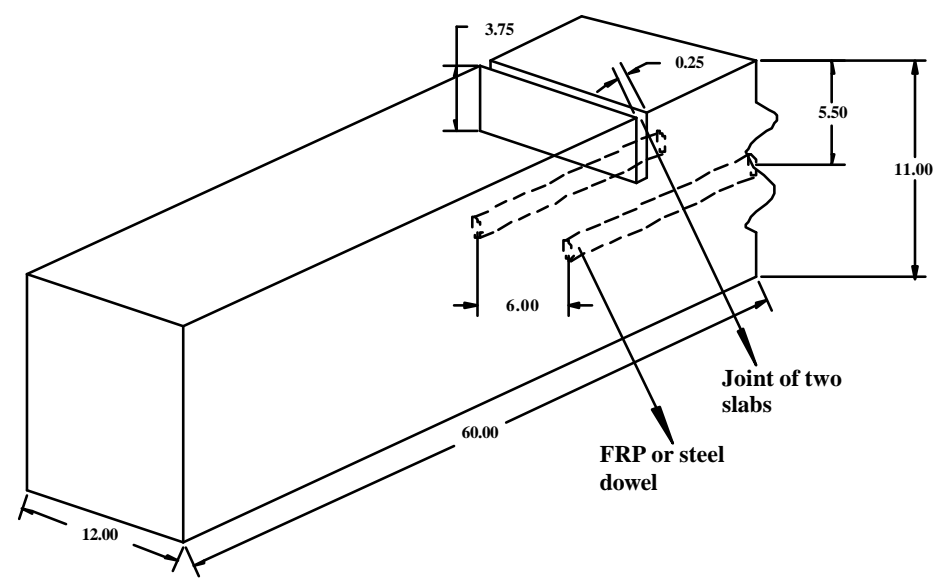

specimen is symmetrical about the joint plan (unit: inch)

Figure 3.12 Concrete slabs containing two dowels

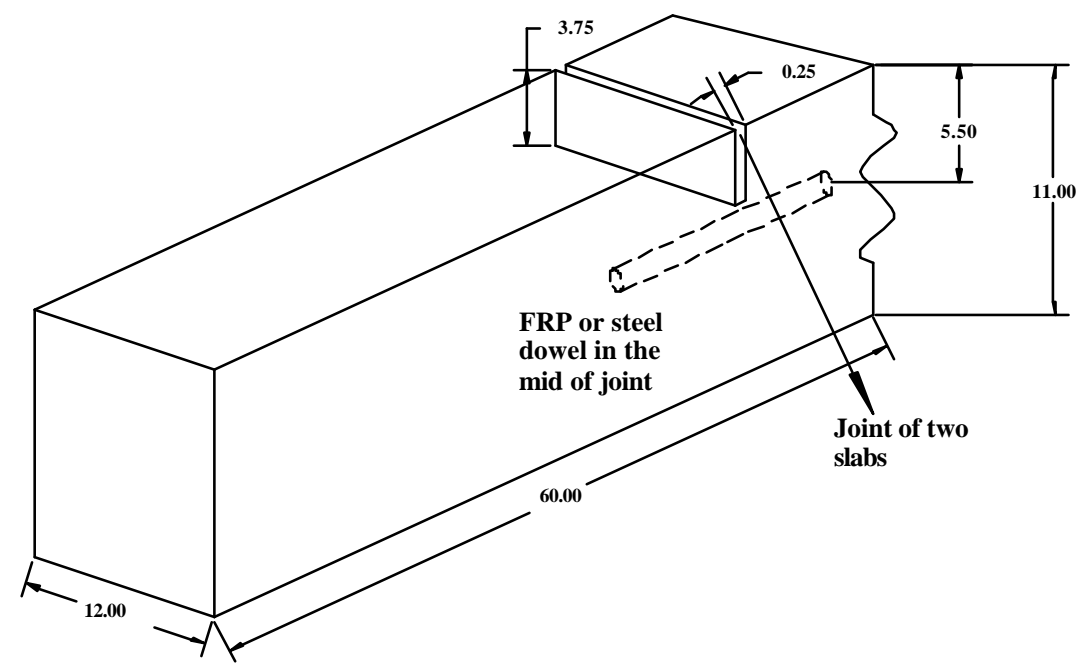

specimen is symmetrical about the joint plan (unit: inch)

Figure 3.13 Concrete slabs containing only one dowel 
Table 3.3 Dowel details in specimens

\begin{tabular}{|c|c|c|c|c|c|c|}
\hline & $\begin{array}{c}\text { Specimen } \\
\#\end{array}$ & $\begin{array}{l}\text { Slab } \\
\text { Depth } \\
\text { (in.) }\end{array}$ & $\begin{array}{c}\text { Dowel } \\
\text { Material }\end{array}$ & $\begin{array}{c}\text { Dowel } \\
\text { Diameter } \\
\text { (in.) }\end{array}$ & $\begin{array}{l}\text { Spacing } \\
\text { (in.) } \\
\text { Center to } \\
\text { center }\end{array}$ & $\begin{array}{c}\text { Number of } \\
\text { dowel in } \\
\text { each } \\
\text { specimen }\end{array}$ \\
\hline $\begin{array}{c}\text { Preliminary } \\
\text { Group }\end{array}$ & $\begin{array}{l}\text { PG-1 } \\
\text { PG-2 }\end{array}$ & $12 "$ & FRP & 1.5 & 12 & 1 \\
\hline Group 1 & $\begin{array}{l}1 \\
2 \\
3\end{array}$ & 11 & $\begin{array}{c}\text { Steel } \\
\text { FRP } \\
\text { FRP }\end{array}$ & $\begin{array}{l}1.0 \\
1.0\end{array}$ & 6 & 2 \\
\hline Group 2 & $\begin{array}{l}4 \\
5\end{array}$ & 11 & $\begin{array}{l}\text { Steel } \\
\text { FRP }\end{array}$ & 1.5 & 12 & 1 \\
\hline
\end{tabular}

\subsubsection{Test Setup and Instrumentation}

Jointed concrete slabs were placed on an aggregates base inside a wooden box to simulate field conditions. The base was 16" high and 18" wide and 120" in length. The modulus of subgrade reaction $\mathrm{k}$ was obtained from tests on this base through load application on a standard steel plate (ASTM, 1986).

Pavement load was applied on one side of the joint (Figures 3.14 and 3.15) using a 55 kip MTS hydraulic actuator through a controller. A 1/4-inch thick steel plate of dimension (10"x16") was connected to the actuator to simulate the load from a dual tire wheel load. Additional neoprene pad was used between steel plate and concrete surface to prevent any local damage during test. Two calibrated Linear Variable Differential 
Transformers (LVDT) were used to measure joint deflections at loaded and unloaded side of joint. Strain gages, LVDTs and load cell from the actuator were connected to a data acquisition system to automatically record data during the tests.

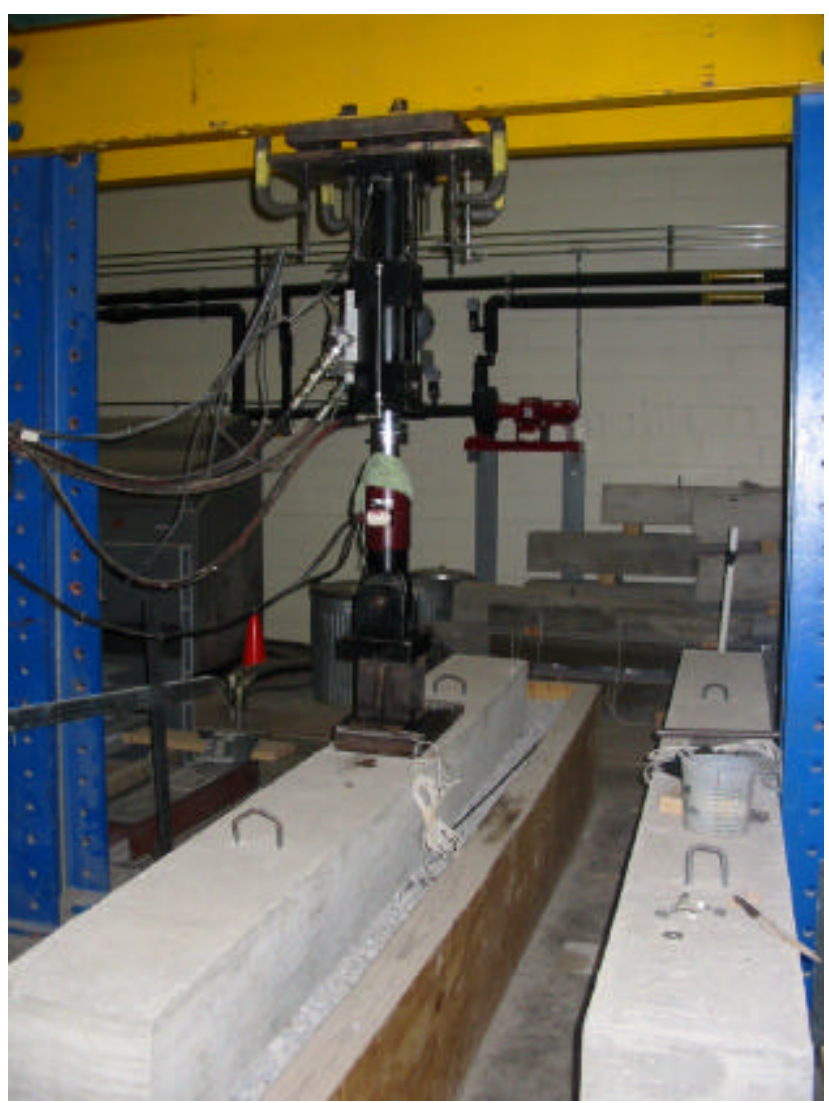

Figure 3.14 Experimental set up 


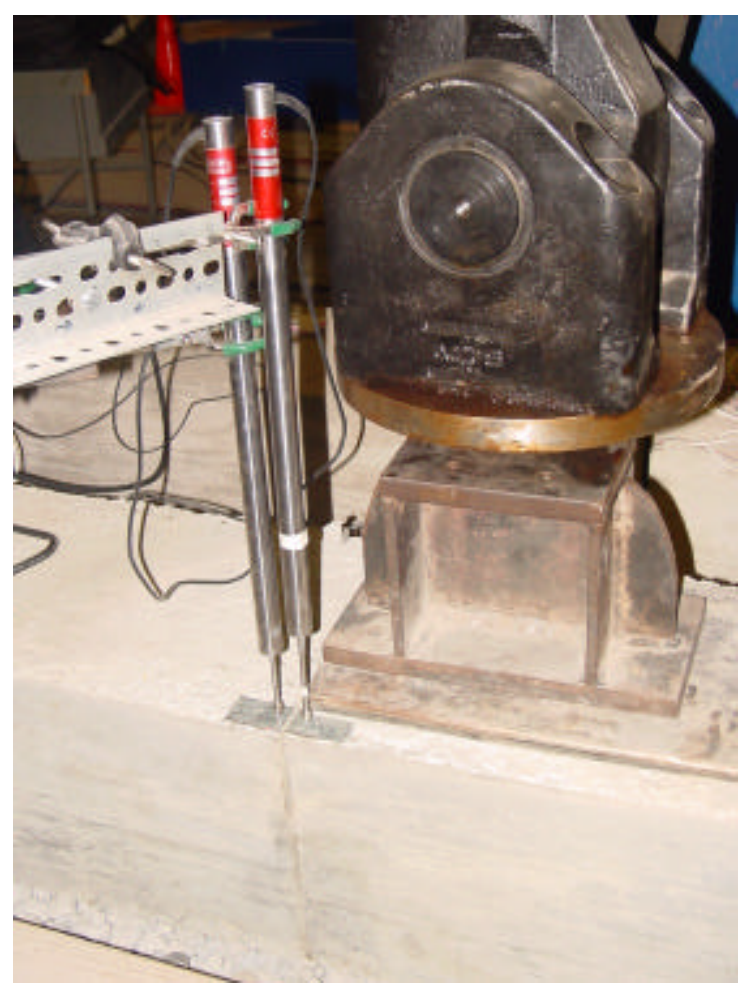

Figure 3.15 LVDTs positioned on both sides of the joint

\subsubsection{Static Testing}

Load was applied at different increments to simulate a HS 25 wheel load and/or higher load. Deflections and strains were recorded automatically by data acquisition system. Details of the load applied on different concrete slabs are shown in Table 3.5.

Table 3.4 Details of static testing

\begin{tabular}{|c|c|}
\hline Specimen \# & Load Range \\
\hline Slab \#1 & $0-12.5$ kips \\
\hline Slab \#2 & $0-12.5$ kips \\
\hline Slab \#3 & $0-12.5$ kips \\
\hline Slab \#4 & $0-11$ kips \\
\hline Slab \#5 & $0-11$ kips \\
\hline
\end{tabular}




\subsubsection{Fatigue Testing}

The load from MTS hydraulic actuator was set required range of fatigue cycles (Table 3.6) and was applied using a sine wave. After every $1,000,000$ cycles, a static test was conducted on the pavement system to measure strain and deflections. Details of fatigue tests are provided in Table 3.6.

Table 3.5: Details of fatigue testing

\begin{tabular}{|c|c|c|c|c|c|c|}
\hline Specimen \# & \multicolumn{5}{|c|}{ Load \& Range (kips) } \\
\hline $\begin{array}{l}\text { No. of Cycles } \\
\text { (million) }\end{array}$ & $0-1$ & $1-1 \frac{1 / 4}{1 / 4-2}$ & $2-3$ & $3-4$ & $4-5$ \\
\hline Slab \#1 & $2-12.5$ & $2-18.75$ & $2-18.75$ & $2-18.75$ & $2-18.75$ & $2-18.75$ \\
\hline Slab \#2 & $2-12.5$ & $2-18.75$ & $2-18.75$ & - & - & - \\
\hline Slab \#3 & $2-12.5$ & $2-12.5$ & - & - & - & - \\
\hline Slab \#4 & $2-11$ & $2-11$ & $2-11$ & $2-11$ & $2-11$ & $2-11$ \\
\hline Slab \#5 & $2-11$ & $2-11$ & $2-11$ & $2-11$ & $2-11$ & $2-11$ \\
\hline
\end{tabular}

NOTE: For Specimens \#1, \#2 and \#3 an overload factor 1.5 was (i.e.1.5xHS25) used to apply higher load during fatigue tests after 1 million cycles.

It should be noted that slabs \#1, \#2 and \#3 have 12.5 kips and slabs \# 4and \#5 have 11 kips of loading corresponding to HS-25 loading as described in Section 6.3, Chapter 6. 


\section{Chapter 4}

\section{EXPERIMENTAL RESULTS AND DISCUSSION}

\subsection{Introduction}

Experimental setup used in the Major Unit Laboratory was previously discussed in Chapter 3. This chapter discusses the experimental results of five jointed concrete slabs with FRP or steel dowels. Parameters evaluated in these tests under static and fatigue loads include:

- $\quad$ Load Transfer Efficiency (LTE)

- Relative Deflection (RD) between loaded and unloaded pavement

- Strain on dowels

Prior to discussing the above three parameters, joint crack patterns observed in our tests are presented. Joint crack patterns have significant effect on Load Transfer Efficiency (LTE), Relative Deflection and dowel strains.

Parameters of two preliminary tests conducted on two pavement slabs with FRP dowels and actual main tests were listed in Table 4.1. Slabs with 6" spacing were placed in Group \#1 whereas slabs with 12” spacing were placed in Group \#2. 
Table 4.1 Parameters of Dowel Groups

\begin{tabular}{|c|c|c|c|c|c|c|}
\hline Group & Slab & $\begin{array}{c}\text { Center } \\
\text { To } \\
\text { Center } \\
\text { Spacing } \\
\text { (in.) }\end{array}$ & $\begin{array}{c}\text { Number } \\
\text { of Dowel } \\
\text { In Slab }\end{array}$ & $\begin{array}{c}\text { Concrete } \\
\text { Strength } \\
\text { (psi) }\end{array}$ & $\begin{array}{c}\text { Dowel } \\
\text { Material }\end{array}$ & $\begin{array}{c}\text { Dowel } \\
\text { Diameter } \\
\text { (in.) }\end{array}$ \\
\hline \multirow{2}{*}{$\begin{array}{c}\text { Preliminary } \\
\text { Group }\end{array}$} & PG-1 & \multirow{2}{*}{12} & \multirow{2}{*}{1} & \multirow{2}{*}{3500} & \multirow{2}{*}{ FRP } & \multirow{2}{*}{1.5} \\
\hline & PG-2 & & & & & \\
\hline \multirow{3}{*}{$\begin{array}{c}\text { GROUP } \\
1\end{array}$} & SLAB 1 & \multirow{3}{*}{6} & \multirow{3}{*}{2} & \multirow{3}{*}{4500} & FRP & 1.0 \\
\hline & SLAB 2 & & & & STEEL & 1.0 \\
\hline & SLAB 3 & & & & FRP & 1.5 \\
\hline \multirow{2}{*}{$\begin{array}{c}\text { GROUP } \\
2\end{array}$} & SLAB 4 & \multirow{2}{*}{12} & \multirow{2}{*}{1} & \multirow{2}{*}{4500} & FRP & 1.5 \\
\hline & SLAB 5 & & & & STEEL & 1.5 \\
\hline
\end{tabular}

\subsection{Joint crack patterns observed in laboratory tests}

Cracks in jointed plain concrete pavement specimens occurred at two locations. One was right at the joint; the other was directly under the loading zone close to dowel edge. Figures 4.1 to 4.3 show three types of crack patterns observed in our tests (also refer to Table 4.2).

- $\quad$ Type I-crack occurred only in the joint (Figure 4.1)

- Type II-cracks occurred at joint and loading zone close to dowel edge. (Figure 4.2)

- Type III-crack occurred away from the joint at the dowel edge in the loading zone (Figure 4.3) 


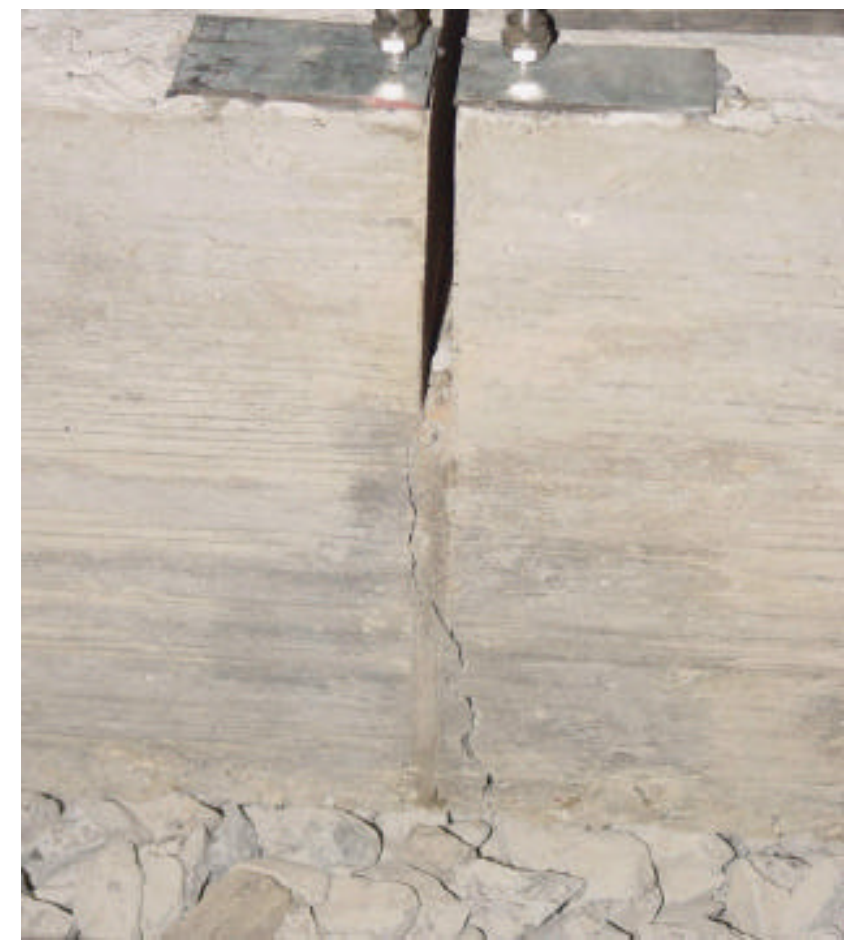

Figure 4.1 Typical crack observed in Slabs \#1, \#4 and \#5 (Table 4.1)

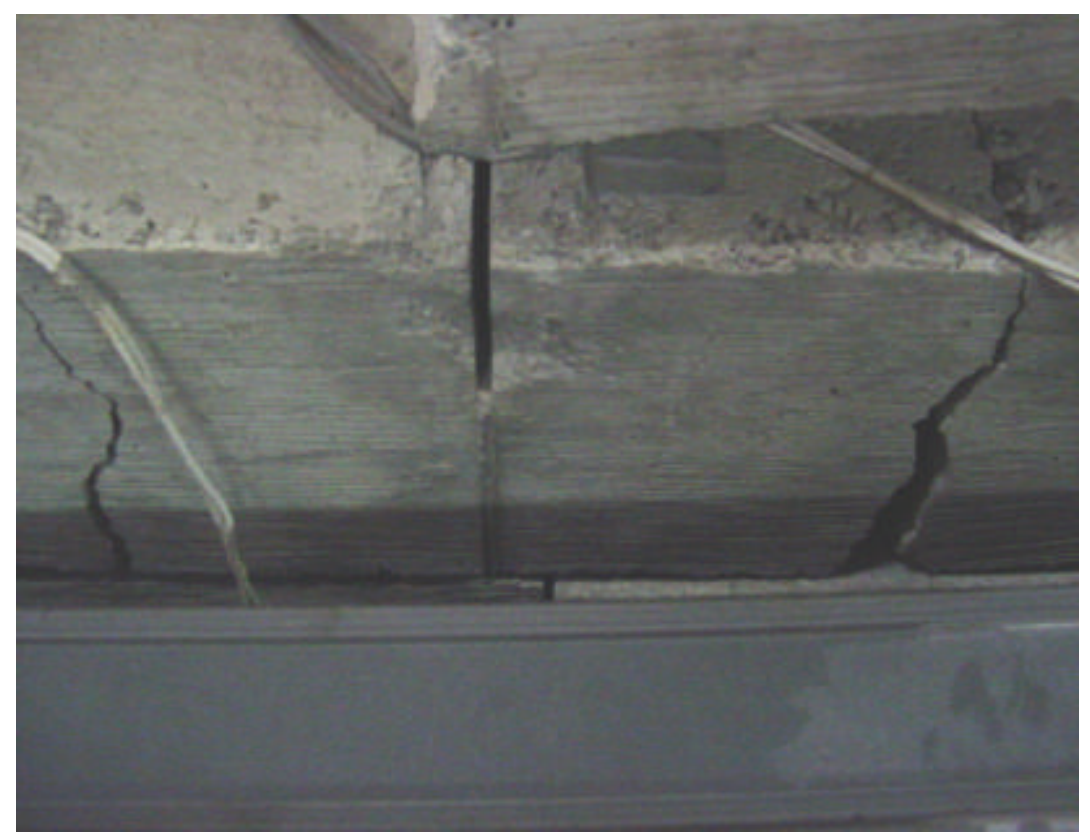

Figure 4.2 Crack observed in Slabs \#2 (Table 4.1) 


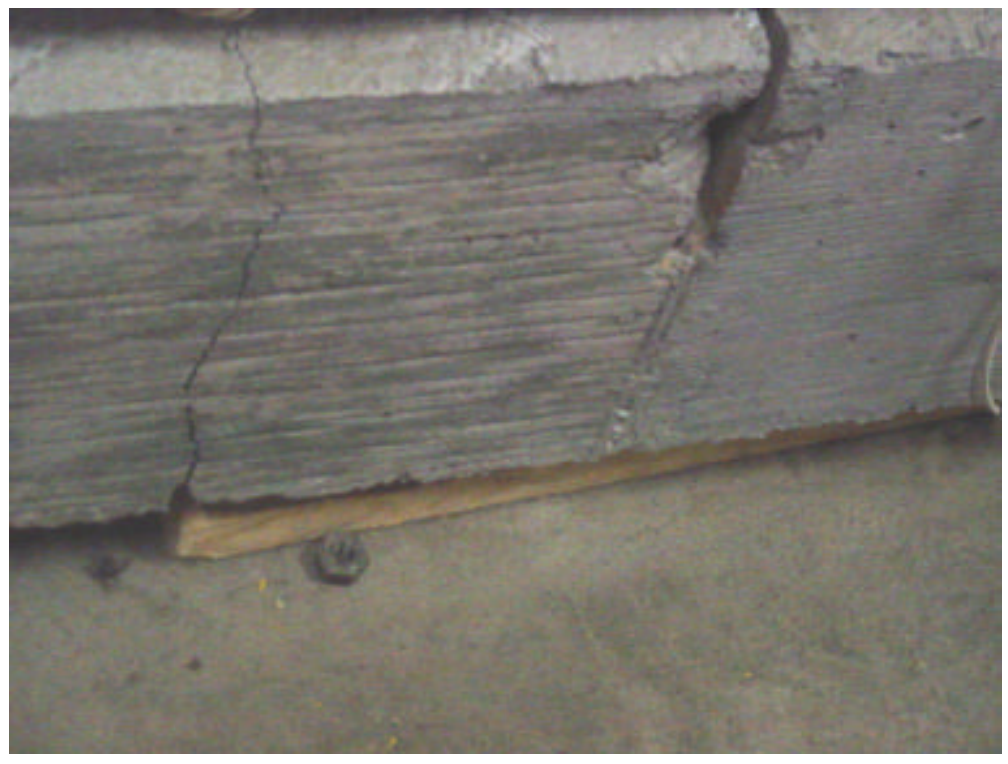

Figure 4.3 Typical crack observed in Slabs \#3 (Table 4.1)

Table 4.2 Cracks in the tested slabs

\begin{tabular}{|c|c|c|c|c|c|c|}
\hline Group \# & Specimen & $\begin{array}{c}\text { Dowel } \\
\text { Material }\end{array}$ & $\begin{array}{c}\text { Concrete } \\
\text { Strength } \\
\text { (psi) }\end{array}$ & $\begin{array}{c}\text { Dowel } \\
\text { Diameter/Spacing } \\
\text { (In.) }\end{array}$ & $\begin{array}{c}\begin{array}{c}\text { Number } \\
\text { of Dowel } \\
\text { in } \\
\text { Specimen }\end{array} \\
\end{array}$ & $\begin{array}{l}\text { Crack } \\
\text { Pattern }\end{array}$ \\
\hline \multirow{2}{*}{$\begin{array}{c}\text { Preliminary } \\
\text { Group }\end{array}$} & PG-1 & \multirow{2}{*}{ FRP } & \multirow{2}{*}{3500} & \multirow{2}{*}{$1.5 @ 12 \mathrm{c} / \mathrm{c}$} & \multirow{2}{*}{1} & \multirow{2}{*}{ I } \\
\hline & PG-2 & & & & & \\
\hline \multirow{3}{*}{$\begin{array}{c}\text { GROUP } \\
1\end{array}$} & SLAB 1 & FRP & \multirow{3}{*}{4500} & $1.0 @ 6 \mathrm{c} / \mathrm{c}$ & \multirow{3}{*}{2} & $\mathrm{I}$ \\
\hline & SLAB 2 & $\begin{array}{l}\text { STEEL } \\
\end{array}$ & & $1.0 @ 6 \mathrm{c} / \mathrm{c}$ & & II \\
\hline & SLAB 3 & FRP & & $1.5 @ 6 \mathrm{c} / \mathrm{c}$ & & III \\
\hline \multirow{2}{*}{$\begin{array}{c}\text { GROUP } \\
2\end{array}$} & SLAB 4 & FRP & \multirow{2}{*}{4500} & \multirow{2}{*}{$1.5 @ 12 \mathrm{c} / \mathrm{c}$} & \multirow{2}{*}{1} & $\mathrm{I}$ \\
\hline & SLAB 5 & STEEL & & & & $\mathrm{I}$ \\
\hline
\end{tabular}

From Table 4.2, specimens PG-1, PG-2, slabs 1, 4 and 5 have crack formation right at the joint. In these cases, dowels provide maximum load transfer across the joints. This is the scenario expected to occur in the field. 
In slab \#3, crack occurred at the loaded zone only, which means that the joint would not have cracked and the crack occurred at loading plate edge away from the joint will act as a joint for concrete to expand or contract under thermal variations. But the dowel will not transfer the load or only a very small portion of applied load will be transferred across this crack. In slab \#2, cracks occurred at both joint and load zone locations.

The reason that cracks occurred away from mid-joint and under loading zone could possibly be attributed to the uneven base surface under loaded side of slab. Because the slabs were not cast directly on the aggregates as field construction method, when load was applied, the uneven surface including possible gradients can cause enough stress concentration at dowel edge, leading to concrete cracking prior to load transfer.

\subsection{Preliminary Tests}

Preliminary static tests on two slabs consisting of one 1.5" diameter FRP dowel at 12" c/c were conducted. Load Transfer Efficiencies (LTEs) obtained from these static tests were both greater than $90 \%$, i.e., much higher than $60 \%$ of LTE as recommended by ACPA, 1991(corresponding to $75 \%$ of Joint Effectiveness, E)

\subsection{Joint Deflections and Joint Load Transfer Efficiency (LTE)}

Deflections of dowel-connected slabs were measured by using LVDTs positioned at both loaded and unloaded side of joints. Load Transfer Efficiency (LTE) and Relative Deflections (RD) were then calculated from measured deflections. 


\subsubsection{Joint Relative Deflection}

\subsubsection{Joint Relative Deflection of Group \#1}

\subsection{Slab\#1}

Slab \#1 consists of two 1.0" diameter FRP dowels with spacing of 6" (refer to Figs. 3.6 and 3.12, also refer to Table 4.2). Static tests were conducted according to Table 4.3. Relative Deflection vs. applied load is shown in Figure 4.4.

Table 4.3 Static Load Applied for Specimen \#1

\begin{tabular}{|c|c|}
\hline Specimen \# & Load Range \\
\hline 1 & $0-12.5$ kips \\
\hline
\end{tabular}

(Note: 12.5 kips was applied corresponding to HS25 load)

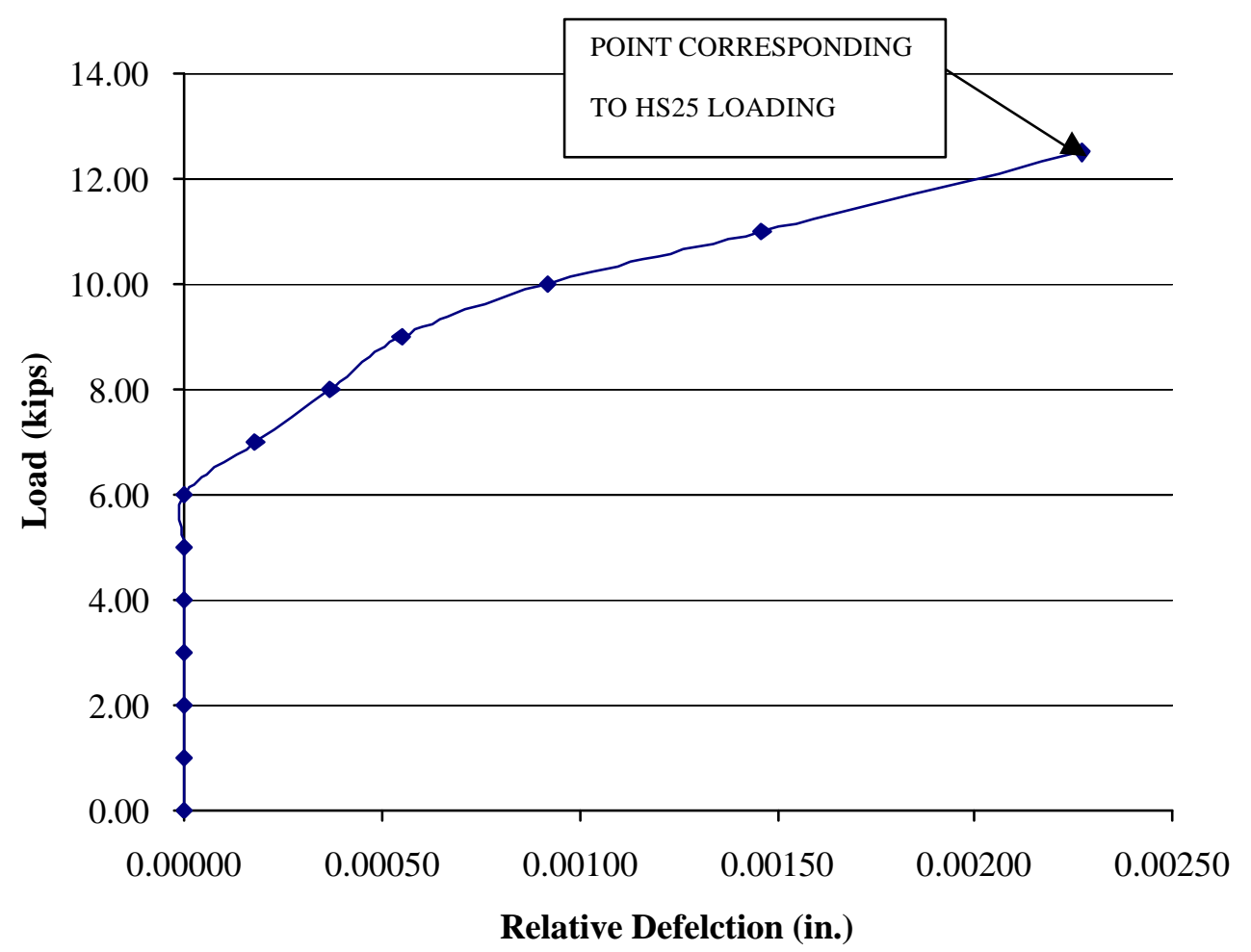

Figure 4.4 Joint Relative Deflection for slab \#1 under static test 
After static testing, fatigue tests were conducted up to 5 million cycles (Table 4.4).

Figures 4.4 to 4.6 show the Relative Deflections obtained from tests. It should be mted that 18.75 kips $(1.5 \times \mathrm{HS} 25$ loading) was applied to the joint after 1 million cycles.

Table 4.4 Load Applied for Fatigue Tests on Slab \#1

\begin{tabular}{|c|c|c|c|c|}
\hline Slab & Wave Shape & Frequency $(\mathrm{Hz})$ & $0-1$ Million Cycles & $1-5$ Million Cycles \\
\hline$\# 1$ & Sine & 4.0 & $2-12.5 \mathrm{kips}$ & $2-18.75 \mathrm{kips}$ \\
\hline
\end{tabular}

(Note: 12.5 kips was applied corresponding to HS25 load and 18.75 kips corresponds to 1.5 times HS25 load)

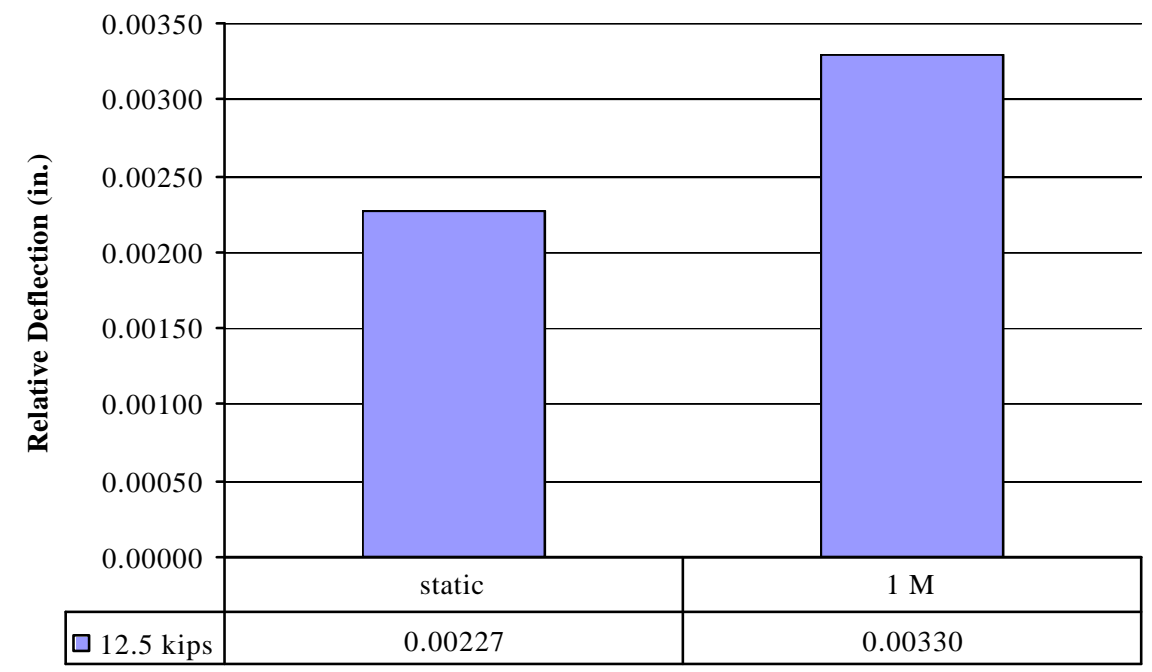

Figure 4.5 Relative Deflections under HS25 loading for slab \#1 at joint width of 0.25 ”' (Static and 1 Million Cycles) 


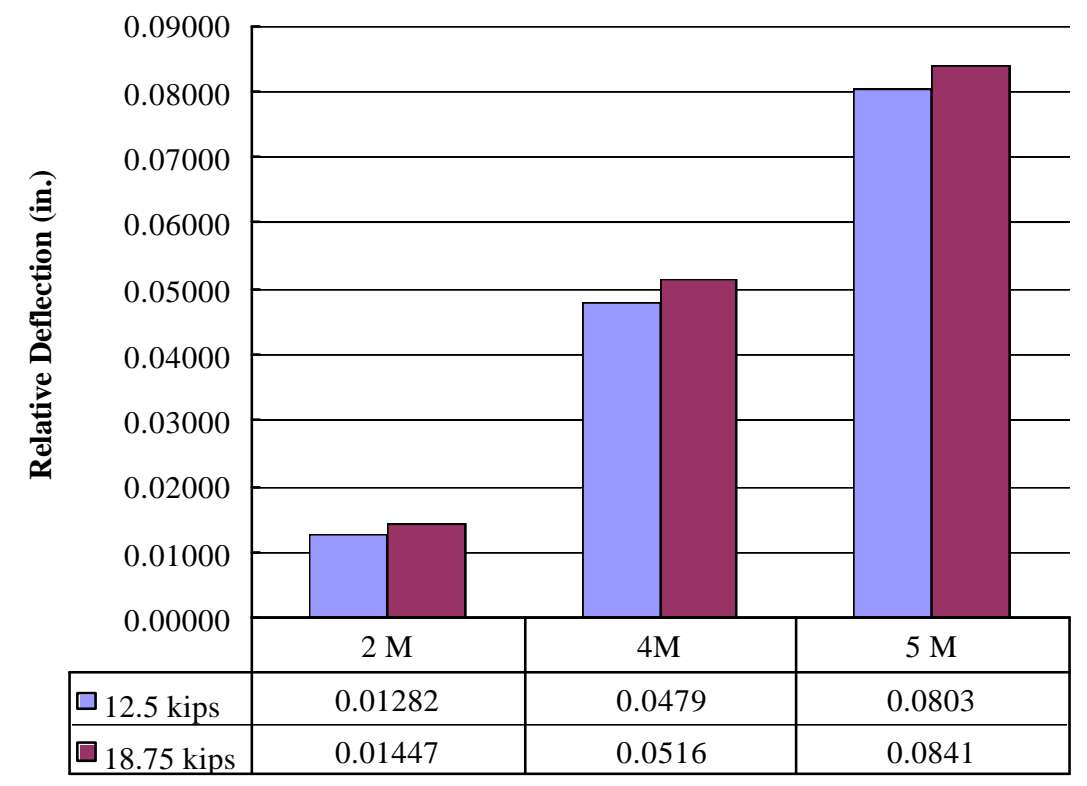

Figure 4.6 Relative Deflections for slab \#1 under fatigue tests (joint width increased from

\subsection{5 " to 0.4 " from 2 to 5 million cycles)}

Note: In Figure 4.6, 12.5 kips was corresponding to HS25 loading and was applied up to 1 million cycles; 18.75 kips was corresponding to 1.5 times HS25 loading was applied for fatigue tests after 1 million cycles and up to 5 million cycles. Also, joint width increased from 0.25 " to 0.4 " during bin and slab repositioning. Thus, the relative deflections after 1 million cycles due to increased joint width are much greater than those from static and 1 million cycle tests ( 0.01282 in. at 2 million cycles vs. 0.0033 in at 1 million cycles.).

\subsection{Slab\#2}

Slab \#2 consisted of two one-inch diameter STEEL dowels with 6" spacing. Static test was conducted on this slab with a load range 0-12.5 kips and crack formation was noticed at dowel edge under lading plate.

Load vs. relative deflection are shown in Figure 4.7. 


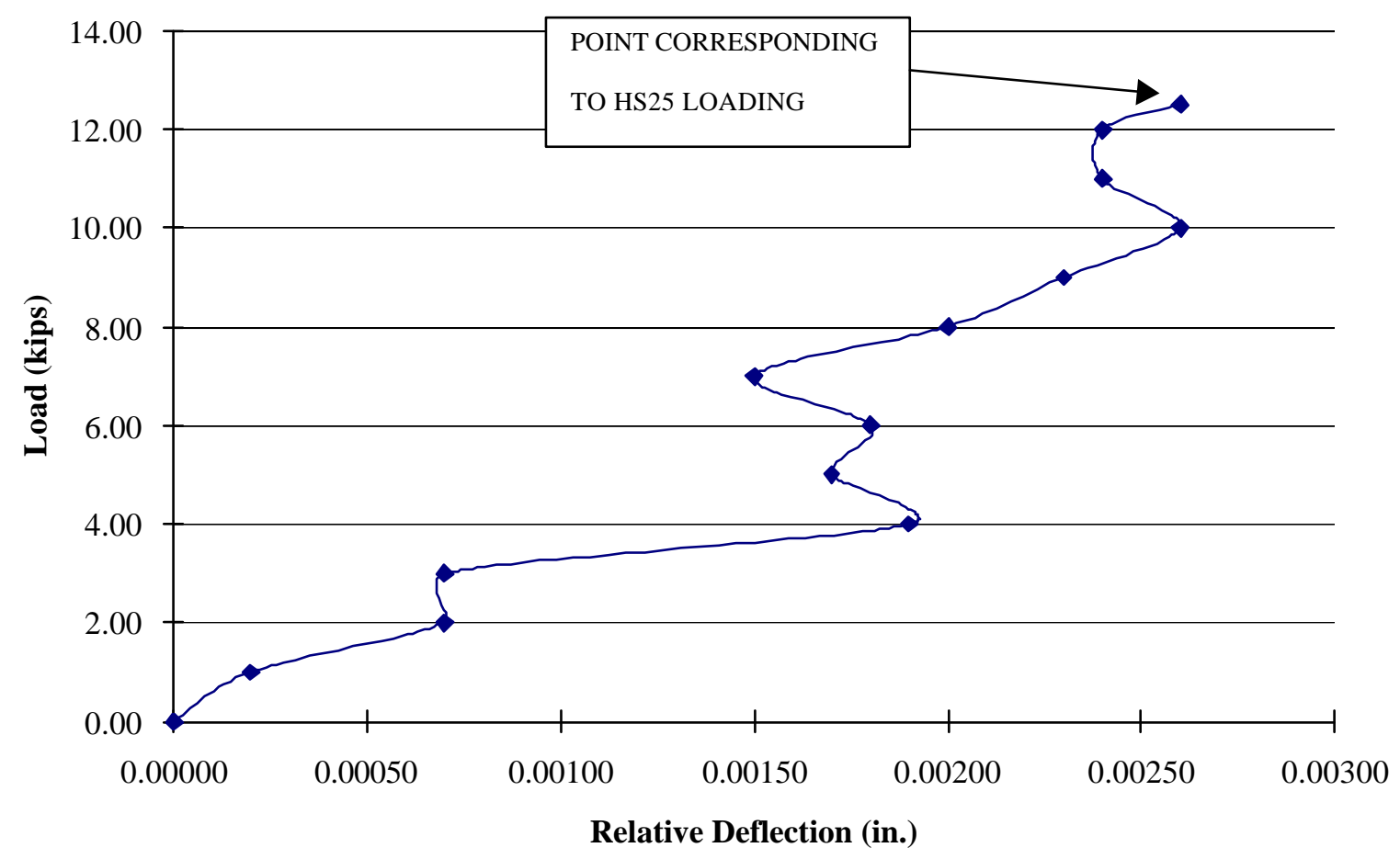

Figure 4.7 Joint Relative Deflection for slab \#2 under static test

After static testing, fatigue tests were conducted according to Table 4.5. Because cracks occurred at locations away from joint, fatigue cycles up to 2 million were applied. Figure 4.8 shows Relative Deflections under fatigue tests.

Table 4.5 Load Applied for Fatigue Tests on Specimen \#2

\begin{tabular}{|c|c|c|c|}
\hline Slab & Frequency (Hz) & $0-1$ Million Cycles & $>1-2$ Million Cycles \\
\hline$\# 2$ & 4.0 & $2-12.5 \mathrm{kips}$ & $2-18.75 \mathrm{kips}$ \\
\hline
\end{tabular}

(Note: 12.5 kips was applied corresponding to HS25 load, 18.75 kips was corresponding to 1.5 times HS25 load) 


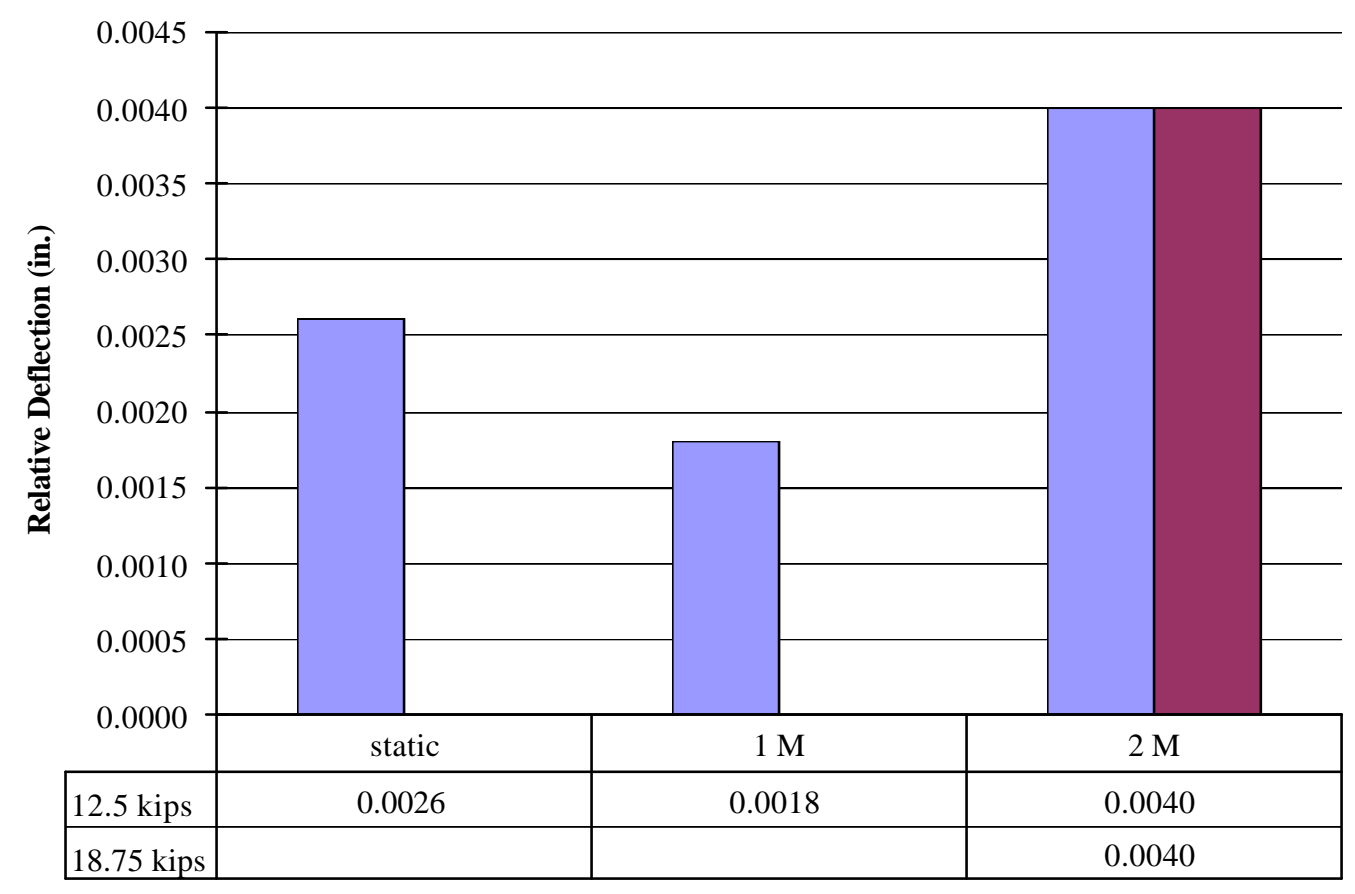

Figure 4.8 Relative Deflections for Specimen \#2 (0 to 2 million cycles)

It should be noted that when cracks occur away from middle joints, only a small portion of load will be transferred across the joint.

\subsection{Slab\#3}

Slab \#3 consisted of two 1.5" diameter FRP dowels with spacing of 6". Static deflections were measured for a load range of 0-12.5 kips and the detail are shown in Figure 4.9. Crack locations were away from the middle joint and hence fatigue tests were conducted up to only one and a quarter million cycles (refer to Table 4.6). 


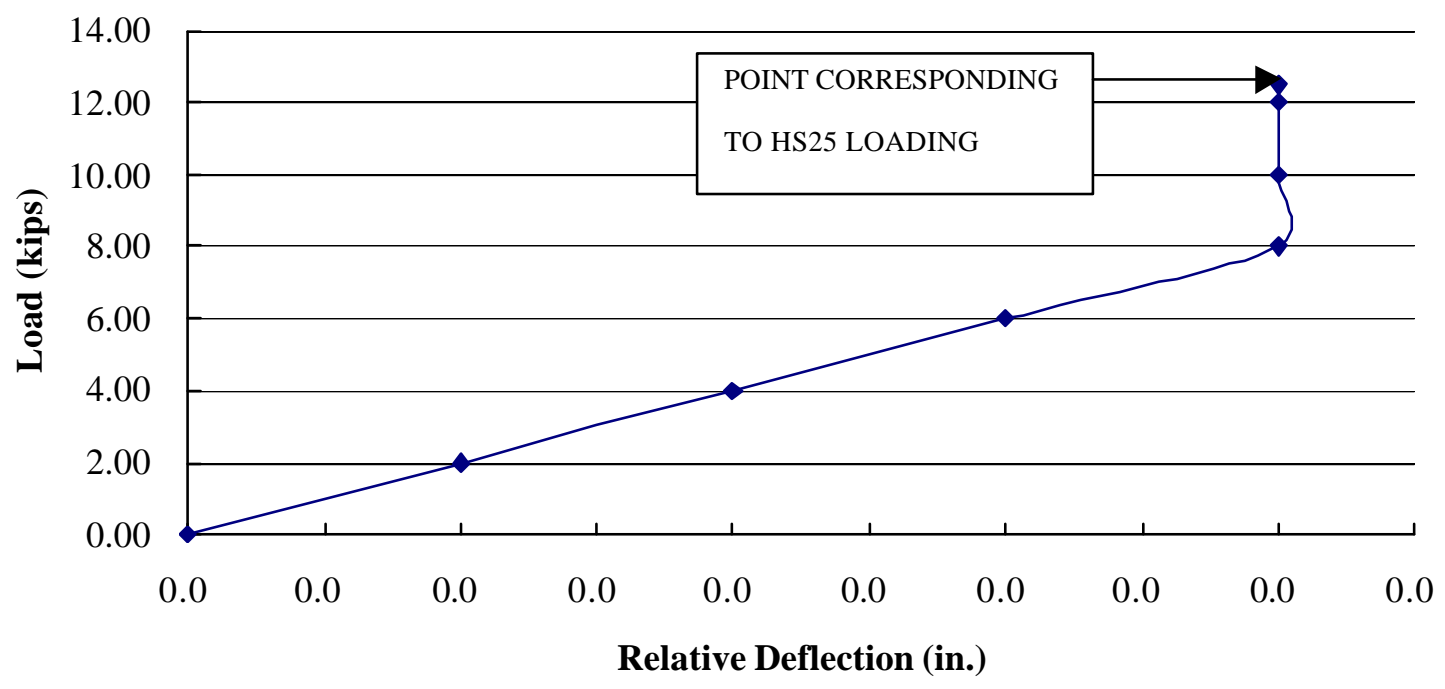

Figure 4.9 Joint Relative Deflection for specimen \#3 under static test

Figure 4.10 shows the Relative Deflections under fatigue tests.

Table 4.6 Load Applied for Fatigue Tests on Slab \#3

\begin{tabular}{|c|c|c|}
\hline Slab \# & Frequency $(\mathrm{Hz})$ & $0-1.25$ Million Cycles \\
\hline 3 & 4.0 & $2-12.5 \mathrm{kips}$ \\
\hline
\end{tabular}




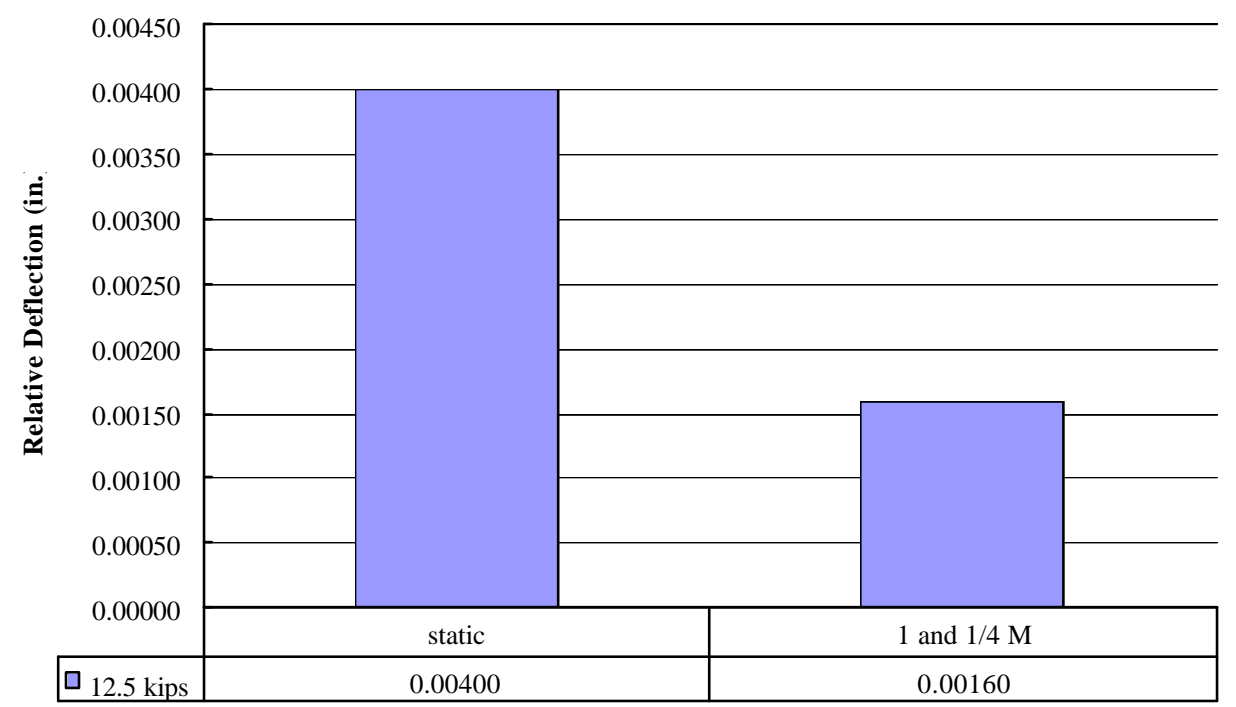

Figure 4.10 Relative Deflections for Specimen\#3 (0 to 1.25 million cycles)

Deviations observed in relative deflection values from slab \#3 are due to crack formation under loading plate at dowel edge.

\subsubsection{Joint Relative Deflection of Group \#2}

\subsection{Slab\#4}

Slab \#4 consisted of one 1.5" diameter FRP dowel representing 12" spacing in actual pavement. Static test was conducted in the range of 0-11 kips.

Load vs. relative deflection are shown in Figure 4.11. 


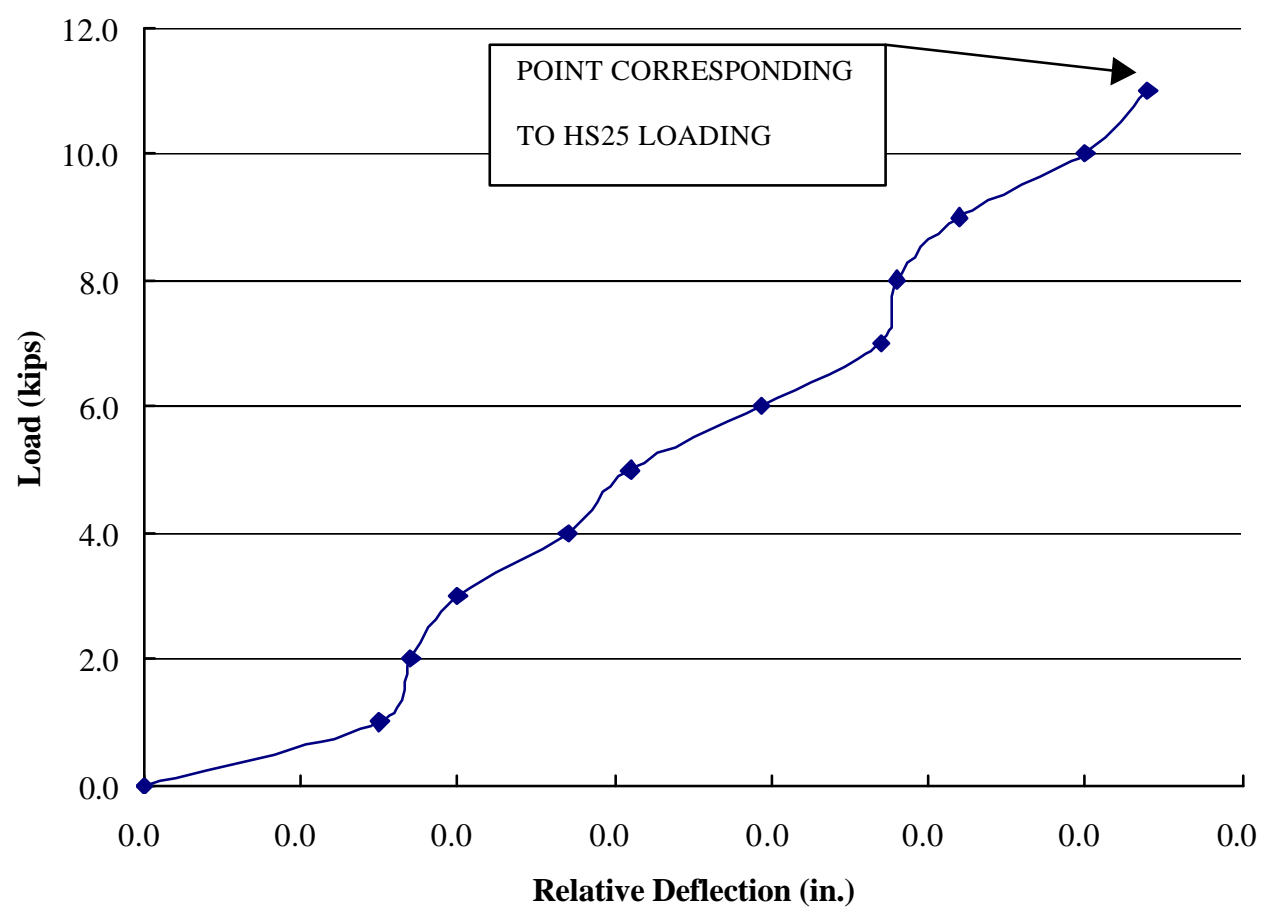

Figure 4.11 Joint Relative Deflection for specimen \#4 under static test

After static test, fatigue tests were conducted as per Table 4.7 up to 5 million cycles. Figures 4.12 and 4.13 show pavement deflections and Relative Deflections under fatigue testing.

Table 4.7 Load Applied for Fatigue Tests on Specimen \#4

\begin{tabular}{|c|c|c|}
\hline Slab \# & Frequency $(\mathrm{Hz})$ & $0-5$ Million Cycles \\
\hline 4 & 4.0 & $2-11.0 \mathrm{kips}$ \\
\hline
\end{tabular}




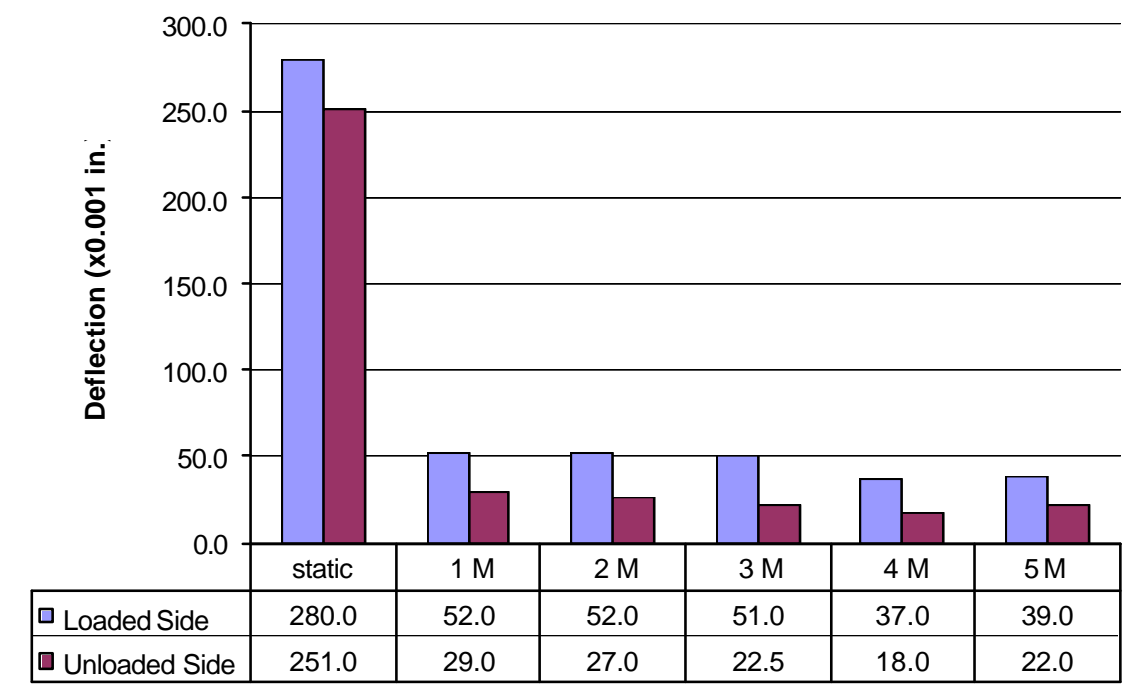

Figure 4.12 Pavement deflections under fatigue test for Slab \#4 (0 to 5 million cycles, FRP dowel @12” c/c)

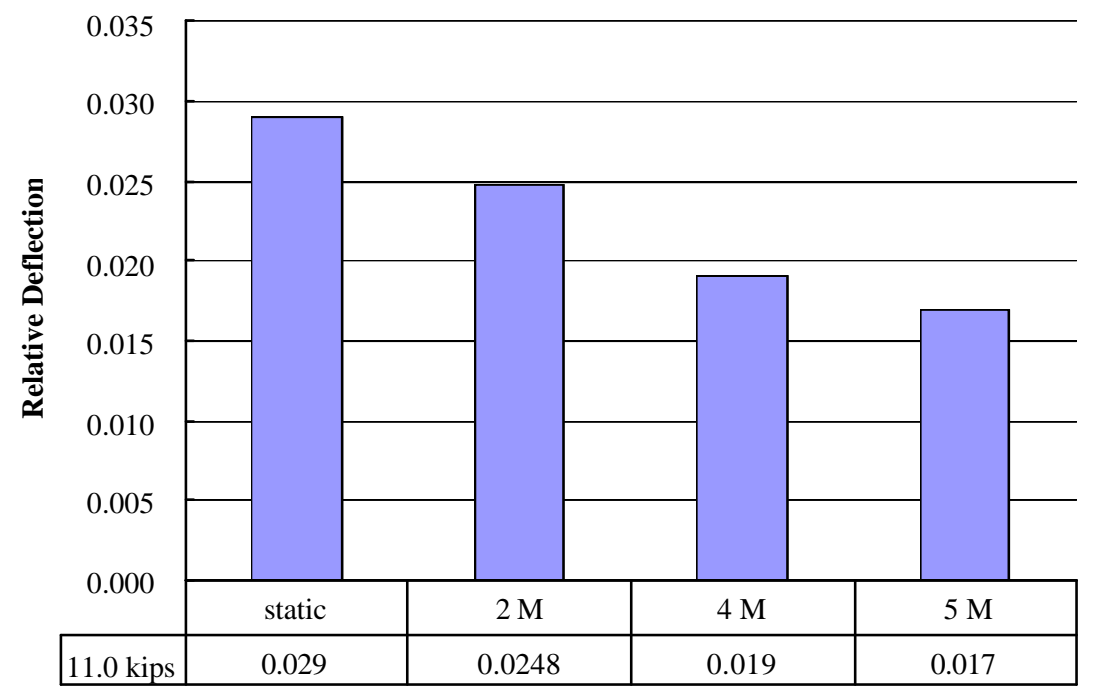

Figure 4.13 Relative Deflections under fatigue test for Specimen\#4 (0 to $5 \mathrm{M}$ )

Slab \#4 was the first slab tested in laboratory. Base materials were compacted before starting the test, but during laboratory fatigue cycles base materials under both side of slabs were getting more compact and the deflections reduced (Figure 4.12). Similar trends were observed 
under increased fatigues cycles in Figure 4.13. Modulus of subgrade reaction, $\mathrm{k}$, was found to have increased from 400 pci to 800 pci after 5 million fatigue cycles.

\subsection{Slab \#5}

Slab \#5 consisted of one 1.5" diameter STEEL dowel representing 12" spacing in the pavement. Static test was conducted in the range of 0-11.0 kips. Fatigue tests were conducted as per Table 4.8. Figure 4.14 shows the Load vs. relative deflection.

Table 4.8 Load Applied for Fatigue Tests on Slab \#5

\begin{tabular}{|c|c|c|}
\hline Slab \# & Frequency $(\mathrm{Hz})$ & $0-5$ Million Cycles \\
\hline 5 & 4.0 & $2-11.0 \mathrm{kips}$ \\
\hline
\end{tabular}

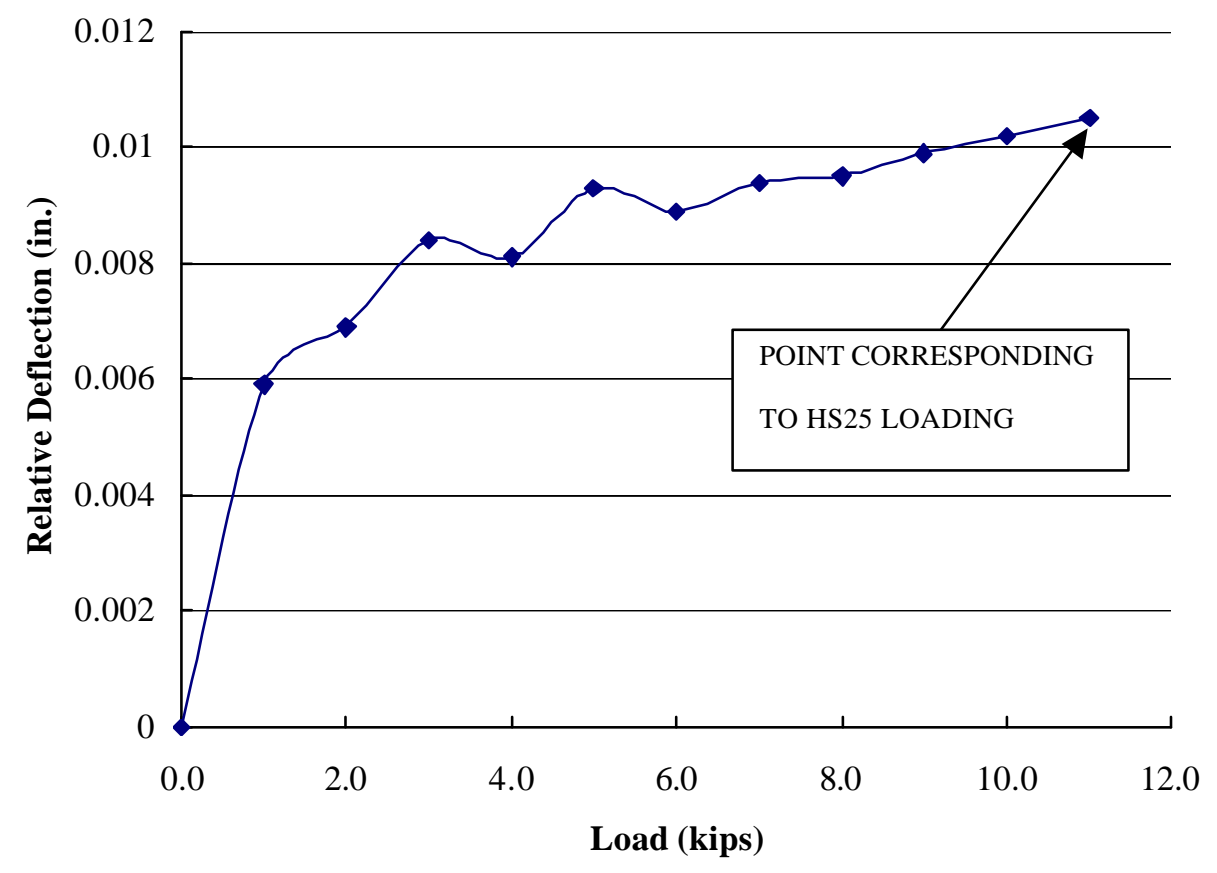

Figure 4.14 Joint Relative Deflection for specimen \#5 under static test

After static testing, fatigue tests were conducted up to 5 million cycles. Figure 4.15 shows Relative Deflections for slab \#5 under fatigue tests. 
Table 4.9 Load Applied for Fatigue Tests on Specimen \#5

\begin{tabular}{|c|c|c|}
\hline Slab \# & Frequency $(\mathrm{Hz})$ & $0-5$ Million Cycles \\
\hline 5 & 4.0 & $2-11.0 \mathrm{kips}$ \\
\hline
\end{tabular}

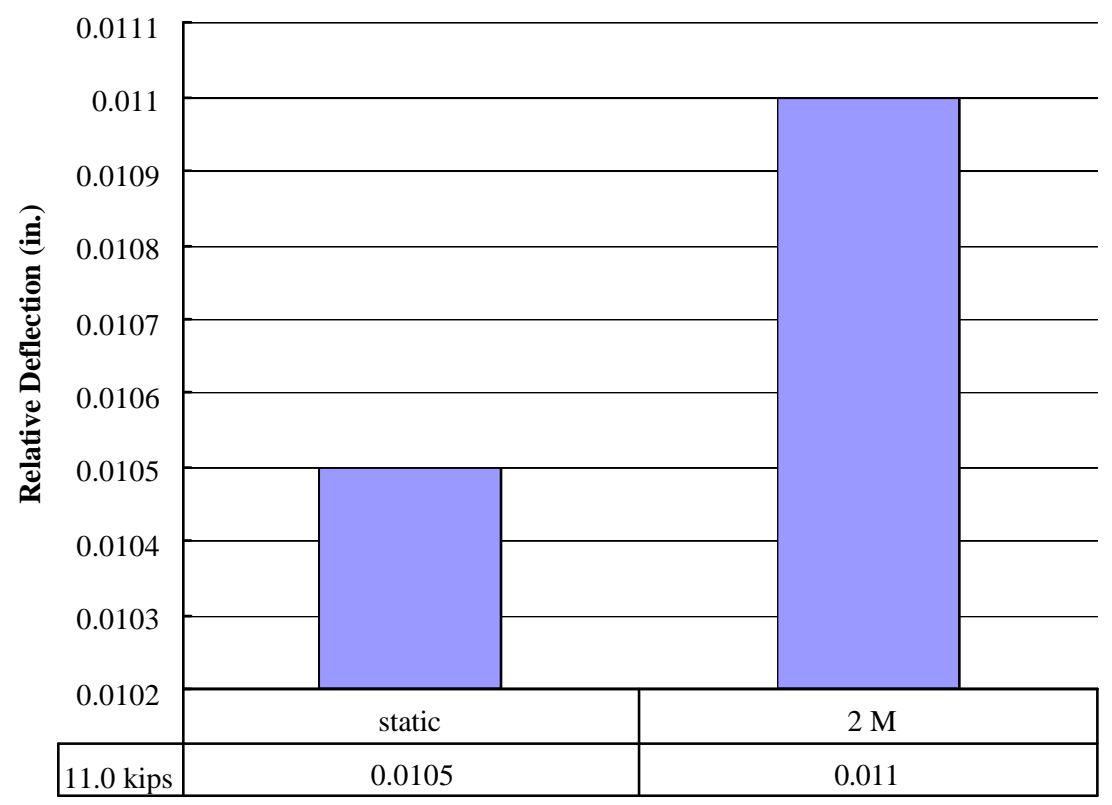

Figure 4.15 Relative Deflections under fatigue test for Specimen \#5 (0 to $5 \mathrm{M}$ )

\subsubsection{Analysis of Relative Deflection}

\subsection{Analysis for Specimen Group \#1 as per Table 4.1 (6”'spacing)}

For slabs \#1, \#2 and \#3, static and fatigue tests results are summarized in Tables 4.10 and 4.11, respectively and their behavior is discussed following the tables.

Table 4.10 Relative Deflection of Group One from Static Tests

\begin{tabular}{|c|c|c|}
\hline Slab Number & Parameters & Static Relative Deflection (in.) \\
\hline Slab\#1 & FRP dowel, 1.0" @6"c/c & 0.00227 \\
\hline Slab \#2 & steel dowel, 1.0" @6"c/c & 0.00260 \\
\hline Slab \#3 & FRP dowel, 1.5" @6"c/c & 0.00400 \\
\hline
\end{tabular}


Table 4.11 Relative Deflection of Group One from Fatigue Tests

\begin{tabular}{|c|c|c|c|c|c|}
\hline \multirow{2}{*}{ Slab Number } & \multicolumn{5}{|c|}{ Relative Deflection (in.) } \\
\cline { 2 - 6 } & $1 \mathrm{M}$ & $2 \mathrm{M}$ & $4 \mathrm{M}$ & $5 \mathrm{M}$ & $\begin{array}{r}\text { Proper Crack at Mid- } \\
\text { joint }\end{array}$ \\
\hline Slab \#1 & 0.0033 & $0.0128^{* \dagger}$ & $0.047 *^{\dagger}$ & $0.0803^{* \dagger}$ & Yes \\
\hline Slab \#2 & 0.0018 & $0.0040^{\dagger}$ & - & - & No \\
\hline Slab \#3 & 0.0001 & - & - & - & No \\
\hline
\end{tabular}

(NOTE: In Table 4.11,

* Joint width increased to $0.4 "$ :

${ }^{\dagger}$ An overload factor 1.5 used so that 1.5 times HS25 load was applied for specimen \#1 and \#2 during fatigue tests started after 1 million cycles)

It can be found that:

1. Larger relative deflection (0.00260") in slab \#2 with steel dowels than slab \#1 with FRP dowel (0.00227”) can be attributed to the cracking pattern in slab\#2, where joint crack occurred at a place other than the mid-joint.

2. Slab \#3 has much larger relative deflection possibly because the crack formation is close to the edge of dowel under steel plate rather than at mid-joint. Therefore, the load transferred by dowel is less including higher relative deflection.

3. When crack occurs at joint bcation where it is expected to occur, the relative deflection data from tests seems to be more consistent, such as the relative deflection for slab \#1 increases from 0.0023 " to 0.0803 ". 
4. Experimental results on relative deflection are sensitive to supporting base stiffness (k). It is suggested to consider the base property before and after each fatigue test.

\subsection{Analysis for Specimen Group \#2 (12” spacing)}

Test results are summarized in Tables 4.12 and 4.13 .

Tables 4.12 Relative Deflection of Group Two from Static Tests

\begin{tabular}{|c|c|c|}
\hline Slab & Static Relative Deflection (in.) & $\begin{array}{c}\text { Proper Crack at Mid- } \\
\text { joint }\end{array}$ \\
\hline Slab \#4 (FRP dowel, 1.5” @ 12"c/c) & 0.029 & Yes \\
\hline Slab \#5 (steel dowel, 1.5” @ 12"c/c) & 0.011 & Yes \\
\hline
\end{tabular}

Tables 4.13 Relative Deflection of Group Two from Fatigue Tests

\begin{tabular}{|c|c|c|c|}
\hline \multirow{2}{*}{ Slab Number } & \multicolumn{3}{|c|}{ Relative Deflection (in.) } \\
\cline { 2 - 4 } & $2 \mathrm{M}$ & $4 \mathrm{M}$ & $5 \mathrm{M}$ \\
\hline 4 & 0.025 & 0.019 & 0.017 \\
\hline 5 & 0.011 & - & - \\
\hline
\end{tabular}


It is noted that:

1. Both slabs \#4 and \#5 had proper crack occurrence at the joint.

2. In static tests (Table 4.13), slab \#4 (1.5" diameter FRP dowel) had a larger difference in deflection between loaded and unloaded side of the pavement (relative deflection)than slab \#5 (1.5" diameter Steel dowel).

3. The relative deflection for both slabs reduced with progression of fatigue load from 0 to 5 million cycles. This is partly attributed to compaction/settlement of aggregate base underneath the pavement slabs with increasing fatigue cycles.

4. Relative deflection decreased more in slab with FRP dowel than with steel dowel, which can be partly attributed to simulation in stiffness between FRP and concrete. Benefits of these reductions may be more evident with freeze-thaw variations.

5. Experimental results on relative deflection are sensitive to supporting base stiffness $(\mathrm{k})$. It is found that the base property (modulus of subgrade reaction, $\mathrm{k}$ ) value changed from 400pci to 800 pci after 5 million fatigue cycles.

\subsubsection{Joint Load Transfer Efficiency (LTE)}

Joint Load Transfer Efficiency (LTE) was calculated from results of static and fatigue tests by using equation (AASHTO, 1993)

$$
L T E=\frac{d_{U}}{d_{L}} \times 100 \%
$$

The American Concrete Pavement Association (ACPA, 1991) gives joint effectiveness to measure the performance of joints (ACPA, 1991).

$$
E=\frac{2 d_{U}}{d_{L}+d_{U}} \times 100 \%
$$


ACPA (1991) recommends that a pavement joint is considered adequate if the effectiveness is $75 \%$ or greater. However LTE and E are related by the following equation:

$$
L T E=\left(\frac{2}{2-E}-1\right) \times 100 \%
$$

According to equation 4.3, a LTE of $60 \%$ corresponds to an E of $75 \%$. When the value of LTE is between $70 \%$ and $100 \%$, the joint provides sufficient load transfer for heavy load.

\subsubsection{Load Transfer Efficiency of Group \#1}

\subsection{SLAB \#1}

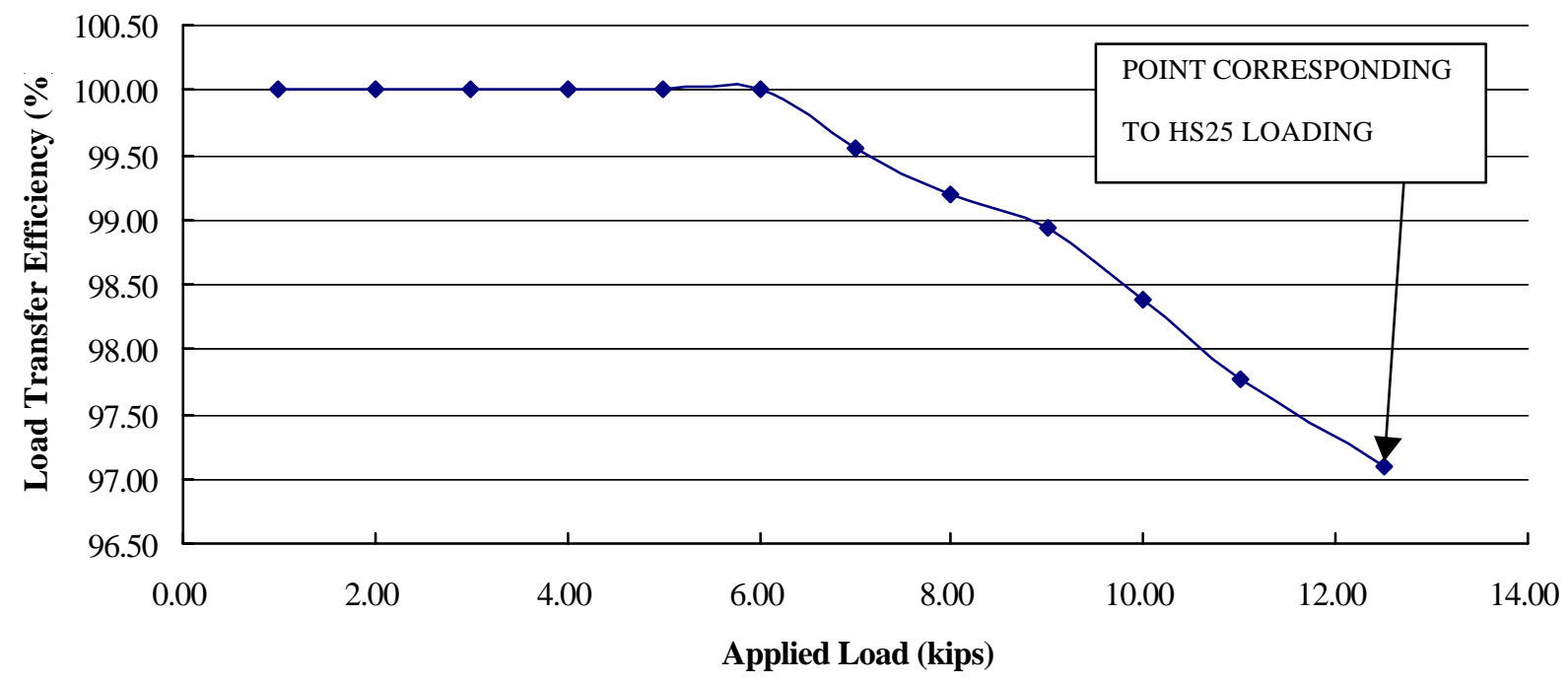

Figure 4.16 Joint Load Transfer Efficiency for slab \#1 


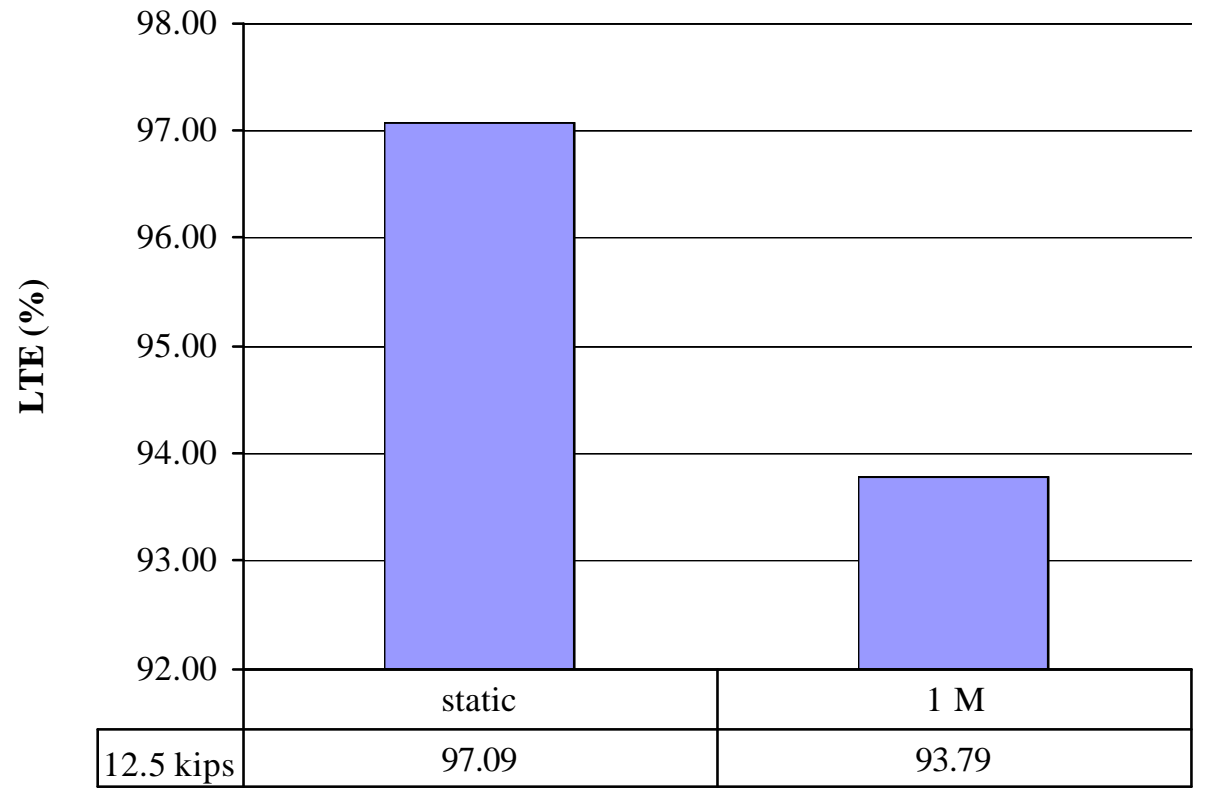

Figure 4.17 LTE corresponding to HS25-loading for slab \#1 (1.0”diameter @ 6” c/c), (Static and 1 Million Cycles)

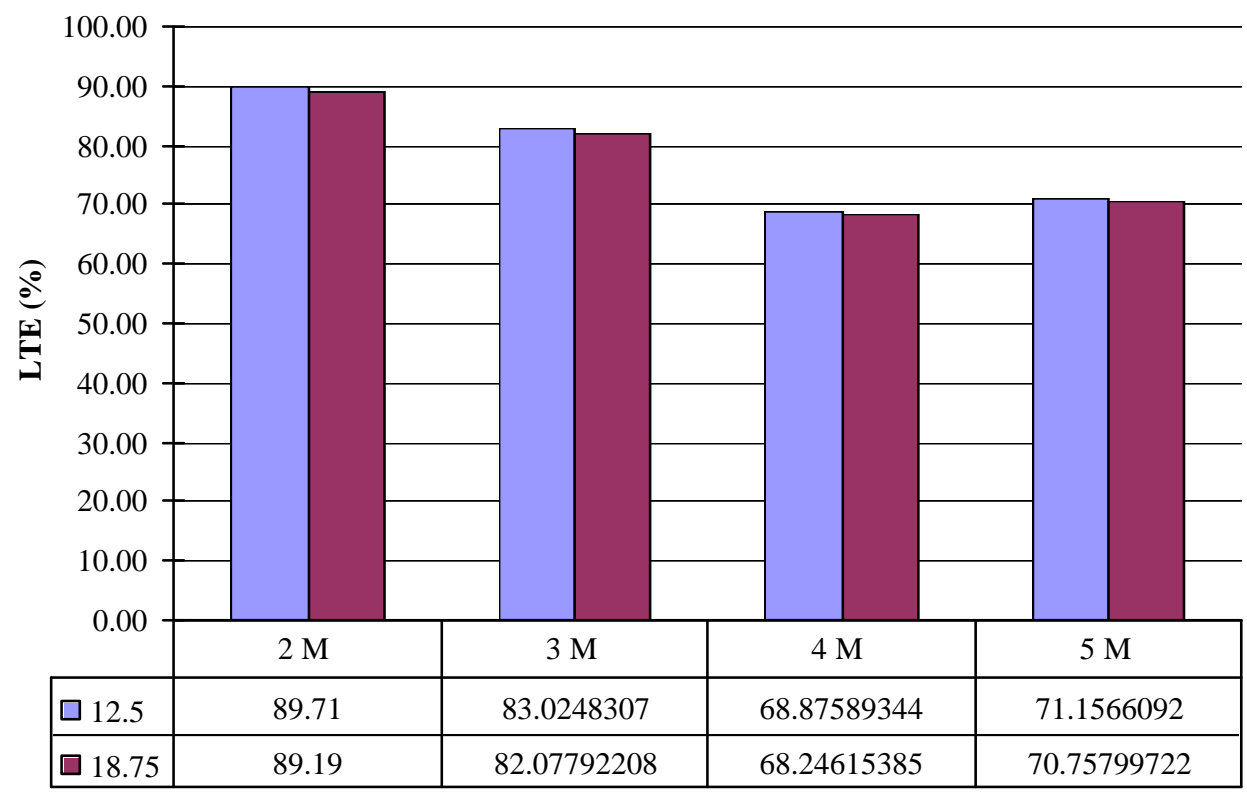

Figure 4.18 LTE for slab \#1 under fatigue tests (>1 million cycles \& joint width increased from 0.25 " to 0.4") 
Note: In Figure 4.18, 12.5 kips was corresponding to HS25 loading and was applied for static test and 1 million cycles, 18.75 kips was corresponding to 1.5 times HS25 loading and was applied for fatigue tests from 2 million to 5 million cycles. Also, joint width was intentionally separated from to $0.25 "$ to $0.4 "$.

In order to find the condition of interface between FRP dowel and concrete interface, after 5 million cycles of HS25 and higher loading, slab \#1 was separated by cutting FRP dowel. Dowel-concrete interface was found to be in good shape with no visible micro cracks (Figure 4.19).

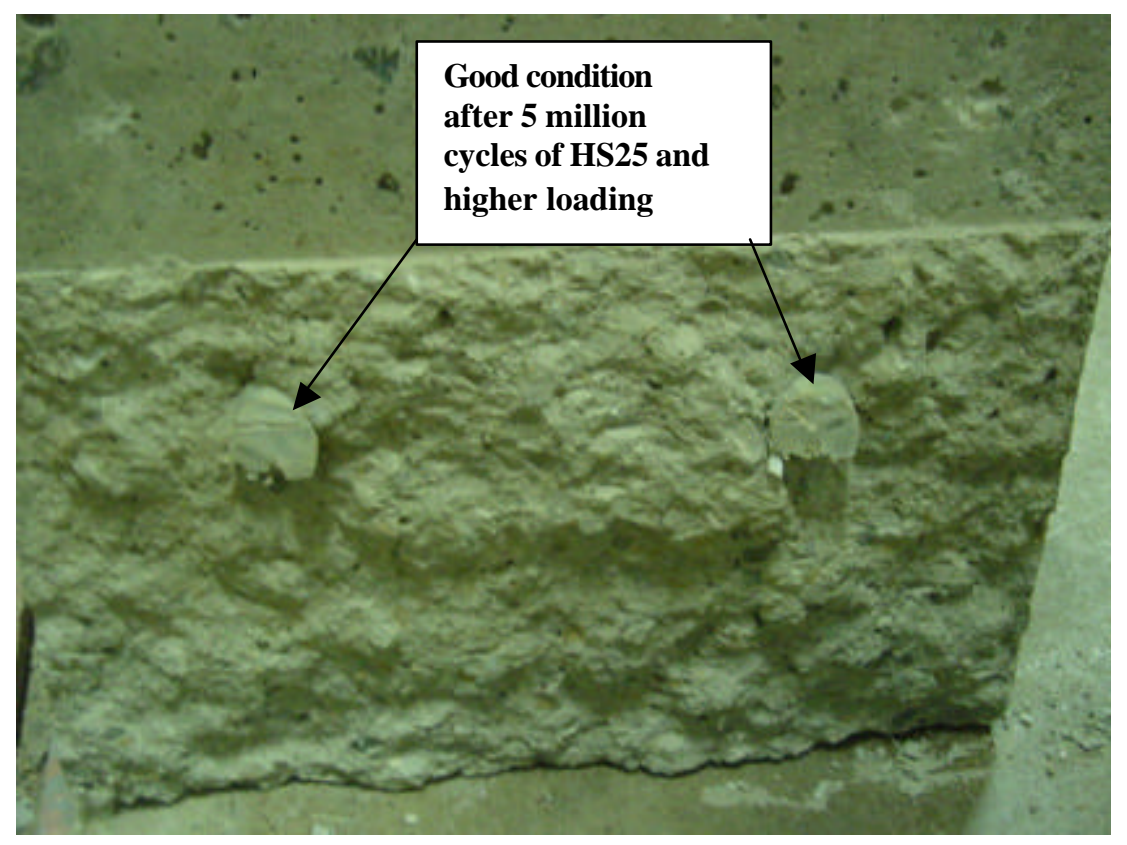

Figure 4.19 Dowel-concrete interface condition in slab \#1 after 5 Million load cycles 


\subsection{SLAB \#2}

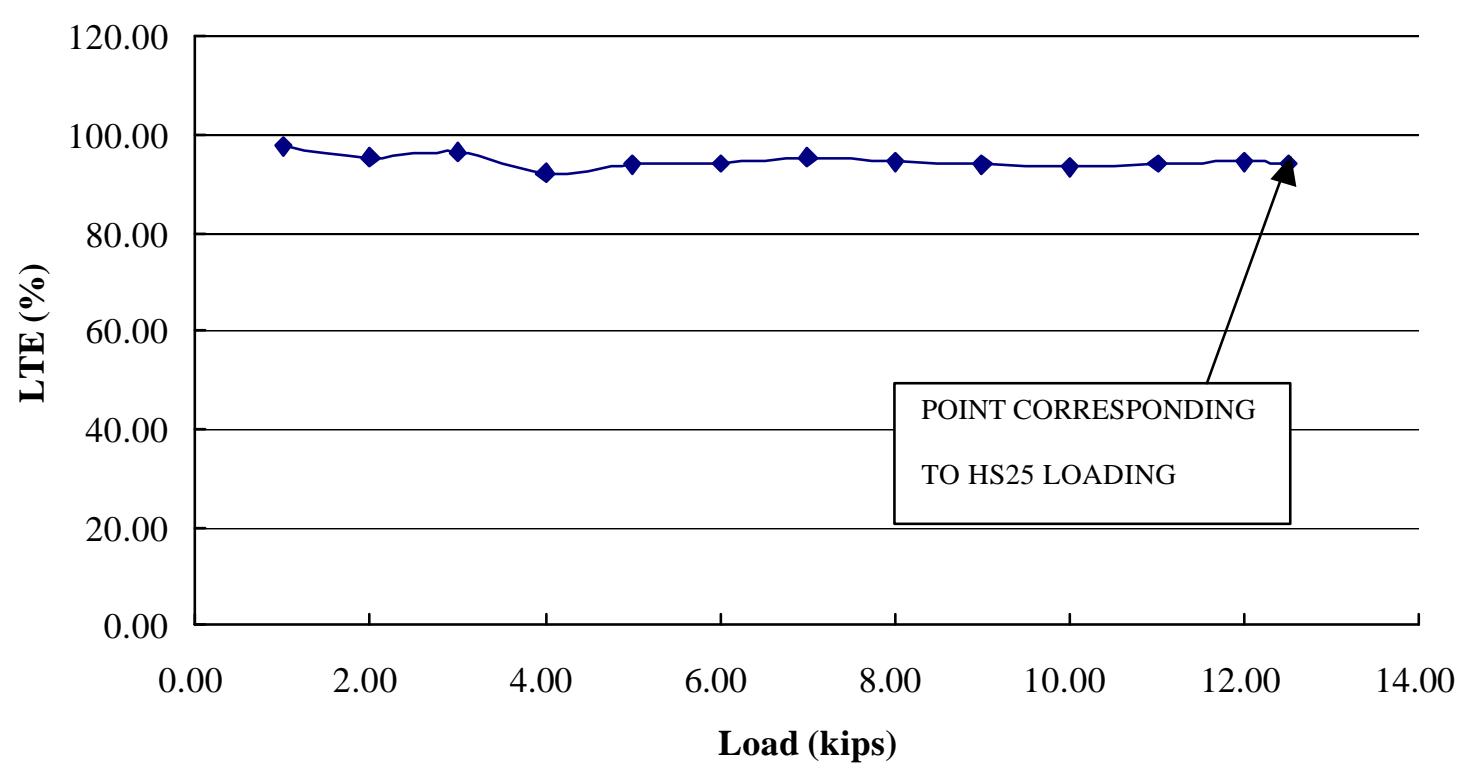

Figure 4.20 Joint Load Transfer Efficiency for slab \#2

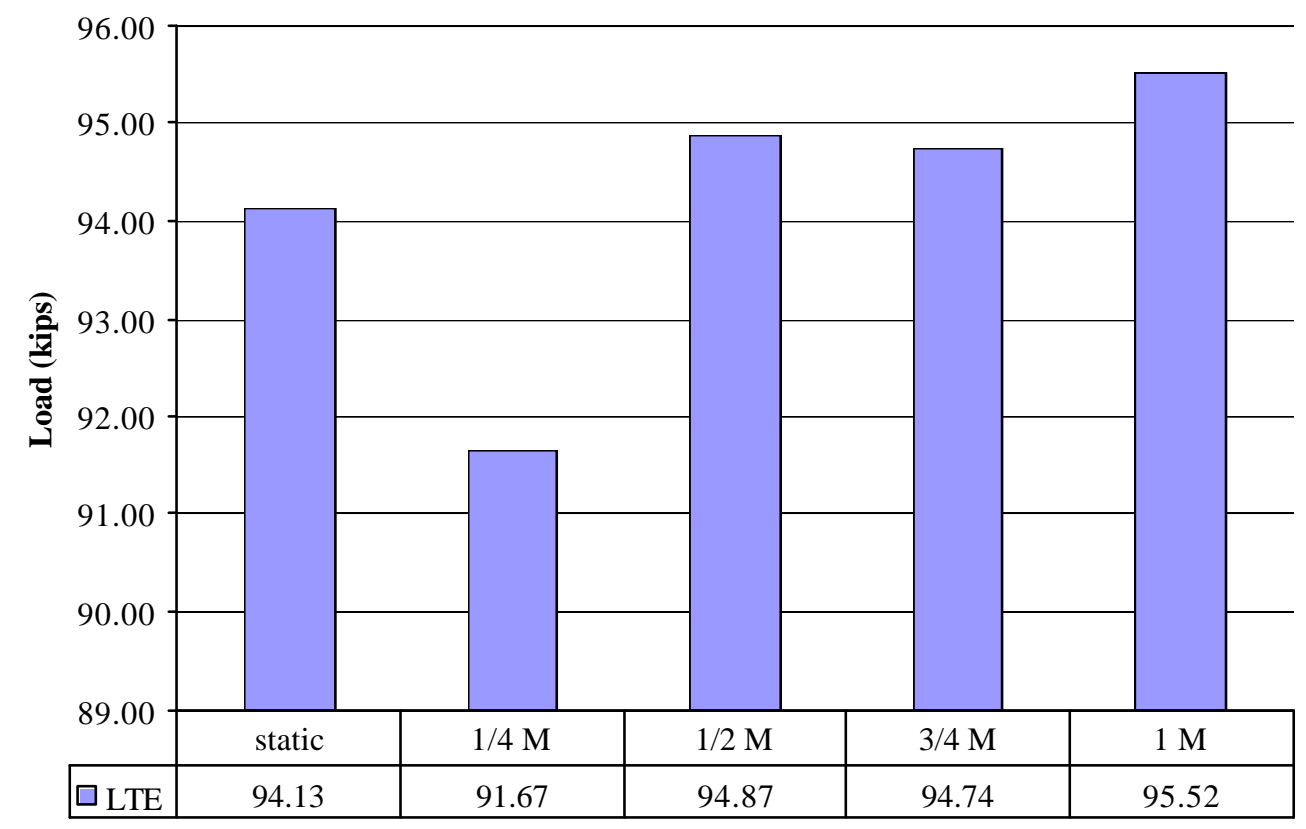

Figure 4.21 LTE under fatigue tests (HS25 loading) for slab \#2 (0 to 1 million cycles) 


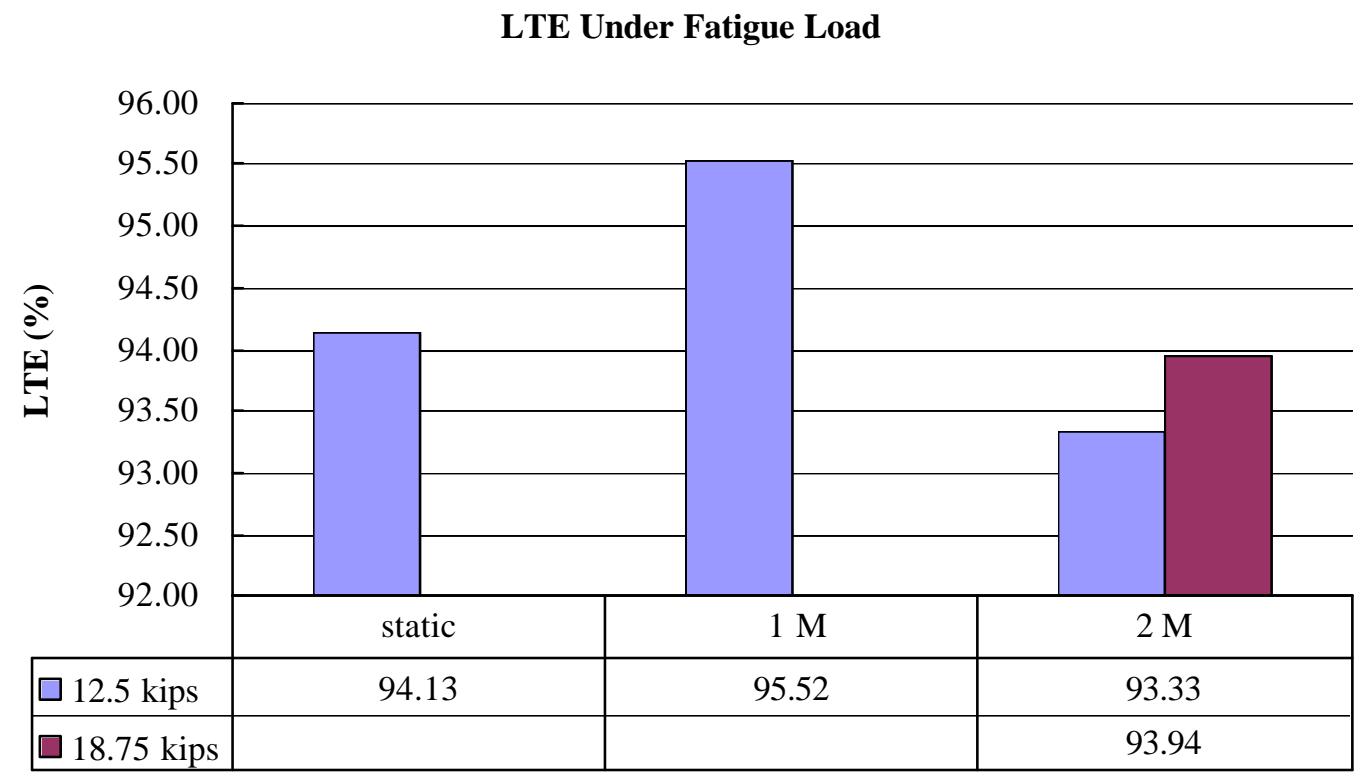

Figure 4.22 LTE under fatigue test for slab \#2 (1 to 2 Million)

(Note: In Figure 4.22, 12.5 kips was corresponding to HS25 loading and was applied for static test and up to 1 million cycles, 18.75 kips was corresponding to 1.5 times HS25 loading and was applied for fatigue tests after 1 million cycles)

\subsection{SLAB \#3}

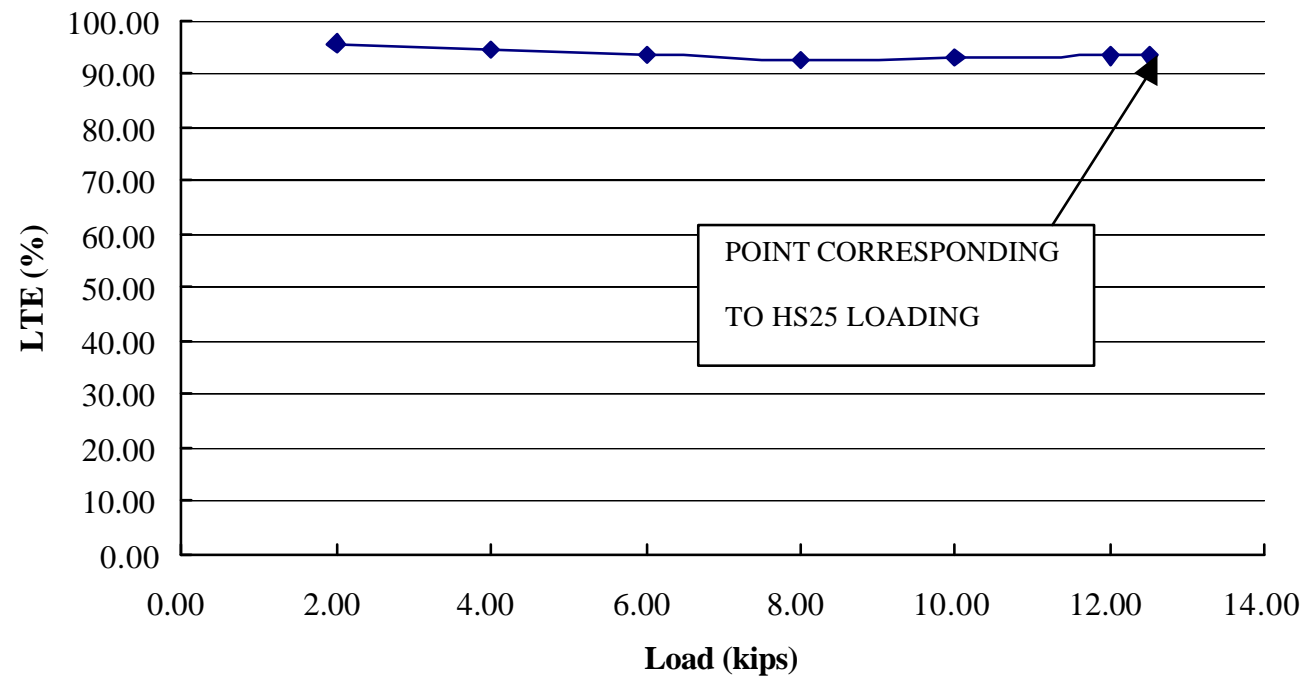

Figure 4.23 Joint Load Transfer Efficiency for slab \#3 


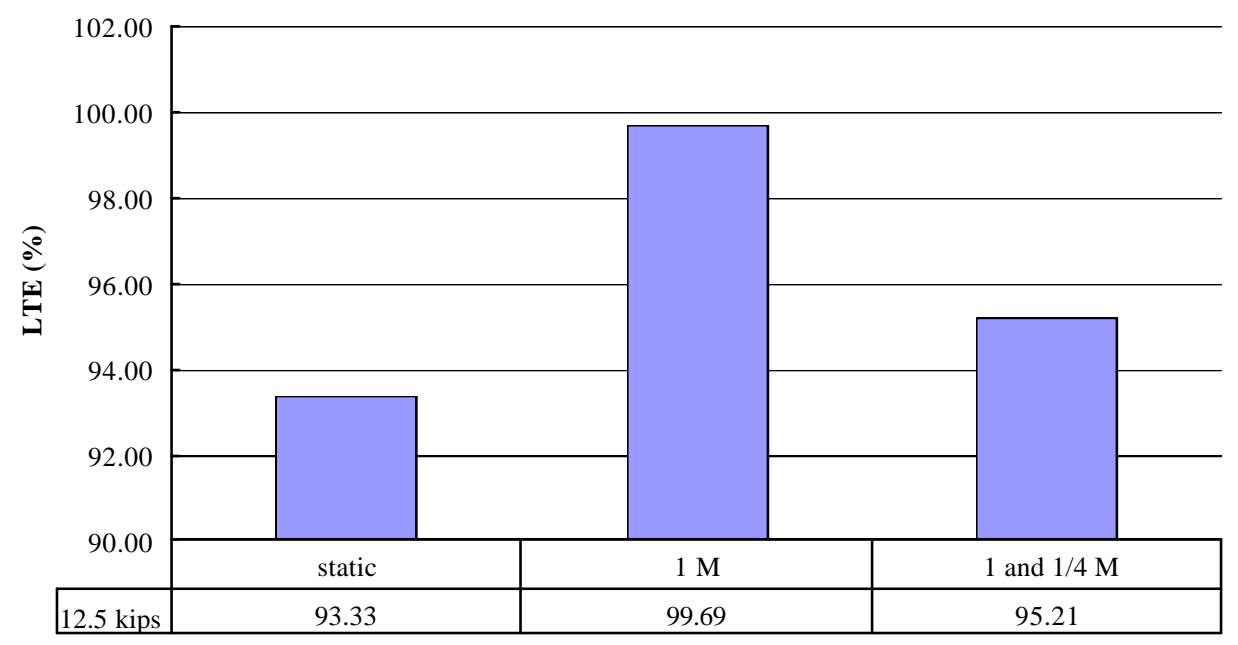

Figure 4.24 LTE under fatigue test for slab \#3 (0 to 1.25 million)

Crack occurred in slab \#3 is away from mid-joint hence these results do not have much significance.

\subsubsection{Joint Load Transfer Efficiency of Group \#2}

\subsection{SLAB \#4}

During static testing, slab \#4 was subjected to loading up to 11 kips, which is corresponding to HS25 loading. 


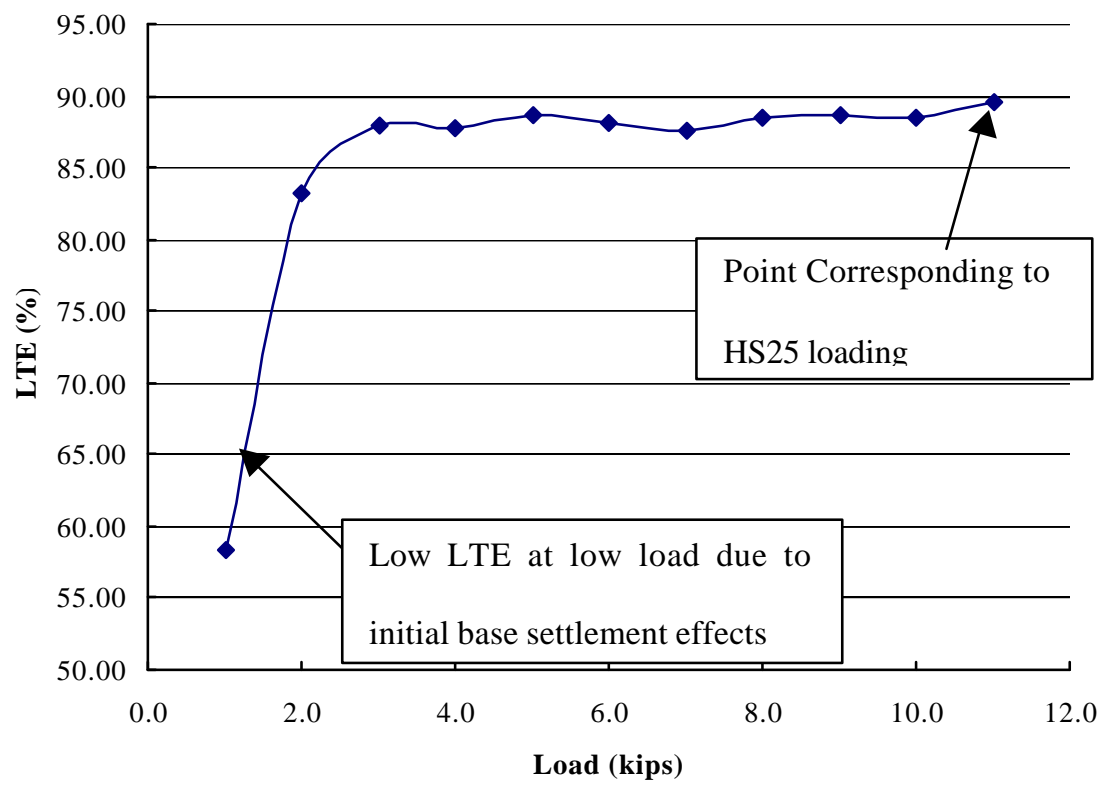

Figure 4.25 Joint Load Transfer Efficiency for slab \#4

In fatigue tests, slab \#4 provided good load transfer efficiency $>80.5 \%$ after 5 million fatigue load cycles when base surface and base material under this slab remained in good condition. When base aggregates were not in contact with the slab due to aggregate compaction or slight sideways flexing of the aggregate bin, LTE was found to have been decreased to about $55 \%$, which is still around $92.1 \%$ of the $60 \%$ LTE that corresponds to the ACPA recommended value on joint effectiveness, E, 75\% (Section 4.4.2). Detailed data are shown in Figure 4.26. 


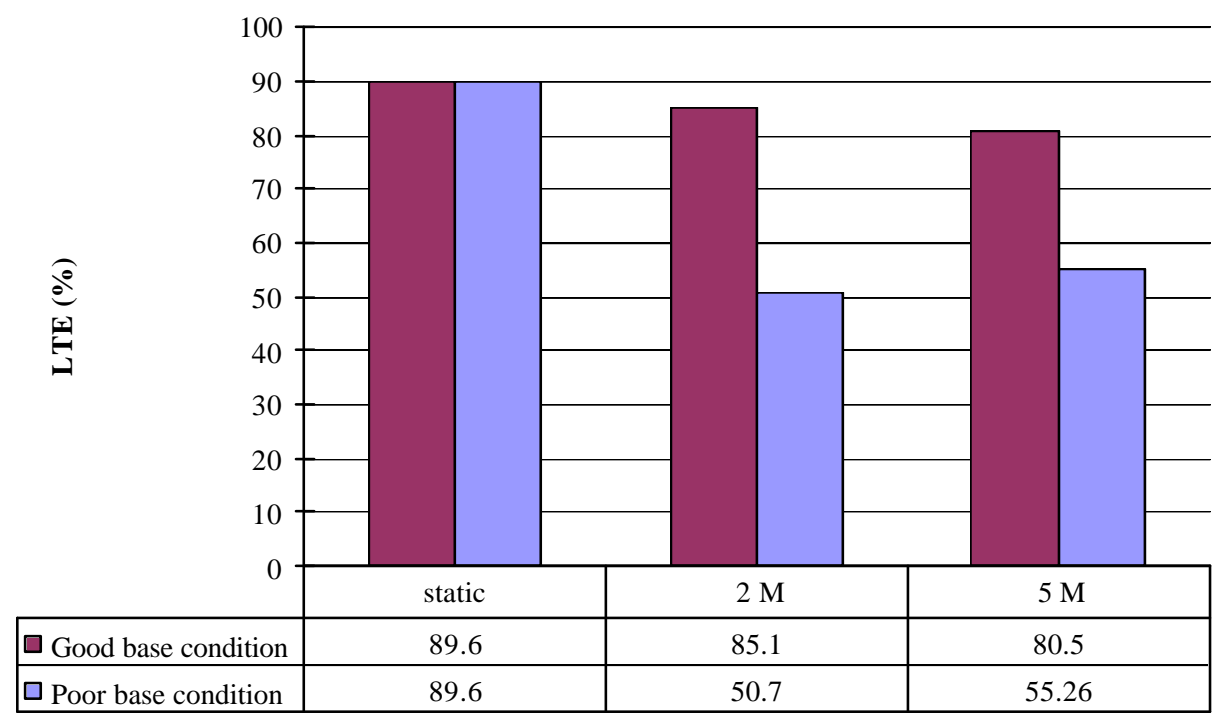

Figure 4.26 LTE under fatigue test for slab \#4 (0 to 5 million)

From Figure 4.26, LTE of slab \#4 containing FRP dowel remained about $80 \%$ with good base condition. With poor base condition LTE reduced from $88 \%$ to $55 \%(92.1 \%$ of the $60 \%$ LTE, which corresponds to the ACPA recommended value on joint effectiveness, E, 75\%). The poor base condition was observed with concave surface on slab-base surface due to aggregate compaction and base settlement. Also, it should be noted that the slabs were not cast directly on top of the aggregates, which leads to some aggregate repositioning under fatigue loading. Modulus of subgrade reaction, $\mathrm{k}$ was found changed from 400 pci to 800 pci after 5 million cycles in poor base condition.

In order to find the condition of interface between FRP dowel and concrete interface, after 5 million cycles of HS25 and higher loading, slab \#4 was separated by cutting FRP dowel. Dowel-concrete interface was found to be in good shape with no visible micro cracks (Figure 4.27). 


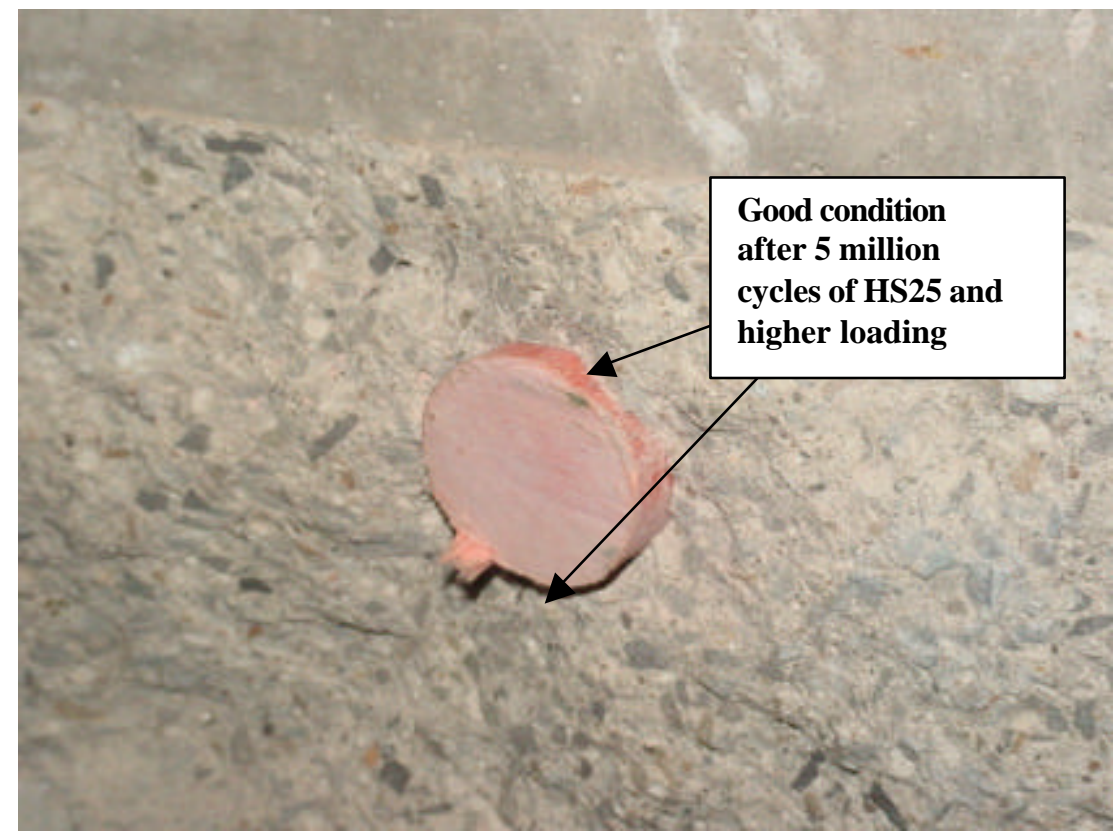

Figure 4.27 Dowel-concrete interface condition in slab \#4 after 5 million load cycles

\subsection{SLAB \#5}

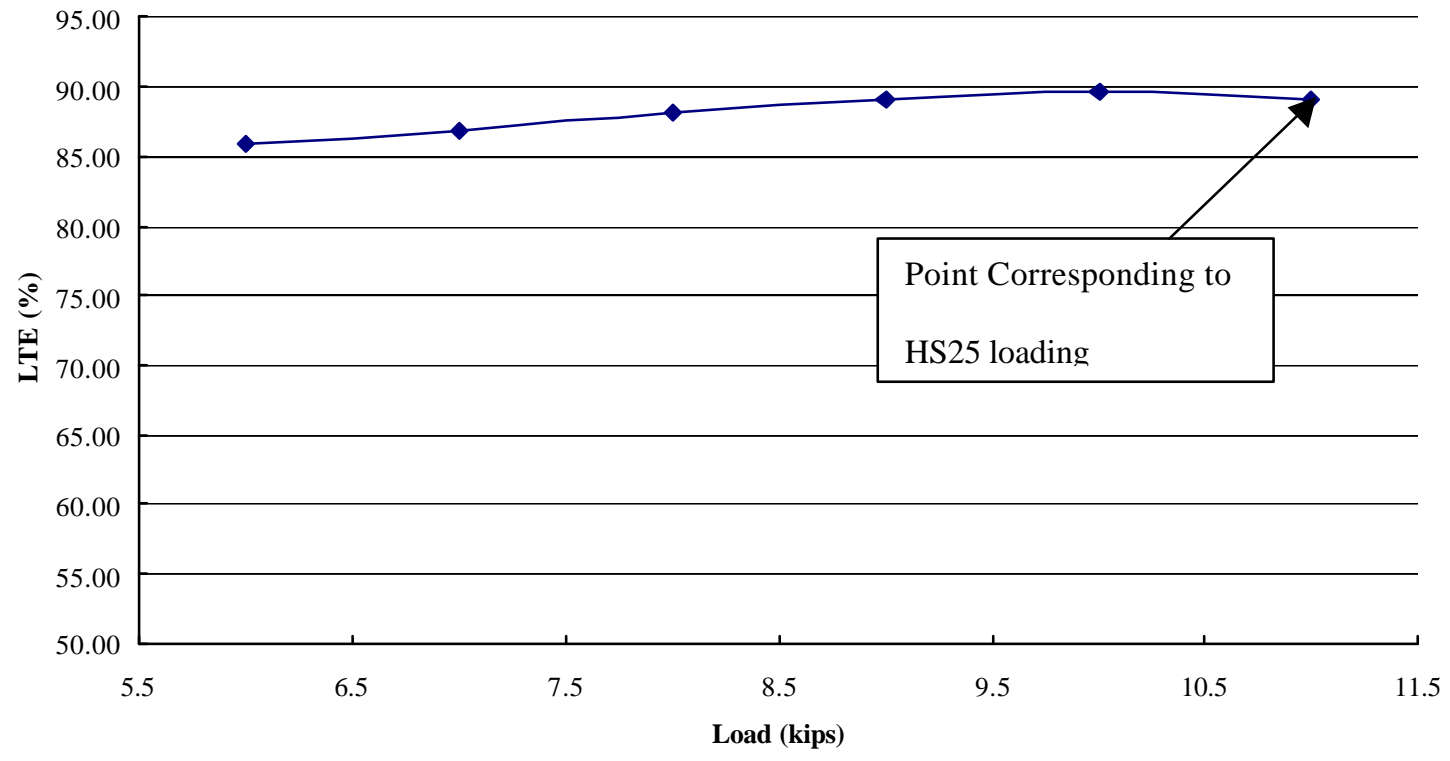

Figure 4.28 Joint Load Transfer Efficiency (LTE) for slab \#5 


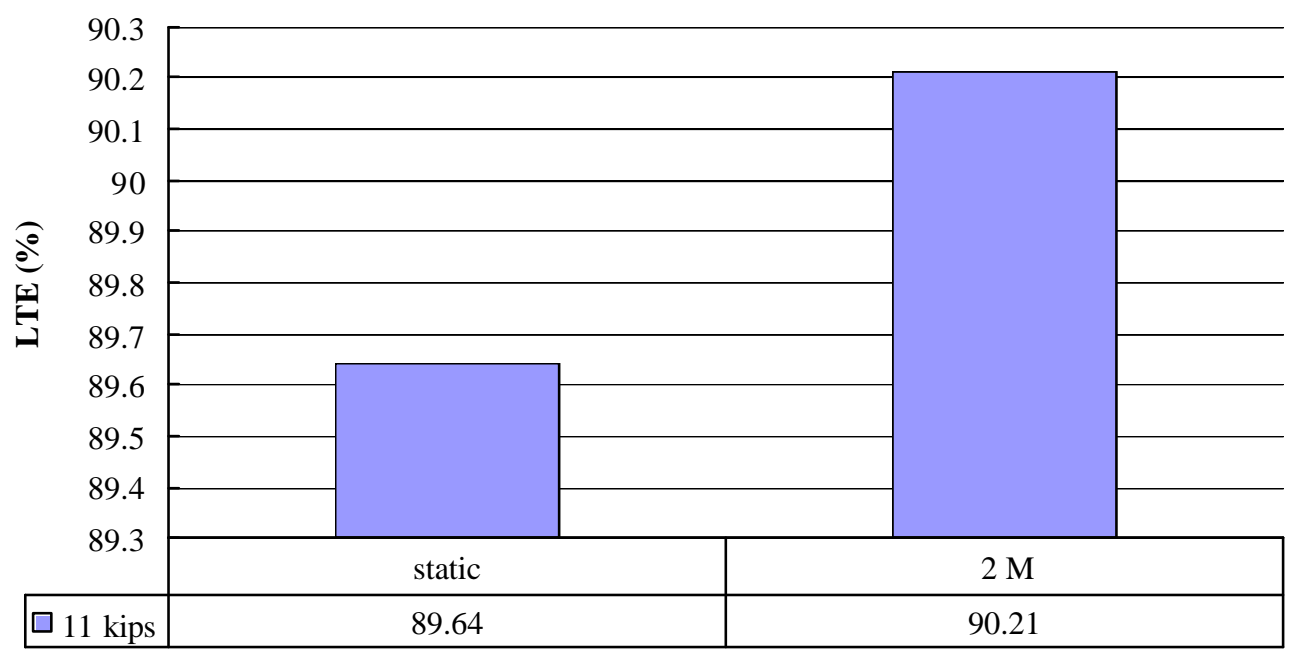

Figure 4.29LTE under fatigue test for slab \#5 (0 to 5 million)

4.4.2.3 Analysis and Discussion for Joint Load Transfer Efficiency

4.4.2.3.1 Analysis and Discussion for Slab Group \#1 (6” spacing)

Tests results were summarized into Tables 4.14 and 4.15.

Tables 4.14 Load Transfer Efficiency of Group One from Static Tests

\begin{tabular}{|c|c|}
\hline Slab & LTE $(\%)$ \\
\hline$\# 1$ & 97.79 \\
\hline$\# 2$ & 94.13 \\
\hline$\# 3$ & 93.33 \\
\hline
\end{tabular}


Tables 4.15 Load Transfer Efficiency of Group \#1 During Fatigue Tests

\begin{tabular}{|c|c|c|c|c|c|}
\hline \multirow{2}{*}{$\begin{array}{c}\text { Specimen } \\
\text { Number }\end{array}$} & $1 \mathrm{M}$ & $2 \mathrm{M}$ & $4 \mathrm{M}$ & $5 \mathrm{M}$ & Proper Crack at Mid- \\
\cline { 2 - 6 } & 93.79 & & & joint \\
\hline 1 & $\left(\mathrm{j} . \mathrm{w} .=0.25^{\prime \prime}\right)$ & $89.7 *^{\dagger}$ & $68.88^{\dagger}$ & $71.5 *^{\dagger}$ & Yes \\
\hline 2 & 95.52 & $93.33^{\dagger}$ & - & - & No \\
\hline 3 & 99.69 & - & - & - & No \\
\hline
\end{tabular}

(NOTE: In Table 4.15,

* Joint width increased to 0.4 ":

${ }^{\dagger}$ An overload factor 1.5 used so that 1.5 times HS25 load was applied for specimen \#1 and \#2 during fatigue tests started from 2 million cycles)

It can be said that:

1. In static tests, all slabs provided good Load Transfer Efficiency, which was greater than $60 \%$ of LTE (corresponding to $75 \%$ of joint effectiveness, E) (ACPA). Slab \#1 (1.0" diameter FRP dowel with 6" spacing) with proper crack formation at mid-joint had a >90\% Load Transfer Efficiency, which was slightly larger than slabs \#2 (1" diameter steel dowel with 6" spacing) and \#3 (1.5" diameter FRP dowel with 6" spacing). Slabs \#2 and \#3 had crack formation away from mid-joint (Table 4.2). In slab \#1, the dowel worked as per design to transfer maximum load.

2. Even when 1.5 times design load (HS25 loading) and an influence of increased joint width (increased from $0.25 "$ to 0.4 ") was considered, the observed TLE in slab \#1 was consistent (reduced from $93.79 \%$ to $71.57 \%$ ) due to the right crack 
position and still higher than $60 \%$ of LTE (corresponding to $75 \%$ of joint effectiveness, E) (ACPA).

3. Pumping and erosion under the loaded side of slab was observed during the tests. This could be the main reason that LTE of slab \#1 reduced. The base settlement is also a reason to cause reduced LTE. It is suggested to check the base property such as ( $\mathrm{k}$, modulus of subgrade reaction) before and after each fatigue test.

\subsection{Analysis and Discussion for Slab Group Two (12” spacing)}

Tests results were summarized in Tables 4.17 and 4.18.

Tables 4.16 Load Transfer Efficiency of Group Two from Static Tests Under Corresponding HS25 Load

\begin{tabular}{|c|c|}
\hline Slab Number & LTE (\%) \\
\hline 4 & 88.48 \\
\hline 5 & 89.00 \\
\hline
\end{tabular}

Tables 4.17 Load Transfer Efficiency of Group Two from Fatigue Tests

\begin{tabular}{|c|c|c|c|}
\hline \multirow{2}{*}{ Slab Number } & \multicolumn{3}{|c|}{ LTE (\%) } \\
\cline { 2 - 4 } & $2 \mathrm{M}$ & $4 \mathrm{M}$ & $5 \mathrm{M}$ \\
\hline \multirow{2}{*}{4} & 85.1 & - & 80.5 \\
\cline { 2 - 4 } & $50.70^{*}$ & 47.22 & $55.26^{*}$ \\
\hline 5 & 90.21 & - & - \\
\hline
\end{tabular}

(Note: in Table 4.17, symbols (*) denotes those results from tests $\left(2 \mathrm{M}^{*}\right.$ and $\left.5 \mathrm{M}^{*}\right)$ conducted on poor base condition). 
It can be found that:

1. Both slabs \#4 and \#5 had proper crack occurrence at the joint.

2. In static tests, both slabs had very good Load Transfer Efficiency (more than $88 \%$ ), which were much greater than $60 \%$ of LTE (corresponding to $75 \%$ of joint effectiveness, E) (ACPA). Thus, FRP dowel performed as well as steel dowel and showed load transfer efficiency as good as steel dowel in static test.

3. After 2 million HS25 fatigue loading cycles, for same dowel diameter and spacing, the concrete pavement containing FRP dowel provided slightly lower LTE (85.1\% vs. $90.21 \%$ ) than pavement containing STEEL dowel (Table 4.17). But with poor base condition, LTE of slab with FRP dowel over STEEL dowel is $(50.71 \%$ vs. $90.21 \%)$.

4. LTE of slab with FRP dowel remained $>80 \%$ after 5 million loading cycles.

\subsubsection{Investigations on Pavement Pumping Problem}

Pumping is a common problem occurring in concrete pavements due to the movement of material underneath the slab or ejection of material from underneath the slab as a result of water pressure. Pumping will cause decreased structural support of the slab, which can lead to linear cracking, corner breaks and faulting.

Two cases pumping tests were conducted (Figs 4.30 and 4.33). In case one, base material under loaded side of slabs was removed for a 2 feet range to simulate the pumping problem occurring in field (Figure 4.30). These tests were conducted only on slabs \#4 (1.5" diameter FRP dowel @ 12" c/c) and \#5 (1.5" diameter steel dowel @ 12" c/c) up to 10 kips. Test results are shown in Figures 4.31 and 4.32. 


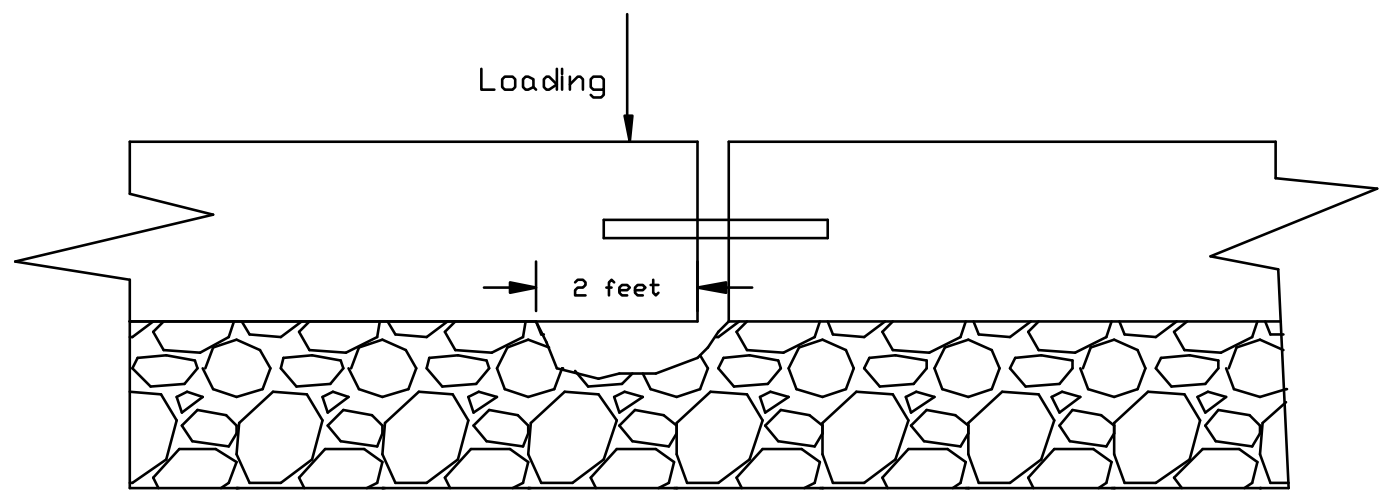

Figure 4.30 Case One -2 ft. Base Material Removal under Loaded Side of Slabs

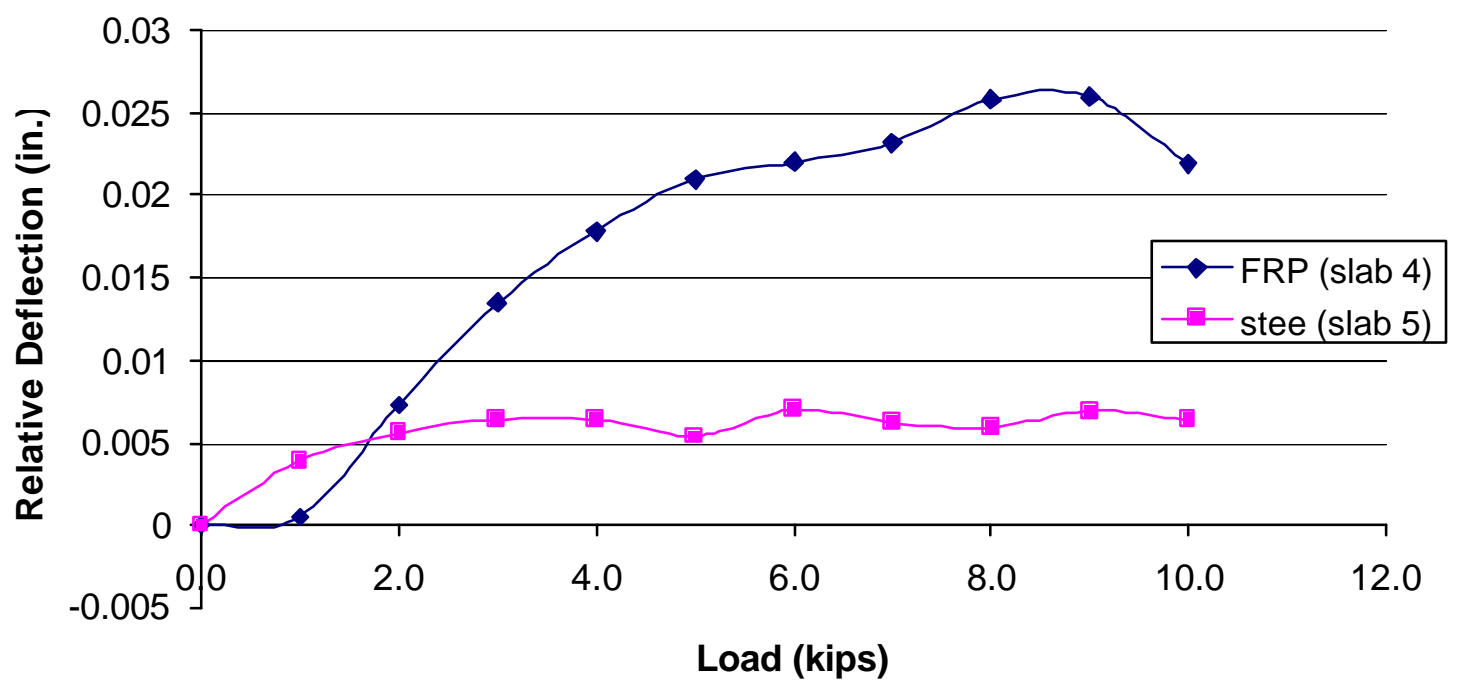

Figure 4.31 Relative Deflection for Pumping Tests (Case One -2 ft. base removal) 


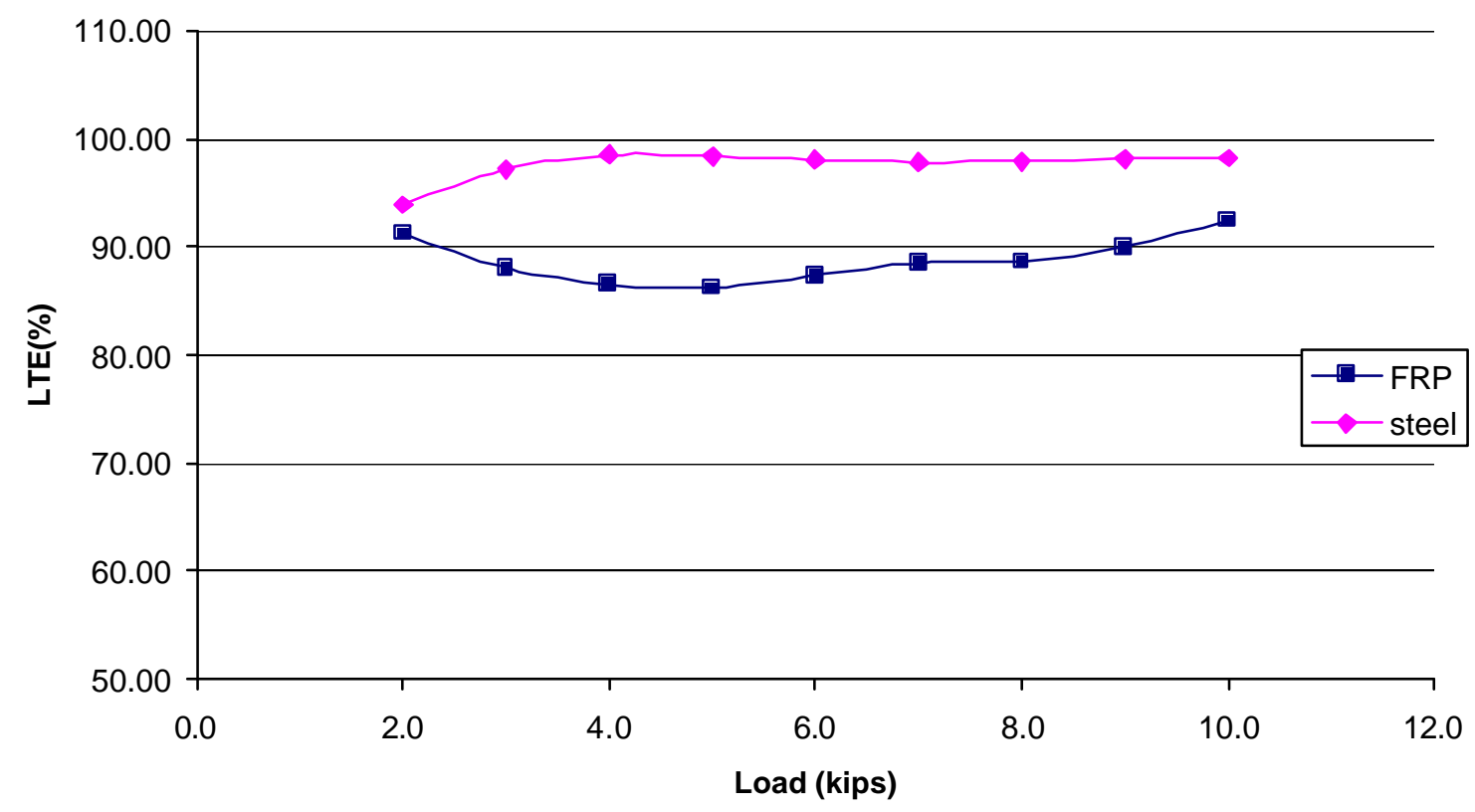

Figure 4.32 Load Transfer Efficiency for Pumping

Tests (Case One -2 ft. Base Removal)

In case two, base material under each side of slabs was removed for a 1-foot range (Figure 4.33). When loading exceeded 3 kips, joint opening closed and the two faces of the joint bearing againsted each other. Hence, tests were conducted only on slabs \#4 and \#5 up to 3 kips in case two. Test results are shown in Figure 4.34 and 4.35.

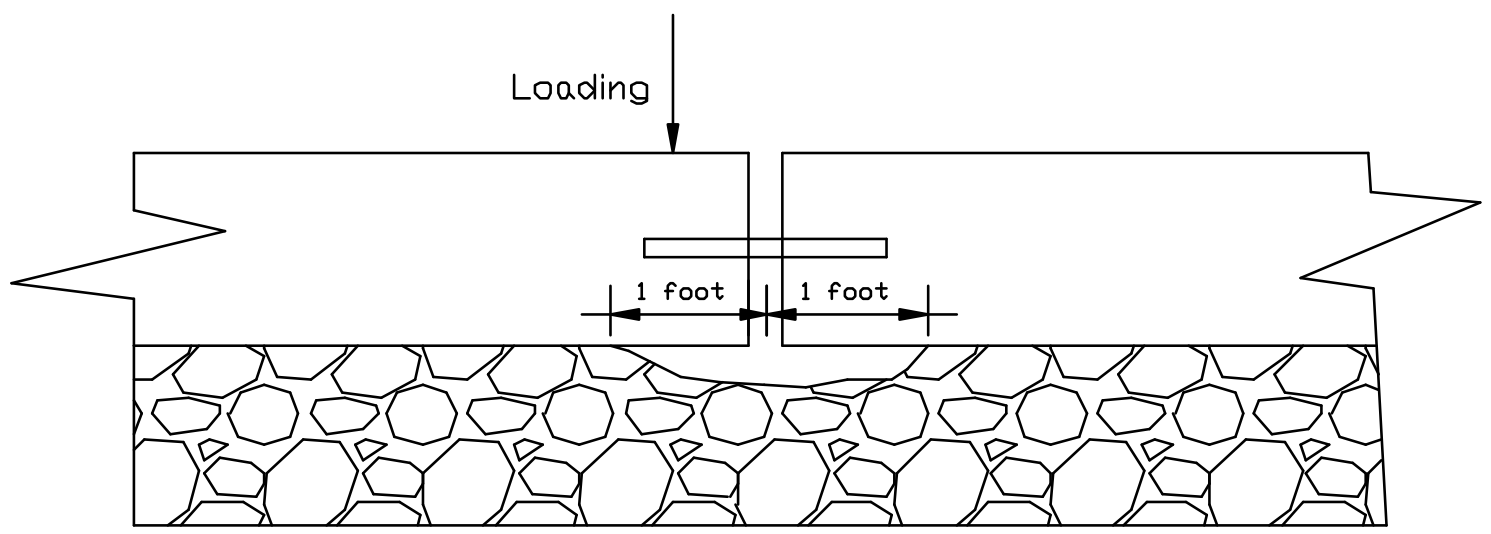

Figure 4.33 Case Two-1 ft. Base Material Removal under Both Sides of Slabs 


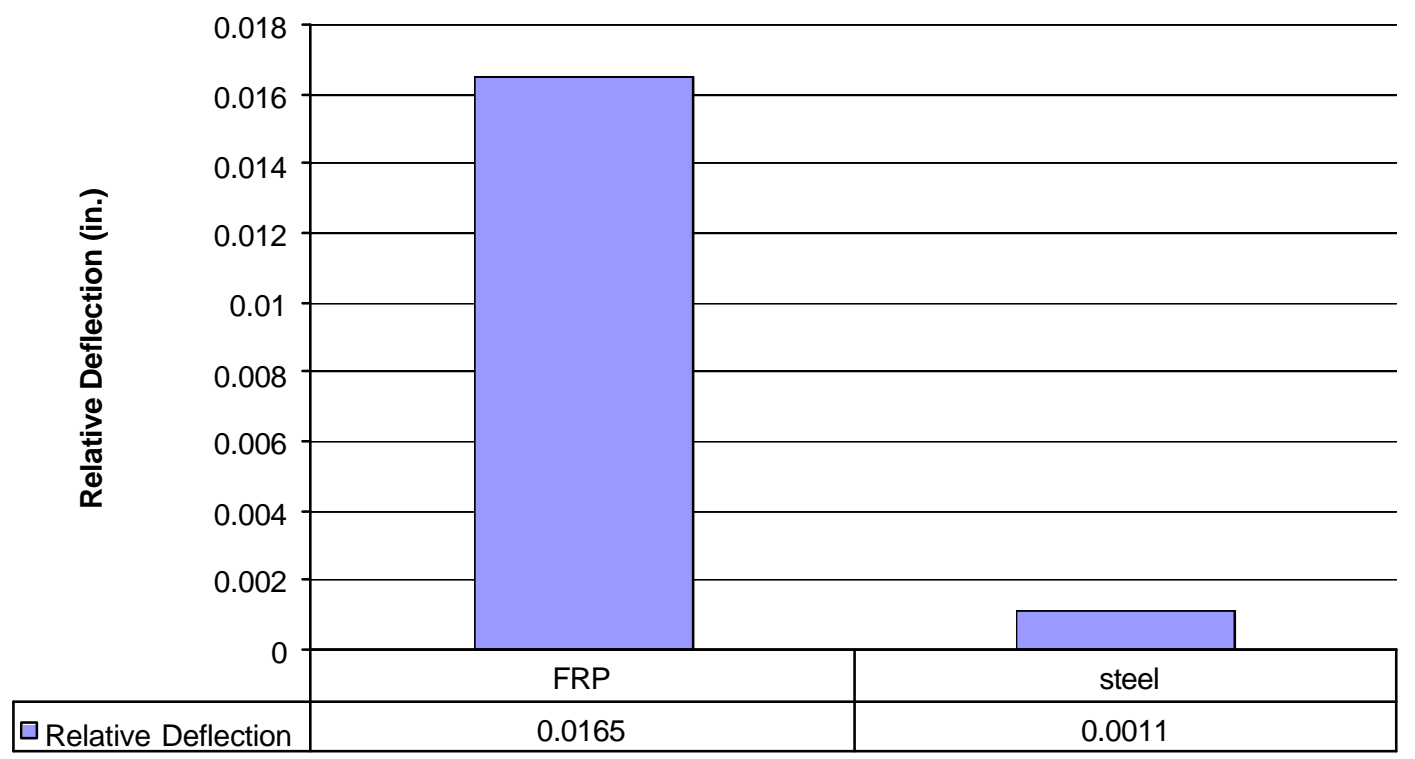

Figure 4.34 Relative Deflection for Pumping Tests under 3 kips loading (Case Two-1 ft. base removal under both slabs)

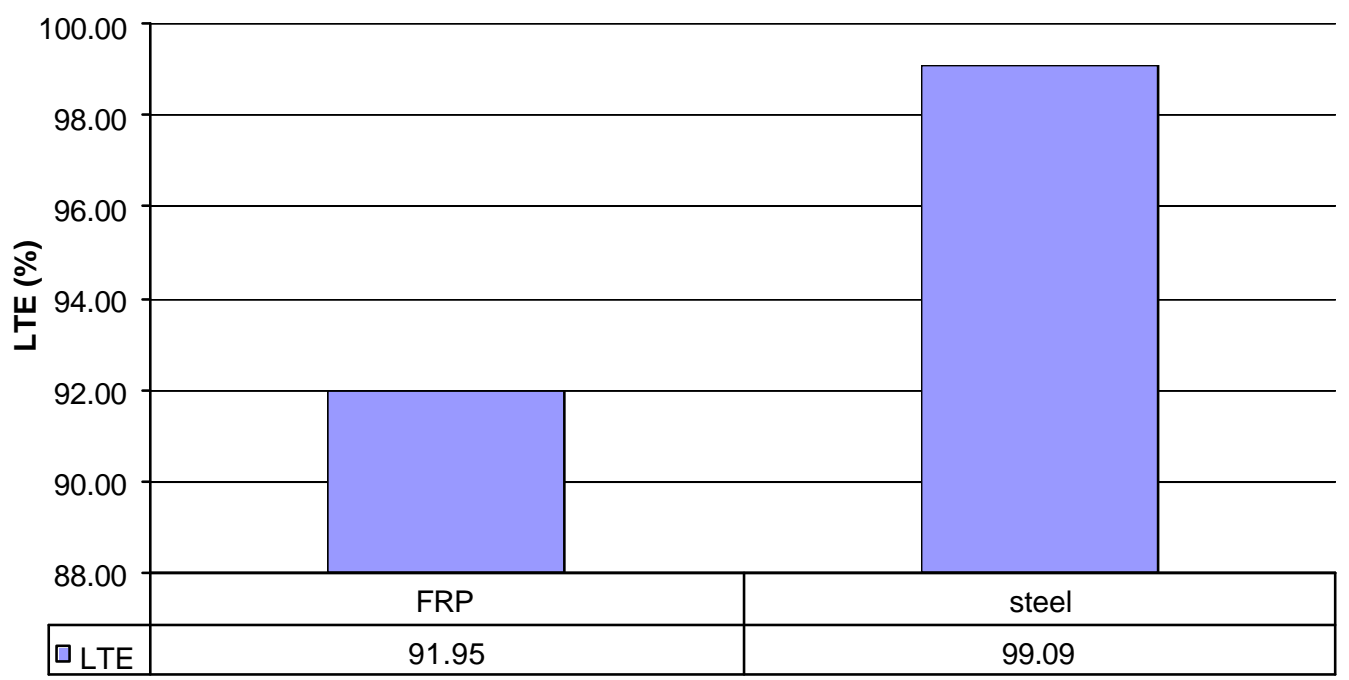

Figure 4.35 Load Transfer Efficiency for Pumping Tests under 3 kips loading (Case Two-1 ft. base removal under both slabs) 
Test results from both cases one and two were compared and summarized into Tables 4.18 and 4.19.

Table 4.18 Evaluation of pumping issue under 10 kips loading

\begin{tabular}{|c|c|c|c|}
\hline Test Case Number & Dowel Material & $\begin{array}{l}\text { Relative Deflection } \\
\qquad\left(\times 10^{-3} \text { in. }\right)\end{array}$ & $\begin{array}{c}\text { Load Transfer } \\
\text { Efficiency (LTE, \%) }\end{array}$ \\
\hline \multirow{2}{*}{$\begin{array}{l}\text { Case One }(2 \mathrm{ft} \text {. base } \\
\text { removal under loaded }\end{array}$} & FRP (slab \#4) & 21.9 & 92.42 \\
\hline & Steel (slab \#5) & 6.4 & 98.21 \\
\hline \multirow{2}{*}{$\begin{array}{l}\text { Case Two (1 ft. base } \\
\text { removal under both }\end{array}$} & FRP (slab \#4) & - & - \\
\hline & Steel (slab \#5) & - & - \\
\hline
\end{tabular}

Table 4.19 Evaluation of pumping issue under 3 kips loading

\begin{tabular}{|c|c|c|c|}
\hline \multirow{2}{*}{ Test Case Number } & Dowel Material & Relative Deflection & Load Transfer \\
& & $\left(\times 10^{-3}\right.$ in. $)$ & Efficiency (LTE, \%) \\
\hline Case One (2 ft. base & FRP (slab \#4) & 13.5 & 88.00 \\
\cline { 2 - 4 } removal under loaded & Steel (slab \#5) & 6.4 & 97.15 \\
\hline $\begin{array}{c}\text { Case Two (1 ft. base } \\
\text { removal under both }\end{array}$ & FRP (slab \#4) & 16.5 & 91.95 \\
\cline { 2 - 4 } slabs) & Steel (slab \#5) & 1.1 & 99.09 \\
\hline
\end{tabular}


It was found:

1. Load Transfer Efficiencies (LTEs) were observed in cases investigated for simulated pavement pumping problem with supporting base removal up to certain length near the joint (Figs.4.30 and 4.33). LTEs were not less than the LTEs obtained from intact base condition (Table 4.16). However, under fatigue load cycles LTE is expected to reduce significantly for specimens without support near joint.

2. LTE obtained in test case two (1 ft. Base Material Removal under Both Sides of Slabs) was greater than $90 \%$ at 3 kips loading, and after loading exceeded 3 kips, two joint faces would bear against each other. Thus Case Two $(1 \mathrm{ft}$. base removal under both slabs) with unsupported slab areas on both sides of the slab was more detrimental than Case One ( $2 \mathrm{ft}$. base removal under loaded slab).

\subsubsection{Strains on Dowels}

Most of the strain gages installed on dowels survived before fatigue tests. However, some of them did not function properly after fatigue tests. Strain readings shown in this chapter are only from slab \#1 (1.0” diameter @ 6" spacing c/c) and slab \#4 (1.5” diameter @12” spacing c/c). 


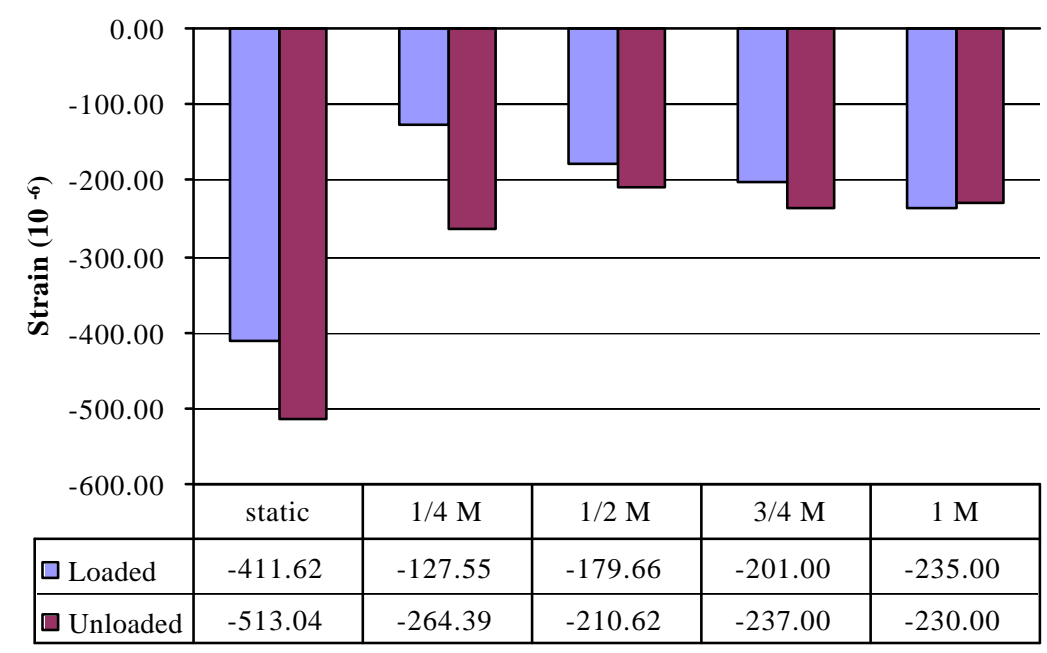

Figure 4.36 Strain gage reading in slab \#1 (1.0” diameter @ 6" c/c) from static test to 1 million cycles under HS25 loading)

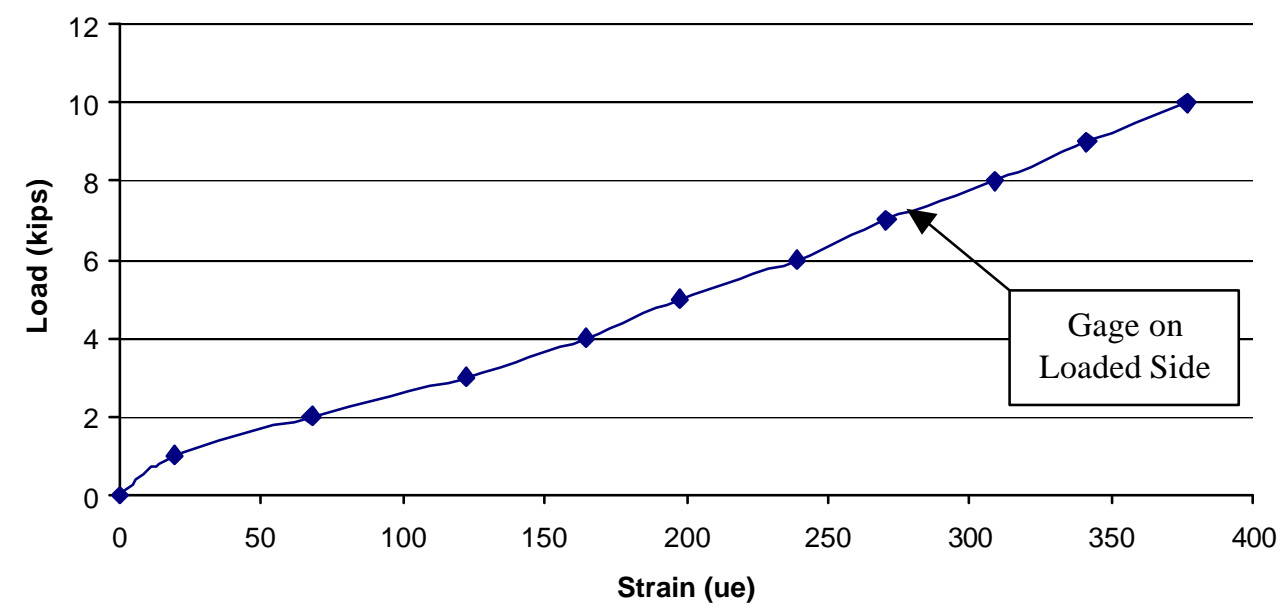

Figure 4.37 Strain gage reading in slab \#4 (1.5” diameter @ 12” c/c) from static test under HS25 loading

Strain values at unloaded side of dowel during static tests from slabs \#1 and \#5 were 513.04 and 376.43 micro-strains, respectively. Both values were less than those from analytical evaluation (ranges from 1000 to 1200 micro-strains). But strain values are typically not used for LTE calculation. 


\section{Chapter 5}

\section{FIELD APPLICATIONS AND TEST RESULTS}

\section{$5.1 \quad$ Introduction}

Experimental tests and results discussed in Chapter 4 have shown that FRP dowels can provide sufficient Load Transfer Efficiency under heavy traffic load rating HS25 load and 1.5 times HS25. The purpose of our field test program is to investigate FRP dowel performance and FRP-Concrete interaction in full-scale highway pavement slabs under realistic loading and field exposure conditions.

Field application and tests were done in collaboration with Department of Highway (DOH), West Virginia Department of Transportation (WVDOT). FRP dowels were used for new pavement construction and rehabilitation of damaged pavement sections. FRP dowel joints were used for new highway pavement construction in Rt.219 and Rt.33 East in Elkins, WV, during September-November 2001. Field tests were conducted in July 2002 and June 2003. FRP dowels were used for pavement rehabilitation at the junction of Rts. 119 and 857, University Avenue, Morgantown, WV, during October 2002.

\subsection{FRP Dowels Used for New Highway Pavement Construction}

FRP dowels were used during the construction of new highway Rt.219 and Rt. 33 East in Elkins, WV. The installation and field test setup are discussed in this section. Field test results are also analyzed and discussed. 


\subsubsection{Field Locations and Installations}

\subsubsection{Field Locations}

Two locations separated by about 4 miles were selected for field installations in corridor H highway at Rt. 219 and Rt. 33 in Elkins, WV. Location 1 (Figures 5.1 \&5.2) was West bound and location 2(Figures $5.3 \& 5.4$ ) was East bound

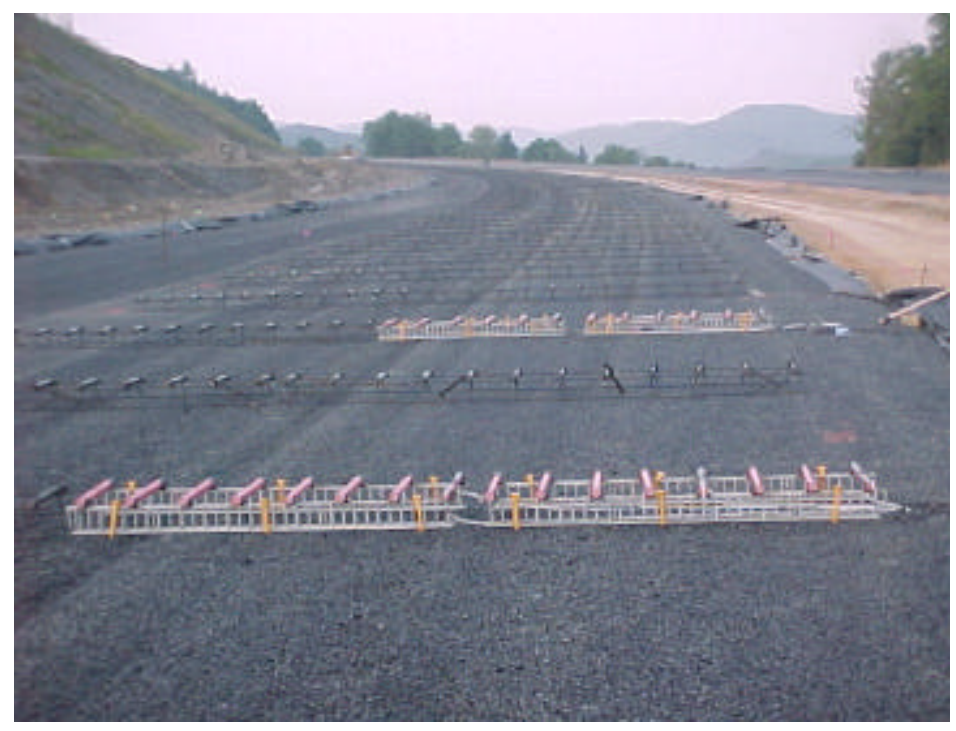

Figure 5.1 Dowel installation at location 1 of corridor H, Rt. 250, Elkins, WV

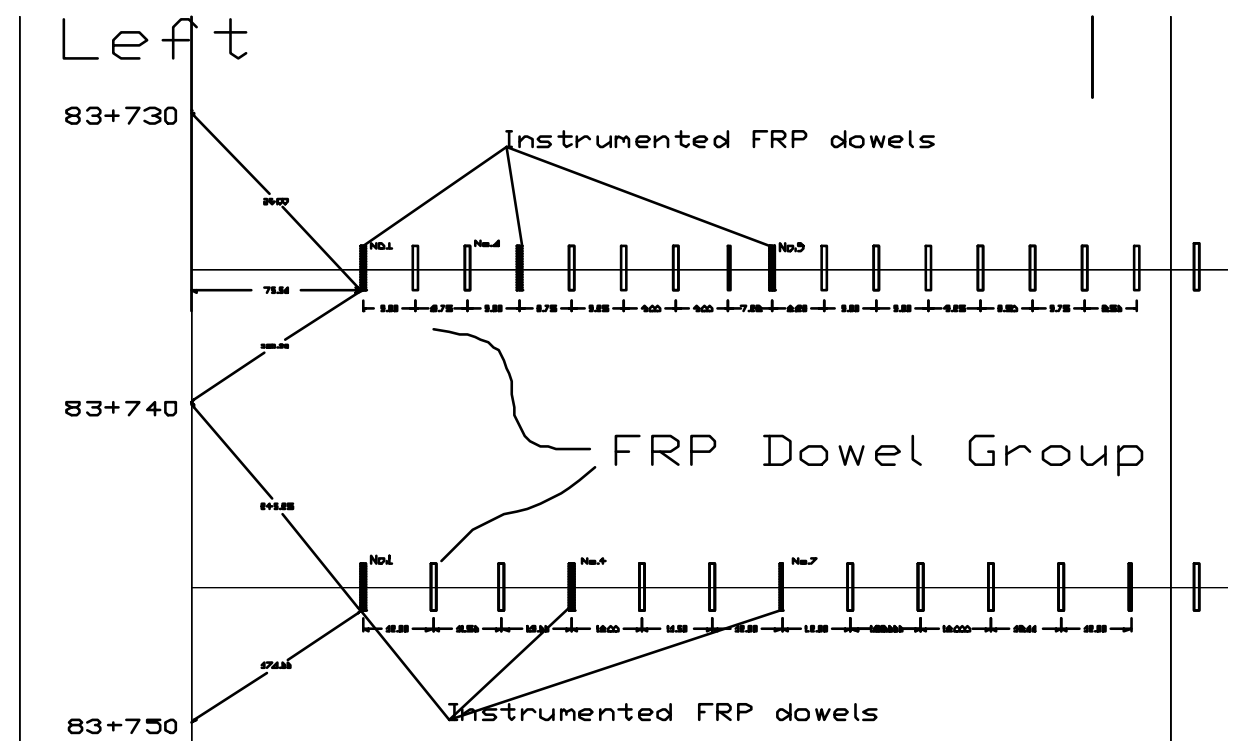

Figure 5.2 FRP dowel positions at location 1 of corridor H, Rt. 250, Elkins, WV (Note:

Only dowels with shading are instrumented) 


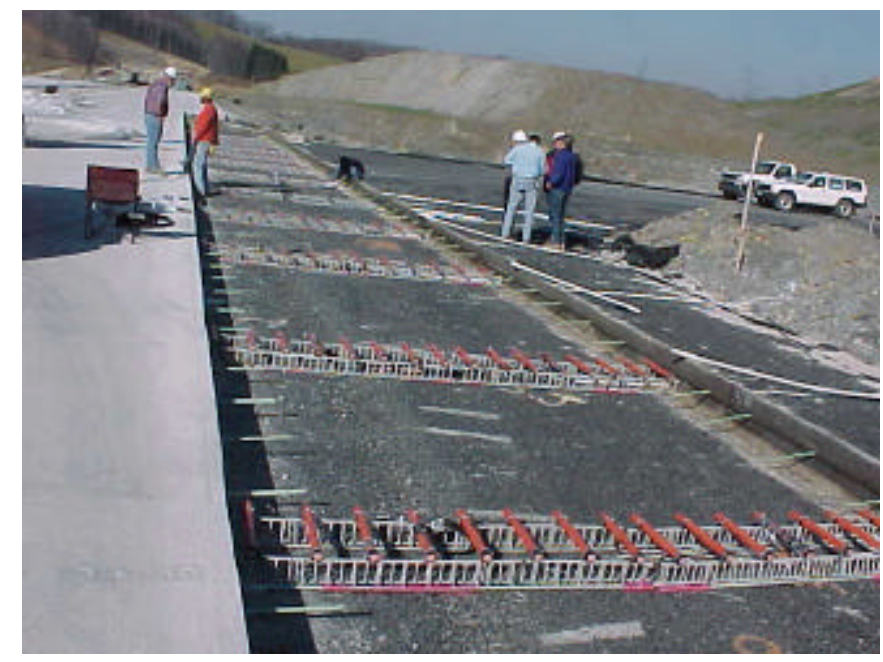

Figure 5.3 FRP dowel bars at location 2 of corridor H, Rt. 219, Elkins, WV

(Note: side pipes carry wires from instrumented dowels to outside of shoulder region)

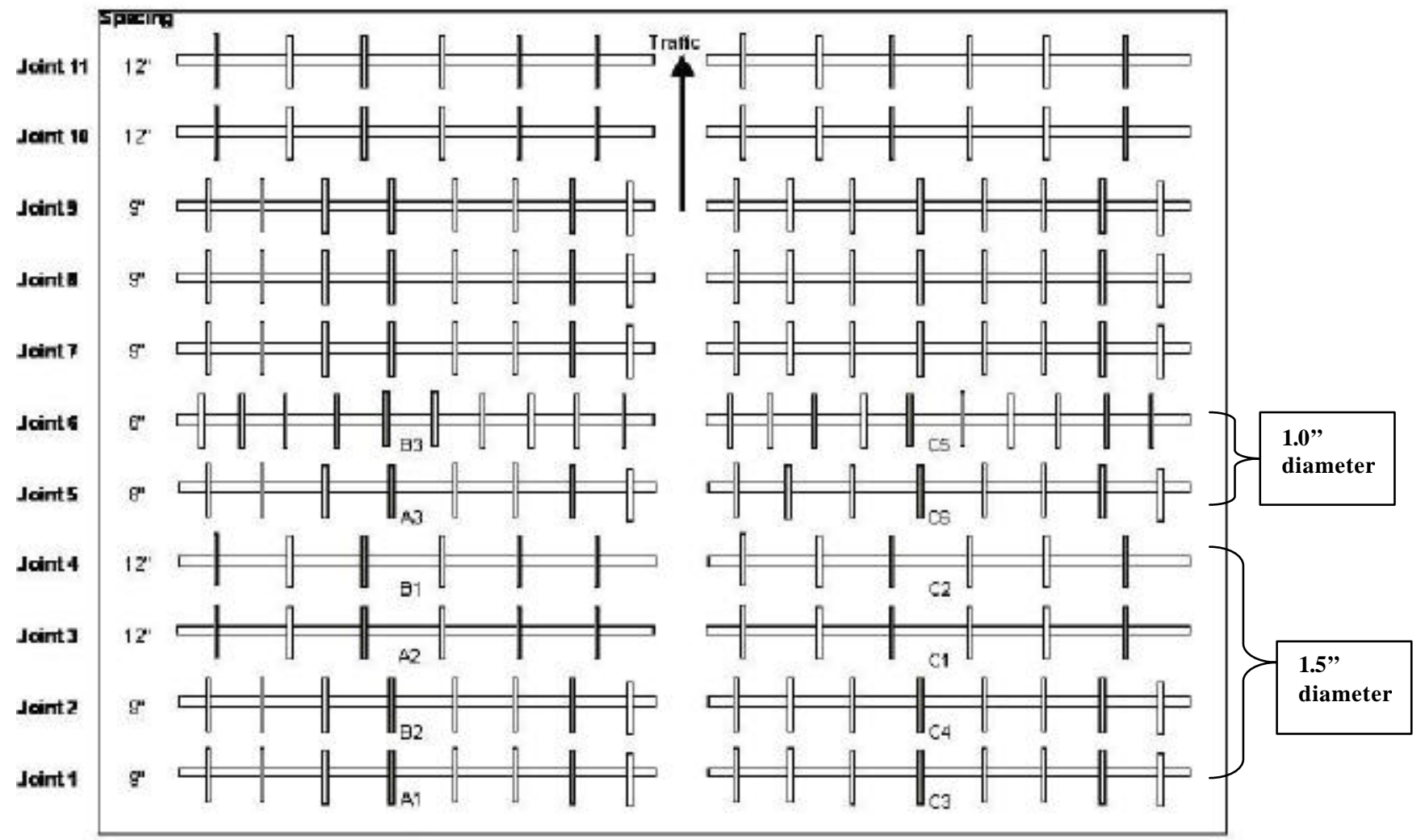

Figure 5.4 FRP dowel positions at location No.2 of corridor H, Rt. 219, Elkins, WV

(Note: Only dowels with shading were instrumented) 


\subsubsection{Field Installation}

FRP dowels were instrumented with strain gages (Figure 5.5) to monitor strains in dowel bars installed in the field. Embeddable concrete strain gages (Figure 5.6) were also installed to monitor strains in the pavement.

Dowel bars with 1.0" diameter (Figure 5.6) and 1.5" diameter (Figure 5.7) were supported by plastic baskets at design spacings of 12, 9, 8 or 6 inches (Figures $5.2 \& 5.4$ ). Plastic baskets were anchored by either steel (Fig. 5.6) or plastic stakes (Fig. 5.7).

Construction was carried out as shown in Figures $5.8 \& 5.9$. Wires from instrumented dowels were carried through hollow PVC pipes to outside of pavement shoulder (Figure 5.9).

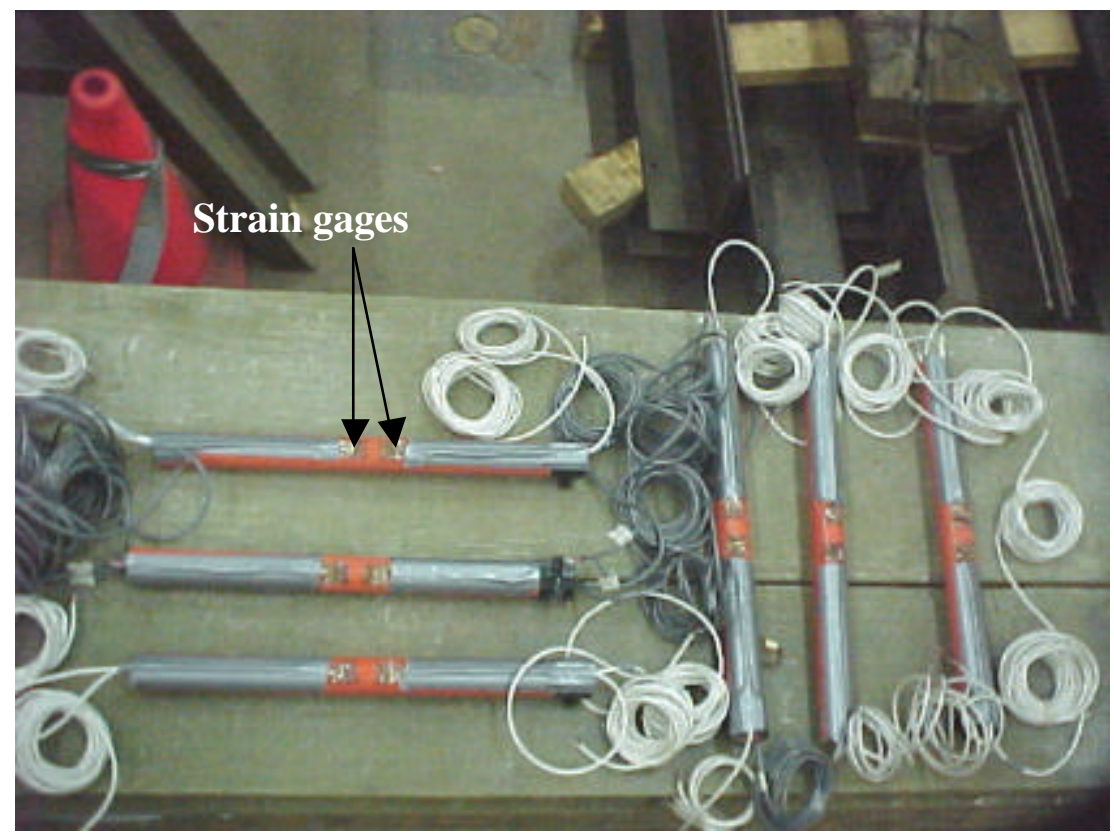

Figure 5.5 FRP dowel bars bonded with strain gages at loaded and unloaded side 


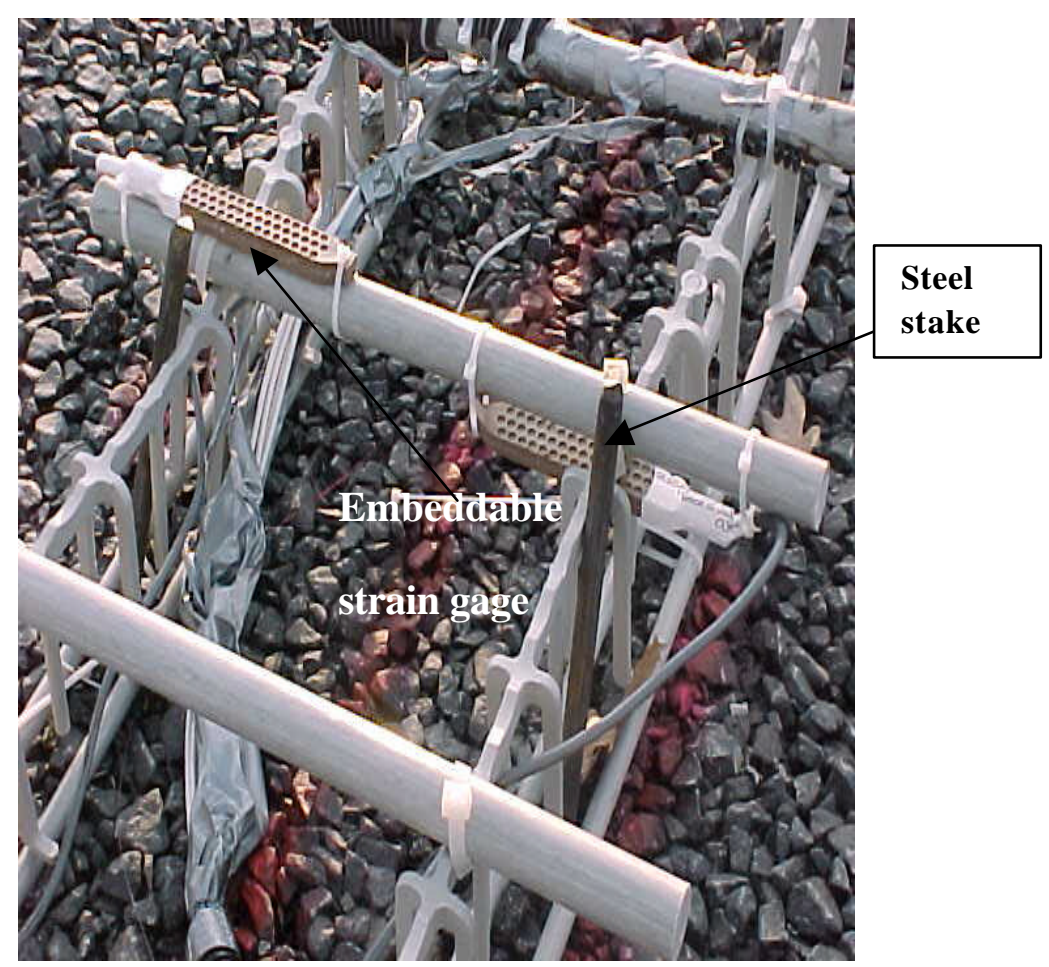

Figure 5.6 Embeddable Concrete Strain Gage with dowels

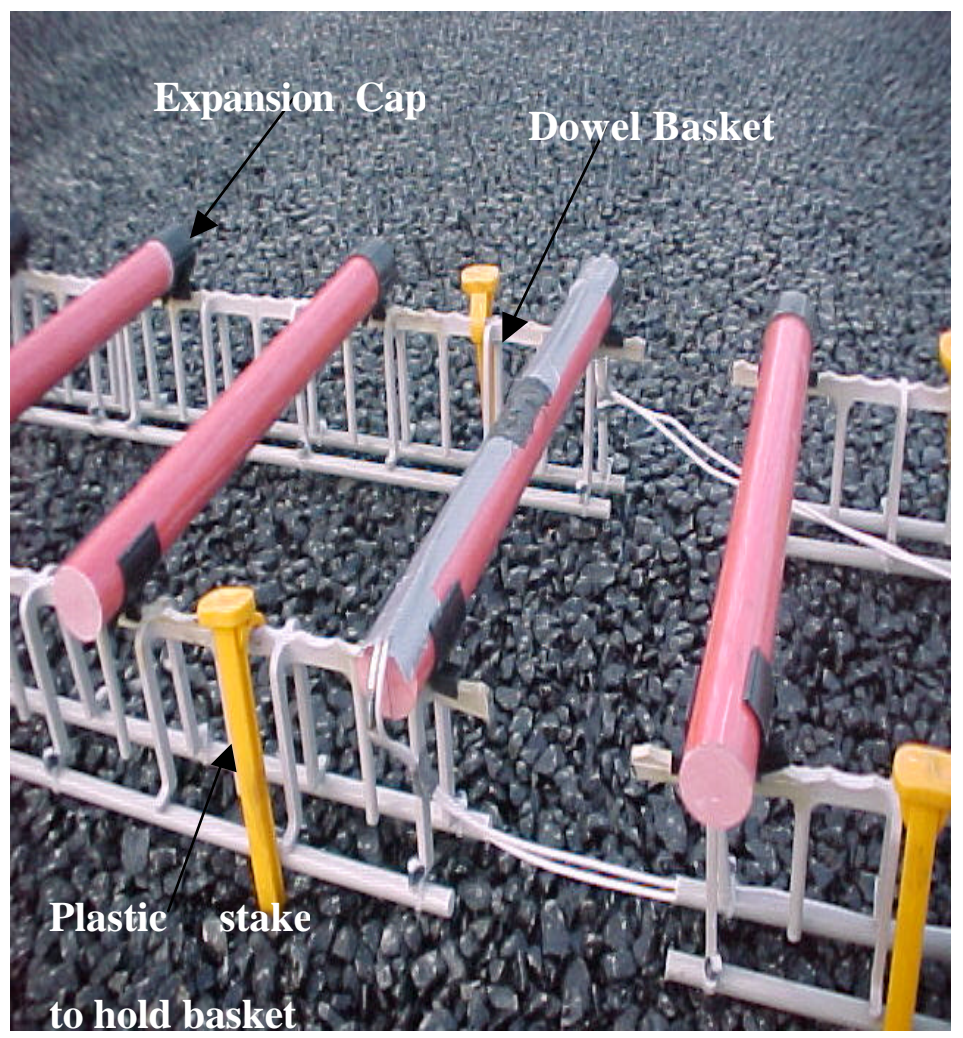

Figure 5.7 FRP dowels in dowel basket 


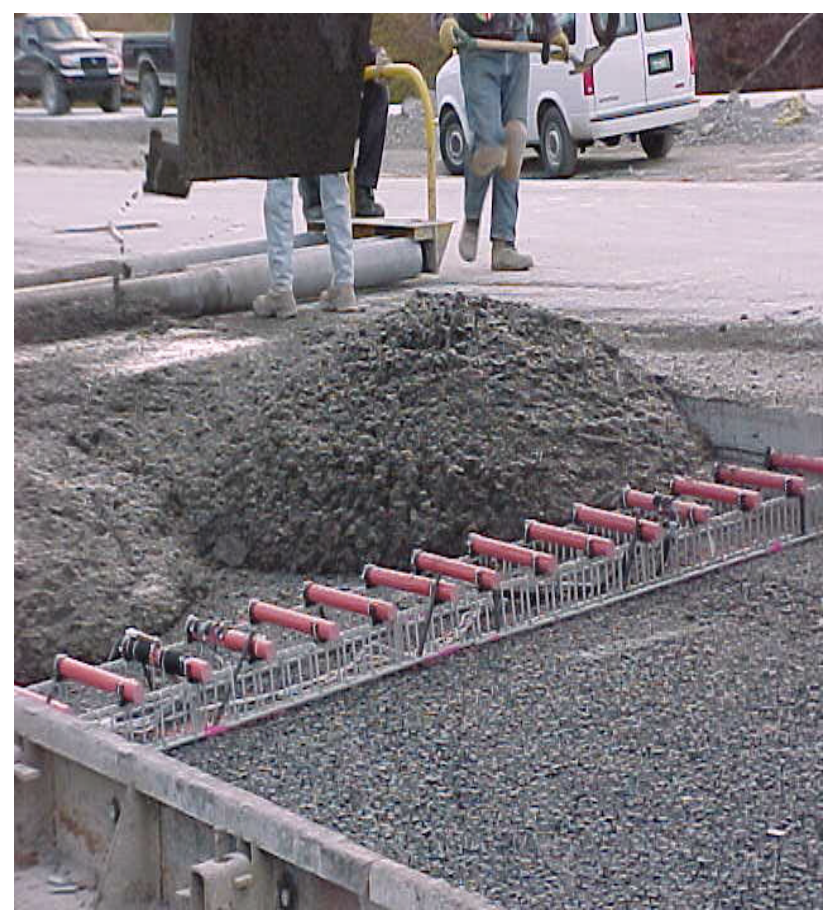

Figure 5.8 Paving operation in progress

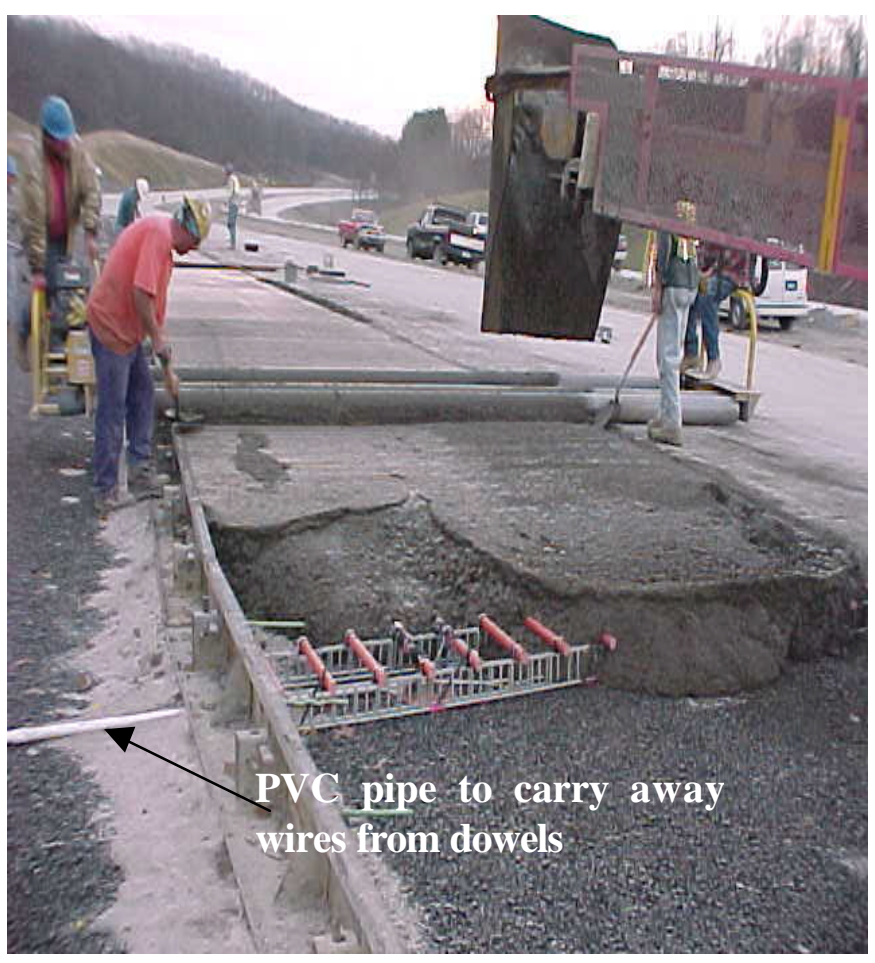

Figure 5.9 FRP dowel bars being covered by concrete 


\subsubsection{Field Tests}

Standard AASHTO Type-3 truck load (AASHTO, 1992) was used to carry out field evaluation before and after opening pavement to the traffic (Figure 5.10). Strain gage readings were recorded prior to and after pavement construction (November 2001), and also during the field testing conducted in July 2002 and June 2003. Automatic data acquisition system was used to collect test data.

\subsubsection{Field Test Before Opening Highway To Traffic In July 2002}

Field test was done before opening pavement to the traffic in July 2002. Static and dynamic tests including brake tests were conducted during this test. Parameters used for field testing are provided in Table 5.1. 
Table 5.1 Parameters of the Field Test at location 2, July 2002.

\begin{tabular}{|c|c|}
\hline Dowel Material & FRP \\
\hline Dowel Diameter & $1.5 ", 1.0 "$ \\
\hline$f_{c}$ & $3500 \mathrm{psi}$ \\
\hline Dowel Spacing & 12" (1.5" dia.), 9" (1.5" dia.), 8"(1.0" dia.), 6"(1.0" dia.) \\
\hline Type of Loading & $\begin{array}{l}\text { - } \text { Truck Type: AASHTO Type } 3 \text { (regular two-axle truck) } \\
\text { - } \text { Gross Weight: } 50000 \mathrm{lbs}(\text { AASHTO), } 53760 \mathrm{lbs} \text { (actual) } \\
\text { - } \text { Front Axel: } 16000 \mathrm{lbs} \text { (AASHTO), } 15780 \mathrm{lbs} \text { (actual) } \\
\text { - } \quad \text { Rear Axel: } 34000 \mathrm{lbs} \text { (AASHTO), } 37980 \mathrm{lbs} \text { (actual) } \\
\text { - } \text { Wheel load: } 8500 \mathrm{lbs} \text { (AASHTO), } 9495 \mathrm{lbs} \text { (actual) }\end{array}$ \\
\hline Types of Tests & $\begin{array}{l}\text { - } \\
\text { - } \quad \text { Dynatic } \\
\text { - } \quad \text { Brake test (speed of } 50 \mathrm{mph} \text { ) }\end{array}$ \\
\hline Instrumentations & $\begin{array}{l}\text { Strain gages } \\
\text { Dial gages for measuring pavement deflection, } \\
\text { Data acquisition system, }\end{array}$ \\
\hline Measurements & $\begin{array}{l}\text { Strain gage reading } \\
\text { Pavement deflection }\end{array}$ \\
\hline Computation & $\begin{array}{l}\text { Strain vs. Loading History } \\
\text { Load Transfer Efficiency (LTE) } \\
\text { Relative Deflection }\end{array}$ \\
\hline
\end{tabular}




\subsection{Test Set Up}

West Virginia State DOT truck with calibrated loads was used in the tests (Table 5.1). The truck was positioned at required locations to apply load on instrumented dowels (Figures 5.4 $\& 5.10)$.

Loading test fro a joint consisted of guiding a truck slowly towards the designated joint from about 50 feet distance. Unloading test for a joint consisted of guiding a truck initially placed on the pavement joint to leave the joint slowly.

All strain gages on FRP dowels and embeddable concrete gages were connected to data acquisition (Figure 5.11). Dial gages were fixed on a long adjustable stand system. Dial gages were positioned according to the spacing of dowels (Figs. 5.1 to 5.4) at the pavement joint considered for testing. Span of the dial gage stand system was long enough to support it on adjacent pavement to avoid influence of support deflections. Strains in dowels and deflection of pavement on loaded and unloaded side of the joint were recorded.

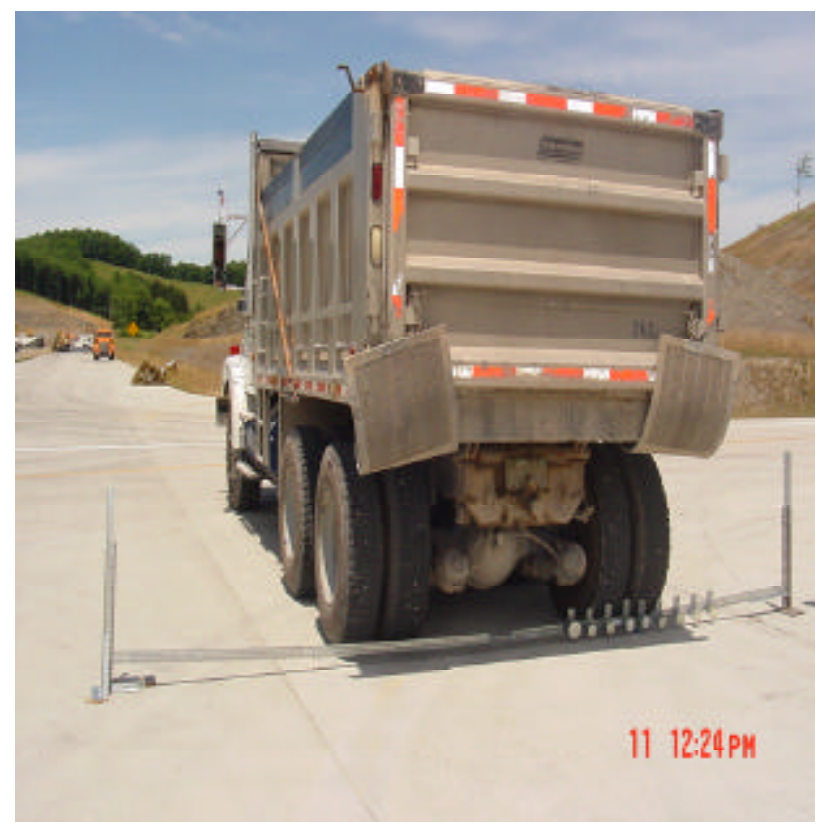

Figure 5.10 Dial gages for measuring pavement deflection under truck loading 


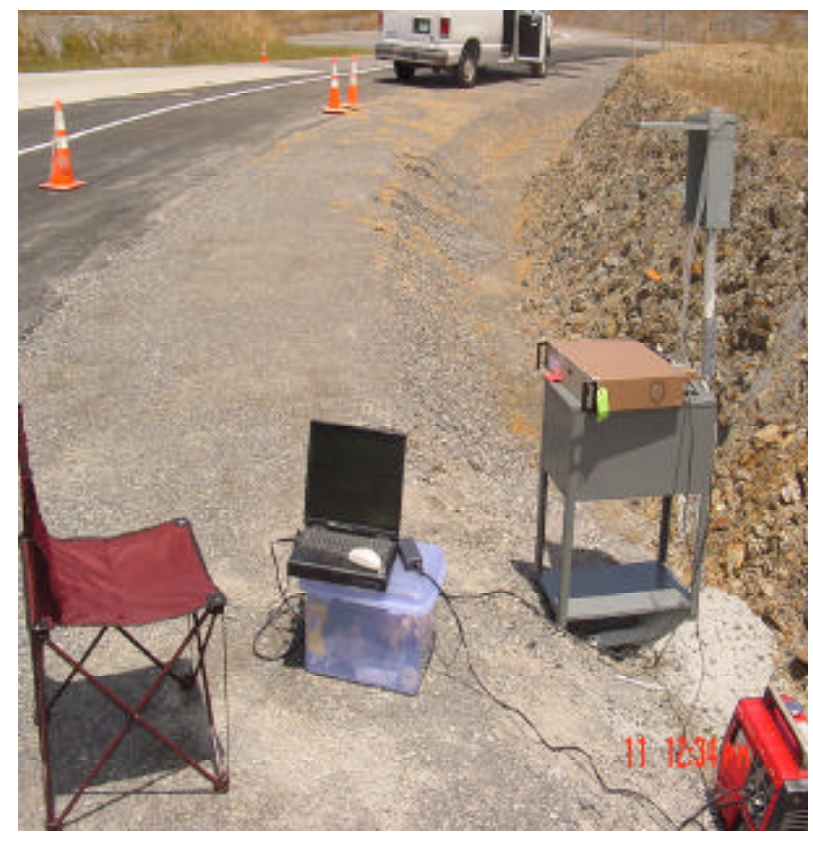

Figure 5.11 Data acquisition system used for field test

\subsection{Test Results And Analysis}

\subsection{Strain Data From Field Static Tests}

About $60 \%$ of strain gages installed on FRP dowels were found to be working properly after field installation and pavement construction. It was also found that some strain data recorded by data acquisition system contained significant noise. Field test results of four cases of FRP dowels were analyzed.

Joints with different diameters and spacing have been described in this section. Data for brake tests and dynamic test from different vehicle speeds are included.

Performance of FRP dowels with different diameters and/or spacings chosen from the field installation (Table 5.2) are discussed in next several sections with respect to the following:

- FRP 1.5" diameter @ 9" c/c (dowel A1)

- FRP 1.5" diameter @ 12" c/c (dowel A2)

- FRP 1.0”@6” c/c (dowel C5) 
- FRP 1.0"@ 8"c/c (dowel C6)

Table 5.2 Joint Details Used for Analysis

\begin{tabular}{|c|c|c|}
\hline Dowel No. & Diameter (inches) & Spacing (inches) \\
\hline A1 & 1.5 & 9 \\
\hline A2 & 1.5 & 12 \\
\hline C5 & 1.0 & 6 \\
\hline C6 & 1.0 & 8 \\
\hline
\end{tabular}

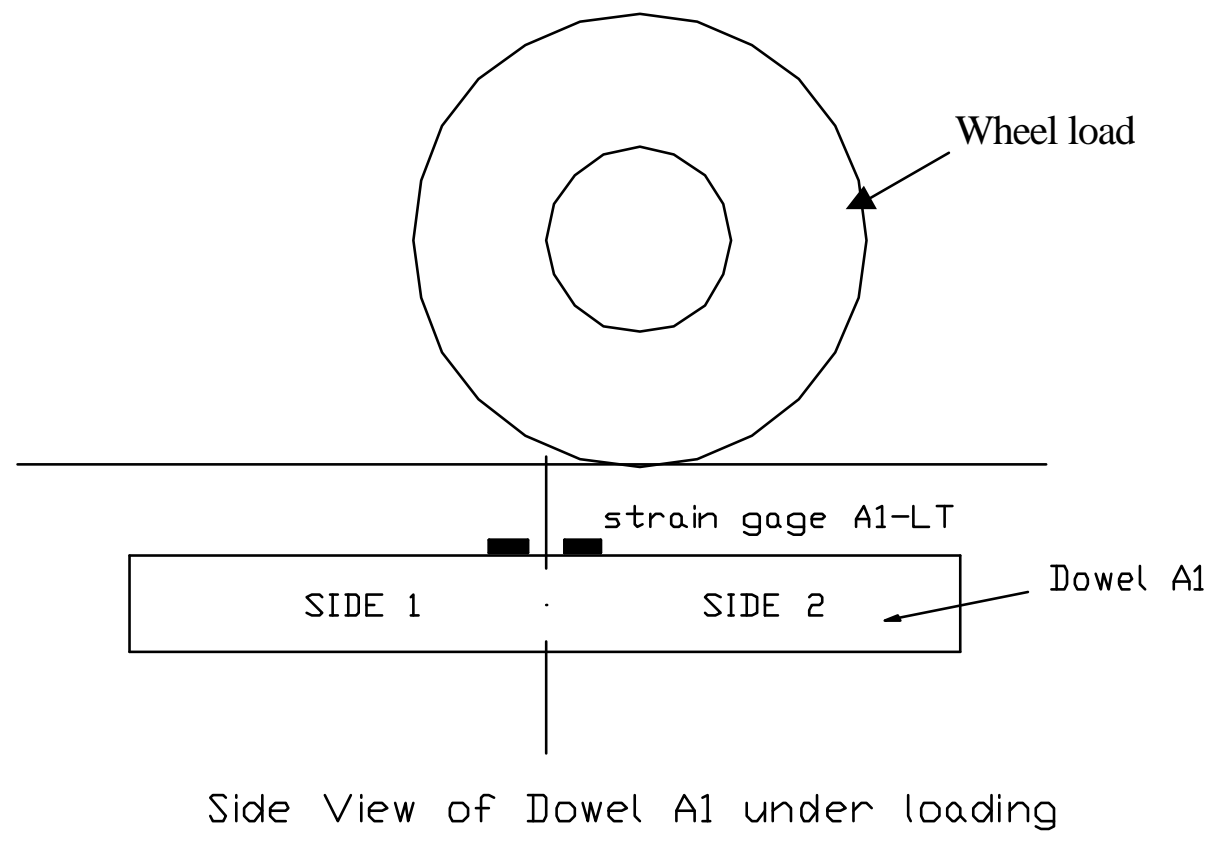

Figure 5.12 Dowel A1 (1.5” dia., 9"' spacing), refer to Figure 5.4 


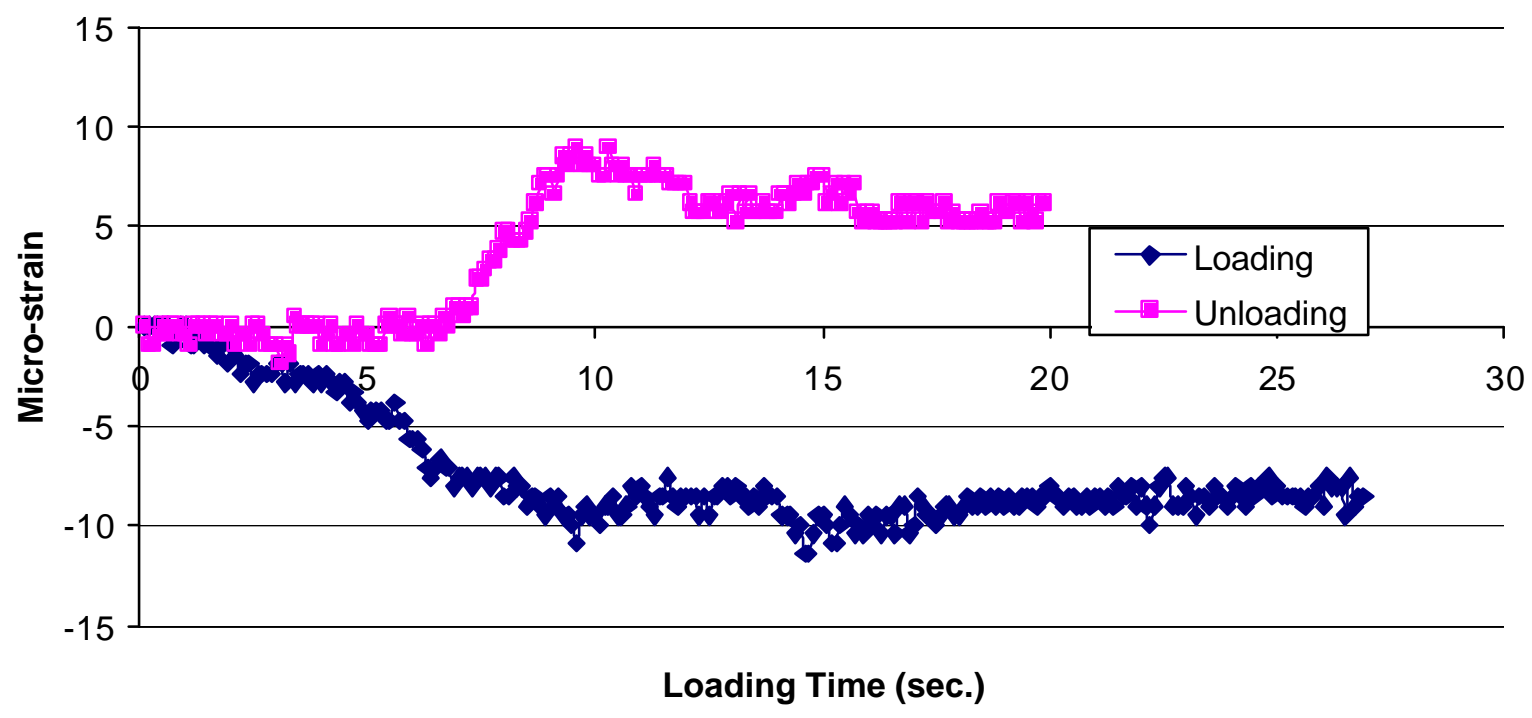

Figure 5.13 Stains in dowel during Loading and Unloading cases for gage A1-LT (1.5” dia., 9" spacing)

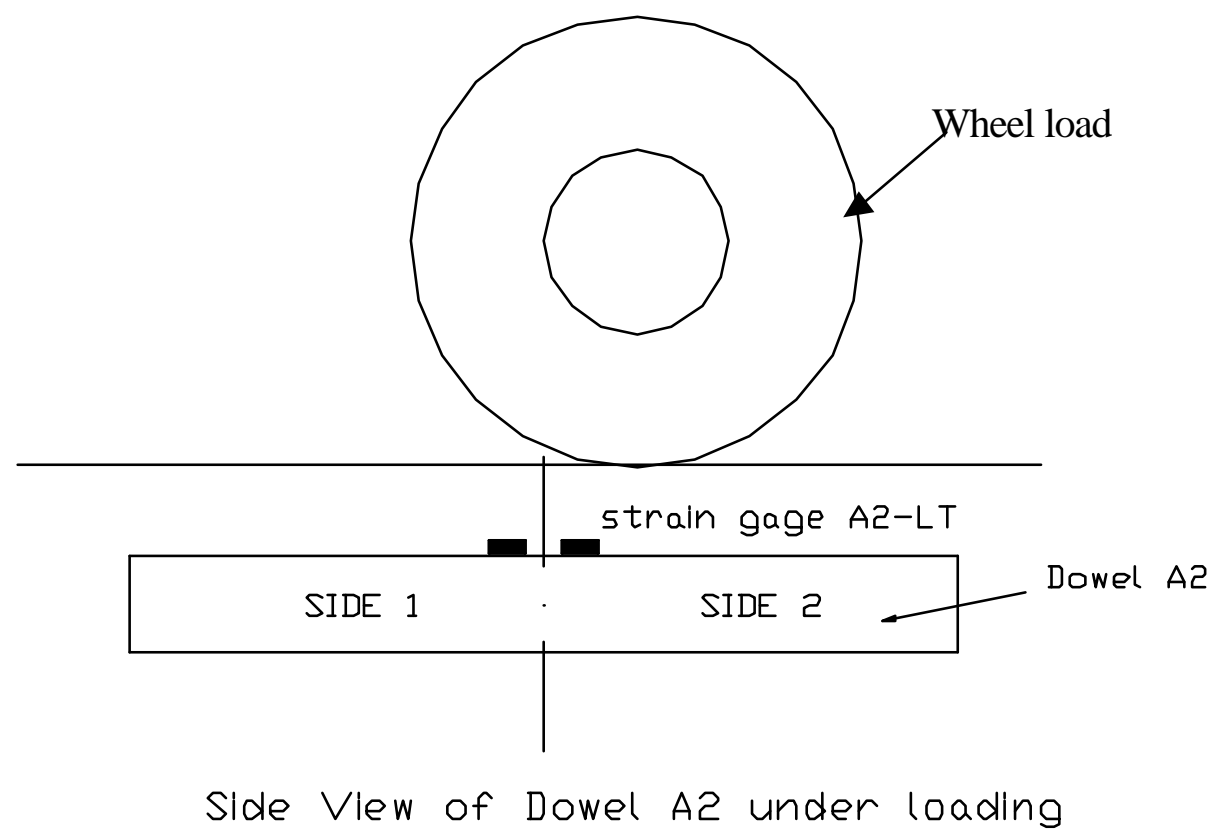

Figure 5.14 Dowel A2 (1.5” dia., 12” spacing), refer to Figure 5.4 


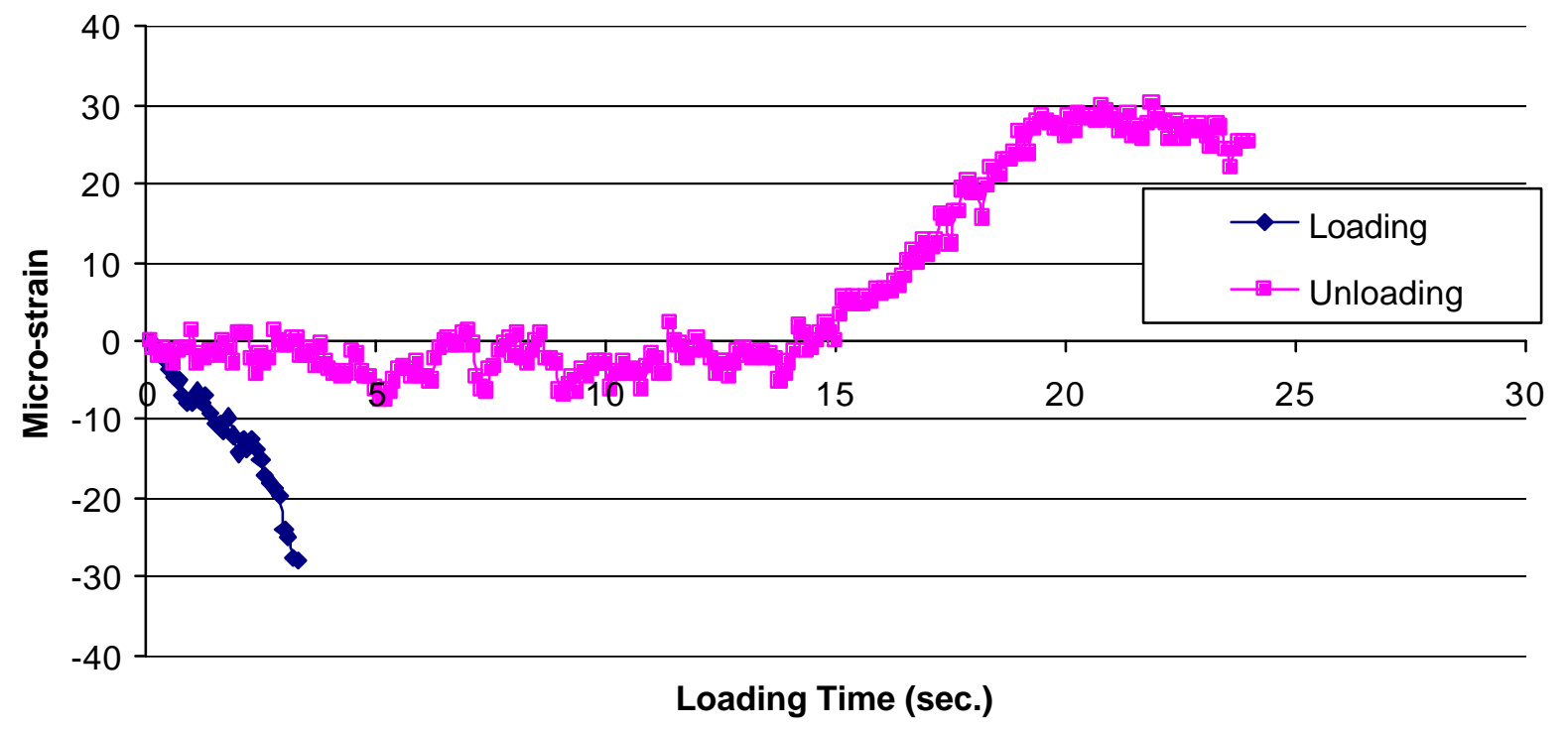

Figure 5.15 Strains in dowel during Loading and Unloading cases for gage A2-LT (1.5” dia., 12" spacing), refer to Figure 5.4

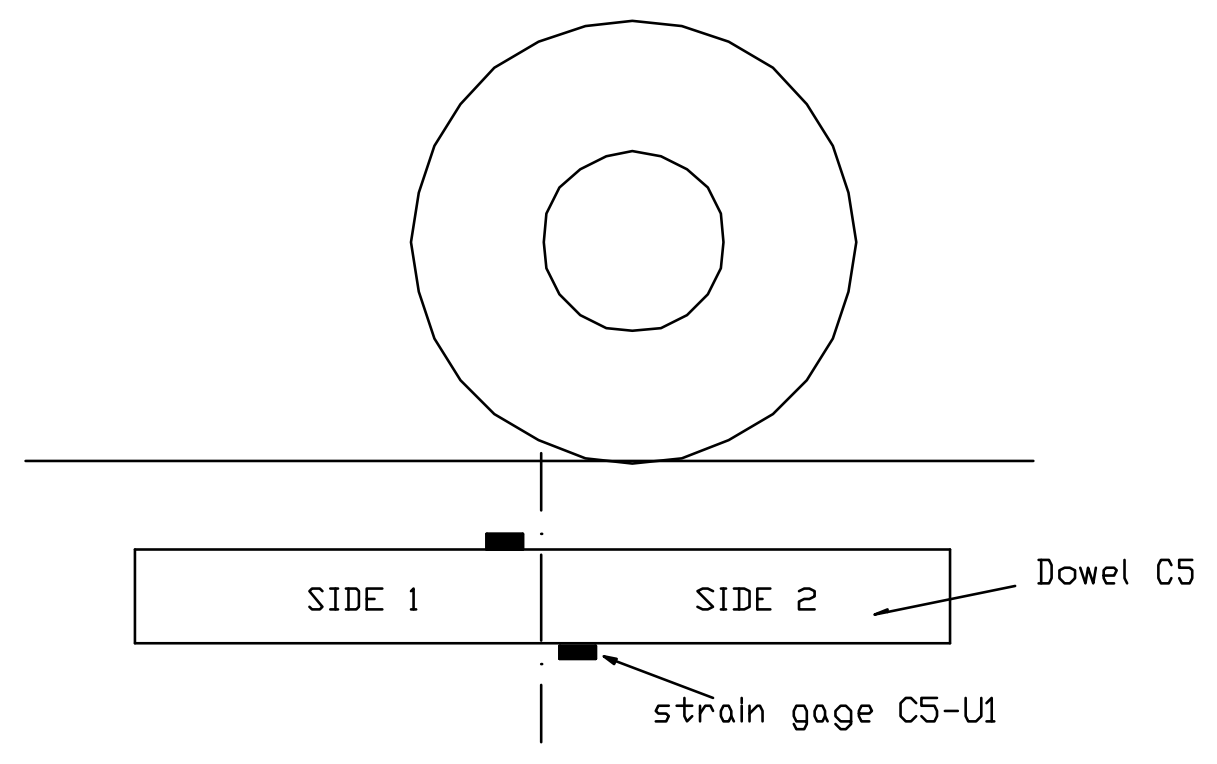

Side View of Dowel C5 under loading

Figure 5.16 Dowel C5 (1.0" dia. 6" spacing), refer to Figure 5.4 


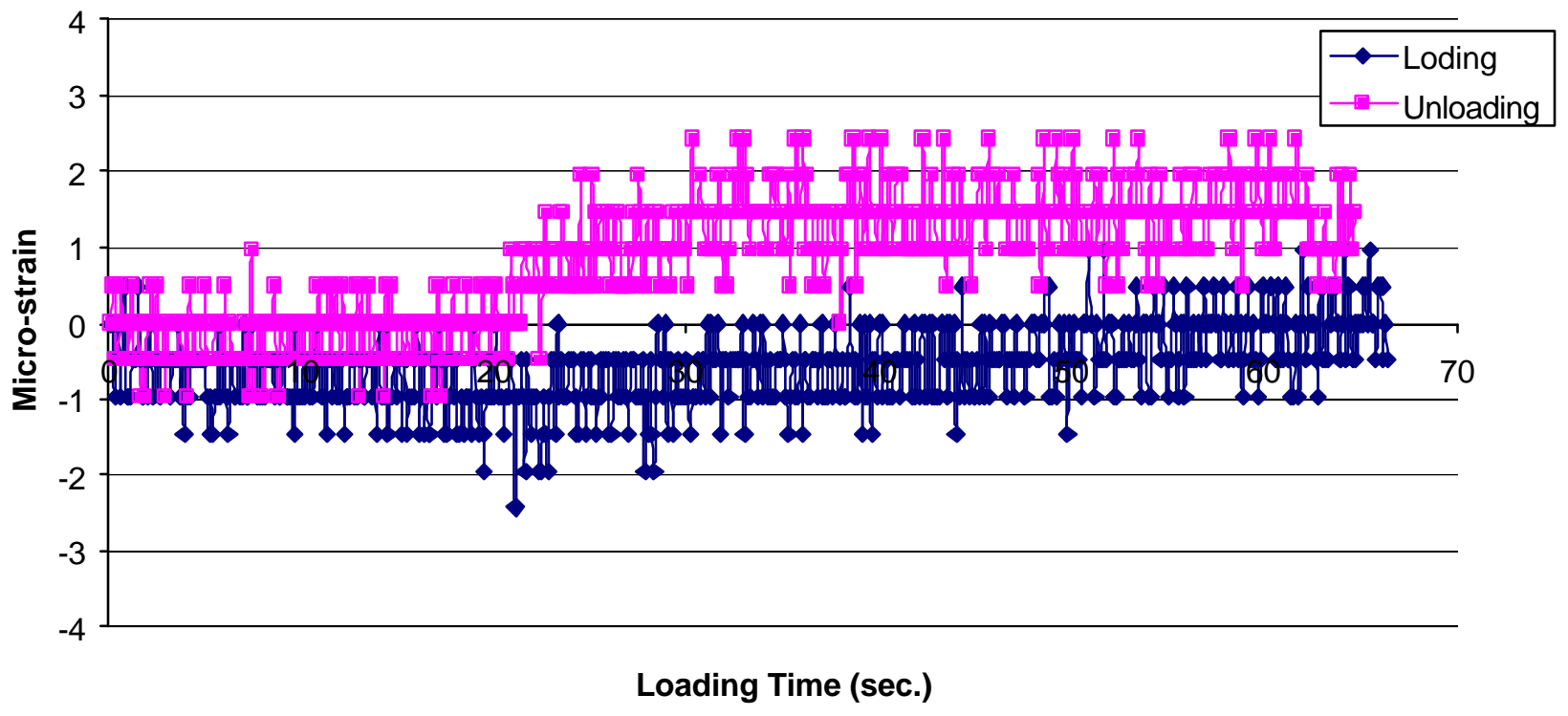

Figure 5.17 Strains in dowel during Loading case for gage C5-U1 (1.0" dia., 6" spacing), refer to Figure 5.4

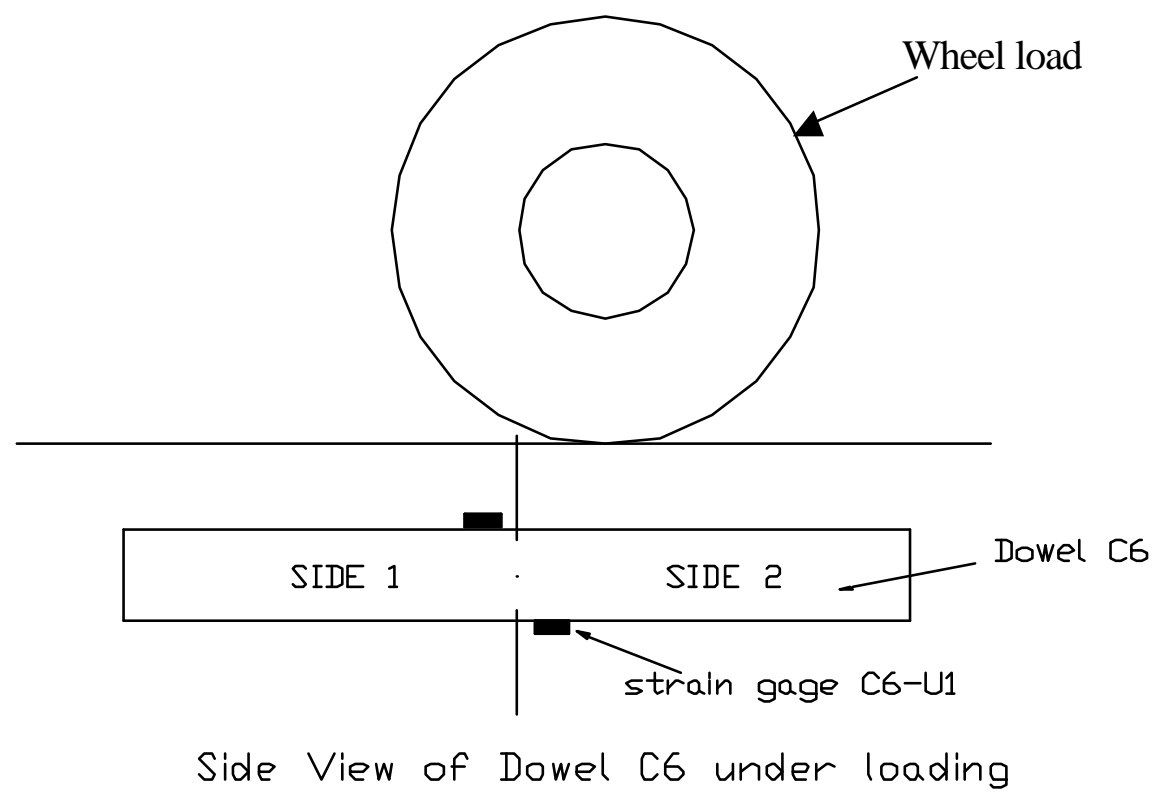

Figure 5.18 Dowel C6 (1.0" dia. 8” spacing), refer to Figure 5.4 


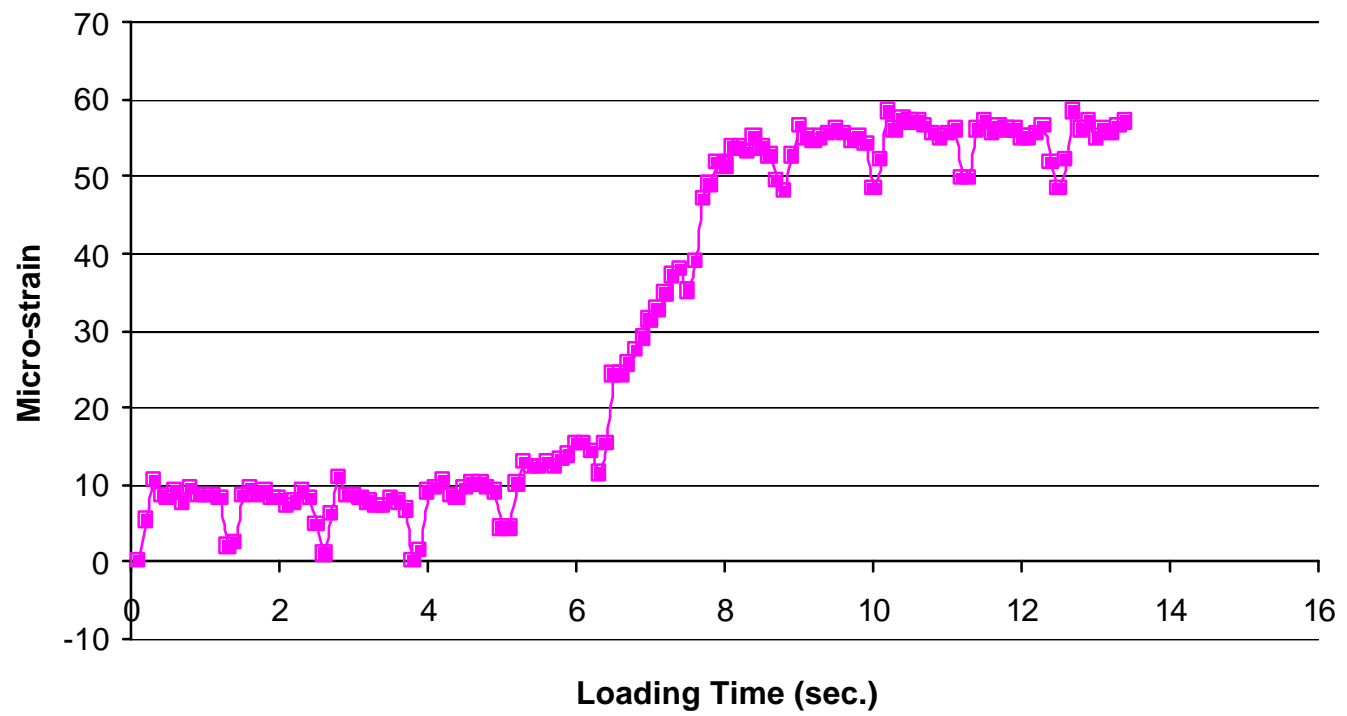

Figure 5.19 Strains on dowel during Loading case for gage C6-U1 (1.0” dia., 8” spacing), refer to Figure 5.4

\subsection{Strain Data From Dynamic Tests}

Dynamic tests were conducted in this field evaluation. Loaded WVDOT Truck with speeds of 10, 20, 30 and $50 \mathrm{mph}$ crossed the selected joint containing instrumented FRP dowels. Data were collected through automatic data acquisition system during truck speeding and braking of the speeding truck at $30 \mathrm{mph}$ close to joint. Test results are shown in Figures 5.20 and 5.21. 


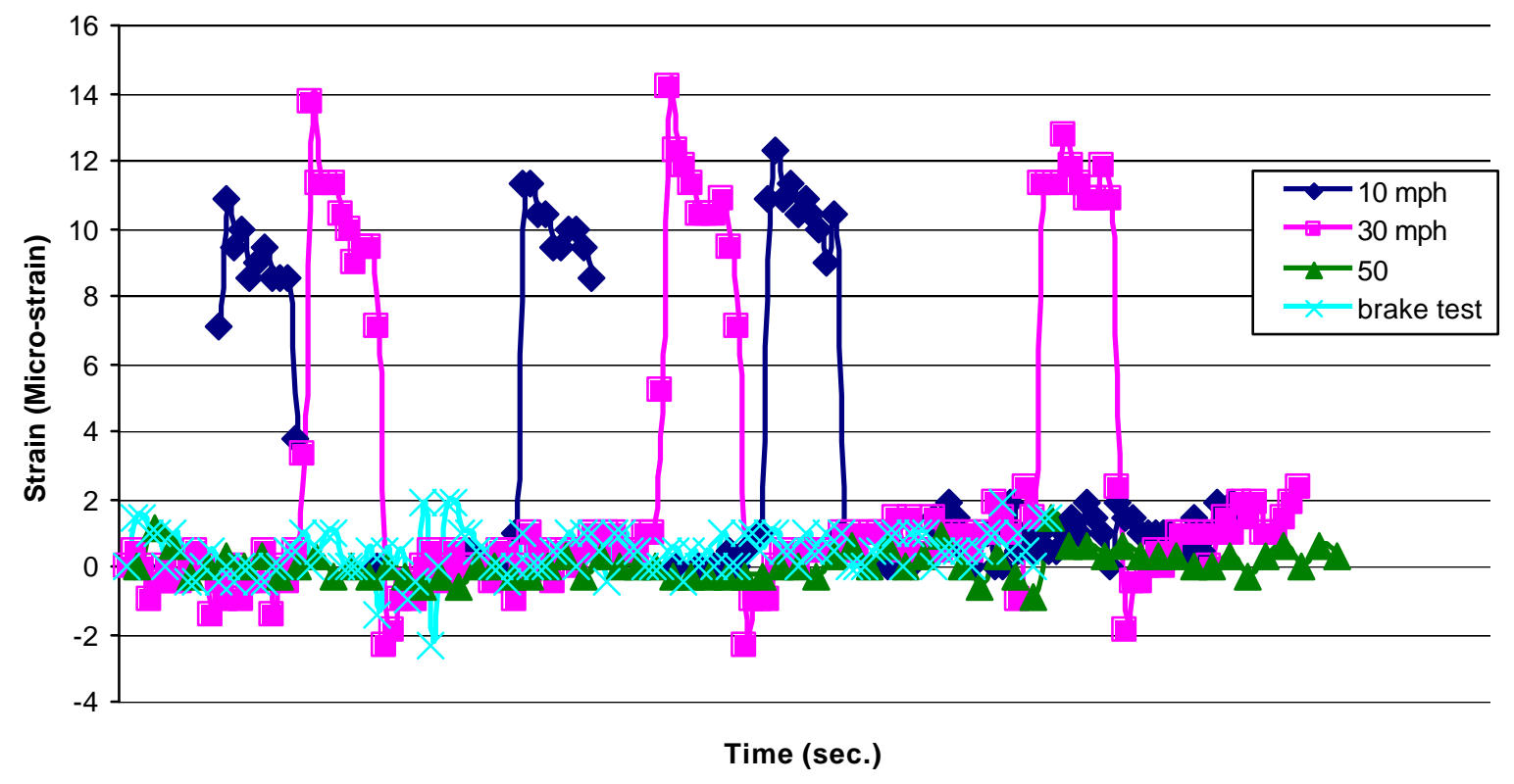

Figure 5.20 Strain from gage A1-LT (1.5” FRP dowel @ 9’ spacing) from dynamic tests

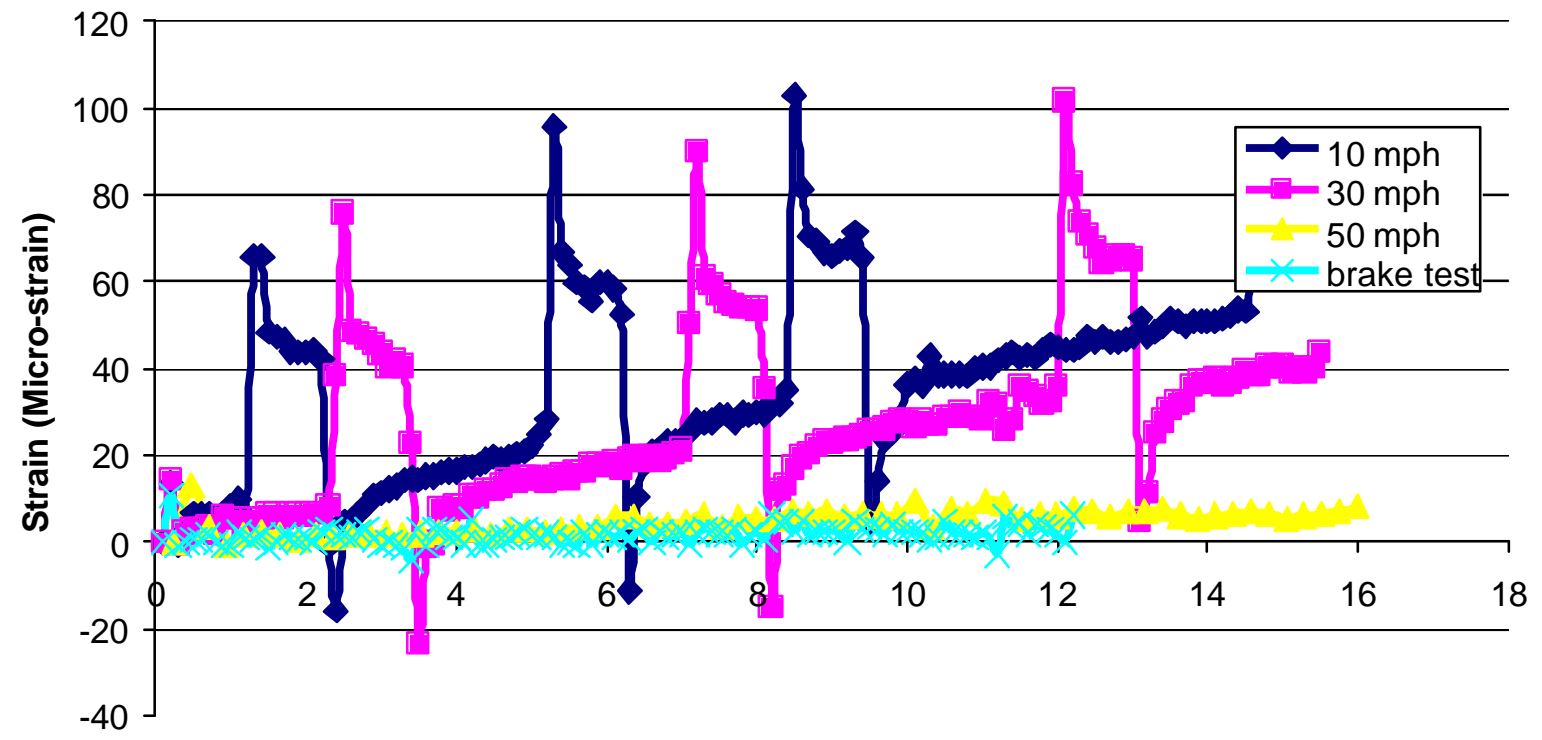

Time (sec.)

Figure 5.21 Strain from gage A2-LT (1.5” FRP dowel @ 12” spacing) from dynamic tests

Dynamic test results recorded contained significant noise, and hence data are not further discussed. 


\subsection{Analysis of Test Result}

Figures (5.12 to 5.19) show changes in dowel strain near pavement joints during truck loading and unloading. Stresses at points on individual dowel can also be obtained according to the Stress-Strain relationship under bending. Table 5.3 is a summary of the above strain value.

Table 5.3 Summary of FRP Dowel Strain During Loading and Unloading

\begin{tabular}{|c|c|c|c|c|}
\hline \multirow{2}{*}{ Dowel No. } & \multirow{2}{*}{$\begin{array}{c}\text { Dowel Diameter } \\
\text { (inches) }\end{array}$} & \multirow{2}{*}{$\begin{array}{c}\text { Dowel Spacing } \\
\text { (inches) }\end{array}$} & \multicolumn{2}{|c|}{ Maximum Strain (Micro-strain) } \\
\cline { 4 - 5 } & 1.5 & 9 & Loading & Unloading \\
\hline A1 & 1.5 & 12 & 9 & 12 \\
\hline A2 & 1.0 & 6 & 31 & 29 \\
\hline C5 & 1.0 & 8 & 60 & N/A \\
\hline C6 & & & & \\
\hline
\end{tabular}

It can be found from Table 5.3 that:

1. Change in strain value for the same dowel during loading and unloading cases is almost same.

2. Effect of dowel spacing

- For FRP dowels (A1 and A2) with 1.5" diameter, dowel A2 with larger spacing (12") had bigger strain change of $31 \mu$ s than dowel A1 with 9" spacing that had a strain change of $9 \mu$ s. Similarly, for FRP dowels C5 and C6 with same 1.0 "diameter, the dowel C5 with smaller spacing (6") showed small strain change (3 $\mu$ s vs. $60 \mu \mathrm{s}$ ) compared to C6 with 8" dowel spacing.

- Thus, decreasing the spacing by $25 \%$ (12" to 9" and 8" to 6") resulted in more number of dowels sharing the load within radius of relative stiffness ( $l_{r}$, Section 6.2.1) leading to $30 \%$ or higher strain reductions in dowels.

- For FRP dowels with 1.0" diameter (C5 and C6), spacing increase from 6" to 8 " had higher influence on strain value change ( $3 \mu$ s vs. $60 \mu$ s) than the increase 
of spacing from 9" to 12" in dowels (A1 and A2) with 1.5 diameters (9 $\mu$ s vs. 31 $\mu \mathrm{s})$.

- Dowels with different diameters and spacings cannot be compared to each other with strain value only. Because FRP dowels act as a group, spacing and diameter are both important factors for the group action. It should be also noted that FRP dowel with smaller diameter typically have better mechanical properties per unit area than larger diameter dowels due $\mathrm{b}$ shear lag effects. (Refer to Chapter 6, Section 6.2.1).

\subsection{Deflection Data}

WVDOT truck was guided toward the pavement joint on top of chosen dowel location so that heavier wheel load, which was located in the rear axles, could be applied. Pavement deflections increased when the WVDOT truck slowly approached the joint. But most of the deflection changes were less than the detectable range of dial gages with a least count of 0.001 ". In the second field test, Linear Variable Differential Transformers (LVDTs) were used for better precision in deflection detection.

\subsubsection{Field Test After Highway Opened To Traffic, June 2003}

This field test was conducted about one year after opening the pavement to traffic. Test parameters are listed in Table5.4, which are similar to those for the first field test, except that the deflection measurements were done by using LVDTs and there were no dynamic/brake tests. Main purpose of this field test was to investigate deflection behavior and Load Transfer Efficiency of concrete pavement joints with different diameter and spacing of FRP dowel bars. Figures 5.22 to 5.25 show details of field test set up. 
Table 5.4 Parameters of the Field Test, June 2003

\begin{tabular}{|l|l|}
\hline Dowel Material & FRP \\
\hline Dowel Diameter & $1.5^{\prime \prime}, 1.0$ " \\
\hline $\mathrm{f}_{\mathrm{c}}$ & $3500 \mathrm{psi}$ \\
\hline Dowel Spacing & $12^{\prime \prime}, 9$ ", 8", 6" \\
\hline Type of Loading & $\begin{array}{l}\text { AASHTO Type 3(regular two-axle truck) loaded truck, } \\
\text { similar to the one described in Table 5.1 }\end{array}$ \\
\hline Types of Tests & Static \\
\hline Instrumentations & Strain gages \\
& $\begin{array}{l}\text { LVDT for measuring pavement deflection } \\
\text { Data acquisition system }\end{array}$ \\
\hline Measurements & Pavement deflection \\
\hline Computation & Strain \\
\hline & Load Transfer Efficiency (LTE) \\
& Relative Deflection \\
\hline
\end{tabular}

It should be noted that the wheel loads due to AASHTO HS25 is $20000 \mathrm{lbs}$, which is about twice the DOT truck wheel load used for this test. Then larger deflections and strains can be expected. 


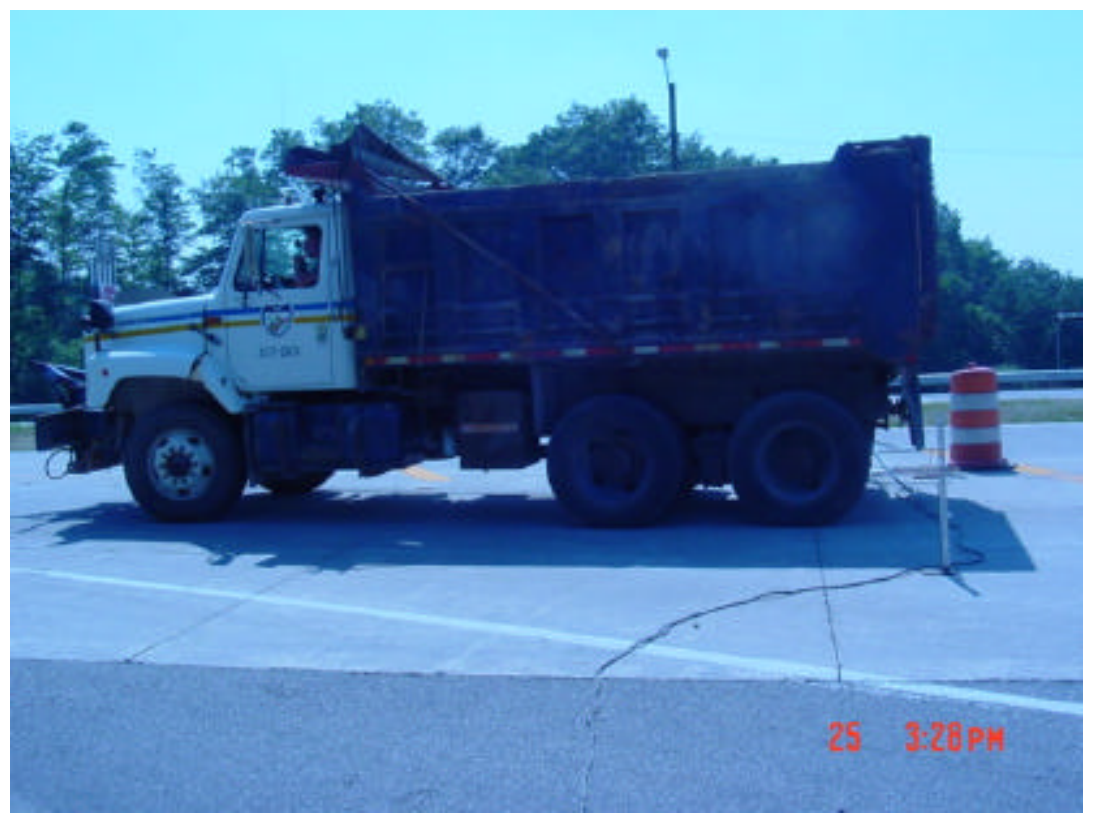

Figure 5.22 DOT truck used for field test

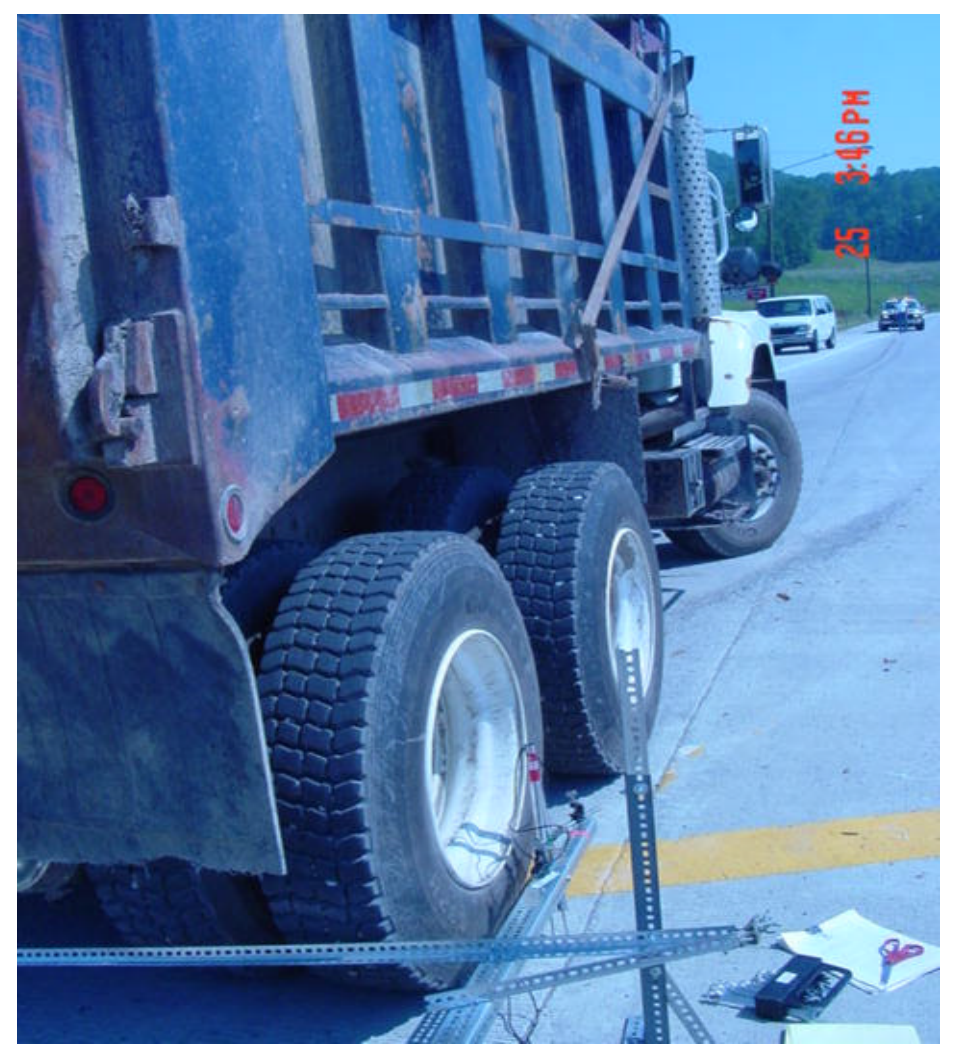

Figure 5.23 WVDOT truck positioned near a joint for test 


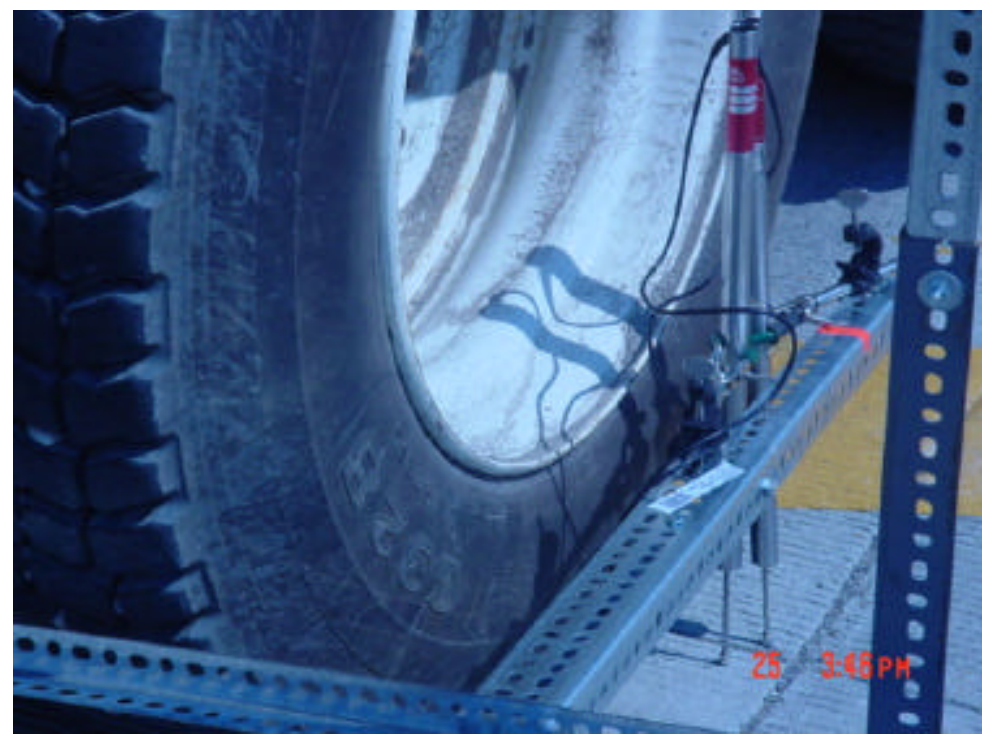

Figure 5.24 Two LVDTs measuring pavement deflections across a joint

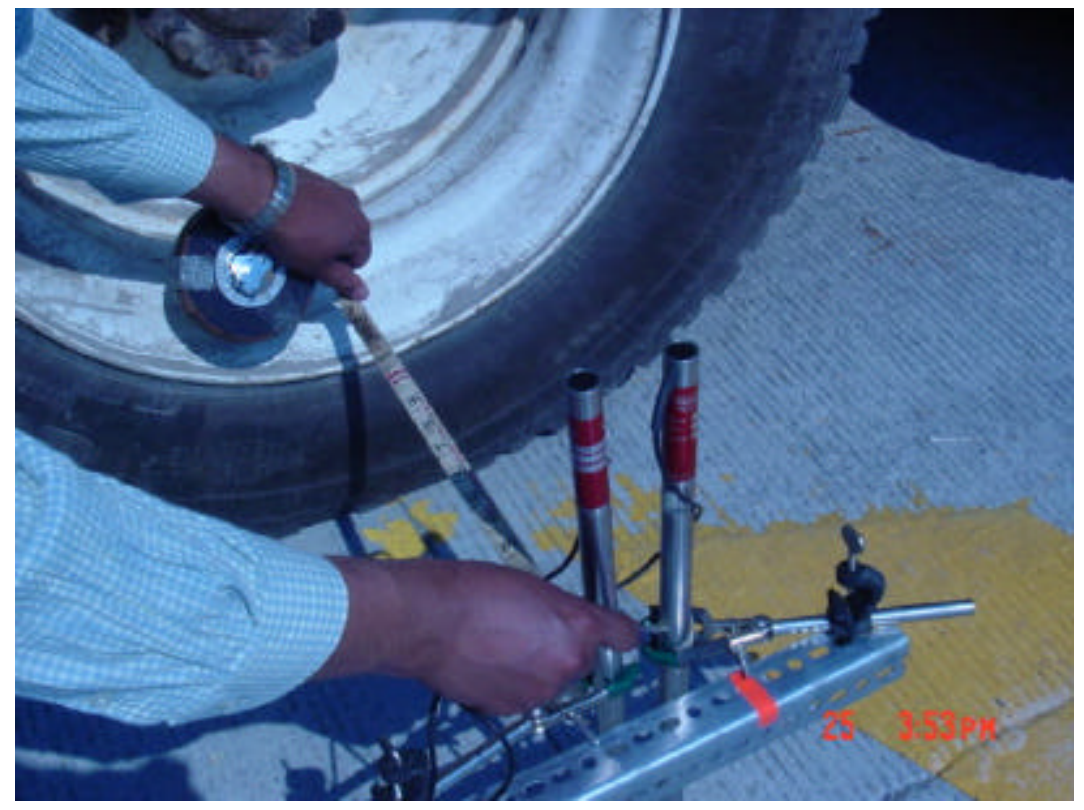

Figure 5.25 Measuring distance from tire to LVDTs (when loading is away from selected dowel) 


\subsection{Test Results from Field Test}

Four concrete pavement joints with instrumented dowels were tested during second field test. Details of the joints and FRP dowels are shown in Table 5.3.

Table 5.5 Pavement joint for deflection analysis

\begin{tabular}{|c|c|c|c|}
\hline Joint No. & $\begin{array}{c}\text { Dowel bar diameter } \\
\text { (in.) }\end{array}$ & $\begin{array}{c}\text { Dowel bar spacing } \\
\text { (in.) }\end{array}$ & 2 \\
\hline 3 & 1.5 & 12 & 2 \\
\hline 2 & 1.5 & 9 & 1 \\
\hline 5 & 1.0 & 8 & 1 \\
\hline 6 & 1.0 & 6 & \\
\hline
\end{tabular}

Test result are shown in Figures 5.26 to 5.33 and further analyzed in Section 5.2.2.2

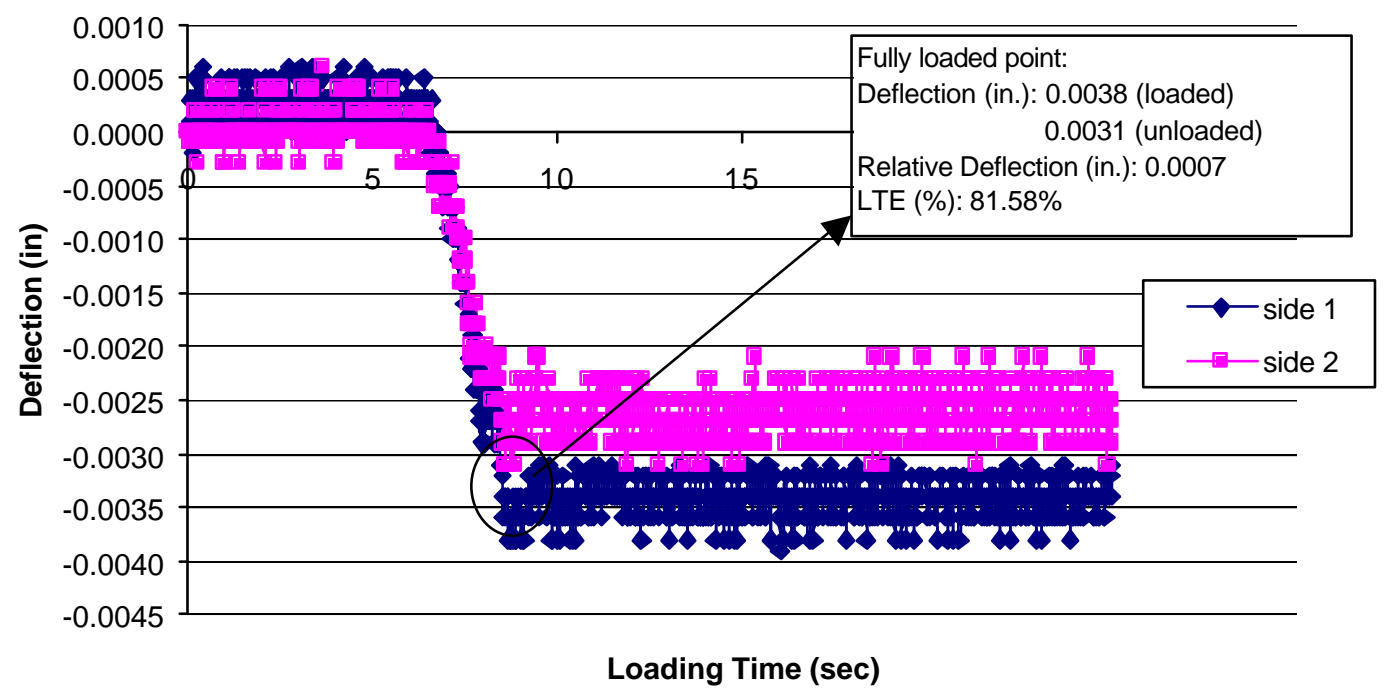

Figure 5.26 Deflection on pavement joint No. 3 (with 1.5” dia. \& 12" spacing FRP dowels) under loading 


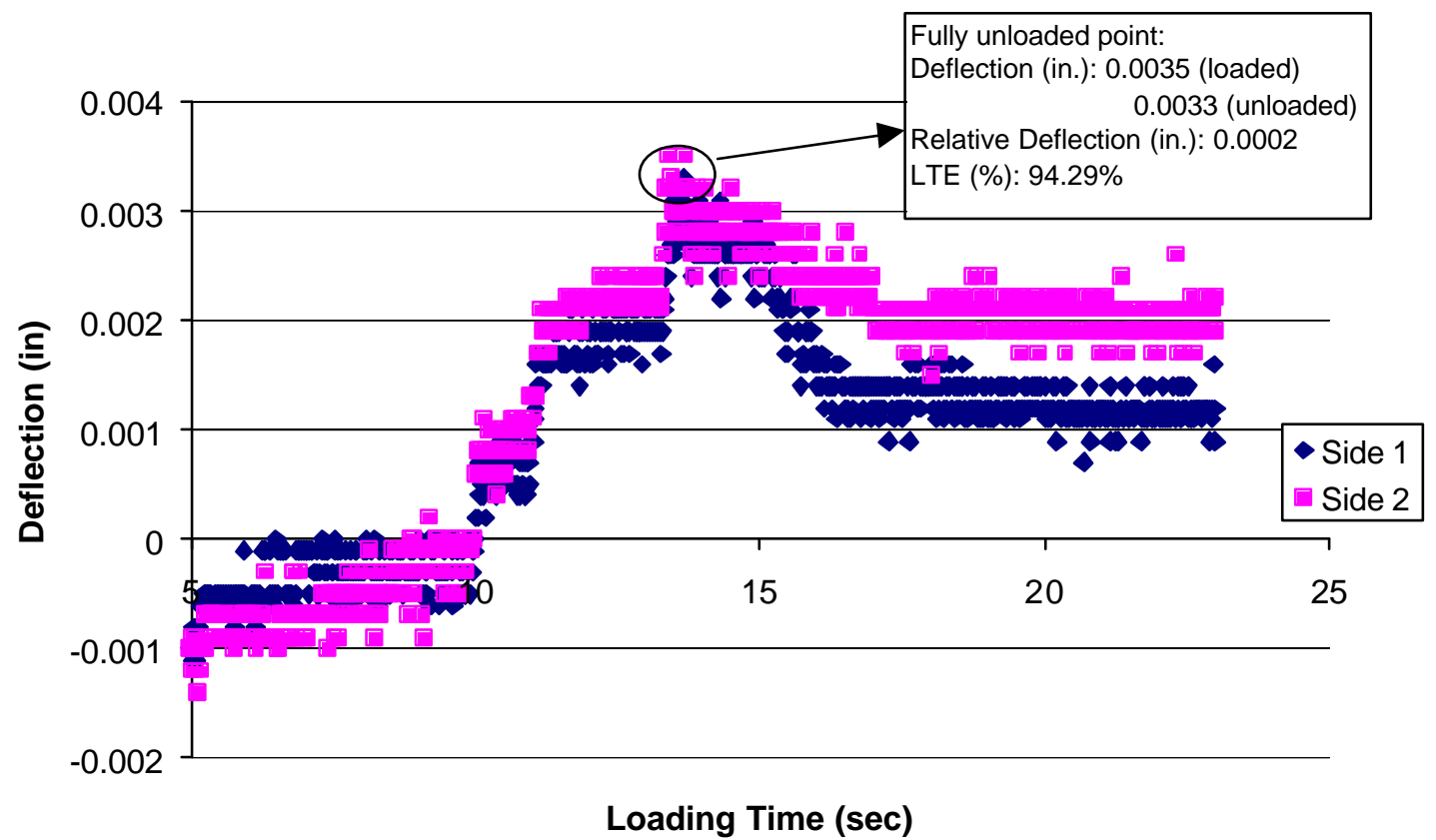

Figure 5.27 Deflection on pavement joint No.2 (with 1.5’ dia. \& 9"' spacing FRP dowels) under unloading

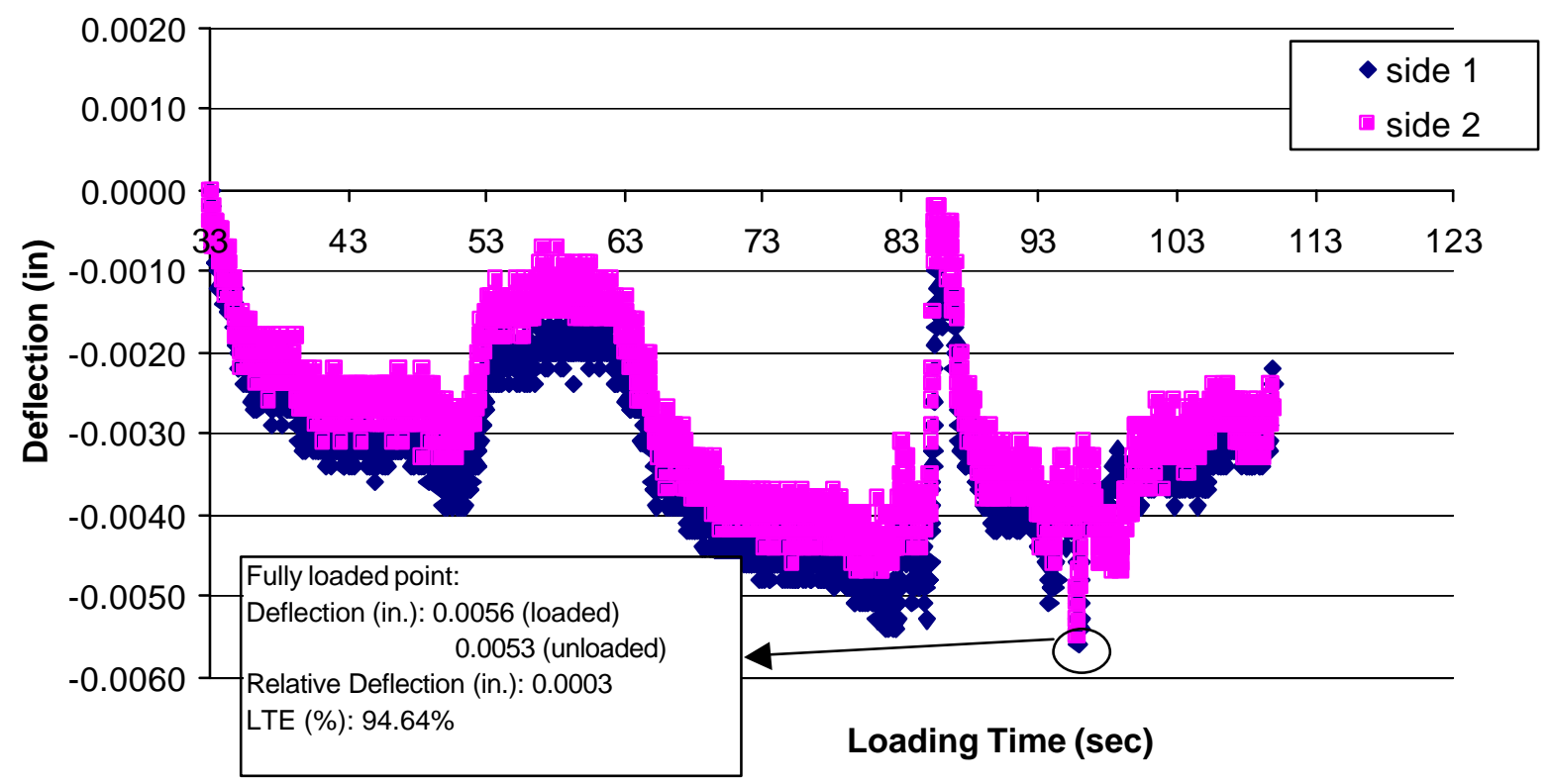

Figure 5.28 Deflection on pavement joint No.2 (with 1.5” dia. \& 9" spacing FRP dowels) under loading 


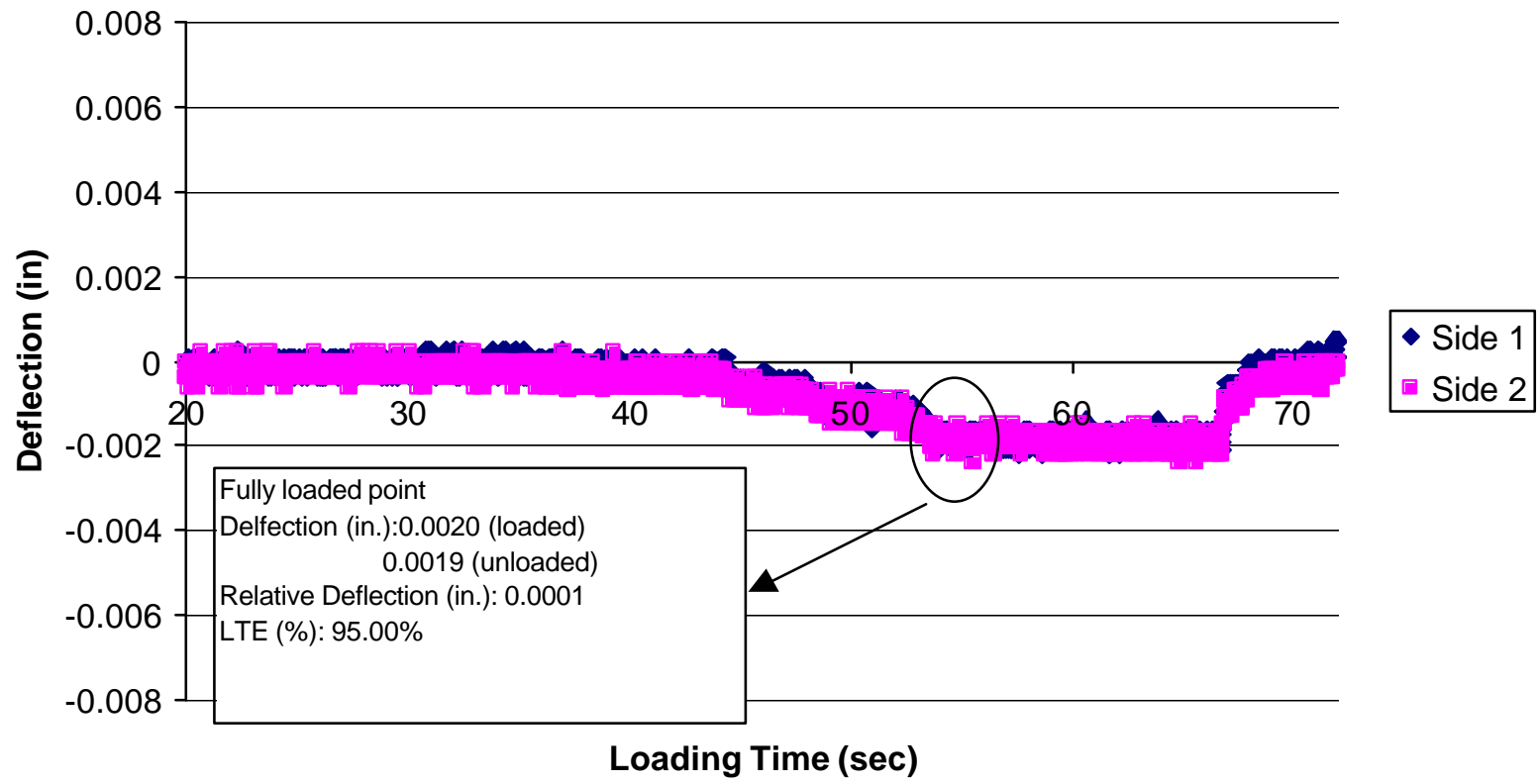

Figure 5.29 Deflection on pavement joint No.5 (with 1.0" dia. \& 8" spacing FRP dowels) under loading

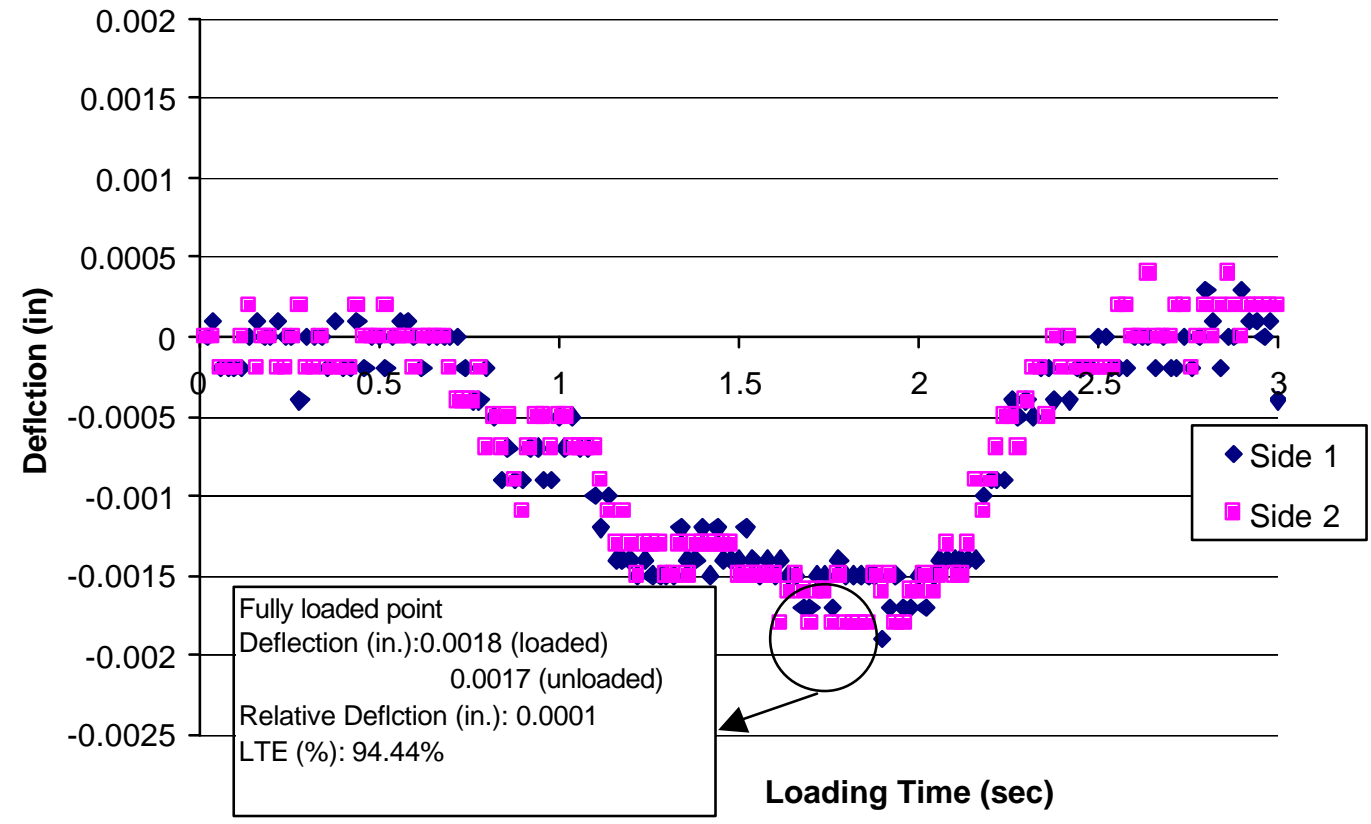

Figure 5.30 Deflection on pavement joint No.6 (with 1.0" dia. \& 6" spacing FRP dowels) under loading 


\subsection{Summary and Analysis of Test Results}

A summary of the test results shown in Figs. 5.26 to 5.30 is provided in Table 5.4 in terms of pavement deflection, Load Transfer Efficiency (LTE) and Relative Deflection for pavement joints having 1.5"and 1.0" diameter FRP dowels with different spacings of 12", 9", 8" and 6".

Table 5.6 Summary of joint deflection under maximum loading force

\begin{tabular}{|c|c|c|c|c|}
\hline \multirow{2}{*}{$\begin{array}{c}\text { Joint Number } \\
\text { (Dia.-Spacing) Refer to } \\
\text { Table }\end{array}$} & \multicolumn{2}{|c|}{$\begin{array}{c}\text { Poad Transfer } \\
\text { Efficiency }\end{array}$} & $\begin{array}{c}\text { Relative } \\
\text { (LTE) }(\%)\end{array}$ & Deflection \\
\cline { 2 - 5 }$\left(10^{-4}\right.$ in. $)$
\end{tabular}

Values in Table 5.4 cannot be compared to each other directly because in addition to diameter and spacing, deflections depend on combination of other parameters such as base/subbase properties, contact area between concrete and base, etc. It should also be noted that truck wheel load position on dowels embedded in concrete may vary from one dowel to the other. 
Pavement surface is serrated to provide friction and hence there is possibility of LVDTs shaft tips sliding into those slots and showing slightly higher deflections. However, additional tests will be conducted in future to compare LTE and relative deflection. For our field test, Load Transfer Efficiency (LTE) is shown in Figure 5.31 and Relative Deflection is shown in Figure 5.32 .

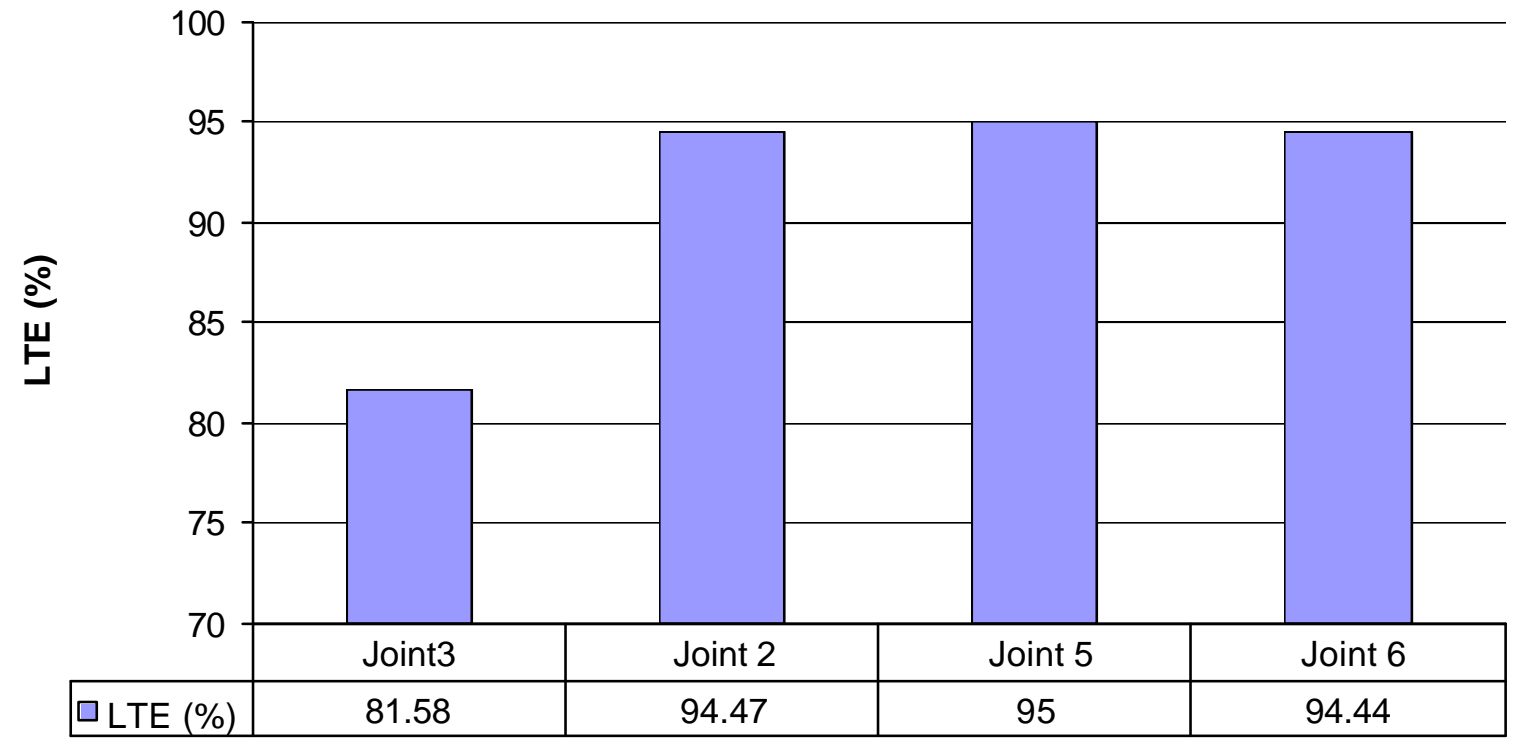

\begin{tabular}{|c|c|c|c|c|}
\hline & JOINT 3 & JOINT 2 & JOINT 5 & JOINT 6 \\
\hline LTE (\%) & 81.58 & 94.47 & 95 & 94.44 \\
\hline Diameter (in.) & 1.5 & 1.5 & 1.0 & 1.0 \\
\hline Spacing (in.) & 12 & 9.0 & 8.0 & 6.0 \\
\hline
\end{tabular}

Figure 5.31 Comparison of LTE from field test (average value was used for joint No.2)

Joint 3 with largest dowel spacing of 12" had the lowest value of LTE among all tested joints (Figure 5.3). It should be noted that small variations in deflection are being measured through LVDTs. Hence, additional field tests will be conducted in the future to ascertain LTE of joints with 12" spacing. 


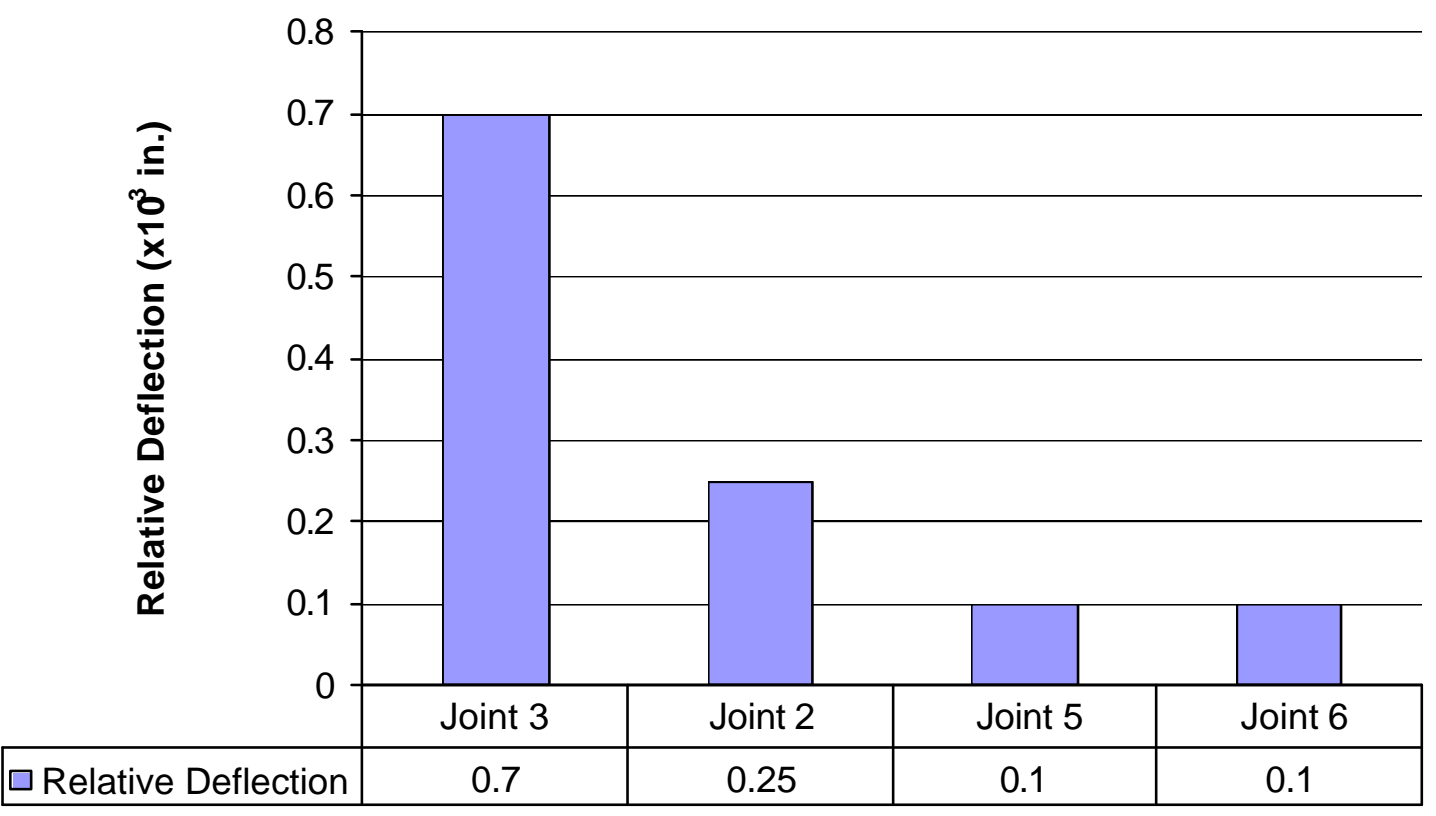

\begin{tabular}{|c|c|c|c|c|}
\hline & JOINT 3 & JOINT 2 & JOINT 5 & JOINT 6 \\
\hline Relative Deflection (x10 ${ }^{-3}$ in.) & 0.70 & 0.25 & 0.10 & 0.10 \\
\hline Diameter (in.) & 1.5 & 1.5 & 1.0 & 1.0 \\
\hline Spacing (in.) & 12 & 9.0 & 8.0 & 6.0 \\
\hline
\end{tabular}

Figure 5.32 Comparison of Relative Deflection from field test (average value was used for joint 2)

Table 5.7 Comparing Joint 2 and Joint 3

\begin{tabular}{|c|c|c|c|}
\hline & $\begin{array}{c}\text { Joint 2 } \\
(1.5 \% @ 9 ” \mathrm{c} / \mathrm{c})\end{array}$ & $\begin{array}{c}\text { Joint 3 } \\
(1.5 ” @ 12 ” \mathrm{c} / \mathrm{c})\end{array}$ & $\begin{array}{c}\text { Percentage of } \\
\text { Difference }(\%)\end{array}$ \\
\hline LTE & 94.47 & 81.58 & 15.8 \\
\hline Relative Deflection $\left(10^{-3} \mathrm{in}.\right)$ & 0.25 & 0.70 & 64.3 \\
\hline
\end{tabular}


From the above results it can be observed that:

- Both 1.5" diameter FRP dowel group and 1.0" diameter FRP dowel group with spacing varying from 12" to 6" provided very good Load Transfer Efficiency (LTE) (greater than LTE of $60 \%$, which is corresponding to ACPA's $75 \%$ joint effectiveness value).

- For dowel groups in pavement joints 2 and 3 that have same dowel diameter (1.5"), joint 2 with smaller dowel spacing (9") had higher Load Trans fer Efficiency (94\%) than that provided by joint 3 with 12" dowel spacing (81.58\%). Additional tests will be conducted on other joint locations.

- Joint 2 with 9" dowel spacing had smaller Relative Deflection $\left(0.25 \times 10^{-3}\right.$ in. $)$ than joint 3 with 12" dowel spacing $\left(0.70 \times 10^{-3}\right.$ in.) for dowel diameter of $1.5^{\prime \prime}$.

- Joint 2 with 9" of spacing) provided $15.4 \%$ increase in Load Transfer Efficiency (LTE) in addition to $64.3 \%$ reduction in Relative Deflection than Joint 3 with 12" spacing for dowel diameter of 1.5" (refer to Table 5.5).

- For pavement joint 5 and 6 (with 1.0" dowel diameter, 8.0" and 6.0" dowel spacing, respectively), the Load Transfer Efficiencies were very close (95\% and 94.44\%). Relative joint deflections were also identical $\left(1 \times 10^{-3} \mathrm{in}\right.$.).

- Currently, there is no requirement or limitation for the Relative Deflection from AASHTO's Guide for Pavement Design.

\subsection{FRP Dowels Used for Highway Pavement Rehabilitation}

FRP dowels were used for pavement rehabilitation at the junction of Rts. 119 and 857, University Avenue, Morgantown, WV. Two joints were selected; one with 1.5" diameter FRP 
dowels $12 " \mathrm{c} / \mathrm{c}$ spacing, the other with $1.5 "$ diameter steel dowel at 12 " c/c. Dowel installation and field test setup are discussed in this section. Test results from both FRP and steel dowels are analyzed and discussed in subsection of 5.3.1.

\subsubsection{Field Location and installation}

\subsubsection{Field Location}

Two joints were selected for rehabilitation of an existing pavement near junction of Rts. 119 and 857, University Avenue, Morgantown, WV as shown in Fig. 5.33. Rehabilitation was carried out during October 2002.

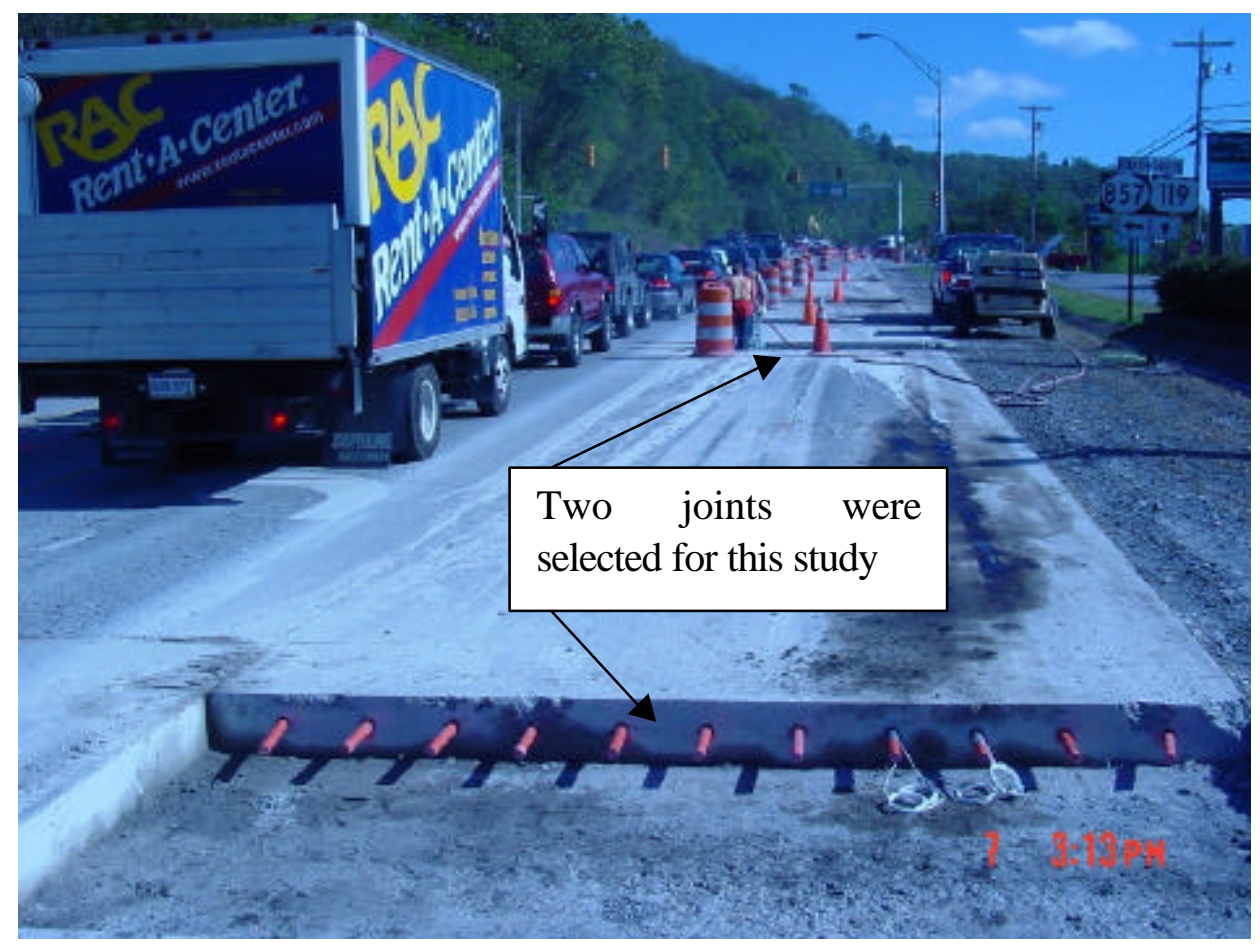

Figure 5.33 Locations of FRP and Steel doweled pavement joints

\subsubsection{Field Installation}

Deteriorated concrete slabs were cut by special concrete Saw-Cutting machine, and then lifted out. 1.5" diameter holes were drilled through the concrete slabs up to 9" deep (half of dowel length). Each pavement joint consisted of eleven 1.5"-diameter dowels spaced at 12" c/c. 
Each joint was provided with two instrumented dowels each. Strain gages were bonded onto both top and bottom surfaces of those dowels prior to installation. Strain gages were about $1 / 2$ " away from the centerline of joint.

After positioning dowels in the drilled holes, epoxy resin was filled into the circumferential gap between concrete and dowel. Rehabilitation carried out using FRP and steel dowels is shown in Figs. 5.34 to 5.37 .

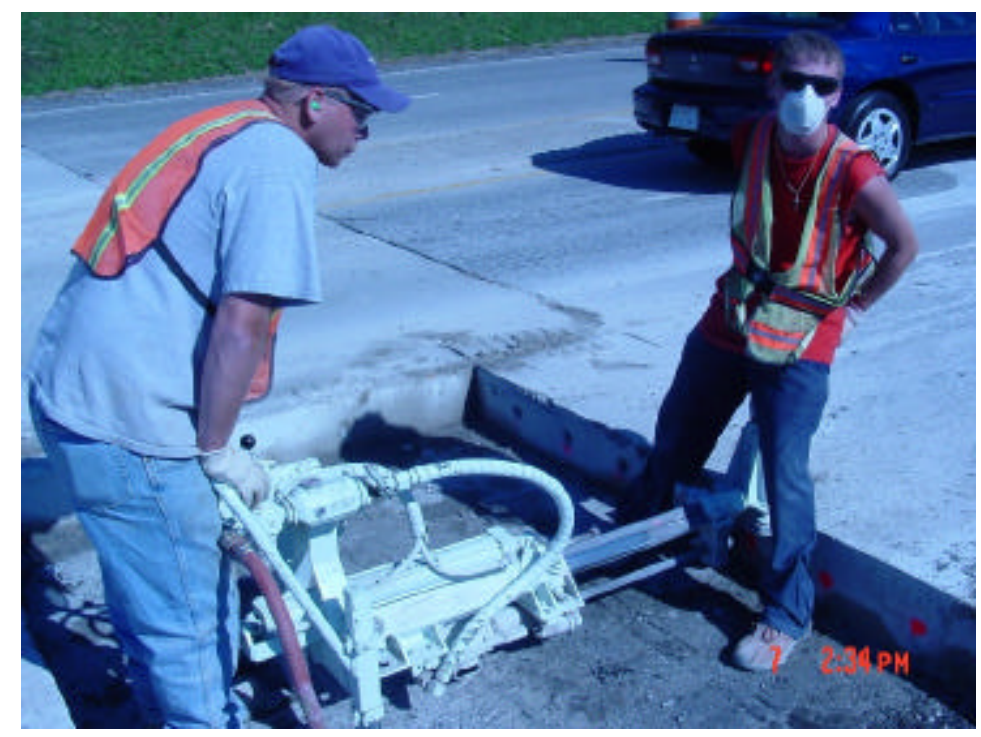

Figure 5.34 Drilling holes for inserting dowels

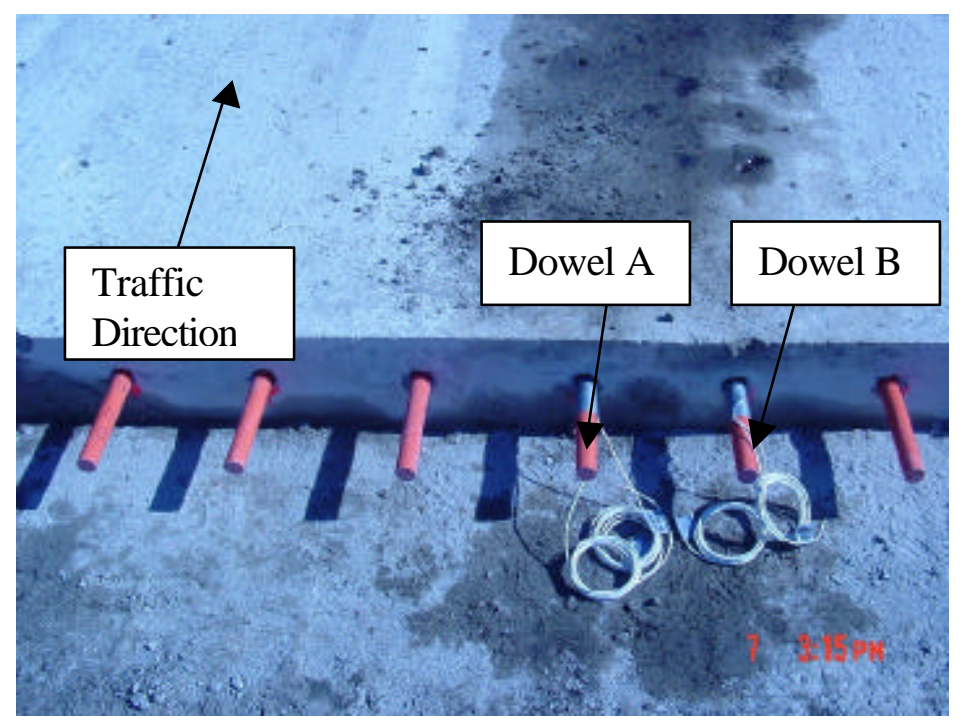

Figure 5.35 FRP dowels in position 


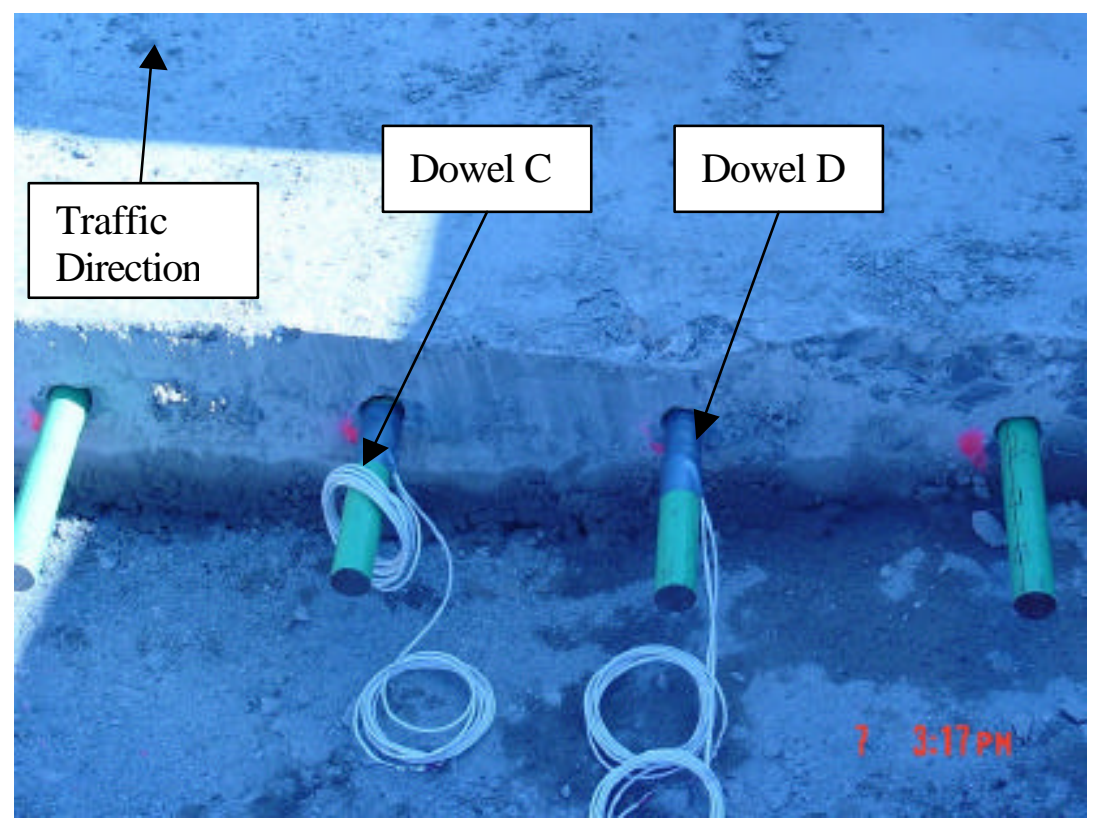

Figure 5.36 Steel dowels in position

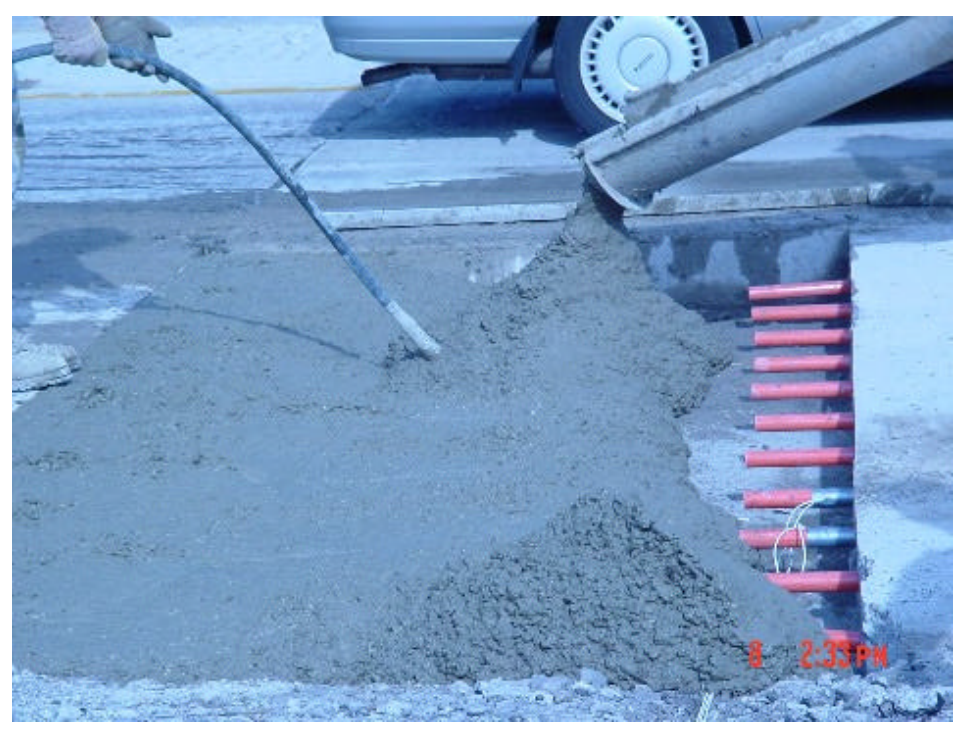

Figure 5.37 Concrete placement and vibration 


\subsubsection{Field Tests}

\subsubsection{Test Setup}

Standard truck load was not used for field loading purpose. Strain reading due to regular traffic (Fig. 5.33) including some loaded trucks driving at 25 to 40 miles per hour were recorded using automatic data acquisition system. Due to the heavy traffic volume existing at this road section, pavement deflection measurement was not recorded.

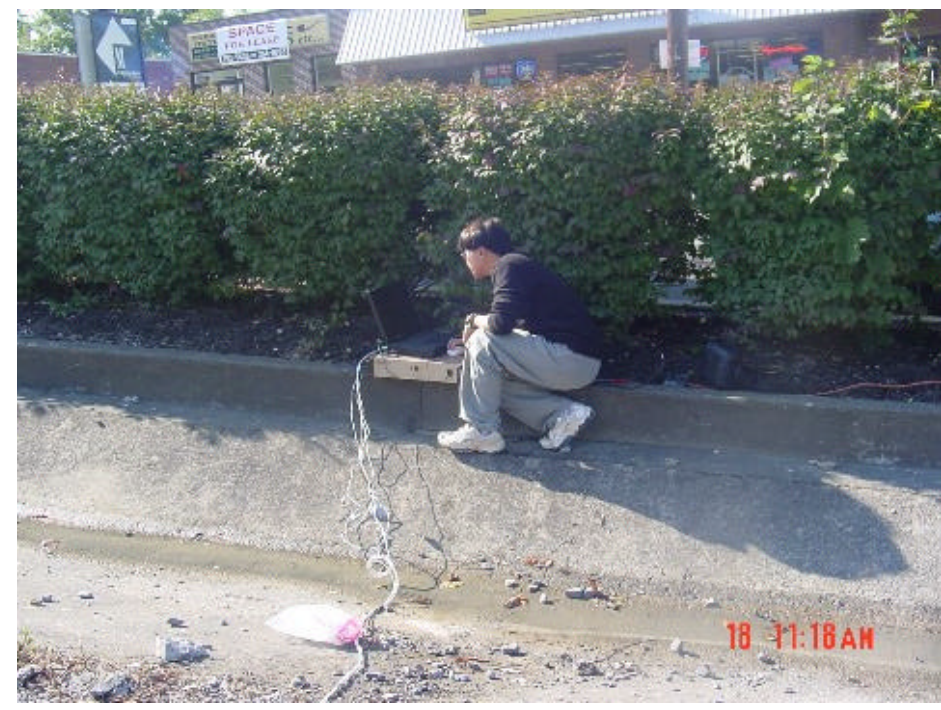

Figure 5.38 Data acquisition recording strain readings

\subsubsection{Results and Analysis}

Both strain gages were installed in vehicle approaching side (Figs 5.35 to 5.37) of the pavement joint. Hence, before a vehicle wheel crossed the joint, strain gage side of the joint remained loaded side and right after the wheel crossed a joint, strain gage side became unloaded side.

Strain readings due to a truck load from regular traffic are shown in Figures 5.39 and 5.40. 


\subsection{FRP Dowel Group}

Strain gage reading from two instrumented FRP dowels (Dowel A and Dowel B in Figure 5.35) are discussed here. Data from strain gages mounted on top of these dowel are shown in Figure 5.39.

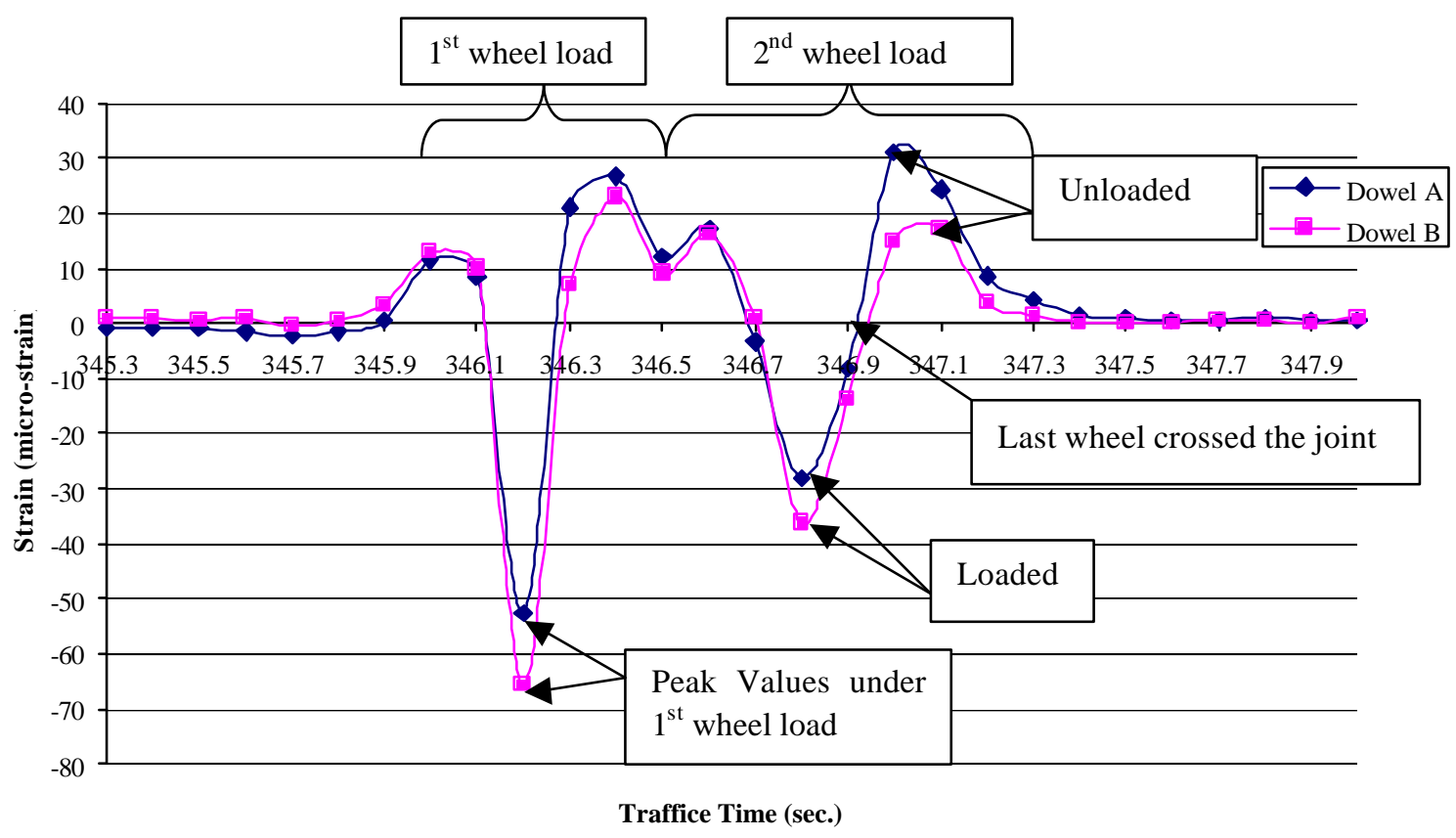

Figure 5.39 Strain from FRP dowels in rehabilitated pavement

Note: Not all data due to continuous traffic are plotted in this figure. Only strain values from a truck load with maximum values are shown here.

Strain gage data between recorded traffic time of $345.9 \mathrm{sec}$. to346.5 sec. correspond to the movement of the fist wheel load. Due to truck load, maximum strains $(-52.52 \mu$ s and -65.8 $\mu \mathrm{s})$ occurred when wheel load was close to the joint in adjacent dowels. Based on strain values, it appears that front axle carried more load than the rear axle and vehicle impact factor may have also played a role. 
Strain gage data between recorded traffic time of $346.7 \mathrm{sec}$. to $347.5 \mathrm{sec}$. correspond to the movement of last wheel load crossing the joint. During this time period, gages from FRP dowels $\mathrm{A}$ and $\mathrm{B}$ experienced a strain change from loaded status $(-28.17 \mu \mathrm{s}$ and $-36.24 \mu \mathrm{s})$ to unloaded status $(31.04 \mu \mathrm{s}$ and $17.16 \mu \mathrm{s})$, respectively. The total strain change is 59.21 $(28.17+31.04) \mu$ s for dowel A and $53.4(36.24+17.16) \mu$ s for dowel B. The ratio of unloaded value to loaded value is $31.04 / 28.17=1.10$ (dowel A) and 17.16/36.24=0.47 (dowel B). These ratios indicate possibility of the wheel loads crossing at an angle over the dowel. It should be noted that the pavement is on an upward gradient with respect to traffic direction.

\subsection{Steel Dowel Group}

Strain gage readings from one instrumented steel dowel (Dowel C in Figure 5.36) are discussed here. Data from strain gage mounted on top of this dowel are shown in Figure 5.40.

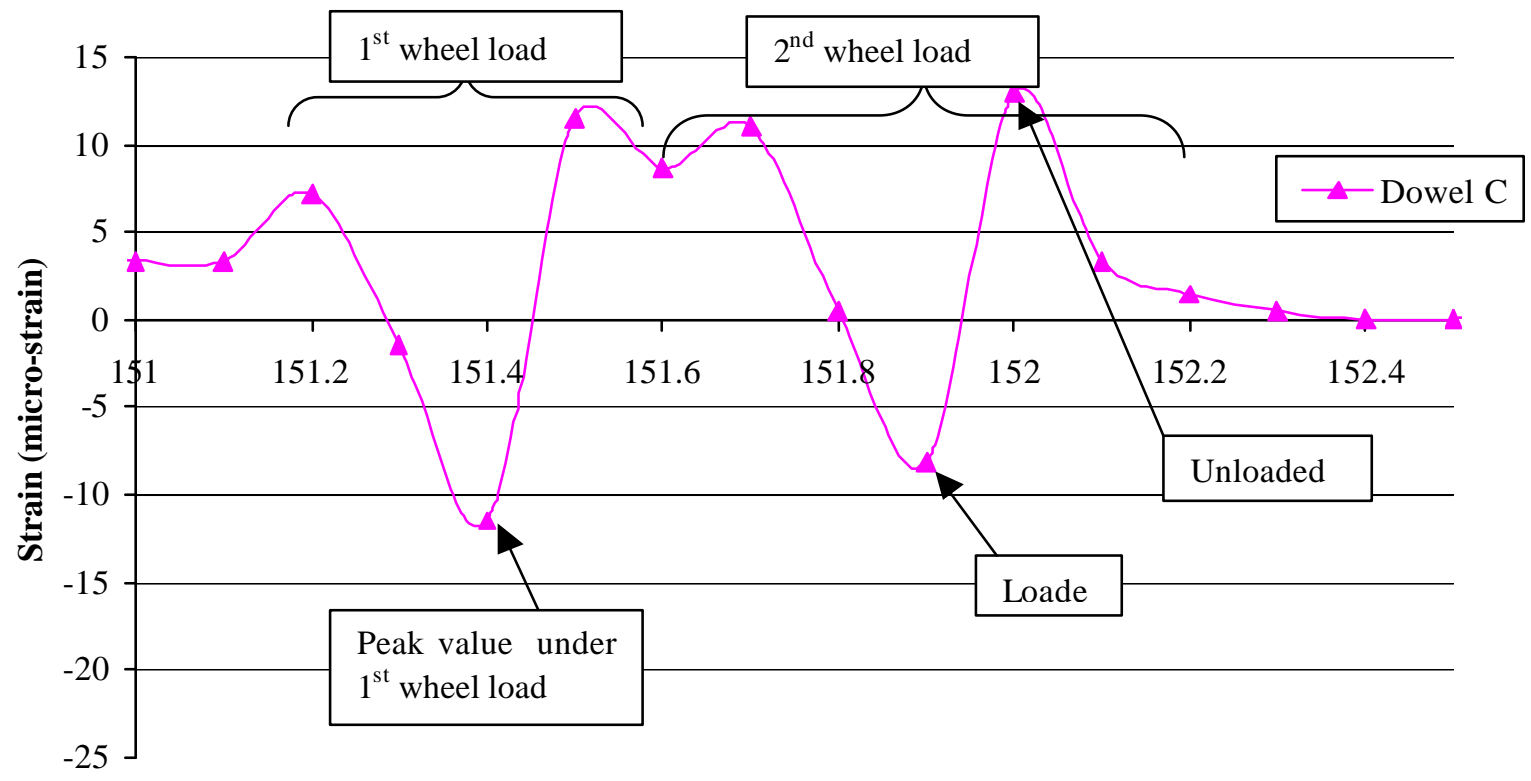

Traffic Time (sec.)

Figure 5.40 Strain from steel dowel in rehabilitated pavement

Note: Not all data due to continuous traffic are plotted in this figure. Only strain values in dowel C from a truck load with maximum values are shown here. 
Strain gage data between traffic time $151.2 \mathrm{sec}$. to $151.6 \mathrm{sec}$. correspond to the movement of the first wheel load crossing the joint. Maximum compressive strains occurred at the beginning of the load, which was $-11.49 \mu$ s, which may partly include vehicle impact effect.

Strain gage data between traffic time $151.8 \mathrm{sec}$. to $152.2 \mathrm{sec}$. correspond to the movement of last wheel load crossing the joint. During this time period, gages from steel dowels $\mathrm{C}$ experienced a strain change from loaded status $(-8.14 \mu \mathrm{s})$ to unloaded status $(12.93 \mu \mathrm{s})$, respectively. The total strain change is $21.07(8.14+12.93) \mu$ s for dowel C. The ratio of unloaded value to loaded value is $12.93 / 8.14=1.59$ (dowel C). Following factors contribute to this ratio of unloaded/loaded strain $>1$, where readings appear to be from those vehicles just beginning to accelerate from their stopped position near traffic lights at junction.

- Pavement rehabilitated with dowels was situated on an upward gradient.

- Dowels on the upward portion of the joint were bonded to the concrete with epoxy.

\subsection{Conclusion}

From both the first and the second field tests conducted on the newly constructed highway in Elkins, WV (see Chapter 5.2), it is concluded that:

1. Change in strain value for the same dowel during loading and unloading cases is almost same.

\section{Effect of dowel spacing}

- For dowel groups in pavement joints 2 and 3 that have same dowel diameter (1.5"), joint 2 with smaller dowel spacing (9") had higher Load Transfer Efficiency (94\%) than that provided by joint 3 with 12" dowel spacing (81.58\%). This is attributed to the smaller dowel spacing used in joint 2, which results in more number of dowels sharing the load within radius of relative stiffness. In 
addition, larger than expected difference in LTE for 9" and 12" spacing will be investigated in future tests.

- Joint 2 (with 1.5" diameter and 9" spacing) had smaller Relative Deflection $\left(0.25 \times 10^{-3}\right.$ in.) than joint 3 with same diameter bar and 12 " spacing $\left(0.70 \times 10^{-3}\right.$ in.).

- Joint 2 (1.5" of diameter and 9" of spacing) provided 15.4\% increase in Load Transfer Efficiency (LTE) in addition to 64.3\% reduction in Relative Deflection than Joint 3 (1.5" of diameter and 12" of spacing), refer to Table 5.5.

- For pavement joint 5 and 6 (with 1.0" dowel diameter, 8.0" and 6.0" dowel spacing, respectively), the Load Transfer Efficiencies were very close (95\% and $94.44 \%)$. Relative joint deflections were also identical $\left(1 \times 10^{-3}\right.$ in.).

- For FRP dowels (A1 and A2) with 1.5" diameter, dowel A2 with larger spacing (12") had bigger strain change of $31 \mu$ s than dowel A1 with 9" spacing that had a strain change of $9 \mu$ s. Similarly, for FRP dowels C5 and C6 with same 1.0 "diameter, the dowelC5 with smaller spacing (6") showed small strain change ( $3 \mu$ s vs. $60 \mu$ s) compared to C6 with 8 " dowel spacing.

- Thus, decreasing the spacing by $25 \%$ (12" to 9" and 8" to 6") resulted in more number of dowels sharing the load within radius of relative stiffness $\left(l_{r}\right.$, Section 6.2.1) leading to $30 \%$ or higher strain reductions in dowels.

- For FRP dowels with 1.0" diameter (C5 and C6), spacing increase from 6" to 8 " had higher influence on strain value change ( $3 \mu \mathrm{s}$ vs. $60 \mu \mathrm{s})$ than the increase of spacing from 9" to 12" in dowels (A1 and A2) with 1.5 diameters (9 $\mu$ s vs. 31 $\mu \mathrm{s})$.

- Dowels with different diameters and spacing cannot be compared directly with only strain value. Because FRP dowels act as a group, spacing and diameter are both important factors for the group action. It should be also noted that FRP dowel with smaller diameter typically have better mechanical properties per unit area than larger diameter dowels due to shear lag effects. (Refer to Section 6.2.1, Chapter 6). 
- Dynamic test results recorded contained significant noise, and hence data are not further discussed.

\section{Effect of dowel diameter}

Both 1.5" diameter FRP dowel group and 1.0" diameter FRP dowel group with spacing varying from 12" to 6" provided very good Load Transfer Efficiency (LTE) (greater than LTE of 60\%, which is corresponding to ACPA's 75\% joint effectiveness value).

4. Currently, there is no requirement or limitation for the Relative Deflection from AASHTO's Guide for Pavement Design. From field tests the maximum Relative Deflection was $0.70 \times 10^{-3}$ in., but for lab testing were a max of $43 \times 10^{-3}$ in. (Table 4.11). It should be noticed that joint width due to different joint models and thermal variables.

From field tests conducted on the rehabilitated pavement in Morgantown, WV (see Chapter 5.3), it is concluded that:

1. Strains at loaded and unloaded status from FRP dowels (A and B) $(28.17 \mu$ s and $36.24 \mu \mathrm{s})$ were greater than that from Steel dowel (C) $(11.49 \mu \mathrm{s})$, which conforms analytical finding of shorter FRP dowel length required than steel dowel (refer to Fig. 6.14).

2. The strain value ratio from same gage at unloaded status to loaded status does not represent real load transfer efficiency.

3. It is suggested that Load transfer efficiency should be discovered from pavement deflection measurement. 


\section{Chapter 6}

\section{ANALYTICAL EVALUATION}

\subsection{Introduction}

Pavement performance (relative deflection and load transfer efficiency) with FRP dowel in Jointed Plain Concrete Pavement (JPCP) as load transfer device depends on many design parameters such as dowel diameter, dowel spacing, joint width between adjacent slabs, pavement thickness, concrete strength, base and subbase properties, environmental conditions including temperature variation, etc. In this chapter analytical evaluation is carried out for pavement slabs with FRP dowels.

Several examples provided in this chapter illustrate computations for group action of dowels, maximum bending and shear deflection of dowel, pavement relative deflection and bearing stresses. Both steel and FRP dowels are utilized for comparison purpose.

Expansion joint model was used as analytical model; contraction joint model was also discussed and compared.

\subsection{Analytical Model}

Computations for a JPCP are carried out by assuming dowel to be a beam and the concrete to be a Winkler foundation. Based on the original solution by Timoshenko and Lessels (1925) for the analysis of beams on an elastic foundation, the differential equation of the deflection of a beam on an elastic foundation is given by:

$$
E I \frac{d^{4} y}{d x^{4}}=-k y
$$

$k$ is the modulus of foundation that is a constant and $\mathrm{y}$ is the deflection. The modulus of foundation denotes the reaction due to load per unit length when the deflection is equal to unity. Timoshenko and Lessels (1925) gave solution to the differential equation (6.1) as: 


$$
y=e^{\beta x}(A \cos \beta x+B \sin \beta x)+e^{-\beta x}(C \cos \beta x+D \sin \beta x)
$$

where,

$$
\begin{aligned}
& \beta=\sqrt[4]{\frac{k}{4 E I}} \text {, Relative stiffness of a dowel embedded in concrete } \\
& \mathrm{k}=\text { modulus of foundation (psi) } \\
& \mathrm{E}=\text { modulus of elasticity of the beam (psi) } \\
& \mathrm{I}=\text { moment of inertia of the beam }\left(\mathrm{in}^{4}\right)
\end{aligned}
$$

$\mathrm{A}, \mathrm{B}, \mathrm{C}$, and $\mathrm{D}$ are constants and are determined from the boundary conditions for a particular beam on elastic foundation. For a semi-infinite beam on an elastic foundation subject to a point load and moment applied at its end, as shown in Fig. 6.1, constant $\mathrm{A}$ and $\mathrm{B}$ are equal to zero and $\mathrm{C}=\mathrm{D}=\frac{P}{8 \beta^{3} E I}$.

After substituting A, B, C and D, equation 6.2 becomes

$$
y=\frac{e^{-\beta x}}{2 \beta^{3} E I}\left[P \cos \beta x-\beta M_{0}(\cos \beta x-\sin \beta x)\right]
$$

Loads $\mathrm{P}$ and $\mathrm{M}_{0}$ are positive in Figure 6.1. By considering downward deflection as positive, and differentiating equation (6.3) with respect to $\mathrm{x}$ gives slope, dy/dx, of the beam along its axis.

$$
\frac{d y}{d x}=\frac{e^{-\beta x}}{2 \beta^{2} E I}\left[\left(2 \beta M_{0}-P\right) \cos \beta x-P \sin \beta x\right]
$$




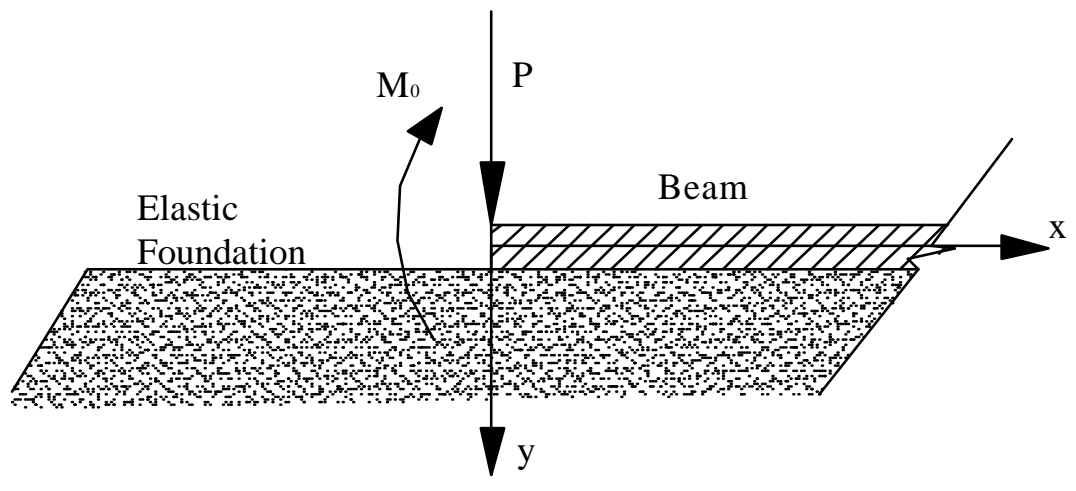

Figure 6.1 Semi-infinite beam on an elastic foundation

Applying the solution for a semi-infinite beam on an elastic foundation to dowel bars, Friberg (1938) developed equations for determining the slope and deflection of a dowel at the face of a joint as shown in Figure 6.2.

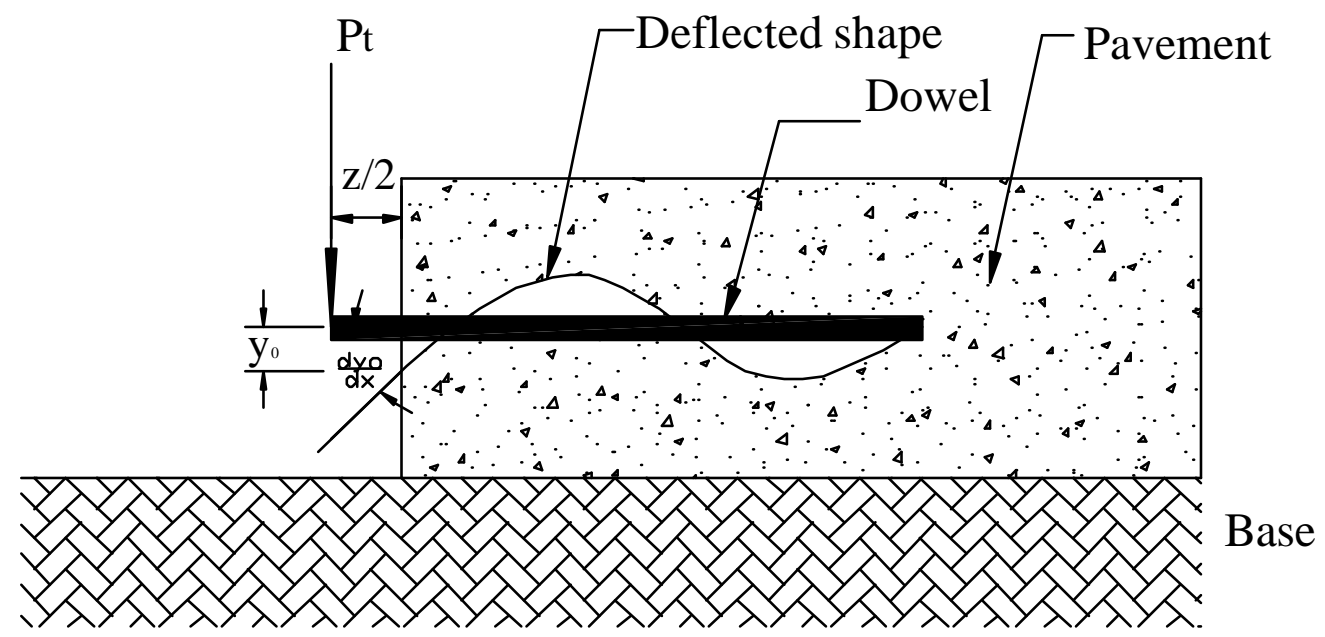

Figure 6.2 Slope and deflection of dowel at joint face

Substituting $-\mathrm{P}_{\mathrm{t}} \mathrm{z} / 2$ for $\mathrm{M}_{0}$ and $\mathrm{x}$ equal to zero in Equation 6.3, slope $\mathrm{dy}_{0} / \mathrm{dx}$ and the maximum deflection, $y_{0}$, of the dowel at the face of the joint are given by Equations (6.6) and (6.7) respectively (Friberg, 1938).

$$
\mathrm{M}_{0}=-\mathrm{P}_{\mathrm{t}} \mathrm{z} / 2
$$




$$
\begin{aligned}
& \frac{d y_{0}}{d x}=\frac{-p_{t}}{2 \beta^{2} E_{d} I_{d}}(1+\beta z) \\
& y_{0}=\frac{P_{t}(2+\beta z)}{4 \beta^{3} E_{d} I_{d}}
\end{aligned}
$$

where,

$$
\begin{aligned}
& \beta=\text { relative stiffness of the dowel bar encased in concrete }\left(\mathrm{in}^{-1}\right) \\
& \mathrm{K}_{0}=\text { modulus of dowel support (pci) } \\
& \mathrm{E}_{\mathrm{d}}=\text { modulus of elasticity of the dowel bar (psi) } \\
& \left.\mathrm{I}_{\mathrm{d}}=\text { moment of inertia of the dowel bar (in }{ }^{4}\right) \\
& \mathrm{P}_{\mathrm{t}}=\text { load transferred through the dowel (lbs) } \\
& \mathrm{d}=\text { diameter of dowel bar (in.) } \\
& \mathrm{Z}=\text { joint width (in.) }
\end{aligned}
$$

Friberg replaced the modulus of foundation, $k$, with the expression $\mathrm{K}_{0} \mathrm{~d}$. The modulus of dowel support, $\mathrm{K}_{0}$, denotes the reaction per unit area due to applied load when the deflection is equal to unity. Thus, relative stiffness of a dowel embedded in concrete, $\beta$, is given by:

$$
\beta=\sqrt[4]{\frac{K_{0} d}{4 E_{d} I_{d}}}
$$

$\mathrm{K}_{0}$ is an important parameter in Friberg's design equation. $\mathrm{K}_{0}$ is determined empirically because of the difficulty in establishing it theoretically. Literature reviews indicate a wide range of values for the modulus of dowel support. Modulus of dowel support $\mathrm{K}_{0}$ increases increased concrete strength $\left(f_{c}{ }^{\prime}\right)$, decreases with increased concrete depth below the dowel, and decreases with increased dowel bar diameter. Yoder and Witczak (1975) found that $\mathrm{K}_{0}$ ranges between 300,000 and 1,500,000 pci. For analytical calculations in this chapter, a value of 1,5000,000 pci $(407 \mathrm{Gpa} / \mathrm{m})$ is used as suggested by Yoder and Witczak to simulate the worst scenario. 
Friberg's equations were derived assuming a dowel bar of semi-infinite length. Dowel bars used in practice are of finite length (typically a total length of 18 "); therefore, this equation would not apply. However, Albertson (1992) and others have shown that this equation can be still applied to dowel bars with a $\beta \mathrm{L}$ value greater than or equal to 2 with little or no error, where the length of the dowel bar embedded in one side of the slab is denoted as $\mathrm{L}$.

\subsubsection{Load Transfer Across a Joint}

If 100 percent load transfer efficiency is achieved by the dowel bars, about 50 percent of the wheel load would be transferred to the subgrade while the other 50 percent would be transferred through the dowels to the adjacent slab. However, repetitive loading of the joint results in the creation of a void directly above or beneath the dowel at the face of the joint. According to Yoder and Witczak (1975), a 5 to 10 percent reduction in load transfer occurs upon formation of this void; therefore, a design load transfer of 45 percent of the applied wheel load is recommended.

$$
P_{t}=0.45 P_{w}
$$

where,

$$
\begin{aligned}
& \mathrm{P}_{\mathrm{t}}=\text { load transferred across the joint (lbs) } \\
& \mathrm{P}_{\mathrm{w}}=\text { applied wheel load (lbs) }
\end{aligned}
$$

Based on Westergaard's solutions (Wstergaard, 1925), Friberg found that only the dowels contained within a distance of $1.8 l_{r}$ from the load, where $l_{r}$ is the radius of relative stiffness defined as the stiffness of the slab relative to the stiffness of the foundation. Radius of relative stiffness $\left(l_{r}\right)$ is determined by the following formula 


$$
l_{r}=\sqrt[4]{\frac{E_{c} h^{3}}{12\left(1-v^{2}\right) k}}
$$

where,

$$
\begin{aligned}
& E_{c}=\text { modulus of elasticity of the pavement concrete (psi) } \\
& E_{c}=57,000\left(f_{c}^{\prime}\right)^{0.5} \\
& \mathrm{~h}=\text { pavement thickness (in.) } \\
& \mathrm{v}=\text { poisson's ratio for the pavement concrete } \\
& k=\text { modulus of subgrade reaction (pci) }
\end{aligned}
$$

Modulus of subgrade reaction $\mathrm{k}$ is a measure of the strength of the supporting soil, which may be the subbase or the subgrade. Its value is given in pounds per square inch per inch deflection as shown in Equation (6.11):

$$
k=\frac{\text { soil pressure }}{\text { soil deflection }}(p c i)
$$

A linear distribution of the load transferred across the joint (Friberg, 1938) is typically used (Fig. 6.3).

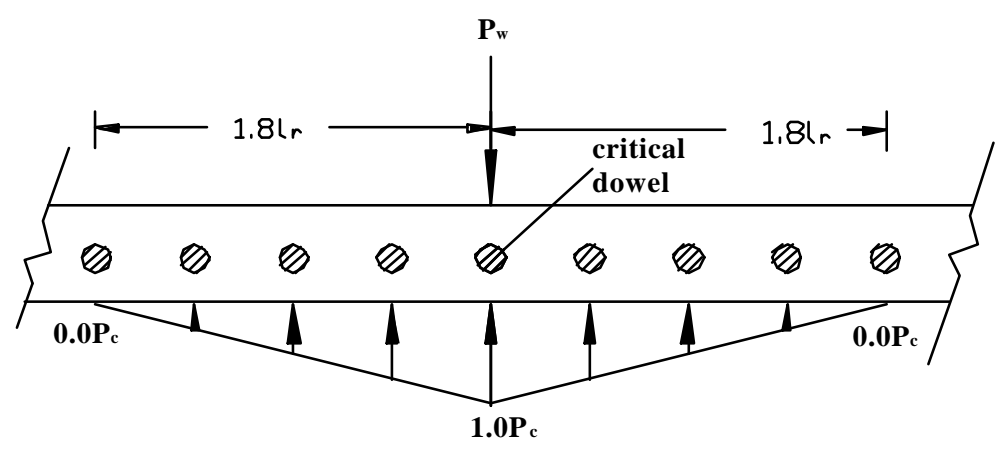

Figure 6.3 Load transfer distribution proposed by Friberg (1938) 
But Tabatabaie et al. (1979) found that an effective length of $1.0 l_{r}$ from the applied wheel load is more appropriate for dowels used in practice today (Figure 6.4). A linear approximation was also shown to exist with the maximum dowel shear occurring directly beneath the load and decreasing to a value of zero at a distance $1.0 l_{r}$ from the load.

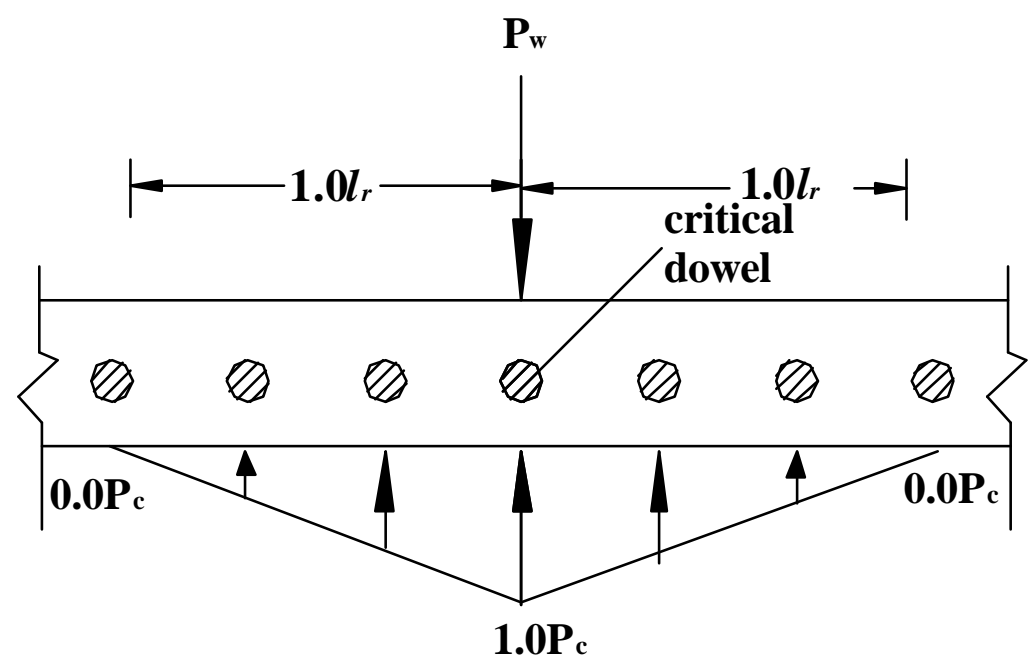

Figure 6.4 Load transfer distribution proposed by Tabatabaie et al. (1979)

From Figure 6.5, the most critical case is that of the critical dowel being located at the edge of a slab.

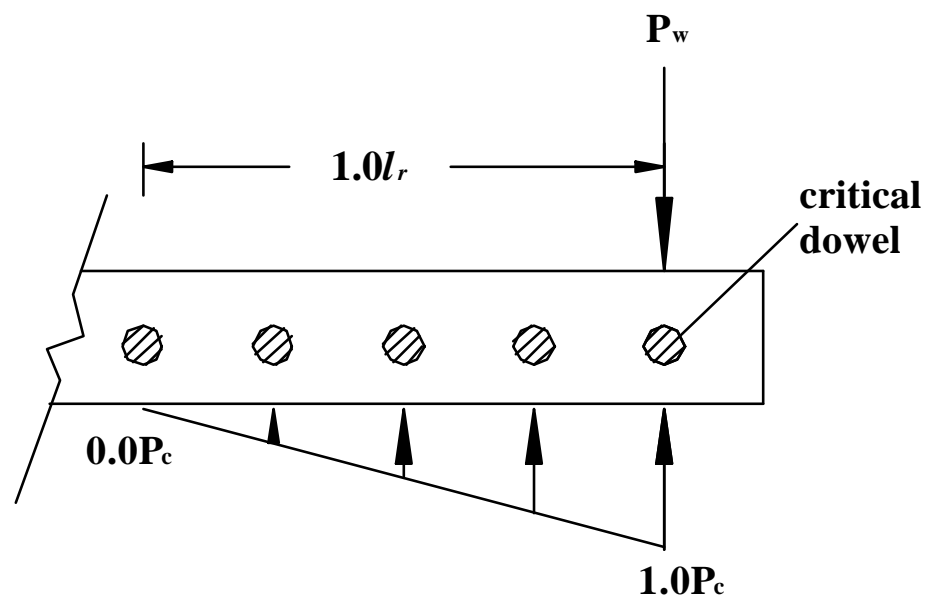

Figure 6.5 Most critical dowel at the edge of a slab 
If the force transferred by a critical dowel, which is located directly beneath the wheel load, is designated as $\mathrm{P}_{c}$, then the shear force in any other dowel within $l_{r}$ is determined by multiplying the height of the triangle below that particular dowel by $\mathrm{P}_{c}$. A value of 1.0 is assumed for the height of the triangle directly below the load as shown in Figure 6.4. The shear force in the dowel directly under the load is obtained by dividing the transferred load, $\mathrm{P}_{\mathrm{t}}$, by the number of effective dowels, as shown in Equation 6.12. Sum of the heights of the triangle under each dowel within $l_{r}$ gives the number of effective dowels.

$$
P_{c}=\frac{\mathrm{P}_{\mathrm{t}}}{\text { number of effective dowels }}
$$

\subsubsection{Dowel Bending Moment and Shear}

The bending moment and shear force along with the dowel from the face of joint can be expressed as:

$$
\begin{aligned}
& M(x)=-E_{d} I_{d} \frac{d^{2} y}{d x^{2}}=\frac{-e^{-\beta x}}{\beta}\left[P_{t} \sin \beta x-\beta M_{0}(\sin \beta x+\cos \beta x)\right] \\
& V(x)=\frac{d M}{d x}=-e^{-\beta x}\left[\left(2 \beta M_{0}-P_{t}\right) \sin \beta x+P_{t} \cos \beta x\right]
\end{aligned}
$$

where,

$$
\begin{aligned}
& \mathrm{x}=\text { distance along dowel from face of concrete (in.) } \\
& M_{0}=\text { bending moment on dowel at face of concrete, (see Eq. 6.5) } \\
& P_{t}=\text { transferred load } \\
& E_{d} I_{d}=\text { flexural rigidity of dowel }
\end{aligned}
$$

\subsubsection{Dowel Bar Deflection and Bearing Stress}

The relative deflection between slabs is shown in Figure 6.6, the expression of $\Delta$ is shown in Equation 6.15. 


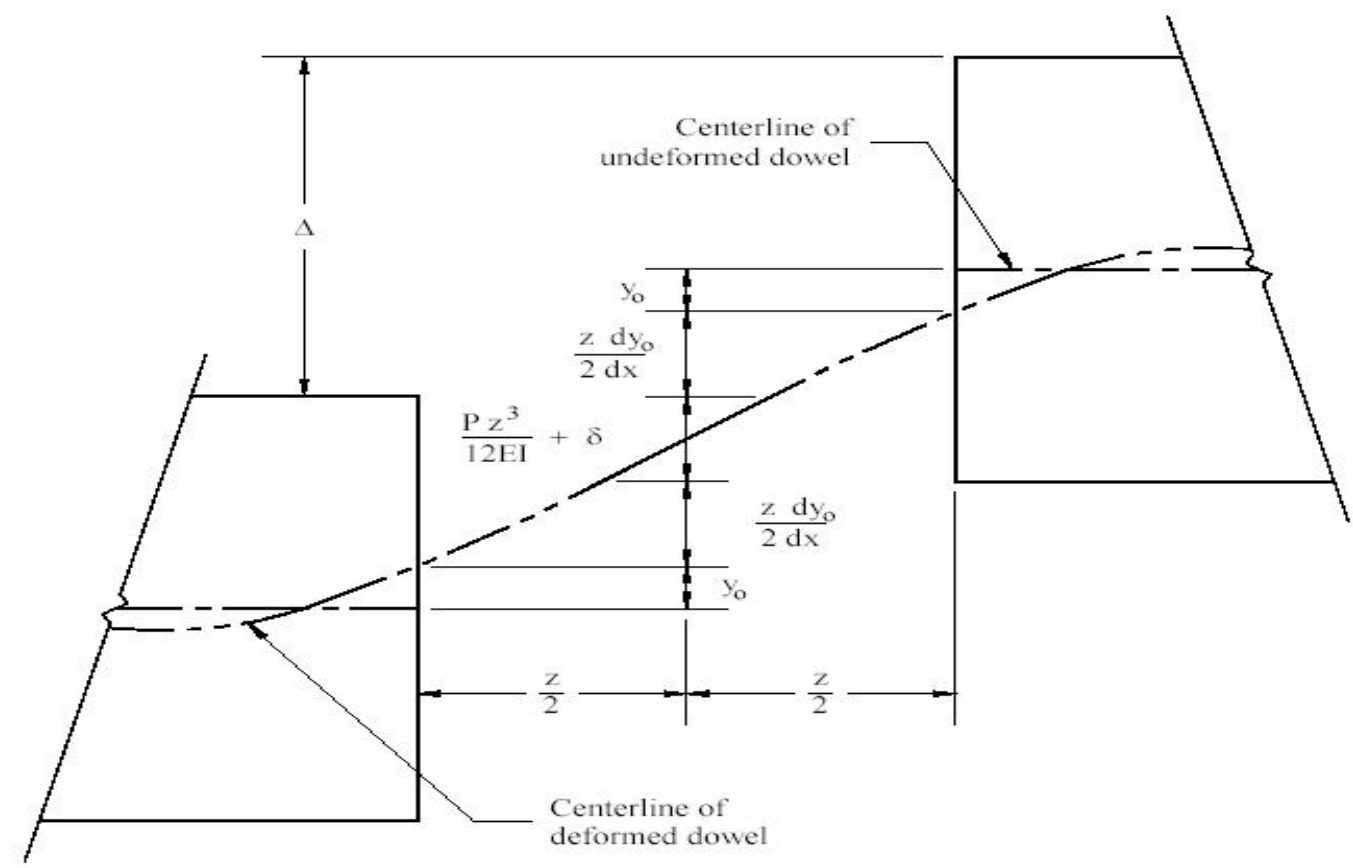

Figure 6.6 Relative deflection between concrete slabs (Porter and Guinn, 2002)

$$
\Delta=2 y_{0}+z\left(\frac{d y_{0}}{d x}\right)+\delta+\frac{P z^{3}}{12 E I}
$$

where,

$\mathrm{y}_{0}$, dowel deflection, (Equation 6.7)

$z\left(\frac{d y_{0}}{d x}\right)$, deflection due the slope of dowel

$\delta=\frac{\lambda P_{t} z}{A G}$, dowel shear deflection

$\lambda=$ form factor, equal to $10 / 9$ for solid circular section

$A=$ cross-sectional area of the dowel bar

$\mathrm{G}=$ shear modulus

$\mathrm{P}_{\mathrm{t}}=$ load transferred by critical dowel

$\mathrm{z}=$ joint width 


$$
\frac{P z^{3}}{12 E I}, \text { flexural deflection }
$$

For small joint width, deflections due to slope and flexure are very small, thus neglecting those terms in Equation 6.15

$$
\Delta=2 \mathrm{y}_{0}+\delta
$$

\subsubsection{Bearing Stress Between Dowel/Concrete Interface}

The load acting on a dowel is transferred to the supporting/embedding concrete through bearing. Assuming the dowel behaves as a beam on an elastic foundation, the bearing stress at the face of the joint, $\sigma_{\mathrm{b}}$ is proportional to the deformation:

$$
\sigma_{b}=\mathrm{K} y_{0}=\mathrm{K} P_{c} \frac{2+\beta z}{4 \beta^{3} E_{d} I_{d}}
$$

The bearing stress defined by Equation 6.18 should not exceed the allowable value. The following equation was given by American Concrete Institute's (ACI) Committee 325 (1956).

$$
f_{b}=\frac{(4-d) f_{c}{ }^{\prime}}{3}
$$

where,

$$
\begin{aligned}
& f_{b}=\text { allowable bearing stress (psi) } \\
& \mathrm{d}=\text { dowel diameter (in.) } \\
& f_{c}{ }^{\prime}=\text { ultimate compressive strength of concrete slab (psi) }
\end{aligned}
$$

\subsubsection{Pavement Joint Efficiency}

The joint efficiency is determined by its ability to transfer part of an applied load across the joint to the adjacent slab. American Association of State Highway and Transportation Office (AASHTO) and American Concrete Pavement Association (ACPA) use deflection 
measurements to determine the efficiency of a joint. Equation 6.20 is given by ACPA (1991) as a means of rating joint effectiveness.

$$
E=\frac{2 d_{U}}{d_{L}+d_{U}} \times 100 \%
$$

where,

$$
\begin{aligned}
& \mathrm{E}=\text { joint effectiveness }(\%) \\
& \mathrm{d}_{\mathrm{U}}=\text { deflection of the unloaded side of a joint (in.) } \\
& \mathrm{d}_{\mathrm{L}}=\text { deflection of the loaded side of a joint (in.) }
\end{aligned}
$$

A joint effectiveness of 75 percent or more is considered adequate for medium to heavy truck loadings (APCP, 1991). AASHTO (1993)adopts the 75\% criteria and gives Equation 6.21 for determining joint effectiveness associated with a $9000 \mathrm{lb}$ wheel load.

$$
L T E=\frac{d_{U}}{d_{L}} \times 100 \%
$$

where,

$$
\text { LTE = Load Transfer Efficiency (\%) }
$$

AASHTO (1993) also suggests that the value of LTE is between 70 and 100 percent is very good load transfer, the joint provides sufficient load transfer. Deflection measurements for use in Equations 6.26 and 6.21 should be taken at the location of the outside wheel path.

However LTE and E are related by the following equation:

$$
L T E=\left(\frac{2}{2-E}-1\right) \times 100 \%
$$

According to equation 4.3, a LTE of $60 \%$ corresponds to an E of $75 \%$. When the value of LTE is between $60 \%$ and $100 \%$, the joint still provides sufficient load transfer for heavy load. 
In this research the Joint Load Transfer Efficiency defined by AASHTO will be used to evaluate the performance of jointed pavements containing dowels.

\subsection{Theoretical Calculation Samples for FRP and Steel Dowel Group}

Calculations have been carried out for two dowel diameters (1.5-inch diameter and 1.0inch diameter) for both FRP and steel dowels. Other parameters considered for calculation are listed in examples 6.1 to 6.4 .

\subsubsection{Theoretical Calculation for Dowel Group with 1.5-inch Diameter Dowels}

Theoretical calculations for concrete pavement joints having FRP and steel dowels with 1.5" diameter (Figure 6.7) are provided in Examples 6.1 to 6.2.

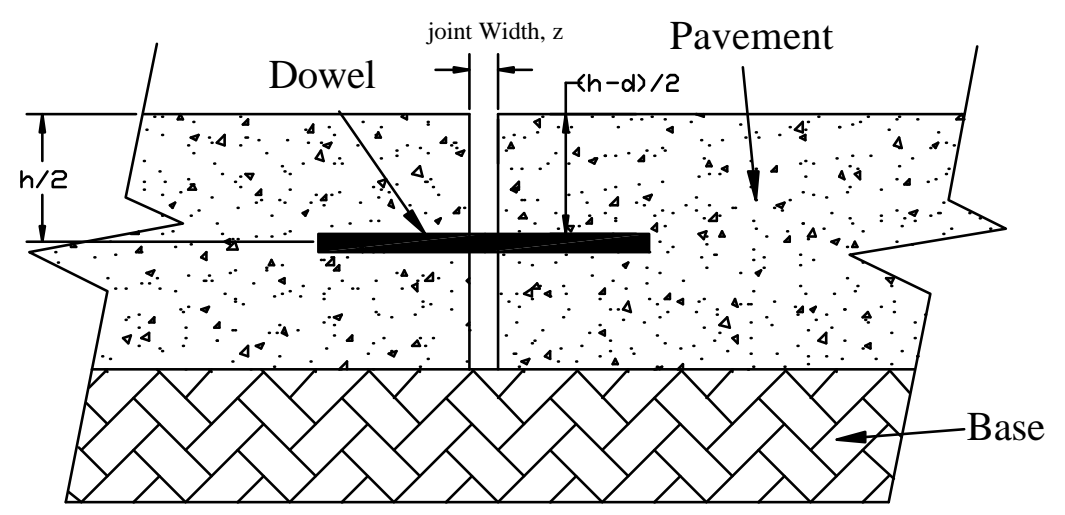

Figure 6.7 Expansion joint model used for theoretical calculation

\subsubsection{Example 6.1}

Example 6.1 calculates the following items for concrete pavement having 1.5" FRP dowels:

a) Radius of relative stiffness

b) Number of effective dowels

c) Load carried by the critical dowel 
d) Relative deflection $\Delta$ between joints

e) Bearing stress on dowel-concrete interface

Note: Parameters listed below correspond to actual laboratory setup and/or field values that provide us with useful comparisons.

1. FRP dowel

- Diameter, $\mathrm{d}=1.5$ in.

- Length, $\mathrm{L}=18$ in.

- Spacing between each dowel, $b=12.0$ in.

- Modulus of elasticity, $\mathrm{E}_{\mathrm{d}}=5.5 \times 10^{6} \mathrm{psi}$

- Shear modulus of dowel, $\mathrm{G}=0.4 \times 10^{6} \mathrm{psi}$

- Moment of inertia of the dowel, $\mathrm{I}_{\mathrm{d}}=\frac{\pi \times d^{4}}{64}=0.248505\left(\mathrm{in}^{4}\right)$

- Cross-sectional area of dowel, $\mathrm{A}=1.77 \mathrm{in.}^{2}$

2. Concrete pavement

- Compressive strength, $f_{c}{ }^{\prime}=4500 \mathrm{psi}$

- Modulus of elasticity, $E_{c}=57000 \times\left(f_{c}{ }^{\prime}\right)^{0.5}=3823676.2 \mathrm{psi}=3.82 \times 10^{6} \mathrm{psi}$

- Pavement thickness, $\mathrm{h}=11$ in.

- Joint width, $\mathrm{z}=0.25$ in.

- Poisson's ratio of concrete, $v=0.2$

- Modulus of dowel support, $\mathrm{K}_{0}=1,500,000 \mathrm{pci}$

3. Base

- Modulus of subgrade reaction, $k=400 \mathrm{pci}$

4. Load 
- Design Traffic Load HS25, applied wheel load $\mathrm{P}_{\mathrm{w}}=20000 \mathrm{lbs}$

- Design load transfer by joint $=45 \%$

- $\quad \mathrm{P}_{\mathrm{t}}=$ load transferred across the joint $=P_{w} \times 0.45=9000 \mathrm{lbs}$

Calculation steps are shown in the following flow chart with equations.

Step 1: Calculate radius of relative stiffness, $l_{r}$, (Eq. 6.10)

Step 2: Calculate number of effective dowels (Figs. 6.4 and 6.5)

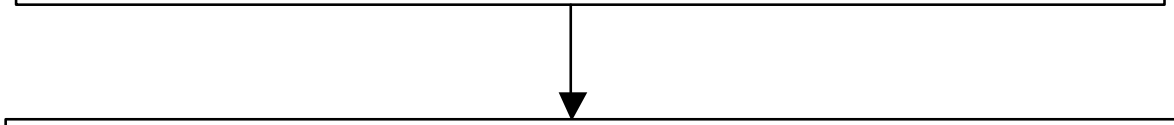

Step 3: Calculate load carried by the critical dowel (Eq. 6.12)

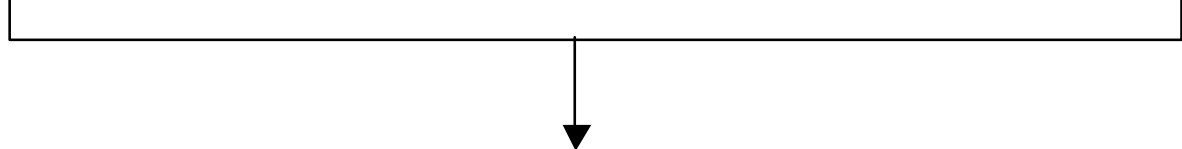

Step 4: Calculate Relative deflection $\Delta$ between joints (Eq. 6.17)

Step 5: Calculate Bearing stress on dowel-concrete interface (Eq. 6.18)

Figure 6.8 Steps for calculating critical dowel load, joint relative deflection and bearing stress in JPCP

Details of the calculations are given below from Setp1 to Step 5.

Step 1. Calculation for radius of relative stiffness

$$
l_{r}=\sqrt[4]{\frac{E_{c} h^{3}}{12\left(1-\mathrm{v}^{2}\right) k}}=\sqrt[4]{\frac{3823676 \times 11^{3}}{12 \times\left(1-0.2^{2}\right) \times 400}}=32.4180 \mathrm{in}
$$

Step 2. Calculation for number of effective dowels

The dowels within $1.0 l_{r}$ distance are effective in load distribution (Figure 6.4) 
Number of dowels in $1.0 l_{r}$ distance $=2 \times \operatorname{INT}\left(l_{r} / \mathrm{b}=32.4180 / 12.0=2.7\right)+1=2 \times 2+1=5$, where $l_{r}=$ radius of relative stiffness, $\mathrm{b}=$ dowel spacing.

The critical dowel in this dowel group, which is the dowel directly under load, has an effect 1.0 (Figures $6.4 \& 6.5$ ), and other dowel contribution were calculated according to the triangular ratio. Load was distributed on 5 dowels $(1$ critical dowel plus 2 effective dowels on each side) by a triangular variation with due consideration to the available pavement width.

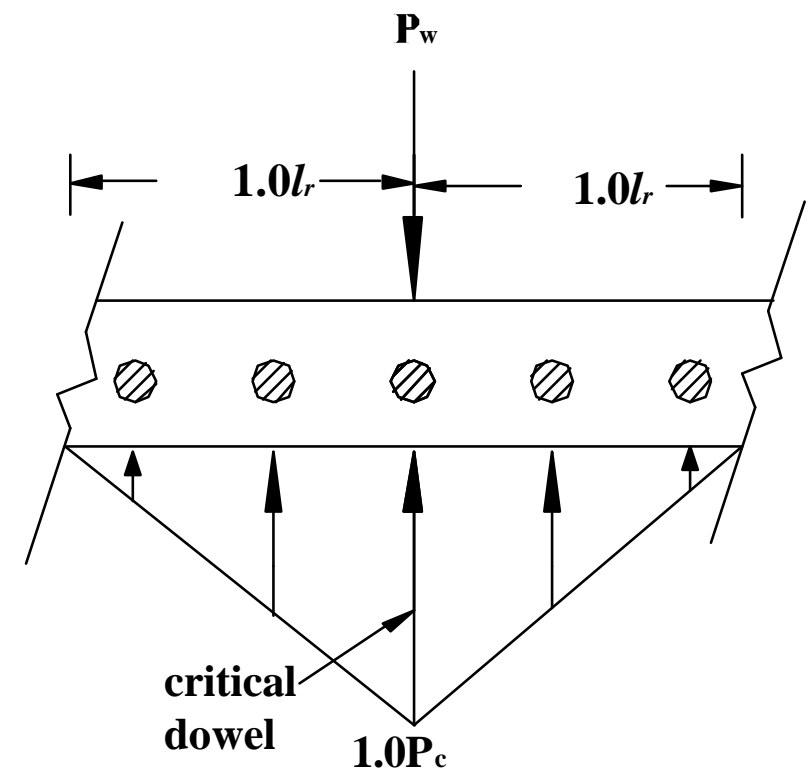

Figure 6.9 Generalized effective dowels for load distribution

In order to obtain most critical load condition, we assume that the critical dowel is located on the edge of a pavement. Thus, the effective dowel number is reduced to 3 (1 critical dowel and 2 effective dowels on one side). 


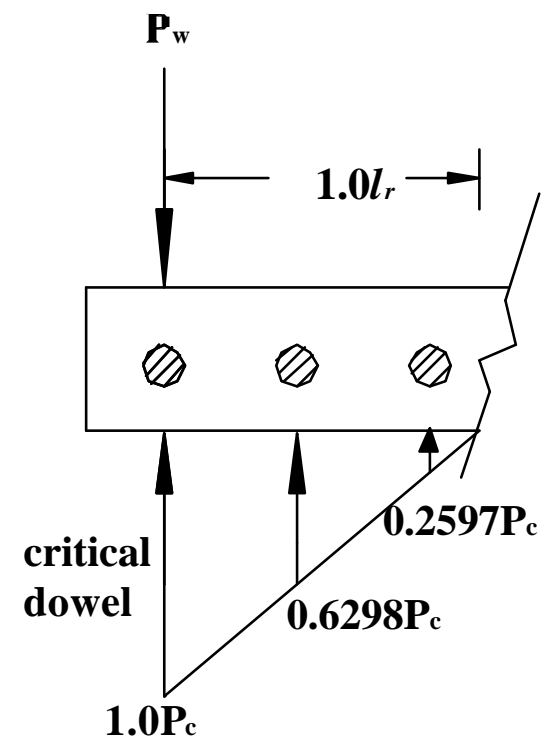

Figure 6.10 Most critical load distribution on effective dowels

From calculations, Number of Effective dowels $=1.0+0.6298+0.2597=1.8895$

Step 3. Calculation for load carried by the critical dowel

When wheel load is applied at the edge of a pavement the critical dowel has to carry most of the transferred load:

$$
P_{c}=\frac{\mathrm{P}_{\mathrm{t}}}{\text { number of effective dowels }}=9000 / 1.8895=4763.1472 \mathrm{lbs}
$$

Note: To obtain the same critical load for lab experiments, it is necessary to apply

$$
\frac{P_{c}}{45 \%}=10584.7716 \mathrm{lbs} \text { at loaded side of the pavements }
$$

Step 4. Calculation for relative deflection $\Delta$ between joints

$$
\text { Maximum dowel deflection, } \begin{aligned}
y_{0} & =\frac{P_{c}(2+\beta z)}{4 \beta^{3} E_{d} I_{d}} \\
& =\frac{4763.1472 \times(2+0.800952 \times 0.25)}{40.800952^{3} \times 5 \times 10^{6} \times 0.2485} \\
& =0.0037307 \mathrm{in} .
\end{aligned}
$$




$$
\text { Where, } \begin{aligned}
\beta & =\sqrt[4]{\frac{K_{0} d}{4 E_{d} I_{d}}} \\
& =\sqrt[4]{\frac{1500000 \times 1.5}{4 \times 5.5 \times 10^{6} \times 0.2485}} \\
& =0.80095168 \mathrm{in}^{-1}
\end{aligned}
$$

Dowel shear deflection, $\delta=\frac{\lambda P_{c} z}{A G}=\frac{(10 \div 9) \times 4763.1472 \times 0.25}{1.77 \times 4 \times 10^{5}}=0.00187 \mathrm{in}$.

Where, $\lambda=$ form factor, equal to $10 / 9$ for solid circular section

So, Total Relative deflection between pavement joints is:

$$
\Delta=2 \mathrm{y}_{0}+\delta=2 \times 0.0037307+0.00187=0.00933 \text { in. }
$$

Step 5. Calculation for bearing stress on dowel-concrete interface

Maximum bearing stress occurs at the place where deflection is maximum,

$$
\begin{aligned}
& \sigma_{b}=\mathrm{K} y_{0} \\
& =1,500,000 \times 0.0037307 \\
& =5596.05 \mathrm{psi}
\end{aligned}
$$

The allowable bearing stress is:

$$
\begin{aligned}
f_{b}= & \frac{(4-d) f_{c}{ }^{\prime}}{3} \\
& =\frac{(4-1.5) \times 4500}{3} \\
& =3750 \mathrm{psi}
\end{aligned}
$$

Thus, $\sigma_{b}>f_{b}(5596.05>3750)$, the bearing stress limit is not satisfied. 


\section{Discussion for Contraction Joint Model:}

Theoretical equations derived for dowels from Expansion Joint Model include shear deflection term $\delta=\frac{\lambda P_{c} z}{A G}$ due to the presence of joints with a width $1 / 4$ ".

However, depth of Contraction and Construction Joint Model (Figure 6.10) (typically 1/4 $-1 / 3$ of the pavement thickness) will not reach dowel surface because dowel is always surrounded by concrete. To calculate these types of concrete pavement joints, the effective joint width $\mathrm{z}$ used for theoretical calculation will be much smaller than 1/4", say $1 / 32$ ". This will result in less maximum bending deflection $\left(y_{0}\right)$ and much smaller shear deflection (Equation 6.16). See Table 6.1 for detailed calculations.

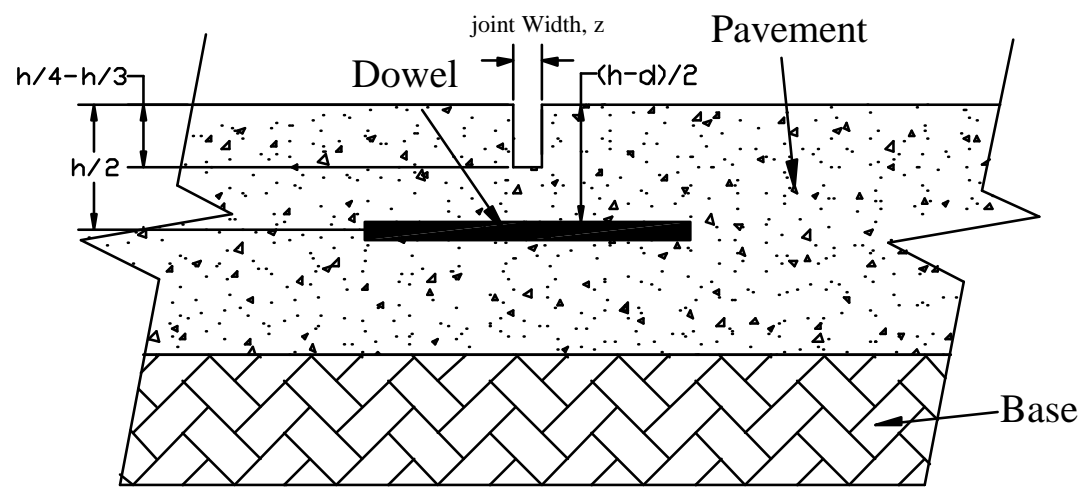

Figure 6.11 Pavement Contraction Joint Model

\subsubsection{Example 6.2}

Example 6.2 calculates the following items for concrete pavement having 1.5" steel dowels:
a) Radius of relative stiffness
b) Number of effective dowels
c) Load carried by the critical dowel 
d) Relative deflection $\Delta$ between joints

e) Bearing stress on dowel-concrete interface

Parameters used for calculation in Example 6.2 are similar to those in Example 6.1, except that the dowel parameters have been changed to steel dowel properties.

Note: Parameters listed below correspond to actual laboratory setup and/or field values that provide us with useful comparisons.

Steel dowel:

- Diameter, $\mathrm{d}=1.5$ in.

- Length, $\mathrm{L}=18$ in.

- $\quad$ Spacing between each dowel, $b=12.0$ in.

- Modulus of elasticity, $\mathrm{E}_{\mathrm{d}}=29 \times 10^{6} \mathrm{psi}$

- Shear modulus of dowel, $\mathrm{G}=11 \times 10^{6} \mathrm{psi}$

- Moment of inertia of the dowel bar, $\mathrm{I}_{\mathrm{d}}=\frac{\pi \times d^{4}}{64}=0.248505\left(\mathrm{in}^{4}\right)$

- Cross-sectional area of dowel, $\mathrm{A}=1.77 \mathrm{in}^{2}$.

Calculation steps are same as that for FRP dowel and shown in Fig. 6.8

Step 1. Calculation for radius of relative stiffness (From example 6.1)

$$
l_{r}=32.4180 \mathrm{in} .
$$

Step 2. Calculation for number of effective dowels (From example 6.1)

The number of dowels $=2 \times \operatorname{INT}\left(l_{r} / \mathrm{b}=32.4180 / 12.0=2.7\right)+1=2 \times 2+1=5$

Number of Effective dowels $=1.0+0.6298+0.2597=1.8895$

Step 3. Calculation for load carried by the critical dowel (From example 6.1)

$$
P_{c}=\frac{\mathrm{P}_{\mathrm{t}}}{\text { number of effective dowels }}=9000 / 1.8895=4763.1472 \mathrm{lbs}
$$


Note: To obtain the same critical load for lab experiments, it is necessary to apply (From example 6.1)

$$
\frac{P_{c}}{45 \%}=10584.7716 \mathrm{lbs} \text { at loaded side of the pavements }
$$

Step 4. Calculation for relative deflection $\Delta$ between joints

$$
\text { Maximum dowel deflection, } \begin{aligned}
y_{0} & =\frac{P_{c}(2+\beta z)}{4 \beta^{3} E_{d} I_{d}} \\
& =\frac{4763.1472 \times(2+0.52856389 \times 0.25)}{4 \times 0.52856389{ }^{3} \times 29 \times 10^{6} \times 0.2485} \\
& =0.002386 \mathrm{in} .
\end{aligned}
$$

Where, $\beta=\sqrt[4]{\frac{K_{0} d}{4 E_{d} I_{d}}}$

$$
\begin{aligned}
& =\sqrt[4]{\frac{1500000 \times 1.5}{4 \times 29 \times 10^{6} \times 0.2485}} \\
& =0.52856389 \mathrm{in}^{-1}
\end{aligned}
$$

Dowel shear deflection, $\delta=\frac{\lambda P_{c} z}{A G}=\frac{(10 \div 9) \times 4763.1472 \times 0.25}{1.77 \times 11 \times 10^{7}}=0.000007 \mathrm{in}$.

Total relative deflection $\Delta=2 \times 0.002386+0.000007=0.004778 \mathrm{in}$.

Step 5. Calculation for the bearing stress on dowel-concrete interface

$$
\begin{aligned}
& \sigma_{b}=\mathrm{K} y_{0} \\
& =1,500,000 \times 0.002386 \\
& =3578.6247 \mathrm{psi}
\end{aligned}
$$

The allowable bearing stress is:

$$
f_{b}=\frac{(4-d) f_{c}{ }^{\prime}}{3}
$$




$$
\begin{aligned}
& =\frac{(4-1.5) 4500}{3} \\
& =3750 \mathrm{psi}
\end{aligned}
$$

Thus, $\sigma_{\mathrm{b}}<f_{b}$, (3578.62psi $\left.<3750 \mathrm{psi}\right)$, the bearing stress limit is satisfied.

\subsubsection{Theoretical Calculation for Dowel Group with 1.0-inch Diameter Dowels}

Theoretical calculations for concrete pavement joints having FRP and steel dowels with 1.5" diameter (Figure 6.7) are provided in Examples 6.3 to 6.4. Expansion Joint Model (Figure 6.7) is used for calculations. For convenience, Figure 6.7 is shown here again.

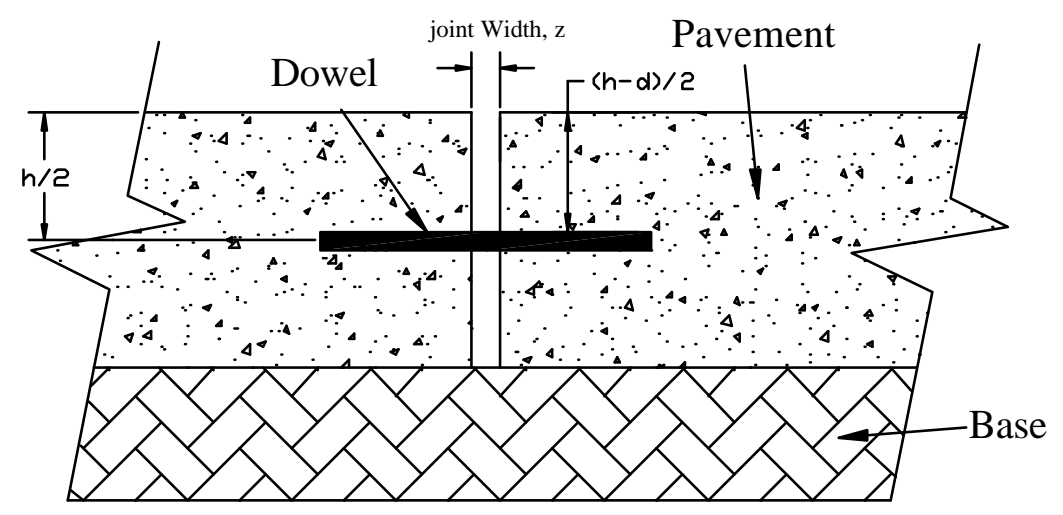

\section{Figure 6.12 Expansion joint model used for theoretical calculation}

\subsubsection{Example 6.3}

Example 6.3 calculates the following items for concrete pavement having 1.0" FRP dowels:
a) Radius of relative stiffness
b) Number of effective dowels
c) Load carried by the critical dowel
d) Relative deflection $(\Delta)$, between joints 
e) Bearing stress on dowel-concrete interface

Note: Parameters listed below correspond to actual laboratory setup and/or field values that provide us with useful comparisons.

1. FRP dowel

- Diameter, $\mathrm{d}=1.0$ inch

- Length, $\mathrm{L}=18$ in.

- Dowel spacing, $b=6.0$ inch

- Modulus of elasticity, $\mathrm{E}_{\mathrm{d}}=6.0 \times 10^{6} \mathrm{psi}$

- Shear modulus of dowel, $\mathrm{G}=0.4 \times 10^{6} \mathrm{psi}$

- Moment of inertia, $\mathrm{I}_{\mathrm{d}}=\frac{\pi \times d^{4}}{64}=0.049087\left(\mathrm{in}^{4}\right)$

- Cross-sectional area, $\mathrm{A}=0.7854$ in. $^{2}$

2. Concrete pavement

- Compressive strength, $f_{c}{ }^{\prime}=4500 \mathrm{psi}$

- Modulus of elasticity, $E_{c}=57000 \times\left(f_{c}{ }^{\prime}\right)^{0.5}=3823676.2 \mathrm{psi}=3.82 \times 10^{6} \mathrm{psi}$

- Pavement thickness, $\mathrm{h}=11$ in.

- Joint width, $\mathrm{z}=0.25$ in.

- Poisson's ratio of concrete, $v=0.2$

- Modulus of dowel support, $\mathrm{K}_{0}=1,500,000 \mathrm{pci}$

3. Base

- Modulus of subgrade reaction, $k=400 \mathrm{pci}$

4. Load

- Design Traffic Load HS25, applied wheel load, $\mathrm{P}_{\mathrm{w}}=20000$ lbs 
- Design load transfer of $45 \%$

- $\mathrm{P}_{\mathrm{t}}=$ load transferred across the joint $=P_{w} \times 0.45=9000 \mathrm{lbs}$

Calculation Steps are same as Examples $6.1 \& 6.2$ and shown in Fig. 6.8. Details of the calculations are given below from Setp1 to Step 5 .

Step 1. Calculation for radius of relative stiffness

$$
l_{r}=\sqrt[4]{\frac{E_{c} h^{3}}{12\left(1-v^{2}\right) k}}=\sqrt[4]{\frac{3823676 \times 11^{3}}{12 \times\left(1-0.2^{2}\right) \times 400}}=32.4180 \mathrm{in} .
$$

Step 2. Calculation for number of effective dowels

The dowels within $1.0 l_{r}$ distance are effective in load distribution.

For the case critical dowel at slab edge (Figure 6.13), the dowels number in $1.0 l_{r}$ distance $=\operatorname{INT}\left(l_{r} / \mathrm{b}=32.4180 / 6.0=5.40\right)+1=5+1=6$, where $l_{l}=$ radius of relative stiffness, $\mathrm{b}=$ dowel spacing.

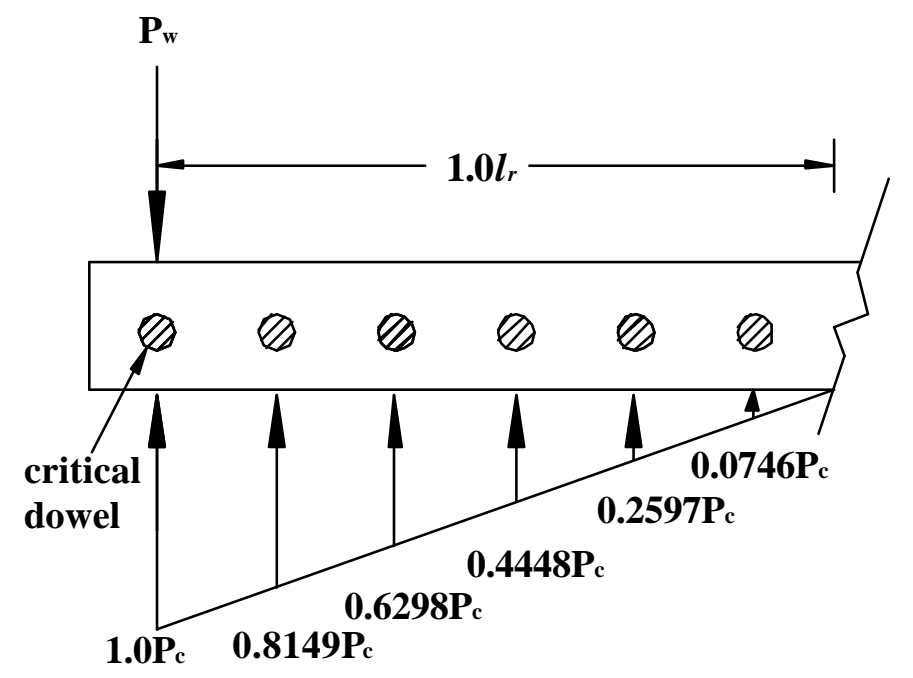

Figure 6.13 Most critical load distribution on effective dowels

From calculations, Number of Effective dowels

$$
\begin{aligned}
& =1+0.8149+0.6298+0.4448+0.2597+0.0746 \\
& =3.2237
\end{aligned}
$$


Step 3. Calculation for the load carried by the critical dowel

When wheel load was applied at the edge of a pavement the critical dowel has to carry the most of the transferred load:

$$
P_{c}=\frac{\mathrm{P}_{\mathrm{t}}}{\text { number of effective dowels }}=9000 / 3.2237=2791.7646 \mathrm{lbs}
$$

Note: For slabs only containing two 1.0 FRP dowels, in order to obtain the same critical load for lab experiments, it is necessary to apply

$$
\frac{(1.0+0.8149) \times P_{C}}{45 \%}=\frac{(1.0+0.8149) \times 2791.76}{45 \%}=12666.93 \text { lbs at loaded side of }
$$

pavements in lab tests (two dowels are considered).

Step 4. Calculation for the relative deflection $\Delta$ between joints

$$
\text { Maximum dowel deflection, } \begin{aligned}
y_{0} & =\frac{P_{c}(2+\beta z)}{4 \beta^{3} E_{d} I_{d}} \\
& =\frac{2791.76 \times(2+1.06225 \times 0.25)}{4 \times 1.06225^{3} \times 6 \times 10^{6} \times 0.049087} \\
& =0.00448 \mathrm{in} .
\end{aligned}
$$

$$
\begin{aligned}
& =\sqrt[4]{\frac{1500000 \times 1.5}{4 \times 6 \times 10^{6} \times 0.049087}} \\
& =1.0623 \mathrm{in}^{-1}
\end{aligned}
$$

Dowel shear deflection, $\delta=\frac{\lambda P_{c} z}{A G}=\frac{(10 \div 9) \times 2791.76 \times 0.25}{0.7854 \times 0.4 \times 10^{6}}=0.002468 \mathrm{in}$.

Where, $\lambda=$ form factor, equal to $10 / 9$ for solid circular section

So, Total Relative deflection between pavement joints is: 


$$
\Delta=2 \mathrm{y}_{0}+\delta=2 \times 0.0048+0.002468=0.01143 \text { in. }
$$

Step 5. Calculation for the bearing stress on dowel-concrete interface

The maximum bearing stress happens at the place where the deflection is the maximum,

$$
\begin{aligned}
& \sigma_{b}=\mathrm{K} y_{0} \\
& =1,500,000 \times 0.0048 \\
& =6718.66 \mathrm{psi}
\end{aligned}
$$

The allowable bearing stress is:

$$
\begin{aligned}
f_{b}= & \frac{(4-d) f_{c}{ }^{\prime}}{3} \\
& =\frac{(4-1.0) 4500}{3} \\
& =4500 \mathrm{psi}
\end{aligned}
$$

Thus, $\sigma_{\mathrm{b}}>f_{b}$, $(6718.66>4500 \mathrm{psi})$ the bearing stress limit is not satisfied.

\section{Discussion for Contraction Joint Model:}

In order to meet the bearing stress limit by adjusting dowel spacing only, FRP dowel spacing should not exceed 3.6". See the detailed data in Table 6.2.

Detailed data of calculations for Contraction Joint Model (Figure 6.10) are shown in Table 6.2, where joint width $\mathrm{z}$ is used as $1 / 32$ ”.

\subsubsection{Example 6.4}

Example 6.4 calculates the following items for concrete pavement having 1.0" steel dowels:
a) Radius of relative stiffness
b) Number of effective dowels
c) Load carried by the critical dowel 
d) Relative deflection $\Delta$ between joints

e) Bearing stress on dowel-concrete interface

Parameters used for calculation in Example 6.4 are similar to those in Example 6.3, except dowel parameters have been changed to steel dowel properties.

Note: Parameters listed below correspond to actual laboratory setup and/or field values that provide us with useful comparisons.

Steel dowel:

- Diameter, $\mathrm{d}=1.0$ in.

- Length, $\mathrm{L}=18$ in.

- Spacing between each dowel, $b=12.0$ in.

- $\quad$ Modulus of elasticity, $\mathrm{E}_{\mathrm{d}}=29 \times 10^{6} \mathrm{psi}$

- Shear modulus of dowel, $\mathrm{G}=11 \times 10^{6} \mathrm{psi}$

- Moment of inertia of the dowel bar, $\mathrm{I}_{\mathrm{d}}=\frac{\pi \times d^{4}}{64}=0.049087\left(\mathrm{in}^{4}\right)$

- Cross-sectional area of dowel, $\mathrm{A}=0.7854 \mathrm{in}^{2}$

Calculation steps are same as those in Example 6.3, which are for FRP dowels.

Step 1. Calculation for the radius of relative stiffness

$$
l_{r}=32.4180 \mathrm{in} .
$$

Step 2. Calculation for the number of effective dowels

The number of dowels $=6$

Number of Effective dowels $=3.2237$

Step 3. Calculation for the load carried by the critical dowel

$$
P_{c}=\frac{\mathrm{P}_{\mathrm{t}}}{\text { number of effective dowels }}=9000 / 3.2237=2791.7646 \mathrm{lbs}
$$


Step 4. Calculation for the relative deflection $\Delta$ between joints

$$
\begin{aligned}
& \text { Maximum dowel deflection, } y_{0}=\frac{P_{c}(2+\beta z)}{4 \beta^{3} E_{d} I_{d}} \\
& =\frac{2791.7676 \times(2+0.7164 \times 0.25)}{4 \times 0.7164^{3} \times 29 \times 10^{6} \times 0.04909} \\
& =0.002906 \mathrm{in.} \\
& \text { Where, } \beta=\sqrt[4]{\frac{K_{0} d}{4 E_{d} I_{d}}} \\
& =\sqrt[4]{\frac{1500000 \times 1.0}{4 \times 29 \times 10^{6 \times 0.04909}}} \\
& =0.716417 \mathrm{in.}^{-1}
\end{aligned}
$$

Dowel shear deflection, $\delta=\frac{\lambda P_{c} z}{A G}=0.000009$ in.

So, Total Relative deflection between pavement joints is:

$$
\Delta=2 \mathrm{y}_{0}+\delta=2 \mathrm{x} 0.002906+0.000009=0.00582 \mathrm{in} .
$$

Step 5. Calculation for the bearing stress on dowel-concrete interface

$$
\begin{aligned}
& \sigma_{b}=\mathrm{K} y_{0} \\
& =1,500,000 \times 0.002906 \\
& =4358.3564 \mathrm{psi}
\end{aligned}
$$

The allowable bearing stress in this case according to ACI is:

$$
\begin{aligned}
f_{b}= & \frac{(4-d) f_{c}{ }^{\prime}}{3} \\
= & 4500 \mathrm{psi}
\end{aligned}
$$

Thus, $\sigma_{\mathrm{b}}<f_{b},(4358.3564 \mathrm{psi}<4500 \mathrm{psi})$ the bearing stress limit is satisfied. 


\subsection{Discussions on 1.5" and 1.0" diameter dowels}

\subsubsection{Comparisons for 1.5”' Diameter Dowel Bars}

Additional calculations were conducted. It is found that in order to meet the bearing stress criteria by adjusting dowel spacing only, FRP dowel spacing should not exceed 7.0". Detailed data are shown in Table 6.1.Other calculation results are also summarized in Table 6.1.

Table 6.1 Calculation Summaries for 1.5” Diameter Dowel $\left(k=400 p c i, f_{c}{ }^{\prime}=4500\right.$ psi $)$

\begin{tabular}{|c|c|c|c|c|c|c|c|c|}
\hline & & Radius of & Load & & & \\
Material & Spacing & Relative & Carried by & Effective & Maximum & Shear & Relative & Bearing \\
& & Stiffness & Critical & Dowel & Deflection & Deflection & Deflection & Stress \\
& & $l_{r}$ (in.) & Dowel & Number & $y_{0}\left(10^{-3}\right.$ in.) & $\delta\left(10^{-3}\right.$ in.) & $\Delta\left(10^{-3}\right.$ in.) & $\sigma_{\mathrm{b}}$ (psi) \\
\hline \hline FRP & 12 & 32.4180 & 4763.15 & 1.8895 & 3.731 & 1.872 & 9.33 & 5596.05 \\
\hline Steel & 12 & 32.4180 & 4763.15 & 1.8895 & 2.386 & 0.007 & 4.78 & 3578.62 \\
\hline \hline FRP & 6 & 32.4180 & 2791.76 & 3.2238 & 2.187 & 1.097 & 5.47 & 3279.92 \\
\hline FRP & 7 & 32.4180 & 3168.22 & 2.8407 & 2.481 & 1.245 & 6.21 & 3722.21 \\
\hline \hline FRP & 12 & 32.4180 & 4763.15 & 1.8895 & 3.434 & 0.234 & 7.10 & 5150.39 \\
\hline FRP** & 7.5 & 32.4180 & 3350.12 & 2.6865 & 2.415 & 0.165 & 4.99 & 3622.48 \\
\hline \hline
\end{tabular}

(Note: Cases FRP $^{*}$ and FRP $^{* *}$ are dowel groups in Contraction Joint Model with joint width $\mathrm{z}$

$=1 / 32$ '. Shaded data indicate that bearing stress limit of 3750 psi in this case is satisfied.

Peak bearing stress at one location doesn't take into account the stiffness match between FRP dowel and concrete, which allows better distribution of bearing stress leading to reduced bearing stress concentration. Tables 6.2 and 6.3 described the detailed data. 
Table 6.2 Peak Bearing Stress and Average Bearing Stress in Dowel (1.5” diameter @ 12" c/c) Downward Area

\begin{tabular}{|c|c|c|c|c|c|c|c|}
\hline & $\begin{array}{c}\text { Maximum } \\
\text { Deflection } \\
y_{0}\left(10^{-3}\right. \\
\text { in. })\end{array}$ & $\begin{array}{c}\text { Modulus } \\
\text { of Dowel } \\
\text { Support } \\
\text { (pci) }\end{array}$ & $\begin{array}{c}\text { Peak } \\
\text { Bearing } \\
\text { Stress (psi) }\end{array}$ & $\begin{array}{c}\text { Average } \\
\text { Deflection in } \\
\text { dowel } \\
\text { downward } \\
\text { bending area } \\
\left(10^{-3} \text { in. }\right)\end{array}$ & $\begin{array}{l}\text { Modulus } \\
\text { of Dowel } \\
\text { Support } \\
\text { (pci) }\end{array}$ & $\begin{array}{c}\text { Average } \\
\text { Bearing } \\
\text { Stress } \\
\text { (psi) }\end{array}$ & $\begin{array}{c}\text { Average } \\
\text { / Peak } \\
\text { Bearing } \\
\text { Stress } \\
(\%)\end{array}$ \\
\hline \multirow[t]{2}{*}{$\overline{~ F R P ~}$} & \multirow[t]{2}{*}{3.731} & 300,000 & 1119.3 & \multirow[t]{2}{*}{1.321} & 300,000 & 396.3 & \multirow{2}{*}{35.40} \\
\hline & & $1,500,000$ & 5596.5 & & $1,500,000$ & 1981.5 & \\
\hline \multirow[t]{2}{*}{ Steel } & \multirow{2}{*}{2.386} & 300,000 & 715.8 & \multirow[t]{2}{*}{0.871} & 300,000 & 261.3 & \multirow{2}{*}{36.50} \\
\hline & & $1,500,000$ & 3578.6 & & $1,500,000$ & 1307.1 & \\
\hline
\end{tabular}

Note: In Table 6.2, the downward dowel length of FRP and steel dowels ranges from 0",

to 2" and 0" to 3" (Fig. 6.14), respectively. Value of Modulus of Dowel Support ranges from 300,000 pci to $1,500,000$ pci (Yoder and Witczak, 1975).

Table 6.3 Peak Bearing Stress and Average Bearing Stress within 1" Dowel (1.5” diameter @ 12” c/c) Length from Joint Face

\begin{tabular}{|c|c|c|c|c|c|c|c|}
\hline & $\begin{array}{c}\text { Maximum } \\
\text { Deflection } \\
y_{0}\left(10^{-3}\right. \\
\text { in. })\end{array}$ & $\begin{array}{l}\text { Modulus } \\
\text { of Dowel } \\
\text { Support } \\
\text { (pci) }\end{array}$ & $\begin{array}{c}\text { Peak } \\
\text { Bearing } \\
\text { Stress } \\
\text { (psi) }\end{array}$ & $\begin{array}{c}\text { Average } \\
\text { Deflection } \\
\text { within } 1.0 " \\
\text { inch distance } \\
\left(10^{-3} \text { in. }\right)\end{array}$ & $\begin{array}{c}\text { Modulus } \\
\text { of Dowel } \\
\text { Support } \\
\text { (pci) }\end{array}$ & $\begin{array}{c}\text { Average } \\
\text { Bearing } \\
\text { Stress } \\
\text { (psi) }\end{array}$ & $\begin{array}{c}\text { Average / } \\
\text { Peak } \\
\text { Bearing } \\
\text { Stress (\%) }\end{array}$ \\
\hline \multirow[t]{2}{*}{ FRP } & \multirow[t]{2}{*}{3.731} & 300,000 & "1119.3 & \multirow[t]{2}{*}{2.275} & 300,000 & 682.5 & \multirow{2}{*}{60.98} \\
\hline & & $1,500,000$ & 5596.5 & & $1,500,000$ & 3412.5 & \\
\hline \multirow[t]{2}{*}{ Steel } & \multirow{2}{*}{2.386} & 300,000 & 715.8 & \multirow[t]{2}{*}{1.752} & 300,000 & 525.6 & \multirow{2}{*}{73.43} \\
\hline & & $1,500,000$ & 3578.6 & & $1,500,000$ & 2628.0 & \\
\hline
\end{tabular}

Note: In Table 6.3, average bearing stresses were calculated for dowel with 1" distance from the face of joint. 


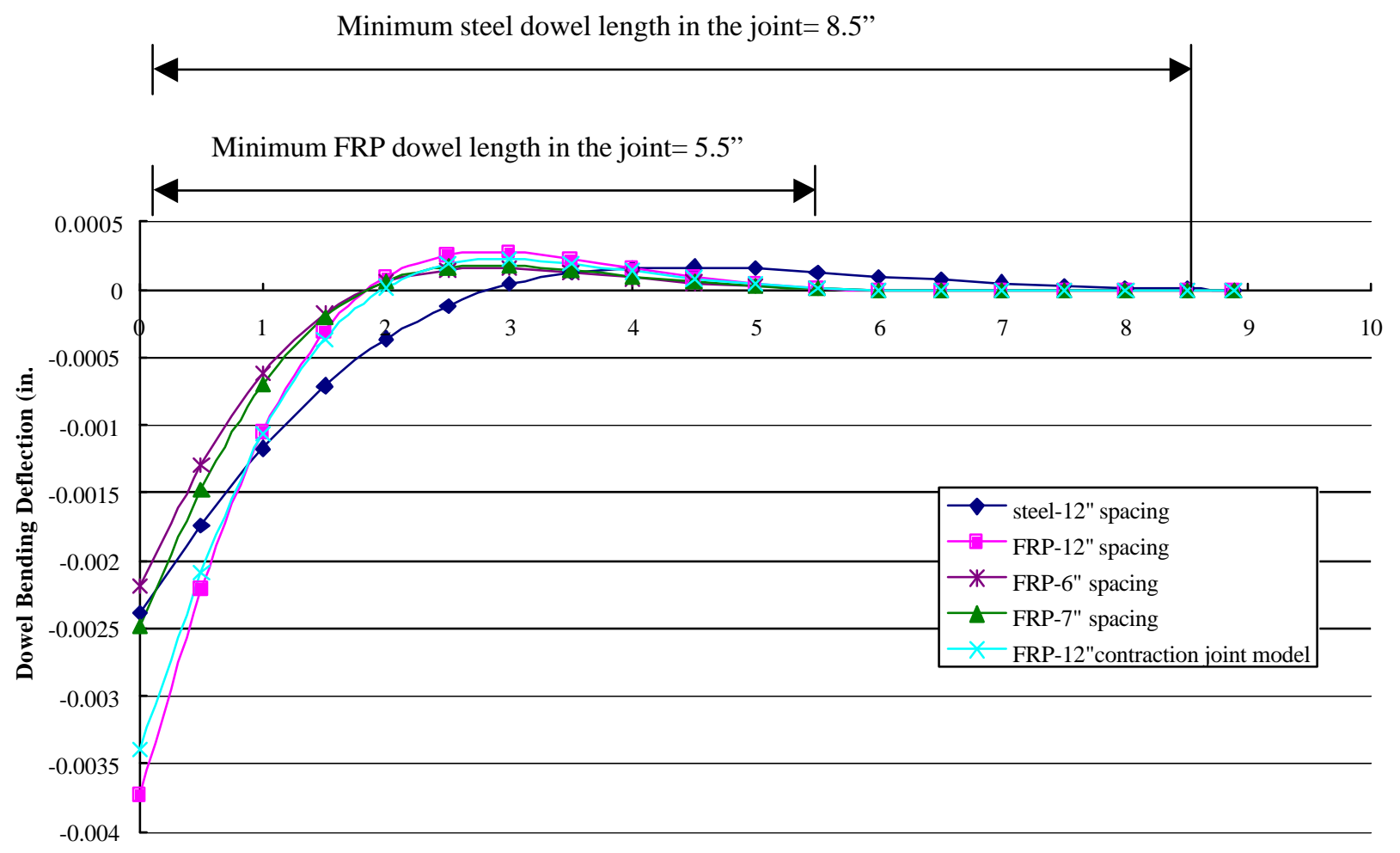

Figure 6.14 Dowel deflected shape (1.5\% diameter)

It can be found that, for dowel with 1.5 " diameter:

\section{Effect of Dowel Material}

- Equations 6.1 to 6.19 are primarily developed for concrete pavement with steel dowels. Theses equations do not take into account better stress distribution and stiffness match between FRP and concrete. For dowels with same spacing, currently used equations provide lower value of maximum dowel deflection $\left(y_{0}\right)$, dowel shear deflection $(\delta)$ and relative deflection $(\Delta)$ for slabs with steel dowels as compared to those with FRP dowels. But the bearing stress $\left(\sigma_{\mathrm{b}}\right)$ obtained from analytical evaluation need to be modified to apply on FRP dowel due to the lower stiffness of FRP over steel, thus leading to better stress distribution. 
- For same design spacing (12"), the maximum bending deflection $\left(y_{0}\right)$ of FRP dowel is $56 \%$ more than that from steel dowel (3.731 vs.2.386 milli-inch). But due to larger shear deflection, the total relative deflection of FRP dowels is 1.95 times the value from steel dowels (9.33 vs. 4.78 milli-inch). But, the total effective dowel number and load carried by corresponding dowels are same (refer to Table 6.1).

\section{Effect of Dowel Spacing}

- As per currently used equations to evaluate JPCP response to wheel load, FRP and steel dowels have identical values for Radius of Relative Stiffness, Number of Effective Dowels and critical dowel load for a particular spacing.

For example, pavement with 12" c/c FRP \& steel dowels having f'=4500 psi and joint width of 0.25 " will have identical $l_{r}(32.4180$ "), Number of Effective Dowels (1.89) and critical dowel load (4763.15 lbs).

- To evaluate wheel load response of JPCP, smaller dowel spacing design will result in same values for Radius of Relative Stiffness, larger value for Number of Effective Dowels and lower value for critical dowel load as compared to larger dowel spacing. For example, pavement with 6" c/c FRP and steel dowels having $\mathrm{fc}^{\prime}=4500 \mathrm{psi}$ and joint width of 0.25 " will have identical $l_{r}$ (32.42" vs. 32.42"), larger Number of Effective Dowel (3.22 vs.1.89) and lower critical dowel carried same load (2791.76 lbs. vs. 4763.15 lbs.) as compared to dowels with 12 " c/c spacing. 
- Only when spacings between FRP dowels (1.5" diameter) were reduced to less than 7" (refer to Table 6.1), dowel maximum bending deflection ( $\left.\mathrm{y}_{0}\right)$ $\left(2.481 \times 10^{-3}\right.$ in.) would be close to the value $\left(2.386 \times 10^{-3}\right.$ in. $)$ of steel dowels (1.5" diameter) with 12 " spacing.

\section{Effect of Joint Width}

- Shear deflection depends on joint width and is significant for FRP dowels. For example, when joint width $\mathrm{z}=0.25$ " with 12 " dowel spacing, shear deflection of FRP dowel $\delta$ ) was $1.872 / 9.33=20.06 \%$ of the total relative deflection. Shear deflection of steel dowel with 0.25 " joint width was only $0.15 \%$ $(0.007 / 4.78)$ of its total relative deflection. When joint width is reduced to 1/32" (FRP* case in Table 6.1), the shear deflection of FRP dowels is only $3.30 \%(0.234 / 7.10)$ as compared to $20.06 \%$ (refer to Table 6.1$)$.

- For same diameter (1.5") FRP dowels, contraction joint model will greatly reduce the shear effect of dowels. For example, relative deflection for joints with FRP dowel bars are greatly reduced (15.34 vs. 7.80 milli-inch) with joint width of $1 / 4$ " reduced to $1 / 32$ ".

\section{Effect of Dowel Length}

- Based on inflection points, (from Figure 6.14), minimum total length needed for steel dowel is $17 "(2 \times 8.5 ")$, whereas FRP dowel bars need minimum length of $11 "$ ( 2 x 5.5"). Required FRP dowel length is only $64.7 \%$ (11/17) of that of the steel dowel. 


\section{Effect on Bearing Stress}

- For a given set of pavement properties in terms of $f_{c}^{\prime}$, thickness, joint width, dowel diameter and spacing, pavement with FRP and steel dowel show significant difference in deflection and bearing stress value.

- Bearing stress around dowelconcrete (1.5" diameter) interface is only associated with maximum bending deflection. In order to meet bearing stress limit (3750 psi in this case) spacings for steel dowel (1.5" diameter) can not exceed 12" whereas spacing for FRP dowels (1.5" diameter) should not be more than 7" (expansion joint) or 7.5" (contraction joint).

- Peak bearing stress at joint location doesn't take into account the stiffness match between FRP dowel and concrete, which allows better distribution of bearing stress leading to reduced bearing stress concentration (Tables 6.2 and 6.3). Theoretical calculations indicate allowable stress is exceeded. However, for 1.5" diameter FRP dowel bars with 12" c/c spacing, average bearing stress is only $35.4 \%$ (distance from joint face to the first reflection point) and $60.98 \%$ (within 1" distance from joint face) of the peak bearing stress.

\subsubsection{Comparisons for 1.0" Diameter Dowel Bars}

After additional calculations it is found that in order to meet the bearing stress criteria by adjusting dowel spacing only, FRP dowel spacing should not exceed 3.7', but for practical purpose it will be adopted as 3.5". Detailed data are shown in Table 6.2. Other calculation results are also summarized in Table 6.4 . 
Table 6.4 Calculation Summaries for 1.0” Diameter Dowel $\left(k=400 p c i, f_{c}{ }^{\prime}=4500\right.$ psi)

\begin{tabular}{|c|c|c|c|c|c|c|c|c|}
\hline $\begin{array}{l}\text { Dowel } \\
\text { Material }\end{array}$ & $\begin{array}{c}\text { Spacing } \\
\text { (in.) }\end{array}$ & $\begin{array}{l}\text { Radius of } \\
\text { Relative } \\
\text { Stiffness } \\
l_{r} \text { (in.) }\end{array}$ & $\begin{array}{c}\text { Load } \\
\text { Carried by } \\
\text { Critical } \\
\text { Dowel } \\
\text { (lbs.) }\end{array}$ & $\begin{array}{c}\text { Effective } \\
\text { Dowel } \\
\text { Number }\end{array}$ & $\begin{array}{l}\text { Maximum } \\
\text { Deflection } \\
y_{0}\left(10^{-3} \mathrm{in} .\right)\end{array}$ & $\begin{array}{c}\text { Shear } \\
\text { Deflection } \\
\delta\left(10^{-3} \text { in. }\right)\end{array}$ & $\begin{array}{l}\text { Relative } \\
\text { Deflection } \\
\Delta\left(10^{-3} \mathrm{in} .\right)\end{array}$ & $\begin{array}{c}\text { Bearing } \\
\text { Stress } \\
\sigma_{\mathrm{b}}(\mathrm{psi})\end{array}$ \\
\hline FRP & 6 & 32.4180 & 2791.76 & 3.2237 & 4.479 & 2.468 & 11.43 & 6718.66 \\
\hline Steel & 6 & 32.4180 & 2791.76 & 3.2237 & 2.906 & 0.009 & 5.82 & 4358.36 \\
\hline FRP & 3.5 & 32.4180 & 1750.43 & 5.1416 & 2.808 & 1.548 & 7.16 & 4212.58 \\
\hline FRP $^{*}$ & 6 & 32.4180 & 2791.76 & 3.2237 & 4.020 & 0.309 & 8.35 & 6029.56 \\
\hline $\mathrm{FRP}^{* *}$ & 4 & 32.4180 & 1974.54 & 4.5580 & 2.843 & 0.218 & 5.90 & 4264.54 \\
\hline
\end{tabular}

(Note: Cases FRP* and FRP ${ }^{* *}$ are the calculations for dowel groups in Contraction Joint Model with joint width $z=1 / 32$ ". Shaded data indicate that bearing stress limit (4500 psi in this case) is satisfied.

Peak bearing stress at one location doesn't take into account the stiffness match between FRP dowel and concrete, which allows better distribution of bearing stress leading to reduced bearing stress concentration. Tables 6.5 and 6.6 described the detailed data. 
Table 6.5 Peak Bearing Stress and Average Bearing Stress in Dowel (1.0” diameter @ 6" c/c) Downward Area

\begin{tabular}{|c|c|c|c|c|c|c|c|}
\hline & $\begin{array}{c}\text { Maximum } \\
\text { Deflection } \\
y_{0}\left(10^{-3}\right. \\
\text { in. })\end{array}$ & $\begin{array}{l}\text { Modulus } \\
\text { of Dowel } \\
\text { Support } \\
\text { (pci) }\end{array}$ & $\begin{array}{c}\text { Peak } \\
\text { Bearing } \\
\text { Stress } \\
\text { (psi) }\end{array}$ & $\begin{array}{c}\text { Average } \\
\text { Deflection in } \\
\text { dowel } \\
\text { downward } \\
\text { bending area } \\
\left(10^{-3} \mathrm{in} .\right)\end{array}$ & $\begin{array}{l}\text { Modulus } \\
\text { of Dowel } \\
\text { Support } \\
\text { (pci) }\end{array}$ & $\begin{array}{c}\text { Average } \\
\text { Bearing } \\
\text { Stress } \\
\text { (psi) }\end{array}$ & $\begin{array}{c}\text { Average } \\
\text { / Peak } \\
\text { Bearing } \\
\text { Stress } \\
(\%)\end{array}$ \\
\hline \multirow[t]{2}{*}{ 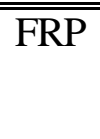 } & \multirow[t]{2}{*}{4.479} & 300,000 & 1343.7 & \multirow[t]{2}{*}{1.565} & 300,000 & 469.5 & \multirow{2}{*}{34.94} \\
\hline & & $1,500,000$ & 6718.5 & & $1,500,000$ & 2347.5 & \\
\hline \multirow[t]{2}{*}{ Steel } & \multirow{2}{*}{2.906} & 300,000 & 871.8 & \multirow[t]{2}{*}{1.159} & 300,000 & 347.7 & \multirow{2}{*}{39.88} \\
\hline & & $1,500,000$ & 4358.4 & & $1,500,000$ & 1739.1 & \\
\hline
\end{tabular}

Note: In Table 6.5, the downward dowel length of FRP and steel dowels ranges from 0" to 1.5 " and 0" to 2" (Fig. 6.15), respectively. Value of Modulus of Dowel Support ranges from 300,000 pci to 1,500,000 pci (Yoder and Witczak, 1975).

Table 6.6 Peak Bearing Stress and Average Bearing Stress within 1” Dowel (1.0” diameter @ 6" c/c) Length from Joint Face

\begin{tabular}{|c|c|c|c|c|c|c|c|}
\hline & $\begin{array}{c}\text { Maximum } \\
\text { Deflection } \\
y_{0}\left(10^{-3}\right. \\
\text { in.) }\end{array}$ & $\begin{array}{c}\text { Modulus } \\
\text { of Dowel } \\
\text { Support } \\
\text { (pci) }\end{array}$ & $\begin{array}{c}\text { Peak } \\
\text { Bearing } \\
\text { Stress } \\
\text { (psi) }\end{array}$ & $\begin{array}{c}\text { Average } \\
\text { Deflection } \\
\text { within 1.0" } \\
\text { inch distance } \\
\left(10^{-3} \mathrm{in} .\right)\end{array}$ & $\begin{array}{c}\text { Modulus } \\
\text { of Dowel } \\
\text { Support } \\
\text { (pci) }\end{array}$ & $\begin{array}{c}\text { Average } \\
\text { Bearing } \\
\text { Stress } \\
\text { (psi) }\end{array}$ & $\begin{array}{c}\text { Average } \\
\text { / Peak } \\
\text { Bearing } \\
\text { Stress } \\
(\%)\end{array}$ \\
\hline \multirow[t]{2}{*}{ FRP } & \multirow{2}{*}{4.479} & ב300,000 & "1343.7 & \multirow[t]{2}{*}{2.259} & 300,000 & "677.7 & \multirow{2}{*}{50.44} \\
\hline & & $1,500,000$ & 6718.5 & & $1,500,000$ & 3388.5 & \\
\hline \multirow[t]{2}{*}{ Steel } & \multirow[t]{2}{*}{2.906} & 300,000 & 871.8 & \multirow[t]{2}{*}{1.879} & 300,000 & 563.7 & \multirow{2}{*}{64.66} \\
\hline & & $1,500,000$ & 4358.4 & & $1,500,000$ & 2818.5 & \\
\hline
\end{tabular}

Note: In Table 6.6, average bearing stresses were calculated for dowel with 1" distance from the face of joint. 


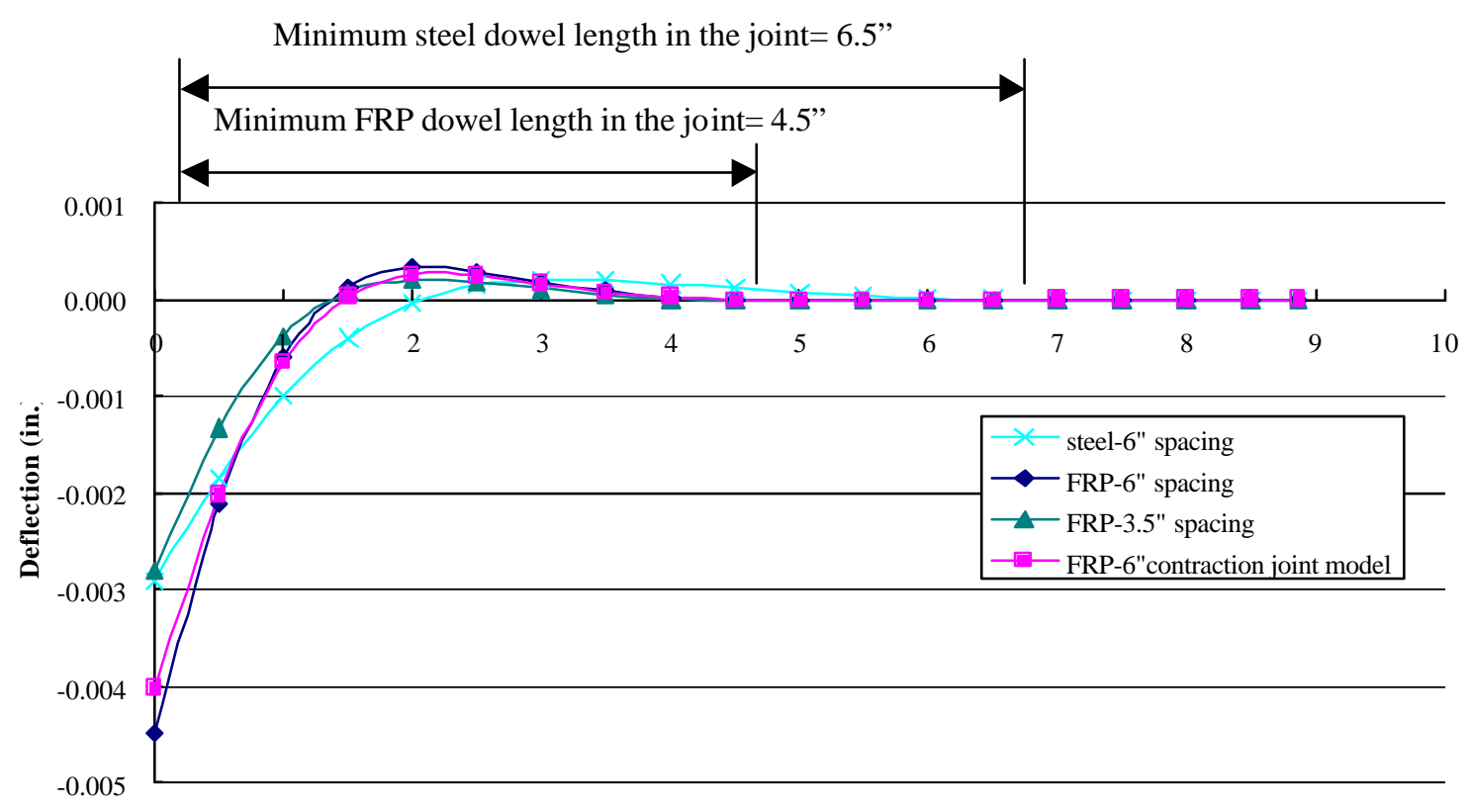

Figure 6.15 Dowel deflected shape

It can be found that, for dowel with 1.0" diameter:

\section{Effect of Dowel Material}

- Based on Equations 6.1 to 6.19 , for dowels with same spacing, steel dowels provide lower value of maximum dowel deflection $\left(y_{0}\right)$, dowel shear deflection $(\delta)$, relative deflection $(\Delta)$ and bearing stress $\left(\sigma_{\mathrm{b}}\right)$.

- For same design spacing (6"), the maximum bending deflection $\left(y_{0}\right)$ of FRP dowels is $54.03 \%$ more than those from steel dowels (4.479 vs.2.906 milliinch). But due to larger shear deflection the total relative deflection of FRP dowels is 1.96 times the value from steel dowels (11.43 vs.5.82 milli-inch).

\section{Effect of Dowel Spacing}

- As per currently used equations (Equations 6.1 to 6.19) to evaluate JPCP response to wheel load, FRP and steel dowels have identical values for Radius 
of Relative Stiffness, Number of Effective Dowels and critical dowel load for a particular spacing. For example, pavement with 6" c/c FRP and steel dowels having fc'=4500psi and joint width of 0.25 " will have identical $l_{r}$ (32.4180"), Number of Effective Dowel (3.2237) and critical dowel carried same load (2791.76 lbs.).

- To evaluate wheel load response of JPCP, smaller dowel spacing design will result in same values for Radius of Relative Stiffness, larger value for Number of Effective Dowels and lower value for critical dowel load as compared to larger dowel spacing. For example, pavement with 3.5 " c/c FRP and steel dowels having fc' $=4500 \mathrm{psi}$ and joint width of 0.25 " will have identical $l_{r}$ (32.4180" vs. 32.4180"), larger Number of Effective Dowel (5.1416 vs.3.2237) and lower critical dowel carried same load (1750.43 lbs. vs.2791.76 lbs.) as compared to dowels with 6" c/c spacing.

- Only when spacings between FRP dowels (1.0" diameter) were reduced to less than 3.5" (refer to Table 6.4), dowel maximum bending deflection $\left(\mathrm{y}_{0}\right)$ $\left(2.808 \times 10^{-3} \mathrm{in}\right.$.) is close to the value $\left(2.906 \times 10^{-3} \mathrm{in}\right.$.) of steel dowels $(1.5 "$ diameter) with 6" spacing.

\section{Effect of Joint Width}

- Shear deflection depends on joint width and is significant for FRP dowels. For example, when joint width $\mathrm{z}=0.25$ " with 6" dowel spacing, shear deflection of FRP dowel $(\delta)$ was $2.468 / 11.43=21.59 \%$ of the total relative deflection. Shear deflection of steel dowel with 0.25 " joint width was only $0.15 \%$ $(0.009 / 5.82)$ of its total relative deflection. When joint width is reduced to 
1/32" (FRP* case in Table 6.1), the shear deflection of FRP dowels is only $3.70 \%(0.309 / 8.35)$ as compared to $21.59 \%$ (refer to Table 6.2).

- For same diameter (1.0") FRP dowels, contraction joint model will greatly reduce the shear effect of dowels. For example, relative deflection for joints with FRP dowel bars are greatly reduced (11.43 vs. 8.35 milli-inch) with joint width of $1 / 4 "$ reduced to $1 / 32 "$.

\section{Effect of Dowel Length}

- Based on inflection points, (from Figure 6.15), minimum needed total length for steel dowel is 13 " (2x6.5"), but for FRP dowel bars the minimum length is 9" (2 x 4.5"). Required FRP dowel length is only $69.23 \%(9 / 13)$ of the required length of steel dowel.

\section{Effect on Bearing Stress}

- For a given set of pavement properties in terms of $f_{c}^{\prime}$, thickness, joint width, dowel diameter and spacing, pavement with FRP and steel dowel show significant difference in deflection and bearing stress value.

- Bearing stress around dowel-concrete (1.0" diameter) interface is only associated with maximum bending deflection. In order to meet bearing stress limit (4500 psi in this case) spacings for steel dowel (1.0" diameter) can not exceed 12" whereas spacing for FRP dowels (1.0" diameter) should not be more than 3.5" (expansion joint) or 4.0" (contraction joint).

- For 1.0" diameter FRP dowel bars with 6" c/c spacing, average bearing stress is only $34.94 \%$ (distance from joint face to the first reflection point) and 
$50.44 \%$ (within 1" distance from joint face) of the peak bearing stress (Tables 6.5 and 6.6).

\subsection{Comparison of Experimental vs. Theoretical Data}

Experimental test results from slabs having normal crack formation were compared with theoretical calculations. As per equations (Eqs. 6.1 to 6.19) used in this chapter, only relative deflection from static testing were compared in this report.

Table 6.7 Comparison of Experiments vs. Theory for Slab Relative Deflection in Static Testing Under HS25 Loading

\begin{tabular}{|c|c|c|c|c|}
\hline \multirow{2}{*}{ Slab } & \multicolumn{2}{|c|}{ Experimental Data $\left(10^{-3}\right.$ in.) } & \multicolumn{2}{|c|}{ Theoretical Data $\left(10^{-3}\right.$ in. $)$} \\
\hline & Static & $\begin{array}{l}\text { Fatigue at } 2 \\
\text { million cycles }\end{array}$ & $\mathrm{K}=1,500,000$ pci & $\mathrm{K}=300,000$ pci \\
\hline $\begin{array}{c}\text { \#1 (FRP dowel, 1.0” } \\
\text { @6”c/c) }\end{array}$ & 2.27 & 12.8 & 11.43 & 31.26 \\
\hline $\begin{array}{c}\text { \#4 (FRP dowel, 1.5” } \\
\text { @ } 12 " \text { c/c) }\end{array}$ & 29 & 25 & 9.33 & 26.07 \\
\hline $\begin{array}{c}\text { \#5 (steel dowel, 1.5" } \\
\text { @ } 12 " \mathrm{c} / \mathrm{c})\end{array}$ & 11 & 11 & 4.78 & 15.7 \\
\hline
\end{tabular}

It was found that

1. For static testing, relative deflection obtained in concrete slabs (\#4) with large FRP dowel spacing (12") in laboratory tests were larger than that from theoretical calculations. But slab \#1 with two FRP dowel bars and small spacing (6") had smaller relative deflection than that from theory (refer to Table 6.7). 
2. After 2 million fatigue load cycles, relative deflection of all these three slabs were within the theoretical relative deflection range calculated by using modulus of dowel support $\mathrm{K}$ from 300,000 to $1,500,000$ pci.

3. The assumption of analytical models do not consider the boundary condition of elastic foundation; in our laboratory tests, both ends of concrete slabs were not constrained, thus during the testing, both ends were slightly lifted up. Also, the assumed "s" shape (Figure 6.6) for deformation of dowel bars under loading may be more like " $v$ " shape for unrestrained slabs. Additional tests are necessary to correlate laboratory deflection to analytical evaluations.

\subsection{Analytical Investigation with Respect to FRP Dowel-Concrete Bearing Stress}

More extensive analytical investigation for FRP dowelconcrete bearing stress was conducted. More parameters were considered for analysis, by using constant values of FRP dowel material properties.

1) Concrete strength $f_{c}^{\prime}: 3000 \mathrm{psi}, 3500 \mathrm{psi}, 4000 \mathrm{psi}$, and $4500 \mathrm{psi}$

2) Concrete pavement thickness $h: 10 ", 11$ " and 12"

3) Concrete joint width z: $0.25 ", 0.125$ "

4) Dowel length: 12", 18" and 24"

5) Dowel diameter $d: 1 ", 1.25 ", 1.5 ", 1.75 "$ and 2"

6) Elasticity modulus of Dowel $E_{d:} 5.5 \times 10^{6} \mathrm{psi}$ and $6 \times 10^{6}$

7) Shear Modulus of Dowel $G: 0.4 * 10^{6} \mathrm{psi}$

8) Dowel spacing $b: 6 ", 8 ", 0$ and 12"

9) Modulus of subgrade reaction $k: 100,400$ and $800 \mathrm{pci}$ 
Modulus of subgrade reaction is a measure of the strength of the supporting soil, which may be the sub-base or the subgrade. Its value is given in pounds per square inch per inch deflection.

10) Modulus of dowel support K: 1,500,000 pci

Following are some of the simplified conclusions drawn based on the theoretical analysis using above parameters:

1) Bearing Stress $\left(\sigma_{b}\right)$ can be reduced

\section{By increasing:}

- Dowel diameter (d)

- Pavement slab thickness (h)

- Concrete strength $\left(f_{c}^{\prime}\right)$

\section{By decreasing:}

- Dowel spacing (b)

- Joint width (z)

- Modulus of subgrade reaction $(k)$

- Modulus of dowel support (K)

2) Bearing Stress $\left(\sigma_{b}\right)$ cannot be significantly affected by the dowel length beyond certain length, for FRP dowels, this length is $64.7 \%$ and $69.23 \%$ of steel dowels for $1.5 "$ and $1.0 "$ dowels respectively.

3) Allowable bearing stress $\left(f_{b}\right)$ can be increased by:

- Decreasing the dowel diameter (d)

- Increasing concrete strength (fc') 


\section{Chapter 7}

\section{CONCLUSIONS AND RECOMMENDATION}

\subsection{Introduction}

In this research, FRP dowel bars with 1.5" and 1.0" diameter spaced at different intervals as load transferring devices in JPCP were evaluated under static and fatigue loads corresponding to HS-25 trucks. Their responses were compared with JPCP consisting of steel dowels under laboratory and field conditions. Performance of JPCP rehabilitated with FRP and steel dowels was also evaluated.

Analysis and discussions corresponding to experimental results and theoretical calculations are summarized in this chapter.

\subsection{Conclusions for Laboratory Tests}

Laboratory evaluations were carried out on contraction joints (Figure 6.11) with FRP and steel dowels, similar to field implementation. During laboratory tests, crack formations were noted right under the joint (refer to as proper crack formation, Figure 4.1 Chapter 4) or away from the joint near dowel edges (Figures 4.2 and 4.3). Proper crack formation at joint location was noted in slab \#1 (6" c/c spacing for 1.0" diameter FRP dowel), slab \#4 (12" c/c spacing for 1.5” diameter FRP dowel) and slab \#5 (12" c/c spacing for 1.5" diameter steel dowel).

Crack formation at locations away from joint and close to the edge of dowel end was observed in slabs \#2 (6" c/c spacing for 1.0" diameter for steel dowel) and \#3 (6" c/c spacing for 1.5 " diameter for steel dowel).

Results are mainly focused upon slabs with proper crack formation at the middle joint. Conclusion on laboratory tests are provided with respect to: 
- Relative Deflection

- $\quad$ Load Transfer Efficiency (LTE)

- Pavement Pumping

- Strains on Dowels

\subsubsection{Joint Relative Deflection}

For Specimens (\#1, \#4 and \#5) Having Proper Crack Formation at Joint Location (Table $\underline{4.1)}$

1. For static testing, relative deflection had decreased by decreasing dowel bar diameter and spacing (0.00227", i.e., 1.0" diameter @ 6" c/c vs. 0.029" for 1.5" diameter FRP dowel @12” c/c spacing).

2. Relative deflection for slabs \#4 reduced (0.029" to $0.025 ")$ with progression of fatigue load from 0 to 2 million cycles. Relative deflection for slab \#5 remained same (0.011"). This is attributed partly to compaction/settlement of aggregate base underneath the pavement slabs with increasing fatigue cycles, resulting in smaller relative deflection. It can also be attributed to similarities in stiffness between FRP ( $5.5 \times 10^{6}$ psi) and concrete $\left(3.8 \times 10^{6}\right.$ psi). Benefits of these reductions may be more evident with freeze-thaw variations.

3. In static tests (Table 4.10), relative deflection in slab \#1 with two 1.0" diameter FRP dowel had low relative deflection (0.00227") corresponding to HS25 loading. Analytical values for relative deflection were found to be larger than experimental value (0.0084" for contraction joint and 0.01143 " for expansion joint).

4. In static tests (Table 4.13), slab \#4 with 1.5" diameter FRP dowel had a larger relative deflection (0.0029") than slab \#5 with 1.5" diameter Steel dowel (0.011") 
where the ratio of relative deflections was $2.64(0.029 / 0.011)$ corresponding to HS-25 loading.

For Specimens Having Crack Formation Away From Joint Location (Table 4.1)

Slightly larger relative deflection were noted under static tests (Table 4.10) for slab \#2 (1.0" steel dowel) and slab \#3 (1.5" FRP dowel) due to crack formation at dowel edges. In addition to higher relative deflection, the load transferred by dowels is less due to that crack formation.

$\underline{\text { For Base Material Properties (Table 4.1) }}$

Experimental results on relative deflection are sensitive to supporting base stiffness (k). During our tests, base property (modulus of subgrade reaction, $\mathrm{k}$ ) value changed from 400pci to 800 pci after 5 million fatigue cycles were applied on slab \#4. Relative deflection is expected to increase due to increase in value of subgrade reaction $\mathrm{k}$. 


\subsubsection{Joint Load Transfer Efficiency (LTE)}

AASHTO (1993) characterizes Load Transfer Efficiency (LTE) value $>70 \%$ as "very good". APCA (1991) suggested 75\% of Joint Effectiveness (E) as sufficient for heavy traffic load, which corresponds to 60\% of LTE as defined by AASHTO.

\section{For Specimens (\#1, \#4 and \#5) Having Proper Crack Formation at Joint Location}

1. In static tests, all slabs provided good Load Transfer Efficiency (LTE), which was greater than AASHTO and APCA requirements. Slab \#1 (1.0" diameter FRP dowel with 6" c/c spacing) had a >90\% Load Transfer Efficiency. Both slabs \#4 (1.5" diameter FRP dowel with 12" c/c spacing) and \#5 (1.5" diameter steel dowel with 12 " c/c spacing) had LTE more than $88 \%$.

2. At the $2^{\text {nd }}$ million cycles, LTE was found to be $93.79 \%$ when 1.5 times design load (HS25 loading) was applied for slab \#1 (1.0" diameter FRP dowel @ 6" c/c spacing) after finishing 1 million fatigue cycles. Later an increased joint width (increased from 0.25 " to 0.4 ") after 2 million cycles was considered, the observed TLE in slab \#1 reduced from $93.79 \%$ to $71.57 \%$, but it was still higher than $60 \%$ of LTE (corresponding to $75 \%$ of joint effectiveness, E) (ACPA).

3. In fatigue tests, slab \#4 provided good load transfer efficiency $>80.5 \%$ after 5 million fatigue load cycles when base surface and base material under this slab remained good condition. When base aggregates were crushed and some of the aggregates were pushed outside of the slab-base contact area (poor base condition), LTE were found to be decreased to about 55\%, but they were still around $92.1 \%$ of the $60 \%$ LTE, which corresponds to the ACPA recommended value on joint effectiveness, E, 75\%. Detailed data were shown in Figure 4.26. 
4. At 2 million cycles, slab \#4 containing FRP dowel provided slightly lower LTE (85.1\% vs. $90.21 \%$ ) than slab \#5 containing STEEL dowel up to cycles (Table 4.17). But with poor base condition (as defined in bullet 3), LTE of slab with FRP dowel over STEEL dowel was $(50.71 \%$ vs. $90.21 \%)$. The most possible reason caused low LTE was the poor base condition. It should be noted that the modulus of subgrade reaction, $\mathrm{k}$ was found changed from 400 pci to 800 pci after 5 million cycles.

5. Compaction of base was noted especially under loaded side of slab during the tests, which will create slight concave surface under the slab, possibly leading to reduction in LTE. It is suggested to check the base property such as ( $k$, modulus of subgrade reaction) before and after each fatigue test.

For Specimens Having Crack Formation Away Joint Location (Table 4.1)

Due to the crack formation, Load Transfer Efficiencies from slabs \#2 (1" diameter steel dowel with 6" spacing) and \#3 (1.5" diameter FRP dowel with 6" spacing) were slightly lower than that from Slab\#1 in static tests (Table 4.14).

\subsubsection{Investigation of Pavement Pumping Problem}

1. Load Transfer Efficiencies (LTEs) were observed in cases investigated for simulated pavement pumping problem with supporting base removal up to certain length near the joint (Figs.4.30 and 4.33). LTEs were not less than the LTEs obtained from intact base condition (Table 4.16). However, under fatigue load 
cycles LTE is expected to reduce significantly for specimens without support near joint.

2. LTE obtained in test case two (1 ft. Base Material Removal under Both Sides of Slabs) was greater than $90 \%$ at 3 kips loading, and after loading exceeded 3 kips, two joint faces would bear against each other. Thus Case Two $(1 \mathrm{ft}$. base removal under both slabs) with unsupported slab areas on both sides of the slab was more detrimental than Case One ( $2 \mathrm{ft}$. base removal under loaded slab).

\subsubsection{Strains on Dowels}

Strain values at unloaded side of dowel during static tests from slabs \#1 and \#5 were 513.04 and 376.43 micro-strains, respectively. Both values were less than those from analytical evaluation (ranges from 1000 to 1200 micro-strains)(Appendix C). But strain values are typically not used for LTE calculation.

\subsection{Conclusions for Field Applications and Test Results}

\subsubsection{Conclusions for FRP Dowels Used for New Highway Pavement Construction}

1. Effect of dowel spacing

- For dowel groups in pavement joints 2 and 3 that have same dowel diameter (1.5"), joint 2 with smaller dowel spacing (9") had higher Load Transfer Efficiency (94\%) than that provided by joint 3 with 12" dowel spacing $(81.58 \%)$.

- Joint 2 (with 1.5" diameter and 9" spacing) had smaller Relative Deflection $\left(0.25 \times 10^{-3}\right.$ in.) than joint 3 with same diameter bar and 12 " spacing $(0.70 \mathrm{x}$ $10^{-3}$ in.). 
- Joint 2 (1.5" of diameter and 9" of spacing) provided 15.4\% increase in Load Transfer Efficiency (LTE) in addition to $64.3 \%$ reduction in Relative Deflection than Joint 3 (1.5" of diameter and 12" of spacing), refer to Table 5.5.

- Pavement joint 5 and 6 (with 1.0" dowel diameter, 8.0" and 6.0" dowel spacing, respectively), the Load Transfer Efficiencies were very close (95\% and $94.44 \%)$. Relative joint deflections were also identical $\left(1 \times 10^{-3}\right.$ in.).

- For JPCP with 1.0" or 1.5" FRP dowels, larger dowel spacings of 12" (for 1.0" diameter dowel) or 8" (for 1.0" diameter dowel) resulted in higher dowel strains compared t those with 9" or 6" spacing (for 1.5" diameter dowel and 1.0" diameter dowel respectively) under AASHTO Type-3 truck loading.

i. For example, For FRP dowels (A1 and A2) with 1.5" diameter, dowel A2 with larger spacing (12") had bigger strain change of $31 \mu \mathrm{s}$ than dowel A1 with 9" spacing that had a strain change of $9 \mu \mathrm{s}$. Similarly, for FRP dowels C5 and C6 with same 1.0"diameter, the dowel C5 with smaller spacing (6") showed small strain change ( $3 \mu$ s vs. $60 \mu$ s) compared to C6 with 8 " dowel spacing.

ii. Decreasing the spacing by $25 \%$ (12" to 9" and 8" to 6") resulted in more number of dowels sharing the load within radius of relative stiffness $\left(l_{r}\right.$, Section 6.2.1) leading to $30 \%$ or higher strain reductions in dowels.

- For FRP dowels with 1.0" diameter (C5 and C6), spacing increase from 6" to 8" had higher influence on strain value change (3 $\mu$ s vs. $60 \mu$ s) than the increase of spacing from 9" to 12" in dowels (A1 and A2) with 1.5 diameters (9 $\mu$ s vs. $31 \mu s)$.

- Dowels with different diameters and spacing cannot be compared with one another based on only strain value. Because FRP dowels act as a group, 
spacing and diameter are both important factors for the group action. It should be also noted that FRP dowel with smaller diameter typically have better mechanical properties per unit area than larger diameter dowels due to shear lag effects. (Refer to Chapter 6, Section 6.2.1).

2. Effect of dowel diameter

Both 1.5" diameter FRP dowel group and 1.0" diameter FRP dowel group with spacing varying from 12" to 6" provided very good Load Transfer Efficiency (81\% and higher) greater than LTE of $60 \%$, which is corresponding to ACPA's $75 \%$ Joint Effectiveness (E) value.

3. Currently, there is no requirement or limitation for the Relative Deflection from AASHTO's Guide for Pavement Design. From field tests the maximum Relative

Deflection was $0.70 \times 10^{-3}$ in. corresponding to AASHTO Type-3 truck loading, but for laboratory test maximum value was $43 \times 10^{-3}$ in. (Table 4.11) corresponding to HS-25 loading. It should be noted that joint width due to different joint models (contraction vs. expansion joint models) and thermal variables also affect field LTE values.

\subsubsection{Conclusions for FRP Dowels Used for Pavement Rehabilitation}

Pavement rehabilitation was successfully carried out using FRP dowels near junction of Rts. 119 and 857, University Avenue, Morgantown, WV. After one year of rehabilitation, this pavement is performing well without any pavement distress. Strain were monitored on this pavement where has one of the busiest traffic in Morgantown, WV. 
1. Strains at loaded and unloaded status from FRP dowels (A and B) (28.17 $\mu$ s and $36.24 \mu \mathrm{s})$ were greater than those from Steel dowel (C) $(11.49 \mu \mathrm{s})$, which conforms analytical finding of shorter FRP dowel length required than steel dowel and higher deflection in FRP dowel (refer to Fig. 6.14).

2. The strain value ratio from same gage at unloaded status to loaded status does not represent proper measure of load transfer efficiency. It is suggested that Load Transfer Efficiency should be calculated from pavement deflection measurement.

\subsection{Conclusions for Analytical Evaluation}

Calculations have been carried out for two dowel diameters (1.5-inch diameter and 1.0-inch diameter) for both FRP and steel dowels. In those calculations, base modulus of subgrade reaction $\mathrm{k}=400 \mathrm{pci}, \mathrm{f}^{\prime}=4500 \mathrm{psi}$, other parameters considered for calculation are listed in examples 6.1 to 6.4 .

\subsubsection{Conclusions for 1.5" Diameter Dowel with 12" c/c Spacing Effect of Dowel Material}

- Based on current equations, for dowels with same spacing, steel dowels provide lower value of maximum dowel deflection $\left(y_{0}\right)$, dowel shear deflection $(\delta)$, relative deflection $(\Delta)$ and bearing stress $\left(\sigma_{\mathrm{b}}\right)$ as compared to FRP dowels.

- For same design spacing (12"), the maximum bending deflection $\left(y_{0}\right)$ of FRP dowels is $56 \%$ more than those from steel dowels (3.731 vs.2.386 milli-inch). But due to larger shear deflection, the total relative deflection of FRP dowels is 1.95 times the value from steel dowels (9.33 vs. 4.78 milli-inch). 


\section{Effect of Dowel Spacing}

- Currently used equations to evaluate JPCP response to wheel load do not include dowel material properties. Radius of Relative Stiffness, Number of Effective Dowels and critical dowel load remain identical for FRP and steel dowels for a given spacing.

i. For example, pavement with 12 " c/c FRP \& steel dowels having $\mathrm{f}_{\mathrm{c}}{ }^{\prime}=4500 \mathrm{psi}$ and joint width of 0.25 " will have identical $l_{r}$ (32.4180"), Number of Effective Dowels (1.89) and critical dowel load (4763.15 lbs).

- As per currently used equations to evaluate JPCP response to wheel load, smaller dowel spacing design will result in same values for Radius of Relative Stiffness, larger value for Number of Effective Dowels and lower value for critical dowel load as compared to a larger dowel spacing.

i. For example, pavement with 6" c/c FRP and steel dowels having fc' $=4500$ psi and joint width of 0.25 " will have identical $\operatorname{lr}(32.4180$ " vs. 32.4180 ” ), larger Number of Effective Dowel (3.2238 vs.1.8895) and lower critical dowel carried same load (2791.76 lbs. vs. 4763.15 lbs.) as compared to dowels with 12 " c/c spacing.

- Spacings between FRP dowels (1.5" diameter) less than 7" provided dowel maximum dowel bending deflection $\left(\mathrm{y}_{0}\right)\left(2.481 \times 10^{-3}\right.$ in. $)$ that close to the value $\left(2.386 \times 10^{-3}\right.$ in.) provided by steel dowels with 1.5 " diameter and 12 " spacing (refer to Table 6.1). 


\section{Effect of Joint Width}

- Shear deflection depends on joint width and is significant for FRP dowels.

i. For example, when joint width $\mathrm{z}=0.25$ " with 12 " dowel spacing, shear deflection of FRP dowel ( $\delta$ ) was $1.872 / 9.33=20.06 \%$ of the total relative deflection. Shear deflection of steel dowel with 0.25 " joint width was only $0.15 \%(0.007 / 4.78)$ of its total relative deflection. When joint width is reduced to 1/32" (FRP* case in Table 6.1), the shear deflection of FRP dowels is only $3.30 \%(0.234 / 7.10)$ as compared to $20.06 \%$ with 0.25 " joint width (refer to Table 6.1).

- For same diameter (1.5") FRP dowels, contraction joint model will greatly reduce the shear effect of dowels.

i. For example, relative deflection for joints with FRP dowel bars are greatly reduced (15.34 vs. 7.80 milli-inch) with joint width of 1/4" reduced to $1 / 32$ ".

\section{Effect of Dowel Length}

- Required FRP dowel length for 1.5 " diameter is only $64.7 \%(11 / 17)$ of that of steel dowel with same diameter. Based on inflexion points (Figure 6.14), minimum total length needed for steel dowel is 17 " $(2 \times 8.5$ "), whereas FRP dowel bars need $11 "(2 \times 5.5 ")$.

\section{Effect on Bearing Stress}

- For a given set of pavement properties in terms of $f^{\prime}$, thickness, joint width, dowel diameter and spacing, pavement with FRP and steel dowel show significant differences in deflection and bearing stress value.

- For current analytical models, bearing stress around dowel-concrete (1.5" diameter) interface is only associated with maximum bending deflection. In order to meet bearing stress limit (3750 psi in this case) spacings for steel 
dowel (1.5" diameter) can not exceed 12" whereas spacing for FRP dowels (1.5" diameter) should not be more than 7" (expansion joint) or 7.5" (contraction joint) (refer to Table 6.1).

- Peak bearing stress at joint location doesn't take into account the stiffness match between FRP dowel and concrete, which allows better distribution of bearing stress leading to reduced bearing stress concentration. Theoretical calculations indicate allowable stress is exceeded. However, for 1.5 " diameter FRP dowel bars with 12 " c/c spacing, average bearing stress is only $35.4 \%$ (distance from joint face to the first inflexion point) and $60.98 \%$ (within 1" distance from joint face) of the peak bearing stress (Tables 6.2 and 6.3).

- Bearing Stress $\left(\sigma_{b}\right)$ can be reduced by increasing dowel diameter (d), pavement slab thickness $(\mathrm{h})$, and concrete strength $\left(f_{c}^{\prime}\right)$ or by decreasing dowel spacing (b), joint width (z), modulus of subgrade reaction $(k)$, modulus of dowel support $\left(\mathrm{K}_{0}\right)$

\subsubsection{Conclusions for 1.0" Diameter Dowel with 6" c/c Spacing Effect of Dowel Material}

- For same design spacing (6"), the maximum bending deflection $\left(y_{0}\right)$ of FRP dowels is $54.03 \%$ more than those from steel dowels (4.479 vs.2.906 milliinch). But due to larger shear deflection the total relative deflection of FRP dowels is 1.96 times the value from steel dowels (11.43 vs.5.82 milli-inch). 


\section{Effect of Dowel Spacing}

- Trends of the effect of dowel spacing were found to be similar to that of 1.5 " diameter FRP dowel bars.

- Spacings between FRP dowels (1.0" diameter) less than 3.5" provided dowel maximum bending deflection $\left(\mathrm{y}_{0}\right)\left(2.808 \times 10^{-3}\right.$ in.) that close to the value $\left(2.906 \times 10^{-3}\right.$ in.) of steel dowels (1.5" diameter) with 6" spacing (refer to Table 6.4).

\section{Effect of Joint Width}

- Shear deflection depends on joint width and is significant for FRP dowels.

i. For example, when joint width $\mathrm{z}=0.25$ " with 6" dowel spacing, shear deflection of FRP dowel $(\delta)$ was $2.468 / 11.43=21.59 \%$ of the total relative deflection. Shear deflection of steel dowel with 0.25 " joint width was only $0.15 \%(0.009 / 5.82)$ of its total relative deflection. When joint width is reduced to 1/32" (FRP* case in Table 6.1), the shear deflection of FRP dowels is only $3.70 \%(0.309 / 8.35)$ as compared to $21.59 \%$ (refer to Table 6.2).

- For same diameter (1.0") FRP dowels, contraction joint model will greatly reduce the shear effect of dowels.

i. For example, relative deflection for joints with FRP dowel bars are greatly reduced (11.43 vs. 8.35 milli-inch) with joint width of 1/4" reduced to 1/32”.

\section{Effect of Dowel Length}

- Required FRP dowel length for 1.0" diameter is only $69.23 \%(9 / 13)$ of the required length of steel dowel with same diameter. Based on inflexion points (Figure 6.15), minimum total length for steel dowel is 13 " (2x6.5"), whereas for FRP dowel is 9" (2 x 4.5"). 


\section{Effect on Bearing Stress}

- In order to meet bearing stress limit (4500 psi in this case) spacings for steel dowel (1.0" diameter) should be limited to 12 " whereas spacing for FRP dowels (1.0" diameter) should not be more than 3.5" (expansion joint) or 4.0" (contraction joint) (Table 6.4).

- For 1.0" diameter FRP dowel bars with 6" c/c spacing, average bearing stress is only $34.94 \%$ (distance from joint face to the first reflection point) and $50.44 \%$ (within 1" distance from joint face) of the peak bearing stress (Tables 6.5 and 6.6). Hence, based on stress redistribution, peak bearing stress doesn't appear to have damaged concrete surface.

\subsection{General Conclusions from This Research}

1. In this research, FRP dowels were found to be good alternative s to traditional steel dowels for transferring joint loads in JPCP pavements. Joints with FRP dowels provided adequate Load Transfer Efficiency exceeding the values recommended by AASHTO (75\%) and ACPA (60\%) in both laboratory tests and field tests.

2. FRP dowel-concrete interfaces in slab \#1 and slab \#4 after 5 million HS25 load cycles were found to be in excellent condition with no visible damage, microcrack or separation between FRP dowel and surrounding concrete (refer to Figures 4.19 and 4.27).

3. Stiffness match between FRP dowel and concrete leads to comparable FRP dowel flexing under joint loads leading to shorter FRP dowel length. Required length of FRP dowel with 1.5 " diameter is $64.7 \%$ of that for steel dowel with 
same diameter. Required length of FRP dowel with 1.0" diameter is $69.23 \%$ of that for steel dowel with same diameter.

4. Under static loading test, slab with smaller diameter FRP dowel and smaller spacing provided lower relative deflection than FRP dowels with larger diameter and spacing. During fatigue load cycles up to 5 million, relative deflection from slab \#1 with smaller diameter and spacing of FRP dowel appeared to increase (0.0128" to $0.0803 "$ from 2 million cycles to 5 million cycles with joint width 0.4"), whereas relative deflection from slab \#4 with larger diameter and spacing of FRP dowel appeared to decrease $32 \%(0.025 "$ to 0.017 " from 2 million cycles to 5 million cycles with joint width 0.25 ').

5. Load Transfer Efficiency from slab with smaller diameter and spacing (1" @ 6”) of FRP dowel was found to be sufficient $(71.57 \%$, when increased joint width of 0.4 " and higher loading of $1.5 \times \mathrm{HS} 25$ were considered) after 5 million load cycles as per AASHTO (70\% of LTE) and ACPA (75\% of E or $60 \%$ of LTE) suggested values. When good base condition was provided during 5 million loading cycles, slab with 1.5 " diameter and 12 "spacing of FRP dowel provided good LTE (greater than 80.5\%). However, with poor base condition (aggregate movement leading to concave surface under the slab) the LTE was reduced to $55.26 \%$ (which is $92.1 \%$ of $60 \%$ LTE that corresponds to the ACPA recommended value on Joint Effectiveness, $\mathrm{E}=75 \%$ ). Hence, it is very important to have proper slab casting procedure and compacted aggregate base.

6. LET affects the slab integrity and slab stresses, whereas relative deflection affects ride comfort and impact on slab at joints. It is important to consider both 
relative deflection and Load Transfer Efficiency when the performance of JPCP is evaluated. For example, at 5 million cycles, slab \#4 with 1.5 " diameter FRP dowel spaced at 12" c/c had 55.26\% LTE, but its relative deflection (0.017") was less than that of the slab \#1 with 1.0" diameter FRP dowel with 71.6\% LTE spaced at 6" c/c (0.0803").

7. FRP dowel can be used as effective alternatives for construction and rehabilitation of JPCP under highway traffic with advantages of corrosion resistance and decreased maintenance. Long-term performance evaluation of JPCP with FRP dowels is being continued by CFC-WVU.

\subsection{Recommendations}

1. More number of laboratory specimens are recommended to be tested for establishing possible ranges of Load Transfer Efficiency and Relative Deflection values for different diameter, spacing and length of dowel.

2. Further investigate crack formation location by using increased FRP dowel length including deflection shapes.

3. Evaluate actual dowel bar deflected shapes in the slab under different base removal conditions.

4. Evaluate effect of peak bearing stress and average bearing stress on dowel/concrete interface.

5. Evaluate effect of Fiber Volume Fraction on dowel behavior including shear properties that affect joint load transfer efficiency and relative deflection.

6. Evaluate durability of FRP dowel.

7. Utilize Finite Element Modeling to envision stress field in the concrete pavement.

8. Continue long-term field monitoring. 


\section{REFERENCES}

1. Vijay, P.V. and GangaRao, H.V.S., "Development of Fiber Reinforced Plastics for Highway Applicatioin: Aging Behavior of Concrete Beams Reinforced with GFRP bars”, CFC-WVU Report No.99-265 (WVDOH RP \#T-699-FRP1), 1999.

2. Timoshenko, S. and J.M. Lessels, “Applied Elasticity”, Westinghouse Technical Night School Press, Pennsylvania, 1925.

3. American Concrete Pavement Association (ACPA), "Design and Construction of Joints for Concrete Highways", ACPA, Skokie, Illinois, 1991.

4. American Association of State Highway and Transportation Officials (AASHTO), "AASHTO Guide for Design of Pavement Structures", AASHTO, Washington, D.C., 1993.

5. Huang, Y.H., "Pavement Analysis and Design", Prentice Hall, Inc., New Jersey, 1993.

6. Friberg, B.F., "Design of Dowels in Transverse Joints of Concrete Pavements", Transactions, American Society of Civil Engineers. Vol. 105, No. 2081, 1940.

7. Yoder, E.J. and M.W. Witczak, "Principles of Pavement Design", $2^{\text {nd }}$ ed. John Wiley \& Sons, Inc., New York, 1975.

8. Westergaard, H.M., "Computation of Stresses in Concrete Roads", Proceedings, $5^{\text {th }}$ Annual Meeting of the Highway Research Board, Washington, D.C., 1925.

9. Tabatabaie, A.M., E.J. Barenburg, and R.E. Smith., "Longitudinal Joint Systems in Slipformed Rigid Pavements", Vol. II-Analysis of Load Transfer Systems for 
Concrete Pavements. Report No. DOT/FAA.RD-79/4, Federal Aviation administration, U.S. Department of Transportation, 1979.

10. Max L. Porter, Robert J. Guinn Jr., Andrew L. Lundy, Dustin D. Davis, John G. Rhner, "Investigation of Glass Fiber Composite Dowel Bars For Highway Pavement Slabs", Project No. TR-408, Iowa State University, 2001.

11. Albertson, M.D., "Fiber composite and Steel Pavement Dowels", Masters Thesis. Iowa State University, 1992.

12. Max 1. Porter, Robert J. Guinn Jr., "Assessment of Dowel Bar Research", Iowa DOT Project HR-1080, Center for Transportation Research and Education, Iowa State University, 2002.

13. Eddie, D., Shalaby, A., Rizkalla, S., "Glass Fiber-Reinforced Polymer Dowels for Concrete Pavements", American Concrete Institute Structural Journal, vol. 98, no. 2, March-April, 2001.

14. Ahmed, S., Scott M., 'Using Fiber-Reinforced Polymer Load Transfer Devices in Jointed Concrete Pavements", $7^{\text {th }}$ International Conference on Concrete Pavements - Orlando, Florida, USA- September 9-13, 2001.

15. Ambroz, J., "Dowel Bars for You, Me, and PCC", American Highway Technology, http://www.americanhighwaytechnology.com/loadtransfer/loadtransfer.html

16. American Association of State Highway and Transportation Officials (AASHTO), "Standard Specifications for Highway Bridges", $15^{\text {th }}$ ed., AASHTO, Washington, DC., 1992. 
17. V. L. Brown and C. L. Bartholomew, "FRP Dowel Bars in Reinforced Concrete Pavements", 1993.

18. Advisory Circular, Federal Aviation Administration, U.S. Department of Transportation, AC No: 150/5320-6D.

19. American Standard for Testing and Materials (ASTM), “Annual Book of ASTM Standards, Concrete and Aggregates, Vol. 0402.

20. Washington State Department of Transportation (WSDOT), Pavement Guide, http://hotmix.ce.washington.edu/wsdot_web/ 


\section{APPENDIX A}

\section{Test of Timber Tie with FRP Dowels}

Before evaluating FRP dowels in concrete slabs joints, pilot tests were carried out using rectangular timber beams. Long timer beam was cut into two halves and drilled with 1.75 " diameter holes to simulate dowel sockets in a slab. Dowel sockets facilitated placement of instrumented dowel inside the timber beams. Load tests were conducted by turning dowels at 45-degree angles to measure dowel strains from longitudinal and transverse gages (Figs. A.1 to A.3).

Four cases were evaluated based on loading position and timber depth (corresponding to positioning of the timber beam surface on the base), test set up of each case were shown in Figure A.2.

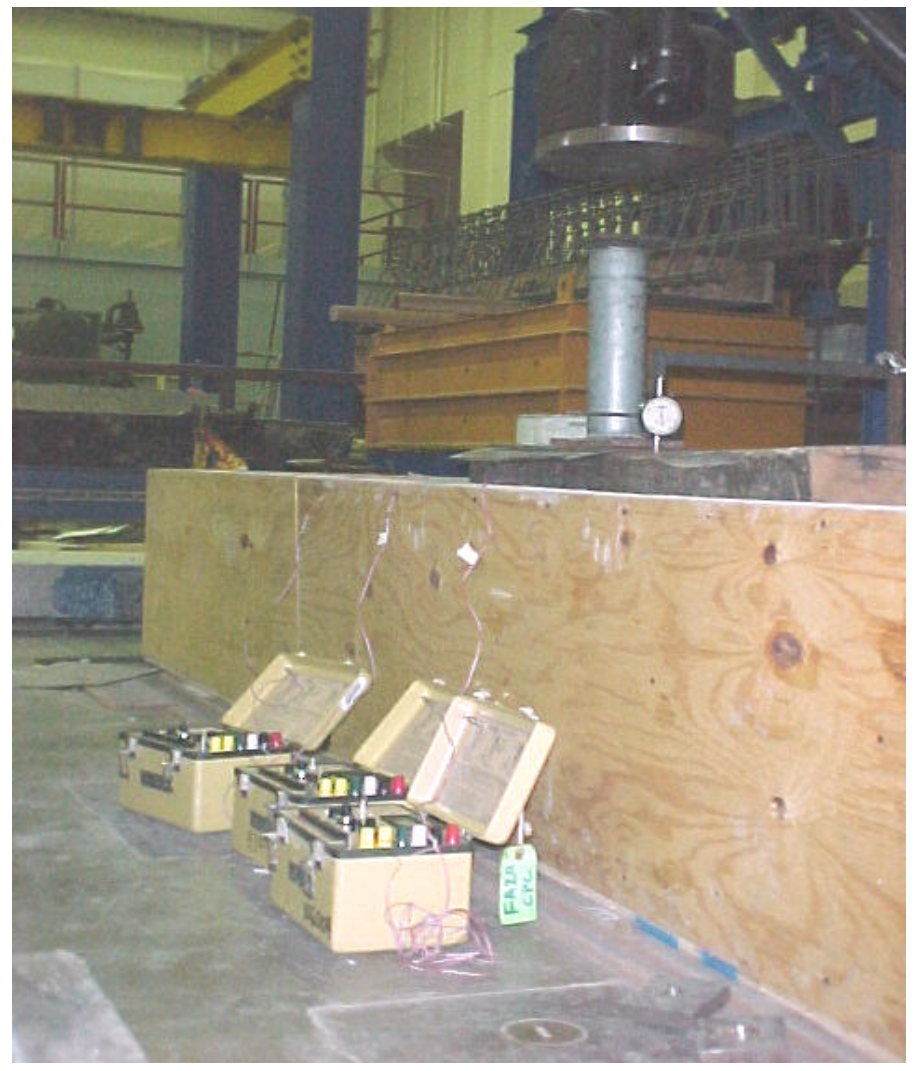

Figure A.1 Lab test of timber tie with FRP dowel bar as the load transfer device 


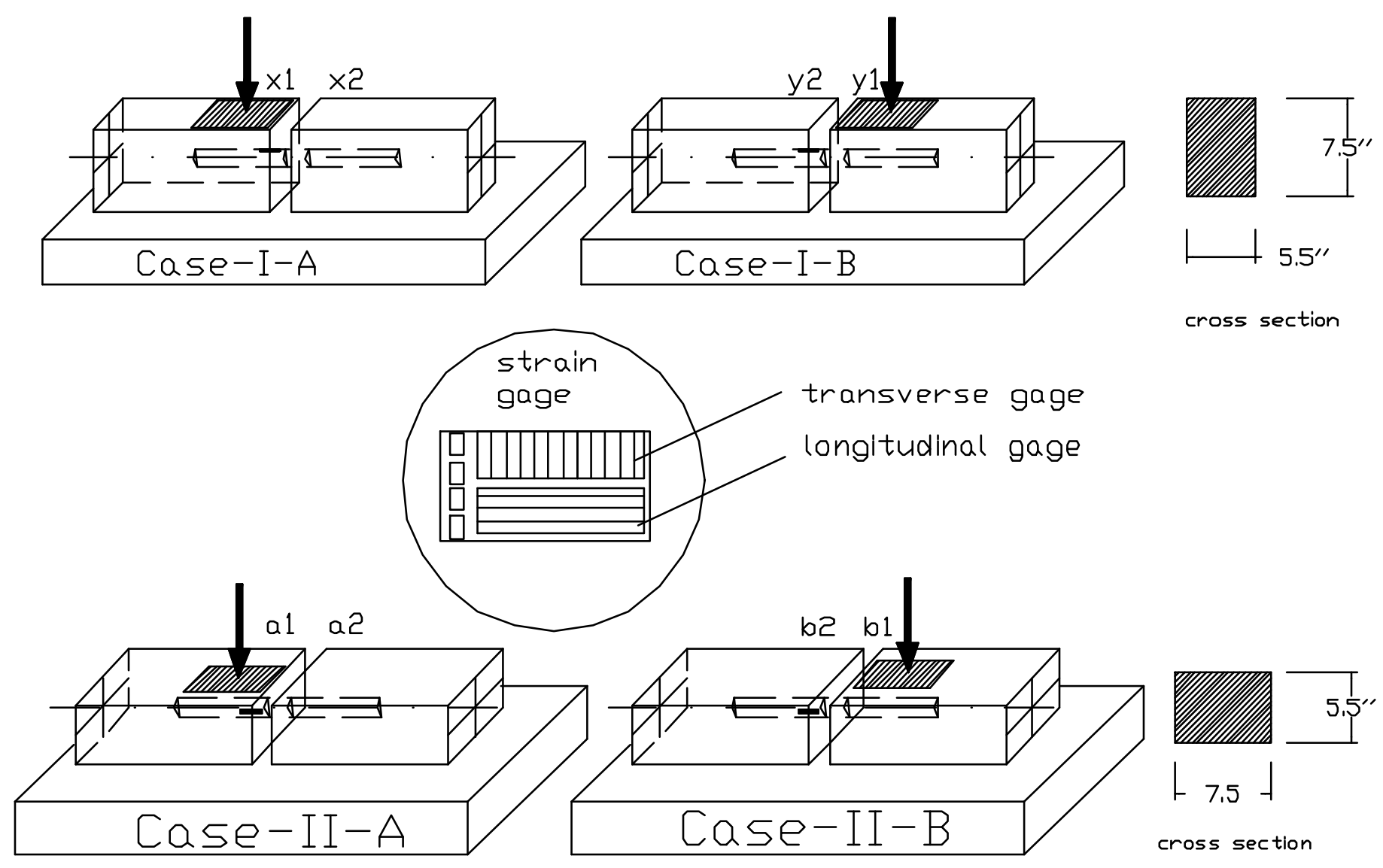

Figure A.2 Four Timber Test Cases 


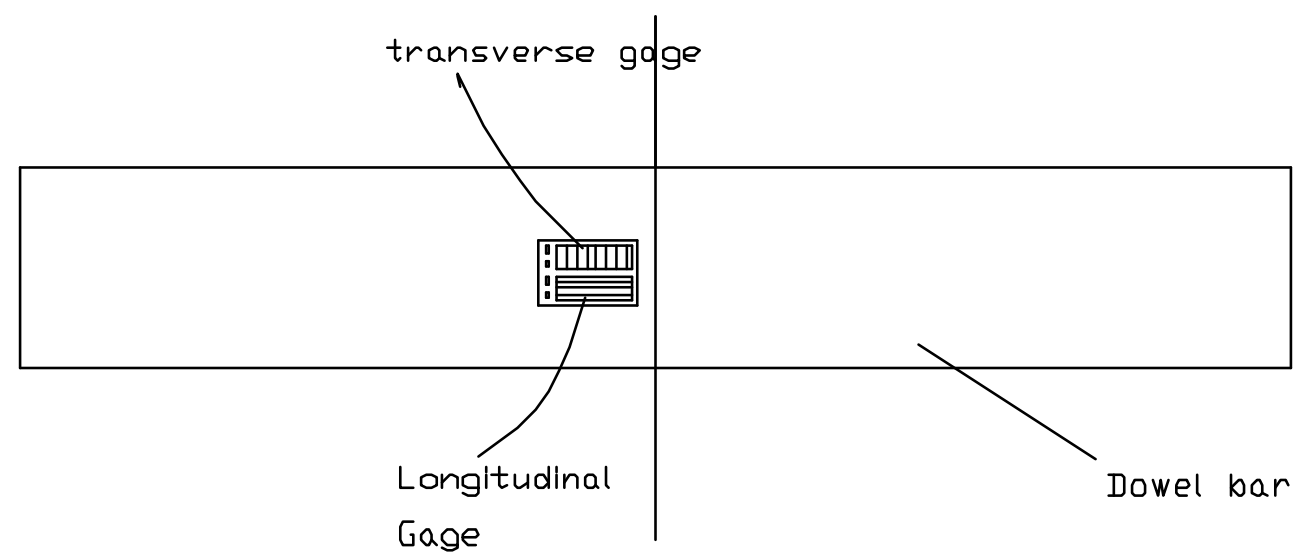

Figure A.3 Rosette strain gages

Table A.1 Strains during loading and unloading on Case-I-A

\section{a) Loading}

\begin{tabular}{|c|c|c|}
\hline $\begin{array}{c}\text { Load } \\
\text { (kips) }\end{array}$ & $\begin{array}{c}\text { Transverse } \\
\text { Gage }\end{array}$ & $\begin{array}{c}\text { Longitudinal } \\
\text { Gage }\end{array}$ \\
\hline 0 & 0 & 0 \\
\hline 1 & 64 & 576 \\
\hline 2 & 229 & 1707 \\
\hline 3 & 377 & 2585 \\
\hline 4 & 493 & 3182 \\
\hline 5 & 624 & 3848 \\
\hline 6 & 725 & 4389 \\
\hline 7 & 804 & 4770 \\
\hline 8 & 871 & 5118 \\
\hline 9 & 933 & 5415 \\
\hline 10 & 1021 & 5668 \\
\hline 11 & 1105 & 5962 \\
\hline 12 & 1166 & 6188 \\
\hline 13 & 1223 & 6384 \\
\hline 14 & 1285 & 6584 \\
\hline 15 & 1347 & 6844 \\
\hline 16 & 1393 & 7011 \\
\hline 17 & 1451 & 7204 \\
\hline 18 & 1515 & 7409 \\
\hline 19 & 1564 & 7599 \\
\hline 20 & 1627 & 7781 \\
\hline
\end{tabular}

b) Unloading

\begin{tabular}{|c|c|c|}
\hline $\begin{array}{c}\text { Load } \\
\text { (kips) }\end{array}$ & $\begin{array}{c}\text { Transverse } \\
\text { Gage }\end{array}$ & $\begin{array}{c}\text { Longitudinal } \\
\text { Gage }\end{array}$ \\
\hline 20 & 1627 & 7836 \\
\hline 19 & 1610 & 7797 \\
\hline 18 & 1580 & 7752 \\
\hline 17 & 1554 & 7707 \\
\hline 16 & 1527 & 7662 \\
\hline 15 & 1498 & 7609 \\
\hline 14 & 1467 & 7562 \\
\hline 13 & 1432 & 7522 \\
\hline 12 & 1391 & 7420 \\
\hline 11 & 1346 & 7365 \\
\hline 10 & 1292 & 7167 \\
\hline 9 & 1226 & 7032 \\
\hline 8 & 1135 & 6982 \\
\hline 7 & 1032 & 6670 \\
\hline 6 & 940 & 6495 \\
\hline 5 & 790 & 5957 \\
\hline 4 & 674 & 5610 \\
\hline 3 & 560 & 4971 \\
\hline 2 & 605 & 3987 \\
\hline 1 & 171 & 2370 \\
\hline 0 & 0 & 0 \\
\hline & & \\
\hline
\end{tabular}


Table A.2 Strains during loading and unloading on Case-I-B

a) Loading

\begin{tabular}{|c|c|c|}
\hline $\begin{array}{c}\text { Load } \\
\text { (kips) }\end{array}$ & $\begin{array}{c}\text { Transverse } \\
\text { Gage }\end{array}$ & $\begin{array}{c}\text { Longitudinal } \\
\text { Gage }\end{array}$ \\
\hline 0 & 0 & 0 \\
\hline 1 & 59 & 49 \\
\hline 2 & 220 & 592 \\
\hline 3 & 511 & 1787 \\
\hline 4 & 734 & 3238 \\
\hline 5 & 799 & 3419 \\
\hline 6 & 899 & 3872 \\
\hline 7 & 908 & 4040 \\
\hline 8 & 1012 & 4325 \\
\hline 9 & 1040 & 4559 \\
\hline 10 & 1067 & 4740 \\
\hline 11 & 1106 & 4901 \\
\hline 12 & 1137 & 5044 \\
\hline 13 & 1144 & 5091 \\
\hline 14 & 1152 & 5119 \\
\hline 15 & 1186 & 5241 \\
\hline 16 & 1206 & 5339 \\
\hline 17 & 1251 & 5473 \\
\hline 18 & 1277 & 5610 \\
\hline 19 & 1310 & 5746 \\
\hline 20 & 1357 & 5920 \\
\hline & & \\
\hline
\end{tabular}

b) Unloading

\begin{tabular}{|c|c|c|}
\hline $\begin{array}{c}\text { Load } \\
\text { (kips) }\end{array}$ & $\begin{array}{c}\text { Transverse } \\
\text { Gage }\end{array}$ & $\begin{array}{c}\text { Longitudinal } \\
\text { Gage }\end{array}$ \\
\hline 20 & 1357 & 5920 \\
\hline 16 & 1332 & 5976 \\
\hline 12 & 1302 & 5931 \\
\hline 8 & 1265 & 5863 \\
\hline 4 & 1081 & 5066 \\
\hline 0 & 0 & 136 \\
\hline
\end{tabular}

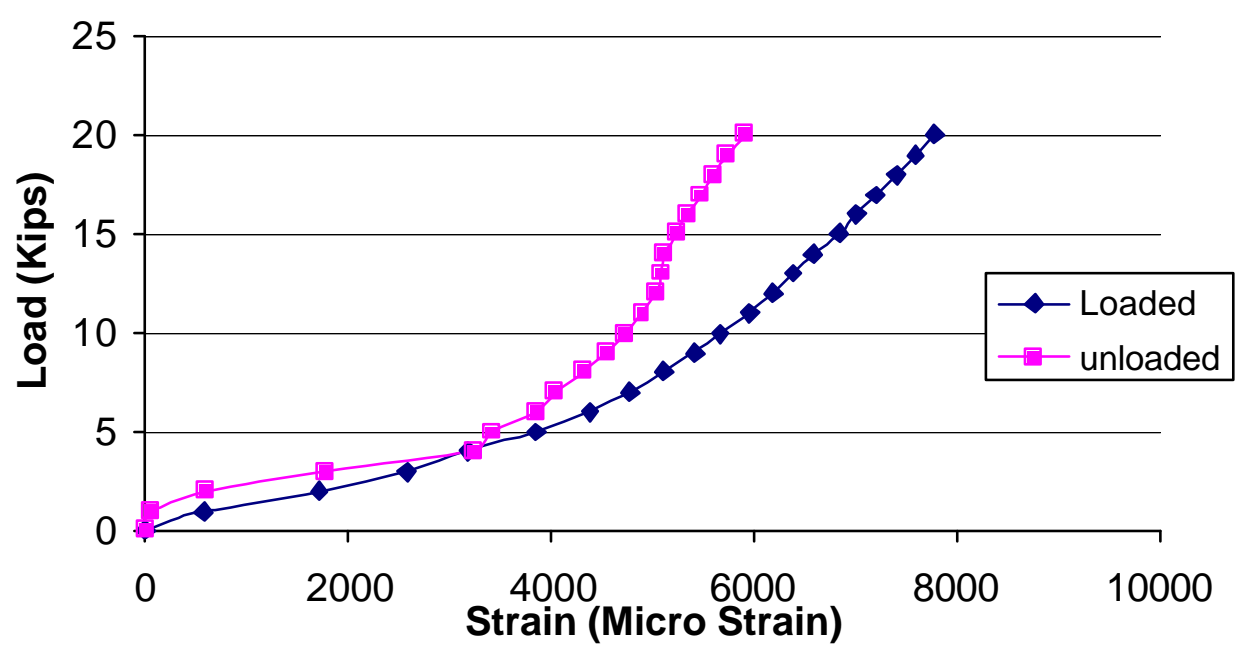

Figure A.4 Plot for Longitudinal Strain Gages (Case-I-A \& Case-I-B) 
Table A.3 Strains during loading and unloading on Case-II-A

a) Loading

\begin{tabular}{|c|c|c|}
\hline $\begin{array}{c}\text { Load } \\
\text { (kips) }\end{array}$ & $\begin{array}{c}\text { Transverse } \\
\text { Gage }\end{array}$ & $\begin{array}{c}\text { Longitudinal } \\
\text { Gage }\end{array}$ \\
\hline 0 & 0 & 0 \\
\hline 2 & 1 & 8 \\
\hline 4 & 1 & 7 \\
\hline 6 & 1 & 7 \\
\hline 8 & 1 & 7 \\
\hline 10 & 1 & 7 \\
\hline 12 & 1 & 7 \\
\hline 14 & 1 & 7 \\
\hline 16 & 1 & 6 \\
\hline 18 & 1 & 7 \\
\hline 20 & 1 & 7 \\
\hline
\end{tabular}

b) Unloading

\begin{tabular}{|c|c|c|}
\hline $\begin{array}{c}\text { Load } \\
\text { (kips) }\end{array}$ & $\begin{array}{c}\text { Transverse } \\
\text { Gage }\end{array}$ & $\begin{array}{c}\text { Longitudinal } \\
\text { Gage }\end{array}$ \\
\hline 20 & 1 & 7 \\
\hline 16 & 1 & 6 \\
\hline 12 & 1 & 6 \\
\hline 8 & 1 & 6 \\
\hline 4 & 1 & 6 \\
\hline 0 & 0 & 0 \\
\hline
\end{tabular}

Table A.4 Deflections of Timber Tie on Case-I-A

\begin{tabular}{|c|c|c|c|c|}
\hline Load (kips) & $\begin{array}{c}\text { Dial gage reading at } \\
\text { Loaded end } \\
\text { (in.) }\end{array}$ & $\begin{array}{c}\text { Deflection at x1 } \\
\text { (in.) }\end{array}$ & $\begin{array}{c}\text { Dial gage reading } \\
\text { at Unloaded End } \\
\text { (in.) }\end{array}$ & $\begin{array}{c}\text { Deflection at x2 } \\
\text { (in.) }\end{array}$ \\
\hline 0 & 0.469 & 0.000 & 0.515 & 0.000 \\
\hline 1 & 0.402 & 0.067 & 0.490 & 0.025 \\
\hline 2 & 0.335 & 0.134 & 0.465 & 0.050 \\
\hline 3 & 0.238 & 0.231 & 0.468 & 0.047 \\
\hline 4 & 0.170 & 0.299 & 0.467 & 0.048 \\
\hline 5 & 0.130 & 0.339 & 0.466 & 0.049 \\
\hline 6 & 0.080 & 0.389 & 0.465 & 0.050 \\
\hline 7 & 0.048 & 0.421 & 0.465 & 0.050 \\
\hline 8 & 0.020 & 0.449 & 0.465 & 0.050 \\
\hline 9 & -0.190 & 0.659 & 0.465 & 0.050 \\
\hline 10 & -0.170 & 0.639 & 0.465 & 0.050 \\
\hline 11 & -0.160 & 0.629 & 0.465 & 0.050 \\
\hline 12 & -0.150 & 0.619 & 0.465 & 0.050 \\
\hline 13 & -0.162 & 0.631 & 0.465 & 0.050 \\
\hline 14 & -0.176 & 0.645 & 0.466 & 0.049 \\
\hline 15 & -0.197 & 0.666 & 0.466 & 0.049 \\
\hline 16 & -0.215 & 0.684 & 0.467 & 0.048 \\
\hline 17 & -0.229 & 0.698 & 0.467 & 0.048 \\
\hline 18 & -0.247 & 0.716 & 0.468 & 0.047 \\
\hline 19 & -0.262 & 0.731 & 0.468 & 0.047 \\
\hline 20 & -0.275 & 0.744 & 0.469 & 0.046 \\
\hline & & & & \\
\hline
\end{tabular}


Table A.5 Deflections of Timber Tie on Case-I- B

\begin{tabular}{|c|c|c|c|c|}
\hline Load (kips) & $\begin{array}{c}\text { Dial gage reading at } \\
\text { Loaded end } \\
\text { (in.) }\end{array}$ & $\begin{array}{c}\text { Deflection at y1 } \\
\text { (in.) }\end{array}$ & $\begin{array}{c}\text { Dial gage reading } \\
\text { at Unloaded End } \\
\text { (in.) }\end{array}$ & $\begin{array}{c}\text { Deflection at y2 } \\
\text { (in.) }\end{array}$ \\
\hline 0 & 0.915 & 0.000 & 0.525 & 0.000 \\
\hline 1 & 0.870 & 0.045 & 0.501 & 0.024 \\
\hline 2 & 0.825 & 0.090 & & 0.119 \\
\hline 3 & 0.660 & 0.255 & & \\
\hline 4 & 0.575 & 0.340 & 0.406 & \\
\hline 5 & 0.515 & 0.400 & & \\
\hline 6 & 0.462 & 0.453 & & \\
\hline 7 & 0.430 & 0.485 & & \\
\hline 8 & 0.390 & 0.525 & 0.397 & \\
\hline 9 & 0.365 & 0.550 & & \\
\hline 10 & 0.331 & 0.584 & & \\
\hline 11 & 0.300 & 0.615 & & \\
\hline 12 & 0.272 & 0.643 & 0.388 & \\
\hline 13 & 0.250 & 0.665 & & \\
\hline 14 & 0.228 & 0.687 & & \\
\hline 15 & 0.202 & 0.713 & & \\
\hline 16 & 0.185 & 0.730 & 0.383 & \\
\hline 17 & 0.165 & 0.750 & & \\
\hline 18 & 0.140 & 0.775 & & \\
\hline 19 & 0.123 & 0.792 & & \\
\hline 20 & 0.090 & 0.825 & 0.382 & \\
\hline
\end{tabular}




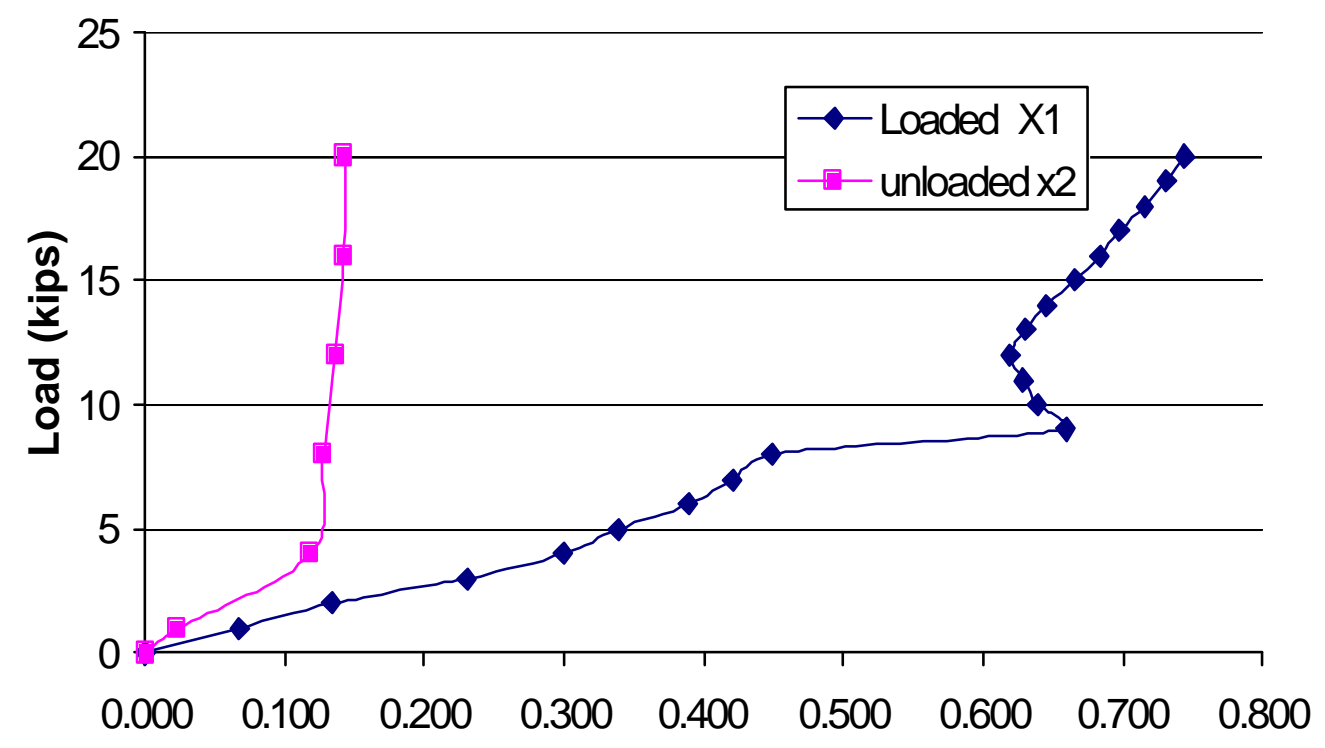

Figure A.5 Load vs. Deflection of Timber Tie for CASE-I-A

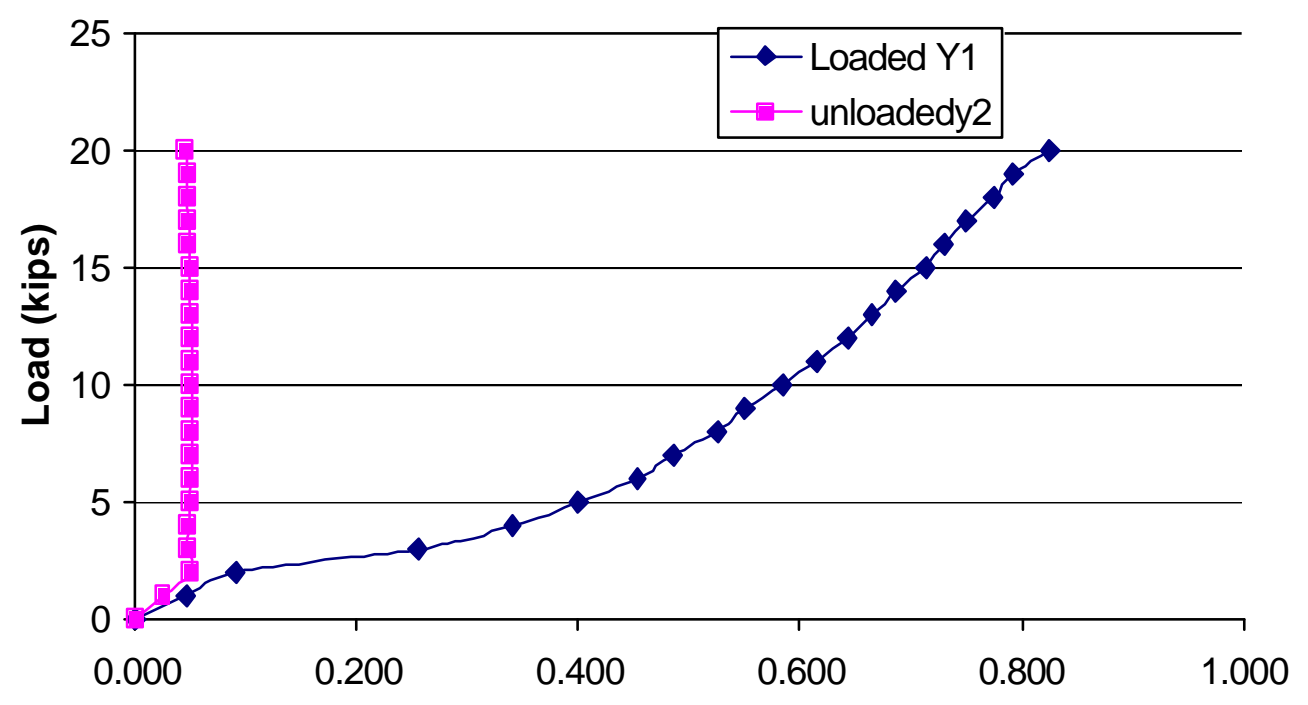

Figure A.6 Load-Deflection (arm with regular gage) for CASE-I-B 
Joint Effectiveness from Case-I-A and Case-I-B Under 20 Kips Loading:

Case-I-A:

$$
\frac{2 \times \text { Deflection at Unloaded Side }}{\text { Deflection Total of Both Sides }}=\frac{2 \times 0.046}{(0.744+0.046)} \times 100 \%=12.15 \%
$$

\section{Case-I-B:}

$$
\frac{2 \times \text { Deflection at Unloaded Side }}{\text { DeflectionTotal of Both Sides }}=\frac{2 \times 0.143}{(0.825+0.143)} \times 100 \%=29.55 \%
$$

In this preliminary test, Joint Effectiveness obtained in timber with 1.5" FRP dowel was low. This is due to several reasons such as the low stiffness of timber material, larger hole diameter (1.75”) for accommodating 1.5" diameter FRP dowel. 


\section{APPENDIX B}

\section{Analytical Evaluation of Effect of FRP Dowel Shear Modulus on Pavement Relative Deflection}

Analytical Evaluation was conducted to find the effect of a dowel shear modulus on pavement relative deflection. Parameters used for calculation were listed below. Detailed data were shown in Tables B.1 and B.2, and Figures B.1 and B.2:

1. FRP dowel

- Diameter, $\mathrm{d}=1.5$ " and $1.0 "$

- Length, $\mathrm{L}=18$ "

- Spacing between each dowel, $\mathrm{b}=6 ", 8 ", 10 "$, and 12.0"

- Modulus of elasticity, $\mathrm{E}_{\mathrm{d}}=5.5 \times 10^{6}$ psi for 1.5 " diameter dowel and $\mathrm{E}_{\mathrm{d}}=$ $6.0 \times 10^{6} \mathrm{psi}$ for $1.0^{\prime \prime}$ diameter

- Shear modulus of dowel, Low $G_{d}=0.4 \times 10^{6}$ psi and High $G_{d}=$ $0.75 \times 10^{6} \mathrm{psi}$

- Moment of inertia of the dowel, $\mathrm{I}_{\mathrm{d}}=\frac{\pi \times d^{4}}{64}=0.248505\left(\mathrm{in}^{4}\right)$

- Cross-sectional area of dowel, $\mathrm{A}=1.77 \mathrm{in}^{2}$

2. Concrete pavement

- Compressive strength, $f_{c}^{\prime}=4500 \mathrm{psi}$

- Modulus of elasticity, $E_{c}=57000 \times\left(f_{c}^{\prime}\right)^{0.5}=3823676.2 \mathrm{psi}=3.82 \times 10^{6} \mathrm{psi}$

- Pavement thickness, $\mathrm{h}=11$ in.

- Joint width, $z=0.25$ in.

- Poisson's ratio of concrete, $v=0.2$

- Modulus of dowel support, $\mathrm{K}_{0}=1,500,000 \mathrm{pci}$

3. Base

- Modulus of subgrade reaction, $k=400 \mathrm{pci}$

4. Load

- Design Traffic Load HS25, applied wheel load $\mathrm{P}_{\mathrm{w}}=20000 \mathrm{lbs}$

- Design load transfer by joint $=45 \%$

- $\quad \mathrm{P}_{\mathrm{t}}=$ load transferred across the joint $=P_{w} \times 0.45=9000 \mathrm{lbs}$ 
Table B.1 Relative Deflection With Low Dowel Shear Modulus $\left(G_{d}=0.4 \times 10^{6}\right.$ psi $)$

\begin{tabular}{|c|c|c|c|c|}
\hline $\begin{array}{c}\text { Dia. of Dowel } \\
\text { (in.) }\end{array}$ & $\begin{array}{c}\text { Bending Deflection } \\
\text { (in.) }\end{array}$ & $\begin{array}{c}\text { Bending Deflection } \\
\text { (in.) }\end{array}$ & $\begin{array}{c}\text { Shear Deflection } \\
\text { (in.) }\end{array}$ & $\begin{array}{c}\text { Total Relative Deflection } \\
\text { (in.) }\end{array}$ \\
\hline 1.0 & 0.0045 & 0.0045 & 0.0025 & 0.0114 \\
\hline 1.5 & 0.0022 & 0.0022 & 0.0011 & 0.0055 \\
\hline 1.0 & 0.0057 & 0.0057 & 0.0031 & 0.0145 \\
\hline 1.5 & 0.0028 & 0.0028 & 0.0014 & 0.0070 \\
\hline 1.0 & 0.0067 & 0.0067 & 0.0037 & 0.0171 \\
\hline 1.5 & 0.0033 & 0.0033 & 0.0016 & 0.0082 \\
\hline 1.0 & 0.0076 & 0.0076 & 0.0042 & 0.0093 \\
\hline 1.5 & 0.0037 & 0.0037 & 0.0019 & \\
\hline
\end{tabular}

Table B.2 Relative Deflection With High Dowel Shear Modulus $\left(G_{d}=7.5 \times 10^{6}\right.$ psi)

\begin{tabular}{|c|c|c|c|c|}
\hline $\begin{array}{c}\text { Dia. of Dowel } \\
\text { (in.) }\end{array}$ & $\begin{array}{c}\text { Bending Deflection } \\
\text { (in.) }\end{array}$ & $\begin{array}{c}\text { Bending Deflection } \\
\text { (in.) }\end{array}$ & $\begin{array}{c}\text { Shear Deflection } \\
\text { (in.) }\end{array}$ & $\begin{array}{c}\text { Total Relative Deflection } \\
\text { (in.) }\end{array}$ \\
\hline 1.0 & 0.0045 & 0.0045 & 0.0013 & 0.0103 \\
\hline 1.5 & 0.0022 & 0.0022 & 0.0006 & 0.0050 \\
\hline 1.0 & 0.0057 & 0.0057 & 0.0017 & 0.0131 \\
\hline 1.5 & 0.0028 & 0.0028 & 0.0007 & 0.0063 \\
\hline 1.0 & 0.0067 & 0.0067 & 0.0020 & 0.0154 \\
\hline 1.5 & 0.0033 & 0.0033 & 0.0009 & 0.0074 \\
\hline 1.0 & 0.0076 & 0.0076 & 0.0022 & 0.0085 \\
\hline 1.5 & 0.0037 & 0.0037 & 0.0010 & \\
\hline
\end{tabular}




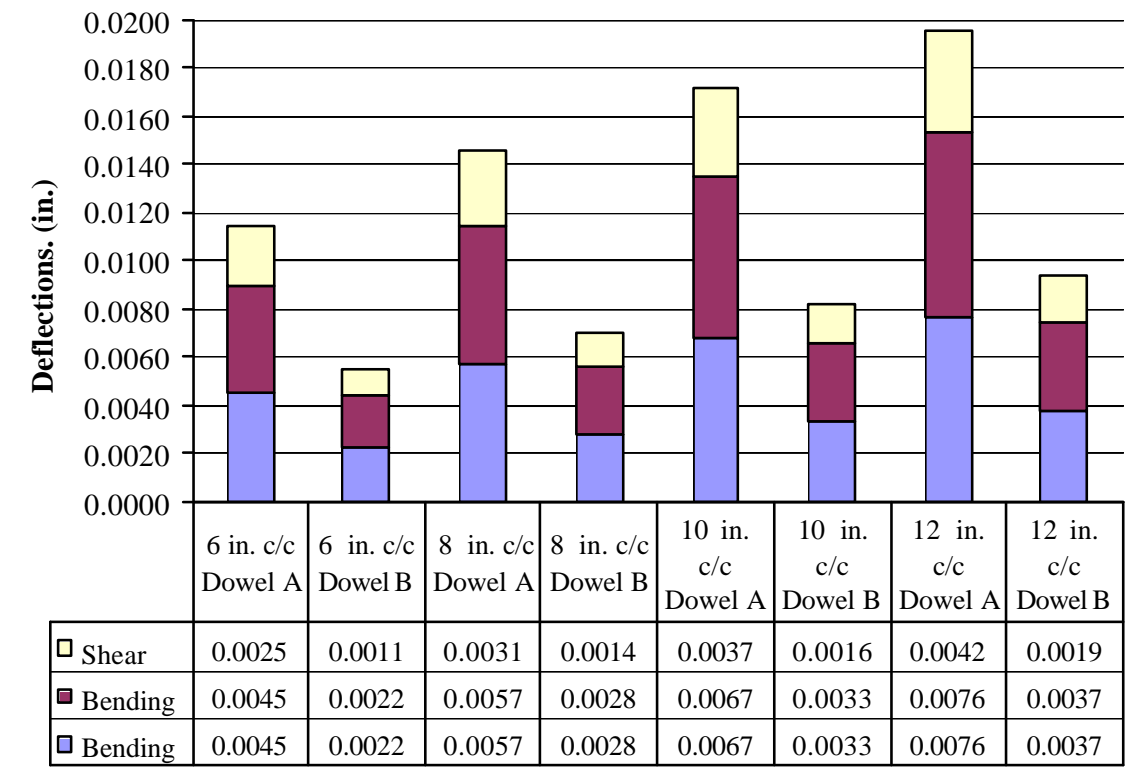

Figure B.1 Components of Relative Deflection for Dowel Types A (1.0" diameter) and B (1.5" diameter), with $k=400 p c i, f_{c}{ }^{\prime}=4500 p s i$, Joint width $=0.25$ " and $G_{d}=0.4 \times 10^{6} p s i$

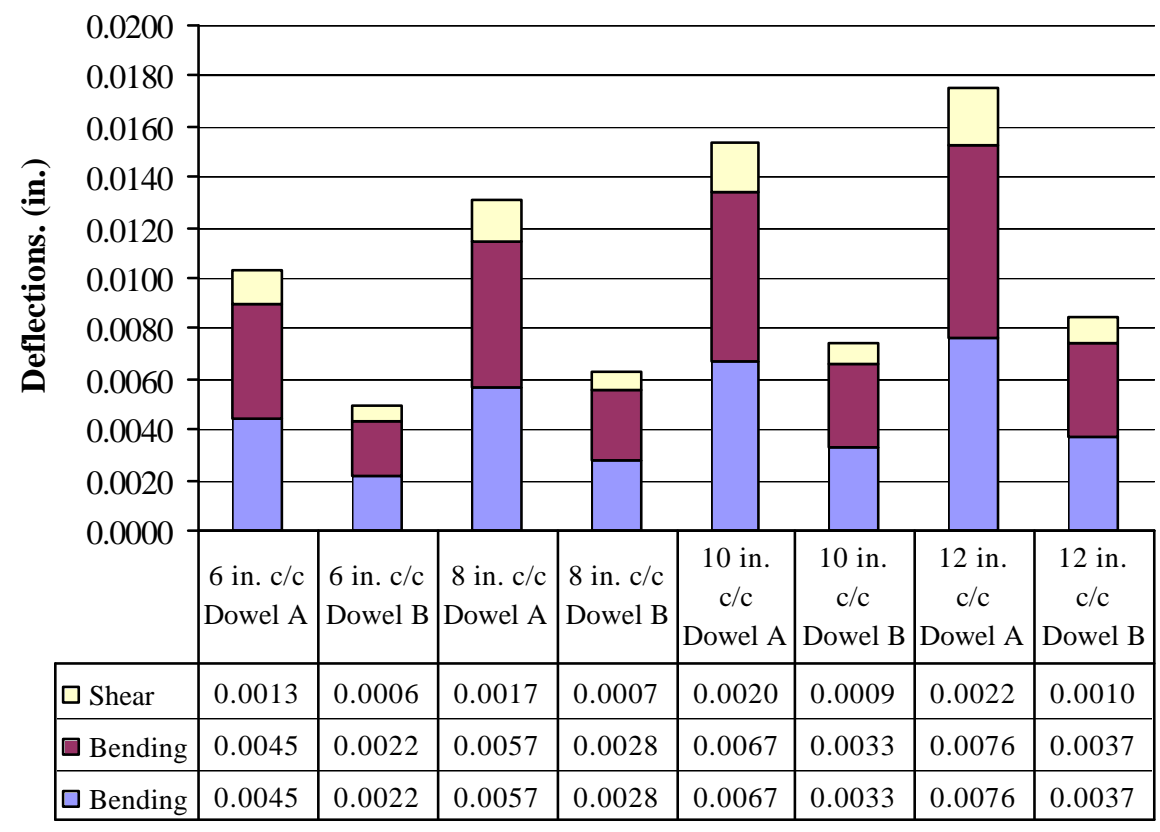

Figure B.2 Components of Relative Deflection for Dowel Types A (1.0" diameter) and B (1.5" diameter), with $k=400 p c i, f_{c}{ }^{\prime}=4500 p s i$, Joint width $=0.25{ }^{\prime \prime}$ and $G_{d}=0.75 \times 10^{6} p s i$ 


\section{APPENDIX C}

\section{Fiber Burnout Tests for Determining Fiber Weight Fraction and Fiber Volume Fraction for FRP Dowels}

Burnout tests were conducted to determine the fiber weight fraction (FWF) and fiber volume fraction (FVF) for both 1.0" diameter FRP dowel and 1.5" diameter FRP dowel bars. Details are listed in Tables C.1 and C.2.

Table C.1 FWF and FVF for FRP dowel with 1.0" diameter

\begin{tabular}{|c|c|c|c|c|c|c|c|}
\hline \multirow[t]{2}{*}{ Sample } & \multicolumn{2}{|c|}{$\begin{array}{c}\text { FRP Sample } \\
\text { Total }\end{array}$} & \multirow[t]{2}{*}{$\begin{array}{c}\text { Resin } \\
\text { Weight (g) }\end{array}$} & \multicolumn{2}{|c|}{ E-glass Fiber } & \multirow{2}{*}{$\begin{array}{c}\text { Fiber } \\
\text { Weight } \\
\text { Fraction } \\
(\text { FWF, \%) }\end{array}$} & \multirow{2}{*}{$\begin{array}{c}\text { Fiber } \\
\text { Volume } \\
\text { Fraction } \\
(\mathrm{FVF}, \%)\end{array}$} \\
\hline & $\begin{array}{l}\text { Weight } \\
\text { (g) }\end{array}$ & $\begin{array}{l}\text { Volume } \\
\left(\text { in }^{3}\right)\end{array}$ & & $\begin{array}{c}\text { Weight } \\
\text { (g) }\end{array}$ & $\begin{array}{c}\text { Volume } \\
\left(\text { in }^{3}\right)\end{array}$ & & \\
\hline A1 & 23.00 & 0.7399 & 6.38 & 16.62 & 0.3977 & 72.26 & 53.75 \\
\hline $\mathrm{A} 2$ & 23.12 & 0.7383 & 6.40 & 16.72 & 0.4001 & 72.31 & 54.20 \\
\hline Average & & & & & & 72.29 & 53.98 \\
\hline
\end{tabular}

NOTE: E-glass fiber volume was calculated by using Eglass fiber weight divided by its density $\left(2.55 \mathrm{~g} / \mathrm{cm}^{3}\right)$, a converter factor $1 \mathrm{~cm}^{3}=0.06102374 \mathrm{in}^{3}$ was used for the calculations.

Table C.2 FWF and FVF for FRP dowel with 1.5" diameter

\begin{tabular}{|c|c|c|c|c|c|c|c|}
\hline Sample & \multicolumn{2}{|c|}{$\begin{array}{c}\text { FRP Sample } \\
\text { Total }\end{array}$} & \multirow{2}{*}{$\begin{array}{c}\text { Resin } \\
\text { Weight }(\mathrm{g})\end{array}$} & \multicolumn{2}{|c|}{$\begin{array}{c}\text { E-glass Fiber } \\
\text { Fiber }\end{array}$} & $\begin{array}{c}\text { Fiber } \\
\text { Weight } \\
\end{array}$ \\
\cline { 2 - 5 } & $\begin{array}{c}\text { Weight } \\
(\mathrm{g})\end{array}$ & $\begin{array}{c}\text { Volume } \\
\left(\mathrm{in}^{3}\right)\end{array}$ & & $\begin{array}{c}\text { Weight } \\
(\mathrm{g})\end{array}$ & $\begin{array}{c}\text { Volume } \\
\left(\mathrm{in}^{3}\right)\end{array}$ & $\begin{array}{c}\text { Fraction } \\
(\mathrm{FWF}, \%)\end{array}$ & $\begin{array}{c}\text { Fraction } \\
(\mathrm{FVF}, \%)\end{array}$ \\
\hline B1 & 54.81 & 1.7737 & 16.736 & 38.074 & 0.9111 & 69.47 & 51.37 \\
\hline B2 & 54.19 & 1.7576 & 16.546 & 37.644 & 0.9009 & 69.47 & 51.25 \\
\hline \hline Average & & & & & & $\mathbf{6 9 . 4 7}$ & $\mathbf{5 1 . 3 1}$ \\
\hline
\end{tabular}

NOTE: E-glass fiber volume was calculated by using Eglass fiber weight divided by its density $\left(2.55 \mathrm{~g} / \mathrm{cm}^{3}, 0.092 \mathrm{lb} / \mathrm{in}^{3}\right)$, a conversion factor $1 \mathrm{~cm}^{3}=0.06102374 \mathrm{in}^{3}$ was used for the calculations. 